


\section{The International Journal of Screendance}

Spring 2016 • Volume 6

ISSN 2154-6878

\section{EDITORS}

Harmony Bench and Simon Ellis

\section{EDITORIAL ASSISTANTS}

Teoma Jackson Naccarato

Emilie Gallier

Karen Wood

Hetty Blades 



\section{The International Journal of Screendance Editorial Board}

DR. ANN COOPER ALBRIGHT

Professor of Theater and Dance

Oberlin College

ELLEN BROMBERG

Associate Professor, Department of

Modern Dance

University of Utah

DR. HARMONY BENCH

Assistant Professor, Department of Dance

The Ohio State University

DR. ERIN BRANNIGAN

Senior Lecturer, Dance

University of New South Wales

DR. SIMON ELLIS

Senior Research Fellow

Centre for Dance Research (C-DaRE)

Coventry University

DR. FRANK GRAY

Director of Screen Archive South East

(SASE)

University of Brighton

CLAUDIA KAPPENBERG

Principal Lecturer, Performance and

Visual Art; School of Arts and Media

University of Brighton
KATRINA MCPHERSON

Independent artist

Glenferness, UK

MIRANDA PENNELL

Independent film and video artist

London, UK

DOUGLAS ROSENBERG

Professor of Art, Department of Art

University of Wisconsin-Madison

DR. THERON SCHMIDT

Lecturer in Theatre and Liberal Arts

King's College London

SILVINA SZPERLING

Director, Internacional Festival de

Videodanza

Buenos Aires, Argentina

DR. SARAH WHATLEY

Professor of Dance, Coventry School of

Art and Design

Coventry University

MARISA ZANOTTI

Senior Lecturer, Dance

University of Chichester 
Cover Design

Simon Ellis

Publication Design

Harmony Bench and Simon Ellis, after Barry Roal Carlsen, University of Wisconsin-Madison

The International Journal of Screendance is published by The Ohio State University Libraries with support from Centre for Dance Research (C-DaRE), Coventry University ISSN 2154-6878

Website: http://screendancejournal.org 


\section{Table of Contents: Field Perceptions}

\section{IJSD Volume 6}

1 Editorial: Field Perceptions

Harmony Bench and Simon Ellis

\section{Articles}

17 Hybrid Texts, Assembled Bodies: Michael Gondry's Merging of Camera and Dancer in "Let Forever Be" Addie Tsai

39 The Meaning of the Moves: Gestural Mythologies and the Generic Film Sarah Friedland

57 A Dance Between Chaos and Complexity: Choreographing the Spasm in Music Videos Melissa Blanco Borelli

78 Ghanaian Screendance Perspectives: The Nuance of 'Sankofaism' as Emerging Aesthetics and Rejection of Orthodoxy Terry B.K. Ofosu, Samuel Benagr

94 New Materials: Natural Elements and the Body in Screendance Sylvie Vitaglione

112 Imagined Archaeology and Enlivening the Proximate Senses in the construction of Blind Torrent - An Interdisciplinary Screendance Project Ruth Way, Russell Frampton

131 The Camera-Dancer. A Dyadic Approach to Choreography Jennifer Nikolai

\section{Provocations and Viewpoints}

153 Watch Films, Watch Dance Films, Watch More Dance Films Katrina McPherson 
166 Testing Ground: Evolving Screendance Practices and Theories and the Leeds International Film Festival Screendance Competition Kyra Norman

178 What Are Screendance Competitions Even For? A Response to the 2015 Leeds International Film Festival Screendance Competition Hamish MacPherson

182 Screendance Cannot be Everything: Defining the Form Ten Years after the (Hu)Manifesto

Wynn Pottratz

\section{Interviews}

189 Screendance: Learning, Teaching, Living Harmony Bench with Jason Bahling, Ben Estabrook, Natalie Gotter, Eric Nordstrom, and Ellen Maynard

197 Unexamined Assumptions: A Conversation between Arabella Stanger and Simon Ellis Arabella Stanger, Simon Ellis

\section{Reviews}

205 Dance Fort: A History by Bebe Miller Hannah Kosstrin

210 Maya Deren: Incomplete Control by Sarah Keller Karen Wood

213 Moving without a Body: Digital Philosophy and Choreographic Thought by Stamatia Portanova Ariadne Mikou 


\section{Editorial: Field Perceptions}

Harmony Bench, The Ohio State University

Simon Ellis, Coventry University

Keywords: screendance, editorial, pedagogy, critical reflection, field, discipline, popular screen

This sixth volume of the International Journal of Screendance started as an open call in which we sought contributions that might "test, provoke and challenge screendance work and practices, debates, and theoretical positions." 1 We hoped-and continue to hope-that IJSD might become a platform through which artists, students, scholars, and audiences are able to address, contextualize, and reflect on experiences and philosophies of dancing with, on, in front of, and next to screens, and how these screens may or may not matter to our creative and intellectual lives.

In volume 5 of IJSD-and our first as editors of the journal-we asked what and who the screendance community might include and involve. This was, in part, a concerted editorial effort to be less precious about the edges of the screendance community, and to recognize that our dancing lives are saturated by screens of all kinds. We did this by including a range of articles, interviews, and opinions, from conventional scholarly writing to first person points of view. In volume 6 we continue this approach to IJSD in order to continue to expand the scholarly and artistic discourses that surround screendance practices and thinking.

Editing submissions based on an open call is indeed a curious and messy experience: it is neither controlled nor ordered. Every call demands a response, but an open call is an invitation to the unknown. Our open call landed with the contributors gathered here, and in answering our solicitation, they returned our open call with a diagrammatic echo of the field. With a positioning ping, each contributor offers a perspective in and on the field we collectively create and share. But how to make sense of this seemingly arbitrary collection of authored ideas, writings, thoughts, and images? As we engage with the authors and their writing, a shape begins to emerge. At times it appears vaguely epidemiological-as if we are not only observing what is there, but also trying to make sense of the patterns, forms, and relationships that exist between and across the materials. Our understandings, biases, research priorities, and tastes (as editors) are consequently shaped by the people who have taken the time to submit to IJSD, who answer its call. Having issued an invitation, we understand that our primary role 
as editors is to listen and respond to the shifts, changes, and plasticity of the field, and in particular the practices that build and stretch the field from the ground up.

Within the context of our editorial role, we have tried to give further shape to the contributions gathered in this issue, to pull out themes and points of connection, to organize them into a collection of ideas that resonate together, even as we recognize the contemporary habit of reading journal articles as stand-alone entities. Standing back, and with the privilege of having first eyes (and ears) on this collection of articles, points of view, interviews, and reviews, there seem to be four distinct containers that reveal the connections between our authors' arguments, methods, interests, and practices. These are:

- Reflections on practice and process

- Screendance pedagogy

- Dance on the popular screen

- Screendance festivals and disciplinary debate

\section{Reflections on practice and process}

Jennifer Nikolais reflects on her improvisation practice working with camera-dancers, and more recently with motion capture technology, in order to propose a type of camera dramaturgy. She positions her thinking and practice in relation to Maya Deren and Dziga Vertov.

Ruth Way and Russell Frampton place anthropological and phenomenological lenses on their film project Blind Torrent which itself calls on histories of site-specific and somatic movement practices. Their "critical praxis" 2 joins a growing body of practiceas-research texts that artist-scholars use to frame their work and share key aspects of research and artistic processes.

Sarah Friedland casts a critical eye on the ways in which gestures-acts that approach meaning - are used as the "choreography of film genre." ${ }^{3}$ Her perspective reflects on the thinking and writing of Roland Barthes in particular, film studies more generally, and calls attention to the ways in which viewers recognize-and embody-gesture in genre films.

Sylvie Vitaglione investigates locations in screendance films by Isabel Rocamora, Thierry de Mey, Jukka Rajala-Granstubbon, Orsola Valenti, and Wim Vandekeybus. Her perspective distinguishes site-specificity from the ways in which the material characteristics of sites provide tangible links between the body and location.

Friedland and Vitaglione's articles both conceive alternative ways in which to imagine and watch the work of other practitioners. Their writing asks us to render our 
experiences and languages as choreographers and movement specialists in relation to moving images on screen.

This volume of IJSD contains three reviews, and each-to a greater or lesser extentinvites questions about the nature of choreographic practice, and how those practices are directly or indirectly mediated by screens and digital technologies. In her review of Sarah Keller's book Maya Deren: Incomplete Control, Karen Wood responds positively to the way in which Keller emphasizes Deren's incomplete practices and willingness to give space to unresolved binaries.

Whereas Deren is widely regarded as a key figure in the evolution of screendance without, however, being a dance-maker, Bebe Miller is a choreographer in the usual sense of the word. Miller adapts her work and process to the small screen in her iBook Dance Fort: A History, turning to the ways in which words, sounds, images, and video might contain the tastes, experiences, and understandings of her stage-based work $A$ History (which itself mines previous works for content). Hannah Kosstrin reviews the iBook, and responds to how the materials of Miller's work become mediated resources for others. It is a screen-based choreography of interaction, review, and exchange.

Finally, we turn to the practice of philosophy and choreographic thinking in relation to digital and mediated technologies. Ariadne Mikou reviews Stamatia Portanova's book Moving without a Body: Digital Philosophy and Choreographic Thoughts and is drawn to how Portanova articulates the ways in which software structures "underpin video dance, motion capture, and choreographic software." ${ }^{4}$ For Mikou, Portanova's work to rethink and extend the perception of movement and choreography is vital.

Together, these reviews reveal contemporary directions in screendance practice and scholarship, moving across platforms and media, abutting dance technology,

revisiting canonical figures, and making new screen spaces available to movement compositions.

\section{Screendance pedagogy}

The growth of screendance is reflected by the popularity of screendance courses and modules in higher education institutions, and as the number of such courses grow, a robust conversation around screendance pedagogy is emerging. To foster and deepen this discussion, renowned screendance artists Douglas Rosenberg and Katrina McPherson organized and led the Symposium on Teaching Screendance at American Dance Festival in 2015 and the Teaching Screendance: Creating a Practice-Based Pedagogy panel at Dance Films Association in 2016. Inspired by these events, we conducted some interviews about current academic training in the UK and US.

IJSD co-editor Simon Ellis discusses experiences of assessing undergraduate screendance with his former colleague Arabella Stanger. Together they reflect on the 
way students adopt genres in their films, the beautiful mix of film literacy and naïvety, and the ways in which opening and closing credits take on a life of their own. Coeditor Harmony Bench brings together a series of interviews with emerging and established screendance filmmakers-Jason Bahling, Ben Estabrook, Natalie Gotter, Ellen Maynard, and Eric Nordstrom - to reflect on academic training, professional life, the economics of screendance, and changes in the field. These discussions offer timely perspectives on screendance teaching and learning.

We find that interviews have become an important feature of this journal as a way to hear from participants in the field of screendance who might not otherwise be represented in these pages, and we will continue to look for provocative and useful conversations between screendance practitioners, scholars, teachers, and students.

Another new idea that has emerged with this issue is that of curated tours of historical and contemporary screendance works that can be found on the Web. We asked Katrina McPherson to trawl the Internet for some of her old and new film favorites. Her tour is broad ranging and surprising, and provides genuine insight into how influence is felt and transmitted in screendance. This model offers an alternate means of writing the collective and personal creative histories of the field and its practitioners, and we are eager to explore this idea further in future issues.

\section{Dance on the popular screen}

Popular film, television, and especially music videos continue to be important to how our readers and contributors write about, think, and practice screendance. These videos are readily available, include open and diverse ways of moving and dancing, and often unite contemporary choreographic forms with popular music. In this volume, there are articles that investigate specifically music videos.

Samuel Benagr and Terry Ofosu consider the cultural value of the music video Heyba by Ghanaian artist Edem. They also discuss the presence of dance on television in Ghana and the ways in which Afrocentrism is influenced by western biases. Benagr and Ofosu reveal that music videos continue to be a vital aspect of how we understand culture, identity, and dancing.

Melissa Blanco-Borelli takes us on a tour of the spasm as choreography in music videos by Talking Heads, Radiohead, and Atoms for Peace. She places the dancing spasm in the context of neoliberal production and productivity, and asks how the spasm might function as a way to resist overproduction.

The work of Michel Gondry-and in particular his music video Let Forever Be-is treated by Addie Tsai as a means to consider the way our lives and bodies shift between analogue and digital experiences. Tsai wonders to what extent Gondry's 
visualization and treatment of the human body might be useful to screendance scholarship and practice.

\section{Screendance festivals and disciplinary debate}

We have three distinct responses to two different European festivals. Kyra Norman and Hamish MacPherson reflect on the Leeds International Film Festival Screendance Competition, and Wyn Pottratz asks some questions of screendance that were provoked by her time at the Light Moves Festival of Screendance in Limerick, Ireland.

London-based artist Hamish MacPherson-speaking from a "little [choreographic] corner," ${ }^{5}$ perhaps even as an outsider to screendance-wonders about the rules for the LIFF Screendance Competition, and also what work lies outside of "glossy but unimaginative examples of conventional contemporary dance in beautifully shot landscapes." ${ }^{\prime}$ There are large questions here-questions that will be familiar to readers of IJSD - about curation, imagination, and even the value of screendance as a field.

For Pottratz, the question of understanding and defining the limits or edges of screendance is important. She asks, "[surely] screendance cannot be everything?"7 and then refers back to Opensource \{Videodance\}, a meeting of artists and scholars first held in Scotland in June 2006. At that time, some of the people involved wrote a (Hu)Manifesto that Pottratz suggests might be worth revisiting at a similar event or conference.

Norman describes her own response to the LIFF Screendance Competition as a review of the "form of the event." ${ }^{8}$ She values the ways in which festivals invite us to view screendances through other screen theories and practices, and discusses the point at which audiences don't appear to be seeing what they understand the form to be. Whereas MacPherson seems to dissolve any need for screendance as a discipline, Norman's interest is in continuing the debate(s) around disciplinary boundaries and how these both nourish the field and afford its possibility for change and adaptation. In pursuing this aim, Norman provides a meta-level discussion of how IJSD contributes to articulating the boundaries of the field, and thus provides a welcome opportunity for critical reflection.

The contributions gathered in this issue generate a composite image of the field-not a snapshot, but series of relations or a particular navigation. We imagine this journal as a city. We understand that from the outside looking in it is easy to believe that the values, agendas, and even tastes of the editorial team and board of IJSD form a type of screendance edifice, a "model of watertight compartments and segregated studies"; 9 perhaps even a walled city. Indeed, we recognize that while, as editors, we wish to reflect the diversity of the field, the very gate-keeping and curatorial positions in which we find ourselves give us and IJSD the trappings of an institution. Further, it is 
only with the support of institutions, specifically The Ohio State University and Coventry University, that we are able to engage in this editorial labor and provide the screendance field with open-access content. Though we rely on them, it is not a striated ${ }^{10}$ city of institutions in which we imagine ourselves. We do not fancy ourselves guides pointing out staid attractions to tourist-readers. How else might we understand cities and the creative and intellectual spaces IJSD tries to carve out?

The Situationists were the 'free-radicals' of urbanism - free artists and professional amateurs ... [who] theorised a city of situations that overlap, patch, collide, criss-cross, cluster, and punctuate a city by surprise. In the city, the past, present and future all overlap in a messy configuration ... hence all of the divergent factors of a city cannot be fully understood, far less controlled or ordered. This recognition of the complex interplay between elements, interactions and people provides a more dynamic way of viewing and understanding the city. ${ }^{11}$

Screendance is not a field with only monuments to remark upon (though we have those too). The field, its points of reference, and its boundaries are not determined in advance. They are all a dynamic effect of participation, and, as Simon Fildes remarks about openspace technology, "Whoever shows up are the right people."12

A field is an effect of relations, of proximities and distances between people and practices that emerge as distinct only against the background of the field. As Brian Massumi notes in his prelude to philosopher and dance scholar Erin Manning's book Always More Than One, "We all chunk. We are all categorizers and users. Life's conventional elements demand that of us. But we are also transcendental fielders. After all, a chunk is a only a chunk against the contrasting background of the field ..."13 Can we grasp the field in its slippery amorphousness without requiring boundaries and defining edges? Can we conceive of the field of screendance as what Manning calls a milieu, inviting a "topological twist"14 into the field, where edges give way to surroundings, ends to middles, and boundaries to in-betweens? Is it possible to sustain a "field perception"15 that does not mistake the field's products for the field's production? Can a field perception further accommodate the different needs of festivals with their market pressures, audiences, scholars, and above all screendance makers? Patterns and affiliations emerge from creative practice, giving shape to the field and chunking out aesthetic and other domains. Yet creative practices necessarily escape the categories and themes they seem to generate (which, in any case, emerge in retrospect and not at the point of making), and screendance festival curators, audiences, and juries routinely reward artists who do not reflect the seemingly agreedupon definitions of the field's contours-its inclusions and its exclusions.

As a case in point, in February 2016, Harmony Bench attended a program of dance films curated by Mitchell Rose. DANCE@30FPS included Home Alone (2013), a 
promotional video for the internationally renowned Israeli dance company Batsheva. Directed by Adi Halfin, Home Alone incorporates many framing and editing techniques audiences have come to expect of screendance. It has received numerous awards at dance film festivals worldwide, and received the Audience Choice award at DANCE@30FPS. And yet it is a commercial-an advertisement for Batsheva's stagebased production. Just as some members of the audience were puzzled by the 2015 Leeds International Film Festival's Jury Prize winner, Mariam Eqbal's animated Choreography for the Scanner (2015), Bench was initially puzzled by Home Alone, and curious about what the inclusion of promotional content in dance film festivals might indicate about where screendance is headed. As these examples as well as the contents of this issue demonstrate, what falls within the larger container of screendance is up for debate-a debate that this journal has encouraged. The first volume of IJSD suggested that screendance had not yet been invented. Now in our sixth volume in as many years, we seem to be solidifying the suggestion that screendance includes any dance or edited movement onscreen, a position discomfiting for some of our readership_-and at times, ourselves.

We recognize, however, that there is collective intelligence in the field, as with any self-organizing creative community. Tensions exist around boundaries and definitions, to be sure, and we offer the proposal that, while the maturation of the field is important, screendance needs to remain ambiguous to itself. There is fecundity in the unknowing, and the willingness to trust the distributed intelligence of the community foregrounds the collective labor involved in making a place in which to work. What we are emphasizing here can be thought of as a form of self-realization. That somehow, among economic, peer, industry, social, and political pressures, we come to understand our field through the act of making it. This is understanding from within as opposed to rules, criteria, and conventions imposed from without. At a stretch we can imagine that the Scottish philosopher and historian David Hume is hinting at the difficulties - even absurdities - of this kind of auto-awareness when he wrote:

For my part, when I enter most intimately into what I call myself, I always stumble on some particular perception or other, of heat or cold, light or shade, love or hatred, pain or pleasure. I never can catch myself at any time without a perception, and never can observe anything but the perception. ${ }^{16}$

Audiences and filmmakers are only ever experiencing perceptions of screendance, not the thing itself. What actions and practices might such sensory perceptions afford? How do they feel? What might they help us say about our field? Implicit in Hume's writing is a sense of connection and disconnection. That as observers and participants in the field of screendance our experiences, ideas, and actions are mediated through perceptual mechanisms, that are themselves filtered and adjusted through personal taste, desire, ambition, history, and memory. Portuguese neuroscientist Antonio 
Damasio describes the human capacity to be aware of one's self while acknowledging the vastness and simplicity of the existential fine print, as self coming to mind. ${ }^{17} \mathrm{He}$ regards consciousness as "Mind with a twist ... since we cannot be conscious without having a mind to be conscious of". ${ }^{18}$ If we can never catch ourselves without a perception, whether that is a field perception or a perception of an individuated chunk of information, how might we understand ourselves (as individuals and as a field) reflexively through what we perceive? Does field perception enable a field consciousness, a self coming to mind that comes to mind collectively through participation? We think so.

Our various-and current-sensory or perceptual worlds intersect with our remembered pasts to produce a kind of consciousness of the field. It is, of course, only partial awareness and our efforts to develop understanding of the nature of screendance are foiled by the limits of our imaginations and experiences. There is also no sense of unity in our perceptions of the field. Instead, there are capacities for relation. We find that the field moves-and we move with it-as we cultivate creative, scholarly, curatorial, pedagogical, and other techniques of relation. The screendance field's plasticity, resilience, and adaptive powers are unable to be contained; not by individuals, and certainly not by the contributors and editors of IJSD. Manning's description of dancing tango feels apt: "I am leading. But that does not mean I am deciding. Leading is more like initiating an opening, entering the gap, and then waiting to follow her response." ${ }^{19}$ We are both connected to and disconnected from the field itself. To what extent might we become conscious participants in such a distal kind of proximity? The temptation to suggest or state that we know what the field is, and what it should and shouldn't be is an effort to contain, and we imagine that this is a mistake. The implications of such a mistake are profound, and increasingly complex as new screendance artists keep asking how they might go about making work.

In her recent book Artist at Work, philosopher and performance arts theorist Bojana Kunst writes:

[The] emancipation of one's production conditions, the constant reflection on the models and protocols of production, is tightly connected to the contemporary models of production in the post-industrialised era. ${ }^{20}$

Following Kunst's lead, perhaps it is the responsibility of screendance artists to understand the politics of their work by observing the conditions of production of their work. In other words, our community (however narrowly or broadly that might be defined) needs artists to continually challenge and question the means by which their work is made, framed, and presented. This demands energy and attention so that we remain open to as yet unthought of visions of performance, materials, screens, and presentation. It is a way of being with the world that is both cautious (lest we fall into the same traps as those before us) and willing to risk all. This is never more important 
than at this time in our discipline when there is a striking tendency -in part rewarded by showcase festivals - for hyper-production in the aesthetics and feel of moving and dancing images. For independent artists, and new graduates emerging from screendance and film-related programs around the world, such modes of production-and perhaps even taste-are not sustainable.

In 2012 Tim Etchells-artistic director of UK-based theatre company Forced Entertainment-said this:

the good work in fact, the best of it, conforms to no agenda, is not a truly comfortable or fully compliant part of any scheme, plan or provision, that what you do as artists sets its own pace, place, aesthetic, [and] context ... and that the end, in the end, is the work you make, and that the work makes its own rules. Nothing less than this is good enough. Everything else is bullshit. ${ }^{21}$

This volume of the International Journal of Screendance represents a diverse crosssection of the interests, practices and curiosities of a screendance community that is developing and changing, and willing to question its own assumptions about the critical questions for the field. In its pages-or on your screens-we recognize that Etchells' words reflect that the cornerstone of screendance is the practice of screendance. Jaime Conde-Salazar writes, "the dance of the future keeps its ears open and this is why it always puts up a subversive resistance ... It never exists to reaffirm and feed institutions (such as authorship, culture, art, etc.) or disciplines (Dance, Work, etc.)." ${ }^{22}$ We must be conscious that the (screen)dance of the future, which can happen in any context, situation, moment, or relationship, does not pass unnoticed in front of us. Perhaps it might be that the goal of screendance practice is to "escape from the boxes ... to produce revelations," ${ }^{23}$ and that IJSD's most useful struggle will be to try and keep up with the activity and change of the community.

We'd like to welcome and thank our new IJSD copy-editing team: Teoma Jackson Naccarato, Emilie Gallier, and Karen Wood. Thanks to Sarah Whatley of C-DaRE at Coventry University for this staffing support, and thanks to Ohio State University for their ongoing commitment to IJSD's digital platform and distribution. In particular we'd like to acknowledge Ingrid Schneider and Melanie Schlosser, who have been so helpful in making this journal happen.

We hope you are able to find ideas contained within the pages of this journal that both support and provoke your thinking. The next volume of IJSD will be published in August of 2016. It is a special volume dedicated to writing about Siobhan Davies and David Hinton's film All This Can Happen, and is guest-edited by Claudia Kappenberg and Sarah Whatley, with editorial assistance from Becca Webber. We will also have an 
open call in May 2016 for contributions to Volume 8 that will be published in Spring 2017.

\section{Biographies}

Harmony Bench is Assistant Professor in the Department of Dance at The Ohio State University where she teaches in the areas of Dance, Media/Digital Humanities, and Performance Studies. Her writing can be found in Dance Research Journal, The International Journal of Performance Arts and Digital Media, Participations, and The International Journal of Screendance, for which she serves as co-editor with Simon Ellis.

Email: bench.9@osu.edu

Website: http://www.harmonybench.com

Simon Ellis is a choreographer, dancer, film-maker, dramaturge and teacher. He is from New Zealand but now lives in London, and is a Senior Research Fellow at the Centre for Dance Research at Coventry University. He is particularly interested in the limits and possibilities of collaboration in choreographic processes.

Email:simonkellis@gmail.com

Website: http://www.skellis.net

\section{Notes}

${ }^{1}$ IJSD call for papers volume 6, https://screendance.wordpress.com/2015/05/17/int-jof-screendance-open-call-for-submissions-volume-6/

${ }^{2}$ Way and Frampton, "Imagined Archaeology," 113.

${ }^{3}$ Friedland, "The Meaning of the Moves," 39.

${ }^{4}$ Mikou, "Moving Without A Body," 215.

${ }^{5}$ MacPherson, "What Are Screendance Competitions Even For?" 178.

${ }^{6}$ Ibid.

${ }^{7}$ See Pottratz, "Screendance Cannot be Everything" in this issue.

${ }^{8}$ Norman, "Testing Ground," 167.

${ }^{9}$ Conde-Salazar, La Danza Del Futuro, 69. 
10 See Deleuze and Guattari, A Thousand Plateaus for a discussion of smooth and striated spaces.

11 Bostwick-Lorenzo Eiroa and Jones, The Spatial and Social Constructs of Creative Situations, 260.

${ }^{12}$ Qtd. in Pottratz, 184.

${ }^{13}$ Massumi, "Prelude," xii.

${ }^{14}$ Ibid.

15 Ibid. In Always More Than One, Manning explores autistic versus neurotypical perception. She suggests that an autistic critique of the neurotypical might be that of premature "chunking" of the experiential world into discrete subjects and objects, whereas autistic perception retains a less-differentiated field of perception. "Autistic perception [is] persistently reminding us not to begin with the pre-chunked. Begin in the middle! it says. Don't assume to know in advance how the chunking will resolve!" (220). In his prelude to the book, Massumi describes autistic perception as "field perception." The notion arises from Manning's text, but the phrasing is Massumi's.

${ }^{16}$ Hume, A Treatise of Human Nature, Book I, Part 4, Section 6.

${ }^{17}$ See Damasio, Self Comes to Mind.

${ }^{18}$ Idem., 5.

${ }^{19}$ Manning, Relationscapes, 30.

${ }^{20}$ Kunst, Artist at Work: Proximity of Art and Capitalism, eBook.

${ }^{21}$ Etchells, "ISDF Opening - Tim Etchells."

${ }^{22}$ Conde-Salazar, 73.

${ }^{23}$ Idem., 70.

\section{References}

Bostwick-Lorenzo Eiroa, Meredith, and Derek Jones. "The Spatial and Social Constructs of Creative Situations." In Bite, 260-66. Rotterdam: Sense Publishers, 2014.

Bench, Harmony, and Simon Ellis. "Int J. of Screendance - Open Call for Submissions Volume 6". Centre for Screendance. Accessed 4 April 2016.

https://screendance.wordpress.com/2015/05/17/int-j-of-screendance-open-call-forsubmissions-volume-6/

Choreography for the Scanner - In Between Frames Series. Dir. Mariam Eqbal. 2015.

Vimeo. https://vimeo.com/128830552

Conde-Salazar, Jaime. La Danza Del Futuro. Madrid: Continuum, 2015. 
Damasio, Antonio. Self Comes to Mind: Constructing the Conscious Brain. New York: Pantheon Books, 2010.

Deleuze, Gilles and Félix Guattari. A Thousand Plateaus: Capitalism and Schizophrenia. Trans. Brian Massumi. Minneapolis: University of Minnesota Press, 1987.

Etchells, Tim. "ISDF Opening - Tim Etchells," June 2012. http://timetchells.com/isdfopening.

Friedland, Sarah. "The Meaning of the Moves: Gestural Mythologies and the Generic Film." The International Journal of Screendance 6 (2016): 39-56.

http://dx.doi.org/10.18061/ijsd.v6i0.4940

Home Alone. Dir. Adi Halfin. 2013. Vimeo. https://vimeo.com/71282287

Hume, David. 1739. A Treatise of Human Nature. Oxford: Clarendon Press, 2007.

Kunst, Bojana. Artist at Work: Proximity of Art and Capitalism. Winchester, UK: John Hunt Publishing, 2015.

MacPherson, Hamish. "What Are Screendance Competitions Even For? A Response to the 2015 Leeds International Film Festival Screendance Competition." The International Journal of Screendance 6 (2016): 178-181. http://dx.doi.org/10.18061/ijsd.v6i0.5063

Manning, Erin. Relationscapes: Movement, Art, Philosophy. Cambridge, MA: MIT Press, 2009. http://dx.doi.org/10.7551/mitpress/9780262134903.001.0001

. Always More than One: Individuation's Dance. Durham: Duke University Press, 2013.

Massumi, Brian. "Prelude." Always More than One: Individuation's Dance, by Erin Manning. Durham: Duke University Press, 2013. ix-xxiii.

Mikou, Ariadne. "Moving Without A Body: Digital Philosophy and Choreographic Thoughts." The International Journal of Screendance 6 (2016): 213-216.

http://dx.doi.org/10.18061/ijsd.v6i0.5064

Norman, Kyra. "Testing ground: evolving screendance practices and theories and the Leeds International Film Festival Screendance Competition." The International Journal of Screendance 6 (2016): 166-177. http://dx.doi.org/10.18061/ijsd.v6i0.5043

Pottratz, Wyn. "Screendance Cannot be Everything: Defining the Form Ten Years after the (Hu)manifesto." The International Journal of Screendance 6 (2016): 182-185.

http://dx.doi.org/10.18061/ijsd.v6i0.5130 
Way, Ruth, and Russell Frampton, "Imagined Archaeology and Enlivening the Proximate Senses in the construction of Blind Torrent - An Interdisciplinary Screendance Project." The International Journal of Screendance 6 (2016): 112-130. http://dx.doi.org/10.18061/ijsd.v6i0.4908 

ARTICLES 



\title{
Hybrid Texts, Assembled Bodies: Michel Gondry's Merging of Camera and Dancer in "Let Forever Be"
}

Addie Tsai, Texas Woman's University

\begin{abstract}
Michel Gondry, a filmmaker who created and directed music videos for Propaganda Films, which produced close to a third of all music videos by 1990 , began his career in music video and film during this time, where he experimented with collaging postmodern and commercial filmmaking. In 1936, cultural critic and German philosopher Walter Benjamin argued that art fundamentally changes in the age of mechanical reproduction, creating questions of authenticity and aura. This article argues that Gondry's video "Let Forever Be," for The Chemical Brothers, illustrates Benjamin's argument not only in that the digital video itself artificially reproduces the bodies embedded within it, but also in Gondry's employment of collage, special effects, and camera-enabled illusions in order to create a simulated and dream-like world.
\end{abstract}

Keywords: Michel Gondry, music video, Busby Berkeley, Walter Benjamin, simulacra

For those who came of age in the digital century, the oversaturation of technology has resulted in a doubled body, as though one hand formed of flesh and sinew curls into a very real fist, and the other of static and pixels remains disconcertingly unreal, viewed anew through the cyber lens. For those who came of age in the digital century, this ontological state is perhaps nothing to write home about. In fact, for many who came of age in the digital century, known vernacularly as millennials, this hybridized life is of no considerable consequence, mostly because it is what they have always known. But for those of us born in the MTV generation, or for those of us who are old enough to remember a time before our current digital existence, this hyperreality came upon us suddenly. ${ }^{1}$

No filmmaker has commented on this strange ontology quite like Michel Gondry ${ }^{2}$ (1963-), in that ephemeral form that continues to inform mediatized texts: the music video. This quirky and fantastically-minded French filmmaker has become well-known for the worlds he animates in his American feature films, a reputation which exploded with his hit Eternal Sunshine of the Spotless Mind. It could be argued that Gondry 
predicted the current state of digitization and how that state would come to affect the brain and body of viewers and makers of today's hybridized world. Contemporary filmmakers cloak cinematic texts in the conventions of the digital age, complete with $\mathrm{CGI}, \mathrm{FX}$, double exposures, parallel editing, compositing, etc. in order to simulate reality. Many of these technological cues were taken straight from Gondry; for example, the famous bullet time technique employed in The Matrix trilogy was pioneered by Gondry four years prior in the music video "Like a Rolling Stone." ${ }^{3}$ Like many other music video filmmakers of the early 1990s, Gondry experimented with filmmaking techniques through the genre of music video that he would later go on to perfect with his feature-length films. However, unlike many other music video and cinema filmmakers, Gondry consciously explored the liminal space between analog film and digital processing as a reflection of a future world, a future time, and a future embodiment.

In this article, I will discuss "Let Forever Be," ${ }^{4}$ a music video Gondry created for The Chemical Brothers that helped cement his reputation for employing a collage of digital and film techniques. "Let Forever Be" was released in 1999, at the turn of the new millennium, and positioned Gondry as a kind of auteur-scholar commenting on the role simulacra plays in contemporary life. "Let Forever Be" contains themes Gondry would later perfect and become known for, merging his skills in art direction and special effects to call attention to the sur- and hyperreality of the digital world, and demonstrating the distance between digital art and the viewer's notion of the real. I will argue that Gondry hybridizes "Let Forever Be" by merging his own content with dance sequences choreographed by Busby Berkeley in the film musical Dames, ${ }^{5}$ collaging film and video in order to emphasize the video's dreamlike reality, and digitally manipulating the hybrid body of the main character, performed by dancer Stephanie Landwehr. I will begin by discussing the primary visual and choreographic influences in "Let Forever Be." Like Gondry, philosopher and cultural critic Walter Benjamin was able to predict, and in some senses spur, the repercussions of the move from the real to the recorded (and thus, to the digital). To that end, I will explore larger questions regarding hybrid embodiment that arise via the special effect techniques employed in "Let Forever Be." Further, I will illustrate how these questions intersect with Benjamin's forecast for transformations of art, aura, and authenticity in a technologically-advanced age.

\section{“Let Forever Be," A Many-Splendored Thing}

Due to the many morphing shots that Gondry employs, and within those shots, the many versions of bodies becoming other bodies, this section is dedicated to describing the various filmic movements in "Let Forever Be."

"Let Forever Be" opens with two concurrent frames zeroing in on a rabbi outside of a high-rise apartment building, who provides the drum beat throughout the music 
video. The camera briefly pans out to the street before it makes its way into a window high up in the building, and settles on our heroine, a young woman still in bed, sound asleep. The screen splits and multiplies into nine symmetrically and compositionally identical frames of the previous image, moving onward to a close up of her alarm clock. This shot splits into fourteen diamond-shaped frames of the alarm clock, some of which overlay one another, contrasting the flat and one-dimensional character of the earlier image of our heroine in bed. One by one, a hand we might presume to be that of the heroine, turns off the alarm clocks; however, the hand is revealed to belong to a dancer.

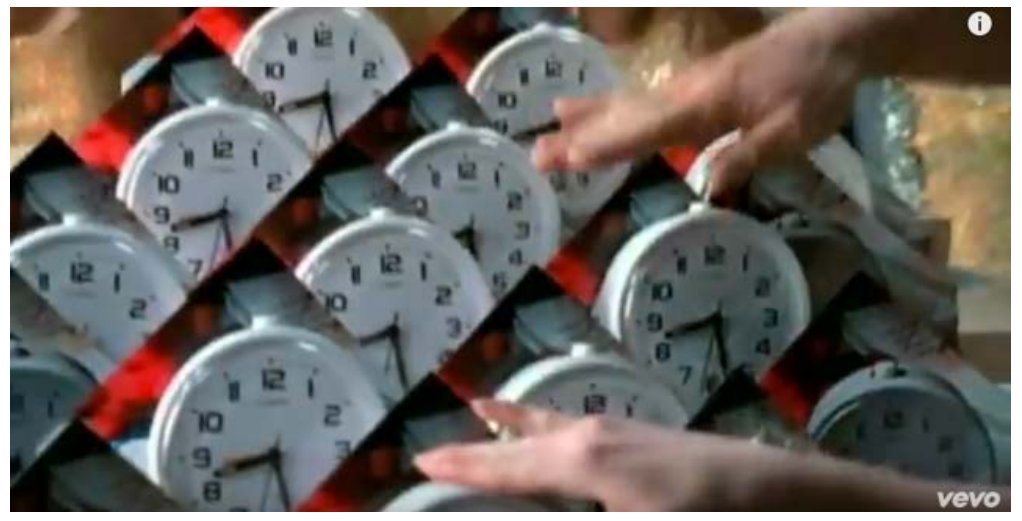

Screenshot of the many alarm clocks from the opening of the video, "Let Forever Be."

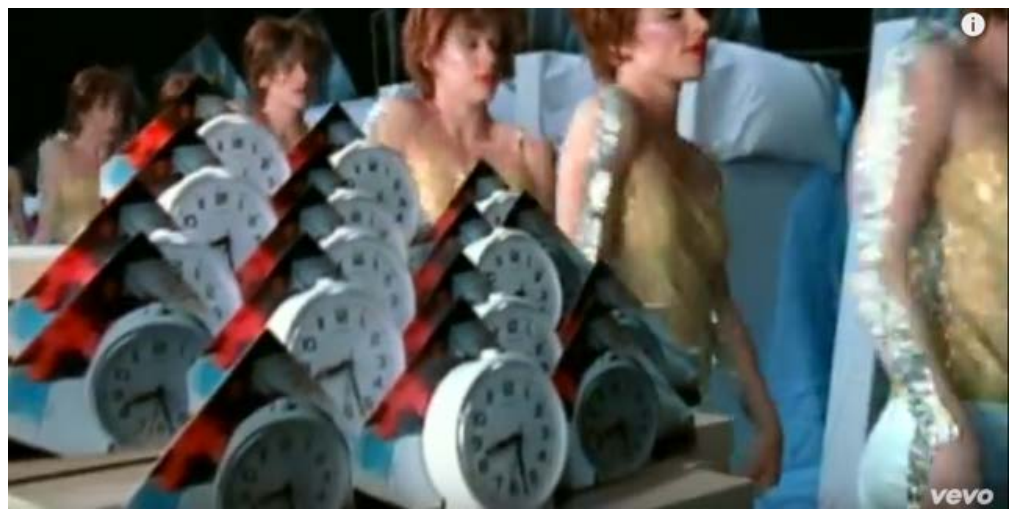

Screenshot of the dissolve between the alarm clocks in the heroine's bedroom to the multiple versions of the heroine-turned-gold lamé disco dancer from the video, "Let Forever Be."

Our new disco dancer, a redhead with bright red lipstick, appears next to a mattress similar to the one in which our heroine slept. She is joined by four or five other dancers who hold her likeness, and they all roll their shoulders backwards and forwards to the music while placing a hand on their heads, all in unison. Next they lunge towards the mattress and tuck themselves into bed. Through digital editing techniques, the shot morphs from the many sparkling dancers to our heroine in bed, who turns off the alarm clock and tilts her head back onto her pillow as though resisting waking up. She then tosses off the covers and, while seated on the edge of the bed, stretches her arms above her. The heroine's yellow tank top and white shorts replace the disco dancers' gold lamé tops and white go-go shorts (both embellished with a glittery silvery stripe down one side). 
This shot dissolves back to the shimmering dancers, who are facing away from the camera with arms stretched towards the sky. They open their arms outwards and down, and then extend an arm forward with a flashy, high developpé. The dancers step away from the mirror through which we see them dance, bringing their arms above their heads in an imprecise port de bras en haut and shaking their hips to the beat. The dancers flick their right arms and right legs, pivoting to face the camera. Their movements continue in this vein, with short thrusts and swivels, and rotations of the hips, feet, and knees, before they turn three times and kneel down in front of a mirror. The image in the mirror then becomes our heroine in a shopping mall, where she races up the escalator in much more subdued attire: sleeveless pink shirt, gray pencil skirt, white stockings, and black shoes.

The shot dissolves into a kaleidoscopic image of the heroine, who appears reproduced six times on the escalator, flattened into a pattern in which her many heads are joined together at the center. Suddenly, the image is no longer of our heroine, but of our dancers lying on a platform, wearing shiny fuchsia tops, sparkly silver skirts, and dressy black flats. The dancers have one knee lifted and rotated over the other leg, while they circle their arms around, crossing over the dancer next to them. The dancers spread their legs to a wide second and stretch their arms towards us as we watch them. They stand, sashaying their hips as they walk down the platform steps, extending their movement vocabulary to include leg extensions, quick turns, and fast arm variations. The dancers walk off stage (and screen) to give the rabbi drummer, who is now also reproduced six times, his moment in the video.

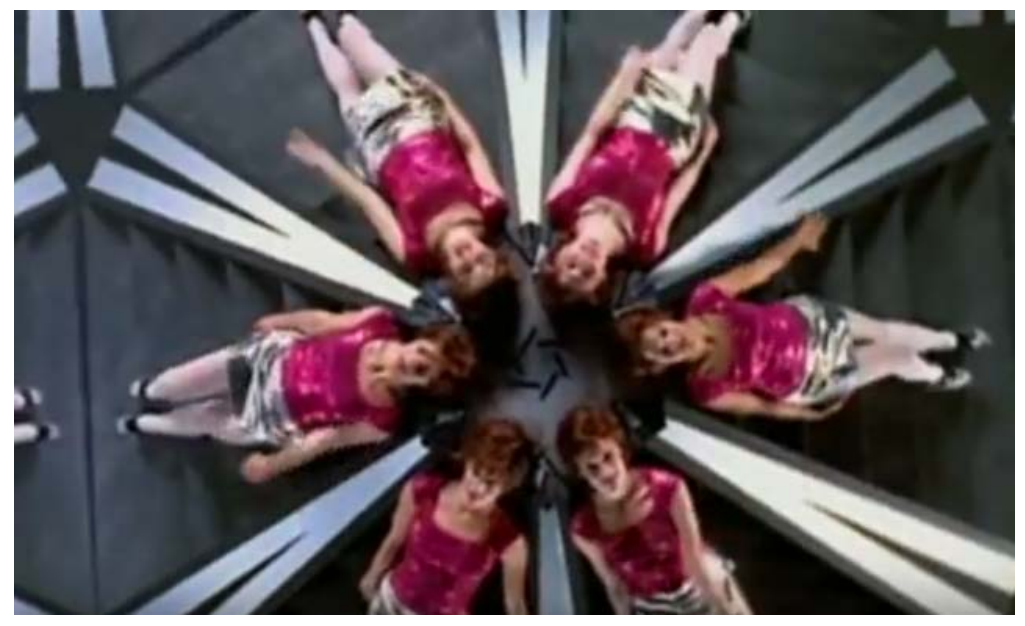

Screenshot of the disco dancers in Berkeley-esque kaleidoscope formation from the video "Let Forever Be." 


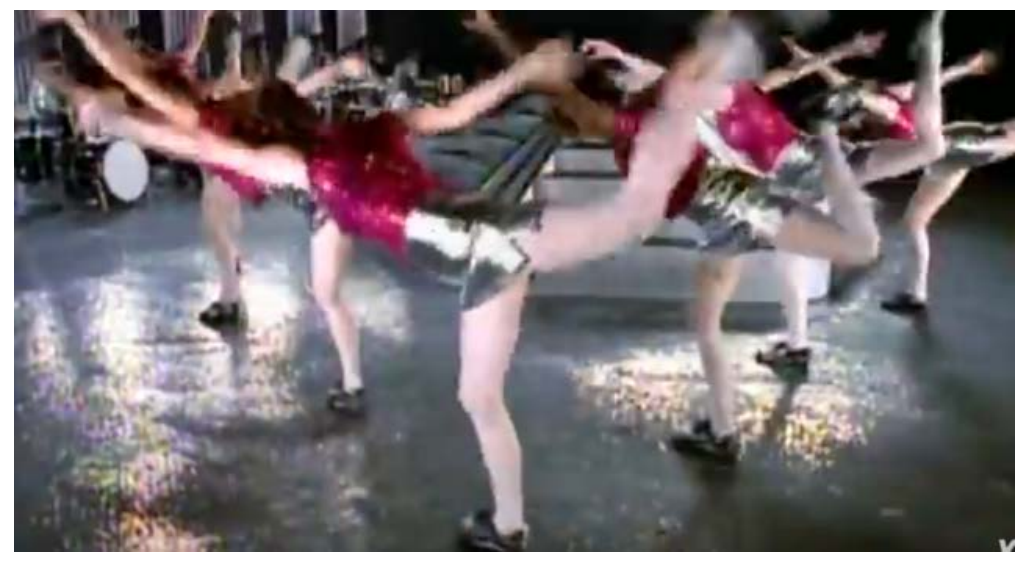

Screenshot of the disco dancers' moves from the video "Let Forever Be."

Gondry uses an initial digital editing technique to dissolve the many reproductions of the drummer back to the original shot of the rabbi playing on the street next to our heroine who is running past him to get to work on time. She briefly looks back to watch and then, leaning the opposite direction just as it seems she is about to fall, the shot changes to two dancers in a split screen, counterbalancing one another with a push and pull of the arm. One of the dancers exits, while another takes her place in the kaleidoscopic image. Just then the shot cuts back to our heroine running up the mall escalator, but not for long, as it again dissolves into a split screen of two copies of the dancer, which pans out to include the many dancers, this time from an earlier shot. The shot is familiar yet slightly altered as the women all begin to pull black turtlenecks over their shiny tops. As the women adjust the turtlenecks over their torsos, it is suddenly our heroine pulling down her own black turtleneck at her job as a cosmetics salesclerk, while chatting with a customer. Our heroine looks from the left to the right as though something feels amiss to her, and now we see the dancers again, back in their pink glittering tops, in seven diamond-shaped frames. The dancers run back to their places where we first witnessed them, pushing on the window frame in front of them, which becomes our heroine's window through which she looks out onto the street where the rabbi plays. She gazes down at her nightstand on which there is no longer an alarm clock, but instead, a tiny drum kit. She gets back into bed. The bed opens out like an accordion into many beds, in which the dancers lie sleeping in identical positions. The dancers spin out onto the stage, where they swing their hips, roll their heads around and spin again, lunging forward and backward. This part of the choreography is the first time the dancers split up briefly into two separate groups of synchronized movement. The dancers pirouette into the pirouette of our heroine on the street, before she stumbles out of the turn, and onto the dancers. The dancers hold oversized images of the heroine's head over their own as they continue to dance. Eventually, they take their positions inside multiple, diamond-cut frames that now appear handmade out of cardboard rather than created digitally. The shot then opens to a close-up of our salesclerk with the same oversized head, which shrinks to its normal size as she applies nail polish on a customer. This shot spans back out to our dancers in black turtlenecks, and then to a kaleidoscopic shot of the drummers, and 
finally to the rabbi, who performs in a corner of our heroine's bedroom. Our heroine, finally aware of her own nightmarish vision, covers her ears while backing away from the rabbi into her changing screen. This image triples, giving way to an image of the dancers dressed in the same clothing as the heroine. The image rotates back and forth, before it is revealed that the image isn't multiplied digitally after all, but is instead a cardboard replica of our heroine in triplicate being held over the dancers' lower bodies as they dance.

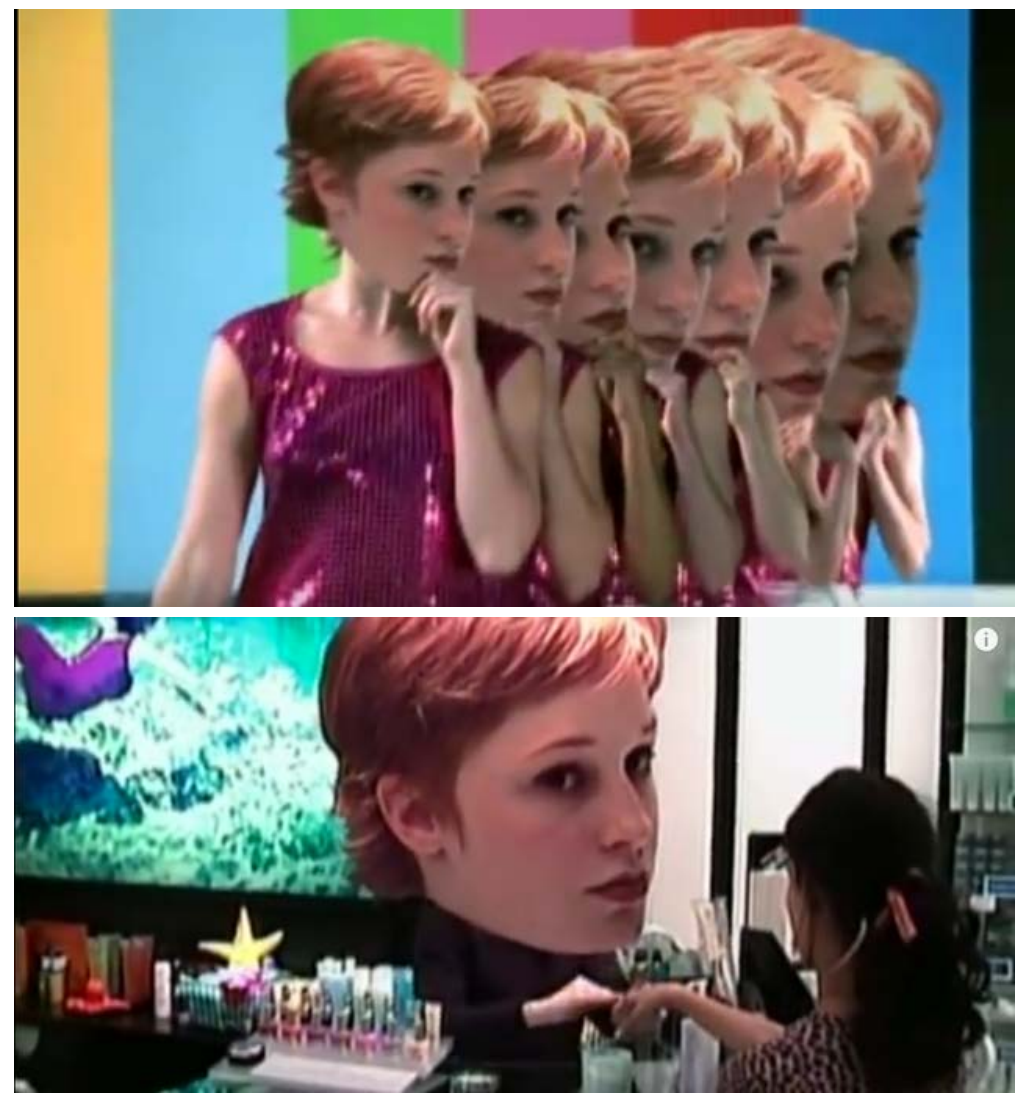

Screenshot of the disco dancers holding oversized cutouts of the heroine's head over their own faces from the video "Let Forever Be."

Screenshot of the heroine attending to customers at her cosmetics counter, complete with her own oversized cutout of her face from the video "Let Forever Be."

We are now back with our heroine, the original, who is in bed again. As she blinks, the shot dissolves into the dancers, who stare at us as they hauntingly blink their glittering eyelids. The many alarm clocks now replace the blinking dancers, which are then replaced by one enormous clock. Our heroine shrinks from the clock's looming size and reminder, and covers her face with her bedspread. A pixelated, moving shot of the blanket moves back and forth across the screen until it slowly fades to black.

\section{The (Dis)Embodiment of Flesh}

In his 1931 dance review of Alfred Jackson's Girls, titled "Girls and Crisis," cultural critic Siegfried Kracauer asks: "What is it that they, like an image become flesh, embody?"6 This question applies to the cosmetics salesclerk in "Let Forever Be," who is trapped between the recurring nightmarish reality of waking to her alarm clock for her job in a 
shopping mall, and the dream of herself as a dozen glittering disco dancers. We as spectators are also made aware of our own hybridized selves through Gondry's manipulation of bodies. Gondry intentionally exposes the processes by which he portrays the real woman waking up from her visions of the nightmare versions of herself. Further, Gondry's works lead us to the question: what parts of our ontological lives are real within this digital experience? In the opening epigraph of his revolutionary text, Simulacra and Simulation, Jean Baudrillard quotes Ecclesiastes: "The simulacrum is never that which conceals the truth-it is the truth which conceals that there is none." "Let Forever Be" arrives almost a century after Walter Benjamin's haunting prediction in one of the most influential essays on the study of film and photography, "The Work of Art in the Age of Mechanical Reproduction." ${ }^{\prime 8}$ Instead of the reproducibility of the artwork calling into question the relationship art holds with authenticity, tradition, and aura, "Let Forever Be" reminds us how technology has become its own character within the artwork, through its constant, multivalent surveillance, and further, that art can also emerge from technology as witness. "Let Forever $\mathrm{Be}^{\prime \prime}$ illustrates the means by which our experiences as viewers have become simulated. Our heroine's dreams of her body multiplied in dazzling and psychedelic forms stands in for our own haunting visions created by an overabundance of and overexposure to digital technologies. Metaphorically speaking, we (the viewers) are the cosmetics girl waking to an army of ringing alarm clocks. We are also the disco dancers constructed from many fused appendages, leading us to question which body is ours: the one refracted in the mirror?; the one whose arms are merged into the central figure?; or the one transformed into a video image, processed through the lens, and made to seem real? Gondry's choices call into question how human bodies operate in a world entrenched in artificial media. This question has implications for millennial spectators trying to understand their bodies within this very real and hyperreal experience of the world. Gondry's constructions of relationships between the body and technology also call into question how bodies change when encountered via film and video, in the context of screendance as well as pop films. One could argue that Gondry can only hybridize the dancing body so far, because Gondry himself is not a choreographer as much as he is a director of processes in film, video, camera, and animation. I contend that the contemporary digital world that emerged from the early 1990s and continues into present-day-one for which Gondry was instrumental in building the language and aesthetic means of expression before many contemporary filmmakers-has irrevocably shifted our sense of the real body versus digitized figures in the cyber frame. ${ }^{9}$ Gondry's fusion techniques offer novel opportunities for choreographers to imagine bodies on film, and bring insights to spectators of other media, such as music video, digital video, and traditional film. These insights contribute to legitimizing dance as a unique discipline, because screendance responds to questions about the body within a culturally determinant space. Our notion of the body can be contextualized upon the cultural world our body inhabits, and screendance can explore this relationship in myriad ways. 
Kracauer's question regarding Alfred Jackson's Girls - "what do they embody?"- has highlighted complications regarding women's bodies in media. Certainly critics have addressed the tendency and history of the music video genre to exploit women as sparkling objects. The current objectification of women in music videos is furthered by the history of the woman's body as duplicated by the machine. ${ }^{10}$ How has the digital age impacted our notion of the body, at once alive and processed, fragmented and reassembled? At this point, as we further explore the implications of Gondry's world rendered real, hybrid, copied, and unreal, we can update Kracauer's question to ask the following: what does the body in "Let Forever Be," as flesh become image, broken apart, and morphed together, embody for those who can no longer distinguish between what is real, simulated, copied, and collaged? How does this multi-layered negotiation contribute to our own understanding (or as Lacan would say, misrecognition) of our own hybrid selves? This section will attend to these questions in order to better understand how, through "Let Forever Be," Gondry deployed Benjamin's theory within the burgeoning music video industry in the late-90s. Ultimately, both Benjamin's theory and Gondry's re-envisioning of his ideas contributed to changing the face of the music video genre as a whole.

Although popular media outlets such as Pitchfork Media, The A.V. Club, Huffington Post, and Paste Magazine have addressed music video as an art form, they fail to address aesthetic and theoretical approaches to music video in relation to cultural theory. Saul Austerlitz's Money for Nothing: A History of the Music Video from the Beatles to the White Stripes and Rob Tannenbaum and Craig Marks's I Want My MTV: The Uncensored Story of the Music Video Revolution provide chronological accounts of music video and MTV respectively. These accounts primarily reveal the historical and social moments that impacted music video, rather than examining the critical moves realized by creators of the form. These texts rarely mention Gondry's vast oeuvre as a music video director, and if mentioned, he is often one name in a list of directors during the height of his career. Austerlitz's text does dedicate a chapter to defending how Gondry and Spike Jonze operate as auteurs, but he mostly offers a subjective, unsupported reading of Gondry's most popular videos from the 1990s. Two particularly illuminating texts, however, offer critical analyses on music video. Rewind, Play, Fast Forward: The Past, Present and Future of the Music Video, is a media studies compilation of papers edited by Henry Keazor and Thorsten Wubbena and delivered during an international and interdisciplinary symposium in 2008 at the Goethe-University Frankfurt/Main. Giulia Gabrielli's essay, "The Contribution of Michel Gondry," explores the relationship between image and music in Gondry's music videos. In her books Experiencing Music Video: Aesthetics and Cultural Context and Unruly Media: Youtube, Music Video, and the New Digital Cinema, Carol Vernallis sets out to "take music video seriously," 11 using film and music theory to read music video as a form of text. Although these publications contribute substantially in terms of building a literature for music video as its own genre, few scholars apply post-structural media theory to music video. 
Film and dance scholars have written widely about screendance, sometimes referred to as dance film, video dance, or dance for camera. Popular topics initially included film artists such as Fred Astaire, Gene Kelly, Busby Berkeley, and Charlie Chaplin. Yannis Tzioumakis and Siân Lincoln's The Time of Our Lives: Dirty Dancing and Popular Culture offers individual essays regarding the cultural impact of the iconic dance film. Further, Melissa Blanco Borelli's The Oxford Handbook of Dance and Popular Screen provides a comprehensive, contemporary discussion of dance on film that seeks to address the breadth and depth of the field, including diverse cultural narratives. The book has a section titled The Music Video and Televisual Bodies, in which dance scholars address audiovisual and televisual dance.

In terms of the dance movement vocabulary itself, many scholars have focused on music videos in which the dance used for aesthetic or narrative content is clearly seen as dance in the traditionally choreographed sense of the genre, such as that choreographed and performed by Beyoncé, Paula Abdul, Janet Jackson, and Justin Timberlake. Gondry, on the other hand, employs choreographed bodies in a nontraditional sense. The dance Gondry employs is often seen as secondary to other elements, such as technological effects or hyperreality. I contend that scholarship on the nontraditional use of dancing bodies in video is important not only for music video, but for the evolving discipline of screendance. ${ }^{12}$

While keeping Gondry's use of Berkeley's choreography in mind, the remainder of this article will focus on the relationship between "Let Forever Be" and Benjamin's theories of reproducible art. Benjamin's writings offer a frame through which to understand the Gondrian world in "Let Forever Be," which operates as a hybrid text, challenging the questions that arise for Benjamin regarding aura, authenticity, ${ }^{13}$ and tradition, particularly in terms of how video products (such as choreographic music videos) ${ }^{14}$ complicate the relationship between the artificial and the real. Many scholars have addressed the connections between Benjamin's theory and traditional film products, but few tie Benjamin's theory to the well-established form of music video.

\section{Walter Benjamin and the Digital Age}

Benjamin discussed the future of art after the invention of the photographic and film camera, quoting Franz Werfel as saying, "The film has not yet realized its true meaning, its real possibilities ... these consist in its unique faculty to express by natural means and with incomparable persuasiveness all that is fairylike, marvelous, supernatural." ${ }^{15}$ Gondry's aesthetic choices point to the impact of advances in film and video technologies on the genre of music video. Benjamin did not live to see Gondry enact his charge regarding the future of the film medium, using the camera's malleability to create fantastical worlds that merge reality and illusion. Benjamin argued that one of the most significant changes to art in a mechanical age would be the emancipation of art from its aura, closely linked with its authenticity. Political theorist Andrew Robinson 
explains aura as "an effect of a work of art being uniquely present in time and space."16 Once art can be reproduced, it no longer exists in any unique present time or space, and according to Benjamin, loses its aura and authenticity. ${ }^{17}$ This is perhaps more true for the music video than for the feature film, because the music video begins its life in a televisual or cyber-enabled viewing experience, whereas the feature film is dominantly experienced in the live environment of the movie theater.

Benjamin seems ambivalent regarding the loss of aura created by mechanical reproduction. On the one hand, art in the mechanical age is emancipated from a controlled place in the tradition from which the works emerge or in which critics situate them. ${ }^{18}$ The reproducible artwork focuses instead on the copied image, creating a distracted, absent-minded viewer. ${ }^{19}$ As such, the mechanical age compromises the political role of the audience as agitator.

Benjamin's theory is useful in exploring Gondry's hybrid approach to "Let Forever Be" as a means to agitate the viewer's understanding of reality and nonreality. Whereas contemporary filmmakers use digitized techniques to connect the gaps between shots in a clear and realistic way, Gondry explicitly exposes his technological processes in order to reveal the ways in which mediatized texts are manipulated by artificial processes.

The question of aura for the screendance product includes within it larger questions than for photographs or paintings as the reproducible art products. Unlike music video, which lives in a digital medium, a live, ${ }^{20}$ authentic dance work occurs in a physical space and time, using live bodies. Although Gondry hybridizes the body with assemblages of body parts in "Let Forever Be," he does film live bodies for the video's content. How does our notion of the dancing body change within the digital video? What consequence does the loss of aura hold for a dancing body refracted, assembled, and choreographed for the video screen?

\section{Is this the real life, or is this just fantasy? ${ }^{21}:$ Gondry's morphing trickery}

In separate interviews featuring Gondry and Noel Gallagher (lead singer of Oasis who provided lead vocals for "Let Forever Be"), which appeared on Director's Series, Vol. 3 The Work of Director Michel Gondry, ${ }^{22}$ Gondry and Gallagher ${ }^{23}$ both discuss the use of film and digital processing to produce different aspects of reality and fantasy for the main character in the video:

I wanted to start to shoot on video but I was afraid because I always thought it would look ugly. I know Spike [Jonze] was doing stuff on video and I was watching that, I was like, yeah it's cool, but eh, I like film. I remember stuff like-especially the 70s TV show in England from the 
BBC - like the Benny Hill. When they would shoot indoors on video, it was a very crisp look, on the outdoor they would shoot on 16 millimeter camera because the video camera was too big at the time. The look was completely different but the action would match. So I had this idea to shoot half the video on film, and half on video, and do invisible transition.

-Gondry

... he came up with the idea that the effects would be real and the girl in her dream state, when she goes into her imaginings, the effects are created, sort of like having a cheesy 80 s kind of video effect[s], it would actually be reality doing the effect.

-Gallagher

Those $80 \mathrm{~s}$, 70s video effect[s] when it was going into kinetoscope, or flaring, or feedback effect, I thought it would be nice to have people miming the effect as actual choreography.

-Gondry

Although influenced by Busby Berkeley's use of the body and the camera in Dames, Gondry extends this interaction, enhanced by the technological advancements of the digital age. When the wide-eyed, coquettish women in Berkeley's dance numbers suddenly notice the camera's gaze, they repurpose their props, such as lipstick, by obstructing the camera's view as though it were a potential suitor or peeping tom. The camera lens becomes personified via the various gestures the women enact towards it. The women are shown in various manners of undress, and parts of their clothing fall over the camera as if it were a spectator. Additionally, when a woman who is being watched proceeds to block the camera's view with a coquettish grin, Berkeley has turned the relationship between the camera and the female figure into a flirtatious one, potent with seduction. ${ }^{24}$

In Gondry's world the camera is similarly omnipresent and all consuming. By blending film and digital, "Let Forever Be" hybridizes the experience of the character in the video, as well as that of the spectators who are toppled to-and-fro between analog and digital processes like the rocking of a cruise ship. Is the girl's dream built from her own subconscious, or has the camera trapped the girl between real life and surreality?

Mitch Goldstein illustrates how Gondry hybridizes the text of "Let Forever Be" through film, video, and the transitions between the two. Goldstein charts Gondry's passages between reality and the dream world in his project, "'Let Forever Be' Data." His charts indicate at what points the video's lyrical, solo, or bridge sections intersect with the narrative moments of reality, nightmare, invasions (when the dreams invade reality), and "morphs" (when Gondry transitions from one world to another). ${ }^{25}$ Goldstein's data 
reveal how the two worlds, of reality and dreaming, gradually close in on one another-just as the transitions between film and video do. In other words, film and video become the lenses through which the viewer interprets the real and non-real. As Benjamin foresaw, technological advancements resulted in a compromising of the authenticity of art, which can be further extended to confusion regarding what version or versions of reality are authentic. Not only is the originality of the artwork impossible to discern within the technological age, but so too is the notion of what is real in our everyday lives. Certainly a body in any music video is an image of a body. In "Let Forever Be," Gondry exposes the body as artificial. Gondry uses technology to remind viewers how similar our digitally filtered experiences are to that of his salesclerk; her own dancing bodies close in on her, much the way technology surrounds us.

To heighten the welded confusion of real and digitized existence, Gondry composes the bodies in the dream state out of multiple bodies of extras, fused electronically with the duplicated bodies on screen. At times, these hybrid bodies are then reflected in a row of mirrors. Taking a cue from Berkeley's floating heads in "I Only Have Eyes For You," Gondry attaches cardboard replicas of Landwehr's face to the actual bodies of the performers.

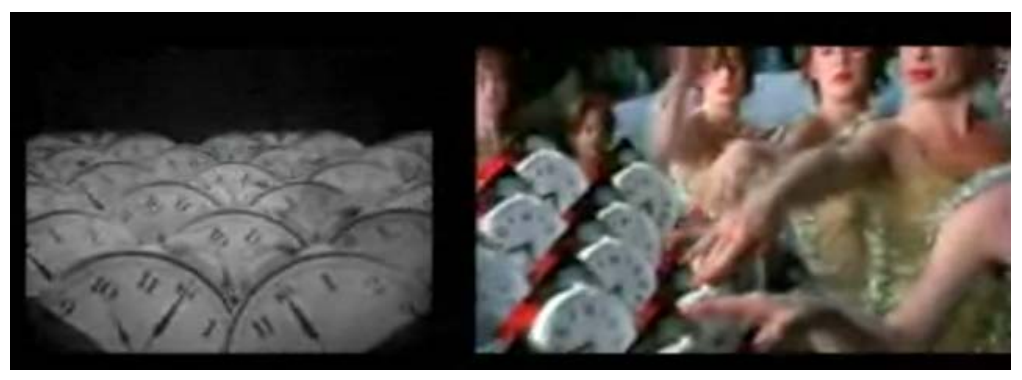

Screenshot from Digital Commons' "Digital Analyzer: Busby Berkeley vs. Michel Gondry."

In this scenario, are the women manufactured through the digital medium, or in real life? The answer is no longer easy to ascertain. In typical Gondry fashion, the heads are revealed to be artificial, as the dancers hold these heads slightly away from their faces. Additionally, Gondry fuses the heroine's real body with the bodies of other dancers who are staged to resemble her. This fusion, along with the mirror-reflected bodies and the head cut-outs, not only reveals the hybrid nature of the body in digital film, but also creates a hybrid body within the narrative of the cinematic text. These unfamiliar bodies are fragmented, spliced, and merged together into a surreal world in which reality and dream do not occupy separate spheres of existence.

\section{Only Have Eyes for Beautiful Dames: Berkeley Gondry-magined}

On the Critical Commons website, in the "Digital Analyzer: Busby Berkeley vs. Michel Gondry," ${ }^{26}$ the Dames sequence is played in real time next to "Let Forever Be." At 49 seconds in both films the screens fill with alarm clocks. Berkeley's alarm clocks are set against black, while Gondry's are shut off by the many disco versions of the cosmetics 
saleswoman. At 58 seconds, Gondry's multiplied bodies fall onto their mattresses in full costume under a blanket of strobe lighting, while Berkeley's women, configured to appear multiplied, fall into their beds. At 3:10, Gondry's dancers hold cut-outs of the heroine's face in front of their own, while in the opening of "I Only Have Eyes For You," Ruby Keeler's head is floating in the black sea where it multiplies, extending into horizontal and vertical lines that then scatter.

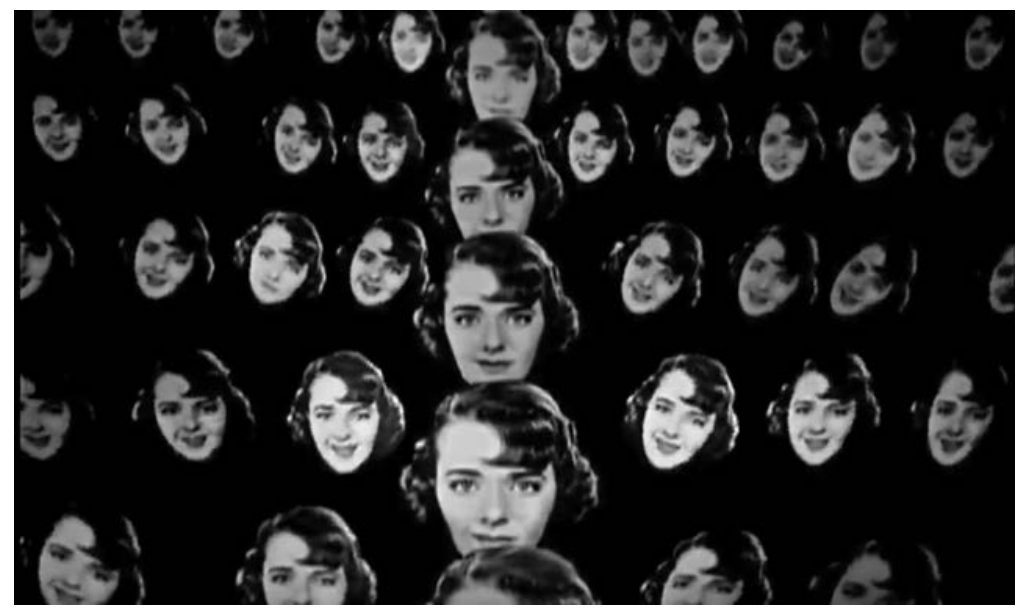

Screenshot of Ruby Keeler's floating heads in Dames, director Ray Enright (1934), and choreographer Busby Berkeley, from the "I Only Have Eyes For You" musical number, starring Ruby Keeler.

Busby Berkeley, chief choreographer of the Warner Brothers musicals from 1933 to 1937, was inspired by the military patterns of the drills he set for the United States Army. Berkeley later served as choreographer for the Ziegfield Follies, bringing precision dance, a dance form in which dancers perform as a group in unison and which emphasizes the "precision" of movement, ${ }^{27}$ to cinematic screen with accompanying camera-formed kaleidoscopes in Hollywood musicals. ${ }^{28}$ By 1930, he had choreographed twenty-one Broadway musicals. Berkeley's choreography drew audiences away from the hardship of their Depression-centered lives through song and dance, transporting them to the mesmerizing fantasy world of bodies and patterns, transformed by illusions crafted with props as well as tools solely available with the film camera. One could argue that because Berkeley could not rely on his own dance experience (he never took a single dance class), he instead became known for his quick understanding and invention of cinematic techniques, such as unusual camera angles, and the incorporation of props like rolling platforms, mirrors, and wide-angle lenses that maximize spatial possibilities in his musical numbers. He became very effective at arranging bodies on stage in geometric patterns that were then mirrored by his techniques with the camera. Because Berkeley's choreography existed solely on film, his dance sequences reflect Benjamin's argument that a mechanically reproducible work of art emancipates itself from the notion of authenticity. Not only does Berkeley's artwork lack an aura, but the dancers in his films lose their uniqueness as individual performers, appearing only as filtered and processed forms. 
Presumably, Gondry was drawn to Berkeley for his privileging of visual and bodily architecture through a camera-enabled world. In an interview, Gondry expressed a shared interest with Berkeley in the potential that choreography has for designing dynamic spatial patterns:

I would see choreography that was boring and conventional and all about close-up as to me choreography should be about architecture and wide shot and geometrical pattern and not about putting your guts out. It's about expressing shapes with your body without showing expression in your voice. ${ }^{29}$

Berkeley popularized dance for a mixed audience at the transition between silent films and "talkies." What does Gondry's work with Berkeley illuminate regarding how filmmakers use the dancing body to represent the pattern of the machine, or further, the body as re-interpreted through mechanic processes of film and video? Given the already hybrid nature of music video, which is further hybridized by Gondry's own aesthetic and technological choices, "Let Forever Be" brings out intersections between live bodies and bodies as re-presented on screen.

Benjamin's text from 1936 intersects with the end of Berkeley's reign at Warner Brothers in 1939. "The Work of Art in the Age of Mechanical Reproduction" was published in Germany while Berkeley used new film cameras to transform bodies into pinwheels in cinemas across the United States. Once a copy can be perfected through the art of technology, Benjamin contends that the question of authenticity is evoked. In the world of instant copies, what is original? In Benjamin's own words, "the presence of the original is the prerequisite to the concept of authenticity"; ${ }^{30}$ thus "the technique of reproduction detaches the reproduced object from the domain of tradition." ${ }^{31}$ I would argue that by embedding references to Dames within "Let Forever Be," Gondry not only links himself to a tradition, but also connects his cinematic text to other choreographic texts. Gondry nods to Berkeley through his employment of fragmentation, synchronization, and multiplication of the body as viewed through the lens of the camera. Benjamin could not have predicted the ease with which worlds can be recreated, distorted, and double-exposed through the camera, as well as via computers that process and edit video footage.

With the digital era, new editing and processing possibilities inspired complex investigations of the relationship between dancer and machine. Earlier choreographers such as Berkeley could only mimic human-machine interactions using live bodies in front of a film camera. Although Berkeley used the camera and illusion to change the way the body was seen, the dancers themselves were real, manufactured to resemble one another to such a precise approximation that they represented the efficiency of the machine found in assembly line production. Gondry was able to move 
beyond Berkeley's machinic metaphors, and fuse bodies digitally onto the real bodies performing the dance in "Let Forever Be."

I propose that Gondry hybridizes "Let Forever Be," using key aesthetic and visual elements from two dance sequences in Dames, namely "Dames" (the title sequence), and "I Only Have Eyes For You." The musical composition "I Only Have Eyes For You" further reveals the complexities of technological reproduction. The song, composed by Harry Warren and lyricist AI Dubin, was written specifically for Dames and has been used in countless films and covered by numerous artists over the last half century. As one can see, the implications of technology are as endless and eternal as the ongoing life of the machine. Many music critics have stated that the target audience for music videos at the time of release of "Let Forever Be" consisted of young white men between eighteen and twenty-four years of age. ${ }^{32}$ These men arguably sought out music video as a preference over live dance performances because the music videos promoted the musical groups they were avidly listening to at the time. Evidence suggests that young men in this time period displayed a lack of interest in dance, particularly as performed in Hollywood musicals. ${ }^{33}$ Gondry employs choreography less familiar to his target audience than that which audiences might be more familiar with from televised productions such as the Rockettes in the Macy's Day parade. Gondry makes a unique contribution by subversively incorporating the visual patterns and movements of precision dance for a contemporary audience. Although the presumably post-adolescent young white men that view Gondry's video may not have particular familiarity or interest in the Berkeley referent, Gondry still capitalizes on the history of using the female body as a backdrop. Gondry utilizes technology for aesthetic purposes, as well as to comment upon the implications of technologically mediated artwork.

Berkeley's dance sequences discussed above provided the primary visual and choreographic inspirations for Gondry in "Let Forever Be." According to film critic Kevin Lee,

["I Only Have Eyes For You" is] ostensibly a cinematic love letter to Warner Brothers stalwart Ruby Keeler, [that] blossoms into a many-splendored meditation in movement: the star image as that well-worn paradox of intimate and accessible, unequivocally singular and infinitely reproducible. Along these lines, Berkeley's compositions oscillate between close-up and wide shot, human figures dissolving into abstract geometries. These themes are pushed to even greater visual extremes in the climactic title number, a celebratory confluence of capitalist desire for abundance, sexual provocation/objectification, avant garde cubism and quasi-fascist pageantry and precision - in other words, it encapsulates the major themes of the 1930 s better than any other ten minutes in cinema. ${ }^{34}$ 
Lee's assertion regarding this sequence mirrors the widely discussed relationship between the precision dance movement of this era and capitalist abundance. The camera enables Berkeley's dissolutions between human figures and abstract geometries.

Taken a step further, in Berkeley's use of staging and choreographing bodies around the lens, the camera is itself a body, used to fragment and duplicate the bodies on screen. In "I Only Have Eyes For You," Berkeley uses the viewer's awareness of the lens to emphasize the voyeuristic nature of the camera and videographer while creating a transition between choreographic phrases. For example, throughout the sequence, many women perform intimate routines on screen, such as bathing or primping themselves in the mirror. Periodically, the subject of a close-up will suddenly notice the lens's focus on her and physically conceal herself from further spectatorship. Other moments reveal the figure closest to the camera taking the powder puff she primps herself with to cover the camera lens, as well as a woman admiring herself at her vanity spraying a puff of vapor from the perfume bottle next to her onto the lens, creating an obscuring fog. These transitions, among others, transform the camera into a titillated viewer. Gondry extends Berkeley's approach to the camera as voyeur in the digital age, personifying it as the surveilling eye of a security camera in the lobby of a building, monitored from a control center. Both artists call explicit attention to the reproducibility of art through the fusion of the camera and body.

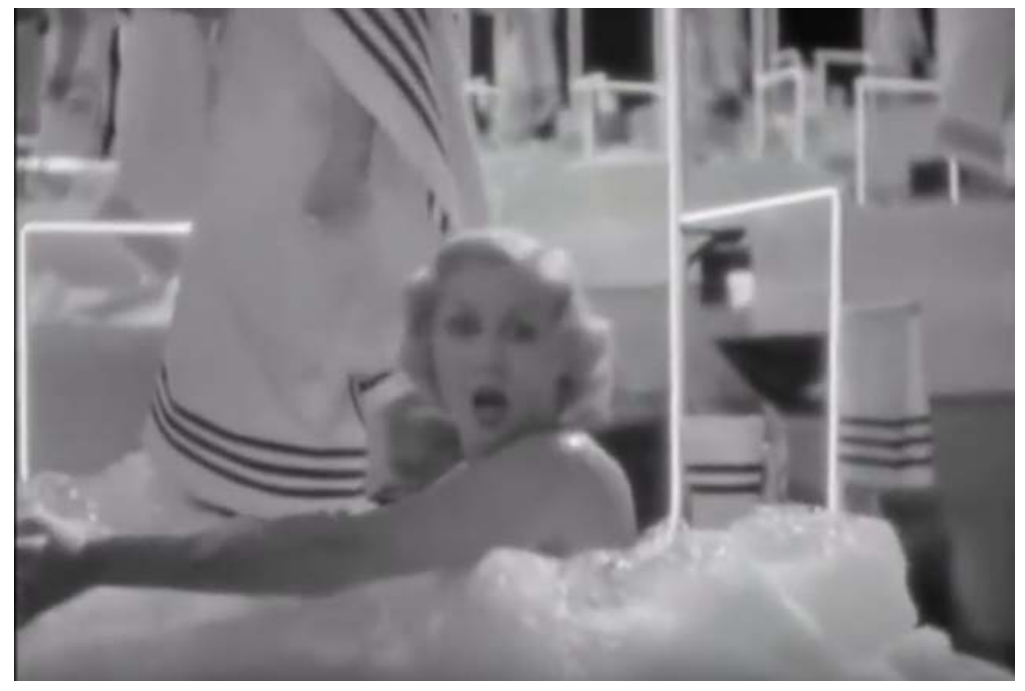

Screenshot of the primping scene in Dames, director Ray Enright (1934), and choreographer Busby Berkeley, from the "I Only Have Eyes For You" musical number. 


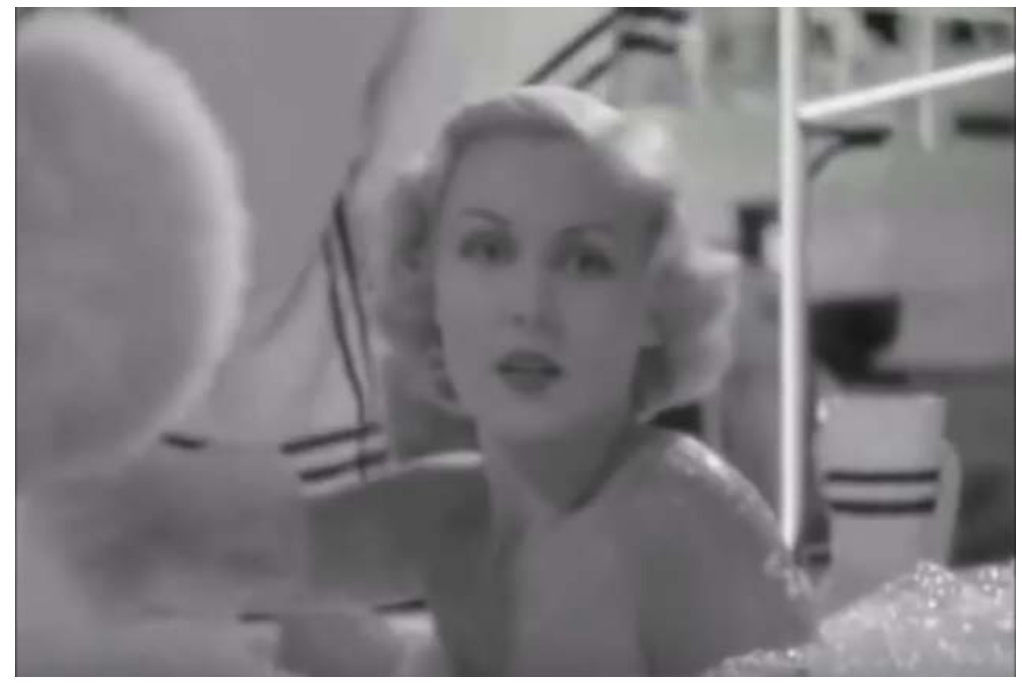

Screenshot of the primping scene in Dames, director Ray Enright (1934), and choreographer Busby Berkeley, from the "I Only Have Eyes For You" musical number.

Through multiple hybrid layers in "Let Forever Be," Gondry addresses Benjamin's questions and adds his own, exploring what uniqueness a body can have when reproduced within media products such as music video. Gondry's questions are a refreshing shift from early contributions to music video, in which filmmakers creating videos for male musical artists incorporated women as backdrops to sell records to their hard rock teenaged fans. Aside from the drummer, "Let Forever Be" is a womanbased landscape. Gondry uses his technological wizardry to expose the questions that arise when female flesh is resituated within cyberspace. He offers a new theoretical lens with which to activate Benjamin's ideas regarding the original and the copy, and explores the implications of the dancing and hybrid body within music video. Gondry does not offer easy answers to Benjamin's questions, but he does expose how the halfreal, half-simulated world in which we live affects our own embodied relationships to the world. In my vision, this video explores a relationship to the body that has potential to be furthered within screendance scholarship and productions.

\section{Biography}

Addie Tsai is a writer, artist, and professor. She currently teaches Literature, Creative Writing, and Dance at Houston Community College. She also teaches at The Jung Center and Texas Woman's University, where she also pursues a Ph.D. in Dance. Addie researches how pop cultural uses of dance demonstrate how subjects negotiate identities dealing with race, gender, class, and sexuality. Addie received an MFA in Poetry from Warren Wilson College. She has collaborated on dance theater productions, most notably with Dominic Walsh Dance Theater, as Co-conceiver of 
Victor Frankenstein and Narrative Collaborator on Camille Claudel. Addie's fiction, nonfiction, and poetry have been published in such journals as The Volta, The Offing, American Letters \& Commentary, and The Collagist.

Email: atsai@twu.edu

Web: http://addietsai.org

\section{Notes}

1 Jean Baudrillard, Simulacra and Simulation, 1. I speak here of reality and hyperreality as defined by Baudrillard: "Today abstraction is no longer that of the map, the double, the mirror or the concept. Simulation is no longer that of a territory, a referential being, or a substance. It is the generation by models of a real without origin or reality: a hyperreal. The territory no longer precedes the map, nor survives it. Henceforth, it is the map that precedes the territory - precession of simulacra - it is the map that engenders the territory ...".

${ }^{2}$ Gondry began his career directing music videos for Propaganda Films, cofounded by David Fincher. For a history of Propaganda's contribution to music video see James Mottram, The Sundance Kids, 149-168. For a comprehensive source on Gondry's career, refer to Lance Bangs, Director's Series, Vol. 3. For an extensive account of MTV, see Rob Tannenbaum and Craig Marks, I Want My MTV.

3 Jessica Kiang, "The Matrix' Anniversary."

${ }^{4}$ Michael Gondry, "Let Forever Be." For more information on the impact of "Let Forever Be" see Scott Plagenhoef, "The Top 50 Music Videos of the 1990s," and Glen Levy, "The 30 All-TIME Best Music Videos." For more on the 1990s in music video history, known as the "era of the director," a consequence of MTV listing the director in the credits of music videos, see: Digital Canvas online, "The Evolution of Music Videos-1990s."

${ }^{5}$ Chor. Busby Berkeley, Dames.

${ }^{6}$ Siegfried Kracauer, "Girls and Crisis," 565.

${ }^{7}$ Baudrillard, 1.

${ }^{8}$ Walter Benjamin, "The Work of Art in the Age of Mechanical Reproduction," 34.

${ }^{9}$ This may seem an exaggeration of Gondry's impact, because even after almost thirty years of creating music videos, short films, and feature-length films, his work remains under examined in media studies and interdisciplinary scholarship. For further details on Gondry's aesthetic contributions, see Giulia Gabrielli, 89-109.

10 See Jennifer S. Aubrey and Cynthia M. Frisby, "Sexual objectification in music videos"; Joe Gow, "Reconsidering gender roles on MTV"; Richard C. Vincent, et al, "Sexism on MTV"; Jeffrey Jensen Arnett, "The Sounds of Sex"; and Yuval Taylor and Jake Austen, Darkest America: Black Minstrelsy from Slavery to Hip-Hop, for a few examples. 
${ }^{11}$ Carol Vernallis, Experiencing Music Video, $\mathrm{x}$.

${ }^{12}$ See Claudia Kappenberg, "Does Screendance need to look like dance?" 89-105.

${ }^{13}$ See W. J. T. Mitchell, "Keywords Glossary," The University of Chicago School of Media Theory for a useful definition of the term "authenticity" in relation to Benjamin's work.

${ }^{14} \mathrm{~A}$ choreographic music video is "a label for this supposed new genre which falls into a content-based classification. Here the bodies that are developing a choreographic performance compose the content" (Gabrielli, 101).

${ }^{15}$ Benjamin, 41.

${ }^{16}$ Andrew Robinson, "Walter Benjamin: Art, Aura, and Authenticity."

${ }^{17}$ Benjamin, 36.

${ }^{18}$ Idem., 39.

${ }^{19}$ Idem., 49.

${ }^{20}$ I use the word "live" here as a distinction from the recorded, as articulated by Steve Wurtzler, quoted in Philip Auslander, Liveness: "As socially and historically produced, the categories of the live and the recorded are defined in a mutually exclusive relationship, in that the notion of the live is premised on the absence of recording and the defining fact of the recorded is the absence of the live." (3). See Auslander for a further historical and theoretical examination of liveness and mediatization.

${ }^{21}$ Freddie Mercury, Bohemian Rhapsody.

${ }^{22}$ Bangs, Director's Series, Vol. 3.

23 Ibid.

${ }^{24}$ Laura Mulvey, "Visual Pleasure and Narrative Cinema," 6-18. In Mulvey's discussion of the gaze as employed by filmmakers such as Berkeley, she quotes Budd Boetticher: "What counts is what the heroine provokes, or rather what she represents. She is the one, or rather the love or fear she inspires in the hero, or else the concern he feels for her, who makes him act the way he does. In herself the woman has not the slightest importance" (20).

${ }^{25}$ Mitch Goldstein, "'Let Forever Be' Data."

${ }^{26}$ Critical Commons, "Difference Analyzer: Busby Berkeley vs. Michel Gondry."

${ }^{27}$ Siegfried Kracauer, The Mass Ornament: Weimar Essays. Kracauer's discussion of precision dance is useful in understanding the lineage from which Berkeley's choreography was born.

${ }^{28}$ Richard Pells, Modernist America, 186.

${ }^{29}$ Bangs, Director's Series, Vol. 3.

${ }^{30}$ Benjamin, 36.

${ }^{31}$ Idem., 37.

32 See Tom Reichert and Jacqueline Lambiase, Sex in Consumer Culture, and Rob Tannenbaum and Craig Marks, I Want My MTV. 
${ }^{33}$ See Maxine Leeds Craig, Sorry I Don't Dance: Why Men Refuse to Move, for a historical tracing of American men's disinterest in dance during the 20th century. See also Auslander for an explanation of the gradual trend away from attending live performance, and an increase in mediatized consumption from the 20th to the 21st centuries.

${ }^{34}$ Kevin Lee, "938. Dames."

\section{References}

Arnett, J. J. "The Sounds of Sex: Sex in Teens' Music and Music Videos." Sexual Teens, Sexual Media: Investigating Media's Influence on Adolescent Sexuality. Eds. J. D. Brown, J. R. Steele, \& K. Walsh-Childers. Mahwah and London: Lawrence Earl, 2002. 253-264.

Aubrey, Jennifer S. \& Cynthia M. Frisby. "Sexual objectification in music videos: A content analysis comparing gender and genre." Mass Communication and Society, 14.4 (2011): 475-501. http://dx.doi.org/10.1080/15205436.2010.513468

Auslander, Philip. Liveness: Performance in a Mediatized Culture. London: Routledge, 1999.

Austerlitz, Saul. Money for Nothing: A History of the Music Video from the Beatles to the White Stripes. New York: Continuum, 2007.

Baudrillard, Jean. Simulacra and Simulation. Ann Arbor: University of Michigan, 1980.

Benjamin, Walter. [1968] "The Work of Art in the Age of Mechanical Reproduction." The Routledge Critical and Cultural Theory Reader. Eds. Neil Badmington and Julia Thomas, New York: Routledge, 2008. 34-56.

Craig, Maxine Leeds. Sorry I Don't Dance: Why Men Refuse to Move. London: Oxford University, 2013. http://dx.doi.org/10.1093/acprof:oso/9780199845279.001.0001

"Dames." Chor. Busby Berkeley. 2011. YouTube.

"Difference Analyzer: Busby Berkeley vs. Michel Gondry." Critical Commons. Posted 2013. http://www.criticalcommons.org/Members/ccManager/clips/differenceanalyzer-busby-berkeley-vs-michel

“THE EVOLUTION OF MUSIC VIDEOS - 1990S." Digital Canvas. Posted 2015. http://digitalcanvas.co/2015/03/11/the-evolution-music-videos-1990s/ 
Director's Series, Vol. 3 - Director Michel Gondry. Dir. Lance Bangs. New York: Palm Pictures. 2004. DVD.

“I ONLY HAVE EYES FOR YOU from 'DAMES' with RUBY KEELER and DICK POWELL 1934." Dir. Ray Enright. 2011. YouTube.

Gabrielli, Guilia. "An Analysis of the Relation between Music and Image: The Contribution of Michel Gondry." Rewind, Play, Fast Forward: The Past, Present, and Future of Music Video. Eds. Henry Keazor and Thorsten Wubbena. London: Transaction Publishers, 2010. 89-109. http://dx.doi.org/10.14361/9783839411858-006

Goldstein, Mitch. "'Let Forever Be' Data." Mitch Goldstein: Through Process, My MFA Thesis in Graphic Design. Posted 2012. http://mfa.mitchgoldstein.com/let-forever-be--data/

Gondry, Michel. The Chemical Brothers - Let Forever Be. Dir. Michel Gondry. 2009. YouTube.

Gow, Joe. "Reconsidering gender roles on MTV: Depictions in the most popular music videos of the early 1990s." Communication Reports 9.2 (1996): 151-161.

Kappenberg, Claudia. "Does Screendance Need to Look Like Dance?" International Journal of Performance Arts and Digital Media 5.2-3 (2009): 89-105.

Kiang, Jessica. "'The Matrix' Anniversary: 7 Pre-Bullet Time VFX Effects that Blew Our Minds". The Playlist. Posted 3 Apr. 2014. http://blogs.indiewire.com/theplaylist/thematrix-anniversary-7-pre-bullet-time-cg-effects-that-blew-our-minds-back-when20140403

Kracauer, Siegfried [1931]. "Girls and Crisis." The Weimar Republic Source Books. Eds. Anton Kaes, Jay Martin, and Edward Dimendberg, Berkeley: University of California Press, 1995. 565-566.

. The Mass Ornament: Weimar Essays. Cambridge: Harvard University, 1995.

Lee, Kevin. “938. Dames (1934, Ray Enright, Busby Berkeley)." Shooting Down Pictures. Posted 12 Dec. 2007. http://alsolikelife.com/shooting/2007/12/938-dames-1934-rayenright-busby-berkeley/

Levy, Glen. "The 30 All-TIME Best Music Videos," TIME, Posted 26 July 2011. http://entertainment.time.com/2011/07/28/the-30-all-time-best-musicvideos/slide/chemical-brothers-let-forever-be-1999/

Mercury, Freddie. "Bohemian Rhapsody." A Night at the Opera. London: Roy Thomas Baker, 1975. 
Mitchell, W. J. T. "The Keywords of Media Theory." The University of Chicago: Theories of Media. Posted 2004. http://csmt.uchicago.edu/glossary2004/navigation.htm

Mottram, James. The Sundance Kids: How the Mavericks Took Back Hollywood. London: Faber and Faber, 2007.

Mulvey, Laura. "Visual Pleasure and Narrative Cinema." Screen, 16.3, (1975): 6-18.

http://dx.doi.org/10.1093/screen/16.3.6

Pells, Richard. Modernist America. New Haven: Yale University, 2011.

Plagenhoef, Scott. "The Top 50 Music Videos of the 1990s." Pitchfork Media. Posted 23 Aug. 2010. http://pitchfork.com/features/staff-lists/7849-the-top-50-music-videos-ofthe-1990s/5/

Reichert, Tom and Jacqueline Lambiase. Sex in Consumer Culture: The Erotic Content of Media and Marketing (Routledge Communication Series). New York: Routledge, 2005.

Robinson, Andrew. "Walter Benjamin: Art, Aura and Authenticity (An A to Z of Theory)." Ceasefire Magazine. Posted 14 Jun. 2013. https://ceasefiremagazine.co.uk/walterbenjamin-art-aura-authenticity/

Smith, Imogen Sara. "Busby Berkeley (1895-1976)." Dance Heritage Coalition. Posted 2012. http://www.danceheritage.org/treasures/berkeley_essay_smith.pdf

Sontag, Susan. On Photography. New York: Picador, 1977.

Tannenbaum, Rob and Craig Marks. I Want My MTV: The Uncensored Story of the Music Video Revolution. New York: Plume, 2012.

Taylor, Yuval and Jake Austen. Darkest America: Black Minstrelsy from Slavery to Hip-Hop. New York: Norton, 2012.

Vernallis, Carol. Experiencing Music Video: Aesthetics and Cultural Context. New York: Columbia University, 2004.

Vincent, Richard C., Dennis K. Davis, and Lilly Ann Boruszkowski. "Sexism on MTV: The Portrayal of Women in Rock Videos." Journalism Quarterly 64.4 (Winter 1987): 750-941. http://jmq.sagepub.com/content/64/4/750.extract 


\title{
The Meaning of the Moves: Gestural Mythologies and the Generic Film
}

Sarah Friedland, Independent Artist

\begin{abstract}
This essay investigates the role of gestures in the production of film genre. These repeated moves-generic gestures-operate in and signify mythologies that produce film genre. This paper seeks to animate theories of the gesture while theorizing film genre as a choreography that is performed across film texts and bodies. It moves the notion of the genre "corpus" towards a mobile concept that privileges the gestural exchanges occurring between bodies of actors, of viewers, and of films.
\end{abstract}

Keywords: gesture, film genre, mythology

i. Cowboys sink into their hips, pushing against their gun holsters. Their hands know when to reach for the gun and shoot.

ii. The last girl spirals around herself, curling her spine. Her back feels the incipience of danger and possible death (killer) behind her.

iii. The girl-falling-in-love's chin cuts transversally through the space around her. Her chin knows what love looks like.

\section{Introduction}

We need to pay more attention to the meaning of the moves in the movies. We need to look at the specificity of gestures: at how the cowboy extends his fingers towards his gun; how the last girl spirals her torso to glimpse her would-be killer; how the girlfalling-in-love tilts her head up to see her lover. These moves-cinematic gesturesoperate in and signify mythologies that are as crucial to film genre's semiosis and production as visual iconography or seminal actors. Gestures are sites-or events-of the generic and its production. Further, the kinesthetic impact of these gestures in the bodies of film spectators - their residues, affects, and memory-are both effects and co-producers of the generic. 
This paper responds, in part, to the lack of attention from academic scholarship to the particularity of the movement of filmic bodies. These moves construct meanings, knowledges, affects, genres, and more, and yet they have been undertheorized in film studies. It is crucial for scholars to approach the study of cinema with a detailed attention to the moves of onscreen bodies. As Erin Brannigan has noted:

while dance studies has often kept its distance from debates in film theory, film has also avoided dialogue with issues in dance studies ... Dance theory offers understandings of the moving body and its ability to produce and express meanings that are particularly useful for addressing both popular film genres and other categories of dancefilm. ${ }^{1}$

This essay takes up a methodology in between film studies, semiotics, and dance and performance studies so as to arrive at a theory of genre production and gesture that privileges neither the moving body nor the moving image but instead explores the unique conditions created through their coproduction and constitution. ${ }^{2}$ In his 2004 book on gesture, Adam Kendon notes that there has been a "revival of gesture studies." ${ }^{3}$ Yet, to my knowledge, that revival has not fully permeated film studies. The gesture is taken up in social psychology, linguistics, and performance studies, largely in terms of non-verbal communication and performance, but it has not been taken up as a distinctly cinematic construction. It is as such that I would like to treat the gesture, recuperating it from a static treatment in which it is assimilated to iconography, poses or linguistic units. Rather than theorize all gestures, this paper addresses a physical gestural modality within Hollywood cinema. It is designed to produce neither a totalizing theorization, nor a historical genealogy, nor even a classification scheme for generic gestures, but rather to isolate filmic gestures that elucidate how film genre is itself choreographic. By treating genre as a choreography, and attending to the specificity of generic gestures, I hope to model the way in which dance studies can fruitfully be brought into theories of film. This project also suggests the multiple ways in which gesture is productive for theorizing film genre while animating the classifications and theorizations of gesture in both theories of film and performance as well as popular notions of gestures. Cinema's construction of genre has mediated understandings and enactments of gesture that go beyond film itself.

By looking to gesture, we move film genre theory away from a static and typological model and towards a mobile concept of genre that attends simultaneously to repetition and difference while rethinking the notion of a corpus, ${ }^{4}$ or body, of generic film texts. As a basic definition of genre films, Barry Grant suggests that "genre movies are composed of certain common elements." ${ }^{5}$ He underscores the role of repetition, stating genre films "tell familiar stories with familiar characters in familiar situations." ${ }^{6}$ In genre theory, the repetition of elements has historically been used as a classification scheme in which the appearance of a certain element signals a corresponding genre. For example the presence of horses or cowboys signals that a film is a Western. In his 
work on genre, Rick Altman suggests that genre exists in a multiplicity of locations. ${ }^{7}$ And yet both genre theory and popular conceptions of genre privilege certain sites. Examples of these sites include the actors who repeatedly appear across films, visual iconography, narrative tropes and plot similarities, to name a few. Attempts in genre theory to read these elements intertextually and to position viewers and their expectations as co-producing and participating in genrefication destabilize the aforementioned theories of genre that are static and formulaic in their classification schemes. For example, Barry Keith Grant's writing on genre underscores the role of viewers, stating how "conventions function as an implied agreement between makers and consumers to accept certain artificialities. ${ }^{8}$ Contemporary genre theorists tend to agree "genres are neither static nor fixed." ${ }^{\text {9 }}$ Yet they have failed to provide an adequate lens or site through which to trace the animate and mobile process by which film genre and the generic is continuously produced. Gestures offer a literally moving site. As Altman notes:

A fundamental problem of genre studies stems from the ever-present desire for a stable and easily identifiable object of analysis. Ever simplifying, genre critics have simply borrowed an ontology, a methodology and an epistemology developed by critics of art and literature for other objects and other purposes, thereby reducing the notion of genre to a corpus of texts or to textual structure. We do better, I suggest, to treat genre as a complex situation, a concatenated series of events regularly repeated according to a recognizable pattern. ${ }^{10}$

The gesture as a mobile site for the study of genre is comparable to the event or situation that Altman craves for his particular analytic. Generic gestures follow a pattern; they repeat, but with difference, in every filmic iteration or performance. Their difference is produced by the particularity of the body performing the gesture, the diegesis in which it is performed, the framing and cinematography that captures it, and the editing which mediates-dis- and re-assembles-it. Considering Derrida's writing of genre as a "corpus of traces,"11 we might think to follow the gesture as a generic trace across film texts and viewing bodies. Tracing the generic via physical gestures enables a more animated and dynamic consideration of film genre.

Gestures can be conceptualized not only as a repetitive tendency of genre films, but as the choreography of film genre itself. They are the unfolding of a generic code inscribed in and through moving bodies, both on and off screen. Particular gestures are repeated and recapitulated, without uniformity, across films. These gestures come to hold conventionalized meanings and functions within genre films. By looking to read genre in the gestures of films, genre becomes not a formula that includes certain iconographic and narrative clichés, but a choreography in which movements are repeated but performed differently in each iteration. For example, while we might conceptualize the choreography of slasher films as including the gesture of a scream, 
in which the last girl's eyes and mouth widen to their most extreme limit, this very gesture will be performed with countless variations in its movement quality as it is performed across film texts and bodies. As Steve Neale has theorized, "genres are instances of repetition and difference." ${ }^{12}$ Bringing in notions of the choreographic and theories of performance to the study of genre film accounts simultaneously for the recurrence of the familiar and the simultaneous presence of difference. The bodies participating in genrefication are threefold: first, they are the bodies of the filmic actors, and, secondly, they are the bodies of viewers. But further, in the exchange between these two bodies, through the gestures that they mutually recognize, share, and endow as significant and signifying, there is produced a third corpus of genre: a body of choreography.

These generic gestures signify as what Roland Barthes designated "myths" - "a second-order semiological system." ${ }^{13}$ With myths, "that which is a sign (namely the associative total of concept and an image) in the first system, becomes a mere signifier in the second"14 such that "the meaning is already complete, it postulates a kind of knowledge, a past, a memory, a comparative order of facts, ideas, decisions." ${ }^{15}$ In the case of generic film gestures, the movements performed do not signify what Barthes calls a "first-order" signified, but rather, an already complete order of knowledge. For example, a young woman kissing a man at the end of a chick flick does not merely signify her love and desire for the particular man in the film, but rather the mythology that for heterosexual women there is "the one" that is somewhere "out there" who will guarantee happiness and fulfillment upon romantic and sexual union. Filmic gestures thus function to inscribe the generic and its mythological meanings through corporeal movement. Film genre theorist Barry Keith Grant also underscores the links between Barthes' notion of "myth" and genre film, writing, "entertainment inevitably contains, reflects and promulgates ideology. It is in this sense of entertainment as ideology that Roland Barthes uses the term myth." ${ }^{16}$ Further, he asserts that Barthes' "description of cultural myth applies perfectly to genre movies: 'myth does not deny things, on the contrary, its function is to talk about them; simplify, it purifies them, it makes them innocent, it gives them a clarity which is not that of an explanation but that of a statement of fact."'17 Generic film gestures possess this excessive clarity; the performance of an individual gesture by a film actor signifies a generic statement of fact. It is this clarity that allows them to circulate, contagiously, between bodies and films, actively participating and catalyzing the process of genrefication. The semiotic and mythological labor of genre films is performed by onscreen bodies and reenacted repetitively by viewing bodies who take up these exchanged gestures, extending genrefication outside the diegesis. 


\section{Animating Theories of the Gesture}

"Gesture" faces a problem of definition. The word is deployed to refer to a variety of phenomena and objects. Its polysemous quality is symptomatic of the way gestures operate. Unlike the specificity and relatively fixed nature of linguistic signifiers and their signifieds, most gestures do not have singular referents or signifieds but rather move or reach towards meanings, and more so, mythologies. Indeed, the current trend in academia of using the word "gesture" to indicate a mode of speculation or a pointing towards a particular area of interest reflects the way in which the gesture (as a physical motion and sign) does not reach a point, but rather moves towards the possibility of one. In these academic utterances, "gesture" is used so as to suggest not a clear act of signification but rather one that approaches signification, moves towards meaning. This current usage suggests a process of constantly approximatingnearing-something. The very moving quality of gestural signification is further reflected in the physical act of gesturing itself in which the body is not static but actively moving towards as a way of producing meaning. In a broad sense, this is how I define and use gesture in this paper: gesturing is meaning through movement, involving a process of animatedly approaching signification.

We need to animate theories of the gesture. Historically, gestures have been studied typologically, placed in paneled diagrams in which each gesture gets a singular static image in a particular pose or position. For example, hand gestures are often represented in still and singular images, the frame cutting the hand off at the wrist, in various positions. Such diagrams are indicative of a popular conception of gesture, a static image or object that is echoed also in certain academic treatments. While static treatments of gesture may appear to be clarifying, such a view actually effaces the ways that, as precisely moving signs that are always in process and production, gestures animatedly produce meaning. In the example of represented hand gestures, the hand becomes an object, a singular entity, and in its pose considered (erroneously, I argue) to be a "gesture." Indeed, the gesture is often mistaken for micro-poses. As such, gesture becomes delimited as a particular configuration of a body part, unrecognized as an act of moving. This static representation threatens to assimilate analysis of movement to the pose and of meaning to a simply linguistic deconstruction. Such assimilation fails to account for the mobile and multiple ways in which gestures signify. Dance and screendance studies, in their attention to the continuity of the body and its meanings, can help to animate theories of the gesture outside of so-called dance texts.

The project of animating semiotics and addressing the continuous within formal structures, while incorporating the interventions of poststructuralism, is one articulated by Brian Massumi, who writes: 
Theoretically, the point of departure would have to be to part company with the linguistic model at the basis of the most widespread concepts of coding (almost always Saussurian in inspiration, often with Lacanian inflections) and find a semiotics willing to engage with continuity. ${ }^{18}$

For Massumi "continuity" is a condition of bodies being mobile as opposed to attending to fixed positions on a grid, a positioning he designates as homologous to the code. While Roland Barthes' writings on myth are based in the Saussurian model that Massumi and poststructuralists try to depart from, the particularity with which he treats the link between the mechanics and texture of movement and the mythological meanings they signify is a salient example of how a semiotic treatment of movement can account for meaning that is continuous. That is, Barthes does not fully achieve the mobile semiotics that Massumi desires, but he gestures towards it. In Mythologies, Barthes analyzes how the body/physique and movements of a wrestler produce spectacles that signify strength and weakness, and triumph and defeat, operating within the larger mythologies of the world of wrestling:

It is at every turn during the fight, in each new situation, that the body of the wrestler casts to the public the magical entertainment of a temperament which finds its natural expression in a gesture...the wrestler arranges comments which are episodic but always opportune, and constantly help the reading of the fight by means of gestures, attitudes and mimicry which make the intention utterly obvious. ${ }^{19}$

Barthes underscores the signifying potential of gesture as well as its mythological function. Nonetheless, Barthes does not fully allow for movement itself to be the significant signifying form. Barthes focuses on the physique of the wrestler, objectifying him and relegating his movement to a performance that is secondary to the body as object (muscle) and image. Yet Barthes further suggests the signifying potential of gesture in his attention to the specificity of the wrestler's moves:

The forearm smash, this loud slap of the forearm, this embryonic punch with which one clouts the chest of one's adversary, and which is accompanied by a dull noise and the exaggerated sagging of a vanquished body. In the forearm smash, catastrophe is brought to the point of maximum obviousness. ${ }^{20}$

In his description of the forearm smash Barthes refers primarily to the noises made by the moves of the wrestler, rather than attending directly to the details of the moves themselves. Yet each onomatopoeic noise he references suggests a particular gesture: smash, slap, punch. His invocation of sound signifies a rich level of textural detail; the sounds appear as evidence of movement quality. As such, Barthes presents mythologies that are formed through movement and its textures and qualities. 
Herein, I will attempt to engage with a semiotics that attends to mobility, as requested by Massumi, and yet achieves the level of detailed engagement with mythological meaning through movement, as demonstrated by Barthes. The gestures, however, will be limited to a cinematic realm, exchanged between film texts and spectators' bodies.

\section{Cinematic Gesture/Genre}

The movement qualities of gestures performed in genre films signify generic mythologies and participate alongside the repetition of other elements in genre production. The static treatment that I previously suggested has dominated the study of gesture is also present in the study of genre films: the complexity of physical movement is neglected or assimilated to the iconography present within the mise-enscène. This assimilation is exemplified by the treatment of the gesture of smoking in noir films. While all the other elements of the mise-en-scène are acknowledged as marking and producing the noir-ness of a film - the contrast of the lighting against the cigarette smoke, the physiognomy of the femme fatale's face, the repetition of certain star actors associated with the genre, etcetera-the actual quality of the face and body that perform the gesture go largely unacknowledged. The slow pace of the femme fatale's lips parting for the cigarette, the way in which her head slowly bows towards the open flame of a man's lighter, the wide and circular opening of the mouth that blows smoke-none of these kinesthetic qualifications of the gesture are given the attention and detail required to mark genre as something corporeal. It is in light of this deficiency that dance studies, and more so screendance studies, can help produce a more nuanced account of filmic movement and its role in genrefication. The specificity of gestural movements performed in film texts-what Brannigan has called the "idiogest"21_produces and constitutes the generic itself. The assimilation or subjugation of gesture to genre's iconography, reduces the meaning of the moves, which yield the generic substance of a film.

More than the mere presence of gestures within genre films, the exchange of these gestures between on-screen and off-screen bodies participates in genre production. This relation between bodies is what Brannigan calls gestural exchange, which she formulates by distinguishing Lyotard's notion of gesture from other definitions:

Lyotard uses the terms gesture and gestus to describe the various elements of aesthetic production and reception which together constitute a model of gestural exchange, from the work of the artist, to the components of the work of art, to the immediate response of the viewer and the labor of the philosopher's discourse. These ideas suggest a gestural contagion and fluidity between performers, between performers and spectators, between films, and between disciplinary boundaries. ${ }^{22}$ 
Brannigan's notion of "gestural exchange" reconfigures the genre film corpus as not merely a collection of texts, but a body of gestural transferences between films and viewers and their discourses. To be clear, while Brannigan and Lyotard's notions of gesture extend beyond physical movements performed by humans, the gestures that I invoke here are solely physical and human.

By addressing genre as a gestural exchange, we are better able to account for its hybridity. Derrida asks in "The Law of Genre," "what if there were lodged within the heart of the law itself, a law of impurity or a principle of contamination?"23 His question, and the larger essay of which it is a part, suggest the way in which texts cannot be sealed off and contained to the marks of one genre, but rather, must participate in many. "Contamination," as a law of genre, suggests the contagious spread of generic elements across texts. Gestural exchange occurs not just between acting and viewing bodies and intertextually across the films of a genre, but between the choreographic corpuses of different genres. For example, the gestures of the cowboy's hands, about to shoot a gun in a Western, are not contained to their Western diegesis. They contaminate and permeate the gun-shooting gestures of action heroes, about to pull the trigger on villains. The gun-shooting of the cowboy is not sealed off from the gun-shooting of other genre's archetypal figures and the choreography they perform. We might trace familiar gestures across genres as a way of addressing gestural exchange as the very means of genrefication. The body itself is a site of contamination; it exchanges and mixes its filmic and mythological moves.

Generic gestures operate with, and are produced by, other filmic elements such as lighting and cinematographic framing. In particular, the close-up produces generic gestures. Of course, gestures occur in genre films that are not framed in close-up, but rather in wide shots. In these cases, however, the gestures are already legible without the particular cinematographic framing. That is, knowledge or discourses about the part of the body (or whole body) gesturing, allow the movement to be discernible as a gesture without the mediation of the frame. For example, a hand can wave goodbye in a wide shot in a film without the need for a close-up to isolate the hand as gesturing. For the human movement or micromovement that is performed by a part of the body that is not easily metonymic like the hand, the frame of the close-up engenders an autonomy that produces the status of "gesture." This process is clarified by Brannigan's theorization of "cinechoreography," which was developed in relation to dance film but can be usefully extended to consider filmic movement more broadly. Drawing on Bela Balacz's theorization of the close-up and faceity, Brannigan underscores the role of the close-up in producing gesture:

The close-up in dancefilm creates a specific cine-choreographic order by extending and redefining the parameters and nature of screen performance and thereby extending the parameters of dance. This is achieved through an attention to the performing body and its micro- 
movements - the smaller detailed movements of the body and its parts. This can often produce a deterritorialization of the body so that any part of the corporeal whole can operate as a site for dance and, thus, meaning production and expression. ${ }^{24}$

By framing in close-up the micro-movements of the body, the work of cinematography creates gestures; that is, the frame produces the gesturing potential of non-territorialized parts of the body. With the segmenting and focusing work of the cinematographic frame, any part of the body can attain the isolation and metonymy that the hand is seen as already possessing. The close-up endows the whole body as inherently (and through segmentation, necessarily) gestural; the metonymic function of gesture is amplified by the segmentation of the cinematic frame. Thus, gesture as such, is a cinematic construction.

\section{Three Gestural Mythologies: Horror, Chick Flick, Western}

The filmic gestures I invoke here encode myths as a part of the narrative and ideological work of genre films. To illustrate this argument, I offer three examples of such gestural, and generic, mythologies. The gestures described below are not emblems or essences of their genres. Rather they are salient examples of how attending to gestural particularity can yield a richer film studies that is better able to account for the production and operation of cultural mythologies. Given this tie to mythology, I borrow, with a difference, Barthes' style of glossing-in brief excerptsmyths from Mythologies. His glosses simultaneously account for the depth of layers and levels of signification that compose myth, while allowing for the at once of the myth:

Myth essentially aims at causing an immediate impression-it does not matter if one is later allowed to see through the myth, its action is assumed to be stronger than the rational explanations which may later belie it. This means that the reading of a myth is exhausted at one stroke. ${ }^{25}$

While gestures offer a semiotic work that is likewise both immediate and affecting, their signified is irreducible. The "difference" that I add to Barthes' method is of focus: a detailed account of the movement of the body.

I have deliberately chosen to address these generic gestures in a descriptive mode that abstracts them from actual films, rather than reading closely particular iterations of gesture within singular film texts. Were I to write of particular gestural iterations, I would be highlighting certain gestures as exemplary of the genre, rather than reading them as particular and unique performances of a generic choreography that is produced across numerous film texts and bodies. In its detailed attention to an abstracted choreography, my mode of address recognizes genre as being iterated and 
produced intertextually. In the inability to study genre in a singular text, Altman iterates the problematic of genre:

Students of genre forever forego such security [offered by a stable object of study]. Genre offers neither a unique object of study nor the stability of an exactly duplicated text. There exists no generic original of which particular events might be represented as performances. Present in no specific place at any particular time, the notion of genre cannot be adequately grasped through the models offered by art, literature, theatre or film. The oldest cliché in genre studies holds that a single text cannot constitute a genre. Less obvious, but no less important, stands the fact that genres are never made up of texts alone, however numerous. Because the very notion of genre depends on the existence of audience activity (prior knowledge of similar texts, intertexual comparisons, specific cognitive tendencies and predictable schema-processing practices), no genre critic can afford to treat so-called generic texts in a vacuum. ${ }^{26}$

The descriptions of movement that follow do not stand as writing of gestures that are "exactly duplicated" in every film of its genre-no such exactly replicable gesture exists. Yet certain characteristics of movements can be read across these different iterations. For example, cowboys might collapse from being shot in the gut in endlessly different ways across film texts, and yet, the majority of these gestures will include a quick and sharp contraction in the abdomen. It is this strain of kinesthetic repetition and familiarity that these descriptive passages attempt to address.

Additionally, this form of address attempts to conjure a collective imagination of the gestural choreography of the genres addressed herein. Film genre theorist Andrew Tudor writes of the role of the imagined in film genre:

to talk about the western is (arbitrary definitions apart) to appeal to a common set of meanings in our culture. From a very early age most of us have built up a picture of the western. We feel that we know a western when we see one, though the edges may be rather blurred ... Genre is what we collectively believe it to be. ${ }^{27}$

By describing these choreographies as abstracted from individual films, I am attempting to address this collective imagination of genre not as a visual and aural knowledge, but as a kinesthetic one. That is, to attempt to conjure the Western not just by the image of a six-shooter and the sound of its deployed bullets, but by the contracting abdomens which violently receive them. The gestures described herein suggest the way in which genre is a choreography that our bodies collectively recognize, participate in, remember, and critique. 
1. Slasher/Horror Film: The slowly spiraling head and upper torso-the look back-of the last girl

As the "last girl" is being chased, she looks back. Her spine knows that she is in danger. So too do the hairs on the back of her neck. She is hunched over as she runs, her spine curved and her abdomen contracted, in anticipation of something-bad-that-has-not-yethappened. Her shoulders rotate inwards, retracting from the danger that lurks behind their sockets. She spirals - turning her torso-as if lightly wringing a rag, from the abdomen to the neck. Something is behind her-risk is always behind the back of the last girl, rarely in front. She feels danger in her back; her spine wants to know who is following her. Her skin wants to know if it will be torn. The spiral is her way to find out, to turn on herself to know her fate, which is directly behind her back, out of sight. Her back feels the risk; her spine must suss it out. The body slowly curves around itself, its spine an axis, reaching finally to the head. Once the head is fully turned, she will know what is behind her. The eyes are the final point of the spiraling gesture. The spiral says she is chased. The spiral says she in danger. The spiral says if she will live or die. The spiral says there is an other who is not her friend or lover. The spiral is her horror, waiting to happen upon the reveal of what or who is behind.

\section{Chick Flick: The timid chin of the girl falling in love}

Her chin is timid. It moves, not with force but with a question. The eyes-which want to see him-must get the chin's permission first. Sometimes he passes her in the hallway at school. As if a cue syncing the musculature of her face with his locomotion, she gets tied to him, gliding her features horizontally to see his passage past lockers and others she does not know. She moves to look. He has passed. The rounded tops of her shoulders know he is still behind her, moving further away She must make a move, fast: her chin cuts transversally through the air, reaching her shoulder blade-it stops-he is behind but not looking. She retraces, her chin sinking, the space between her shoulder and her upper chest. He is not looking back-her chin must therefore return. Her chin looks for love-it stops when love looks back at her face. In the moves of the chin, and the face it drags with it, we see her falling-in-love, with him. Like the last girl whose back determines the danger behind her, this girl's chin thinks, possibly, that it's falling in love. Her chin is suspecting; it suspects that its lateral motion that infects the spiraling spine and turning head moves towards the one she will love. In the turning chin, and what it brings, we see her falling in love. The chin falls first, her gaze follows, and with it we know where her heart is. Thus, her chin gestures in place of her heart's unseen moves.

3. Western: The ready hands of the cowboy, about to shoot

The hands of a cowboy know. Held just beside his legs, they take stock of the air around them. In the vibrations of the air and the sand particles in it, they will know. They keep their shoulders broad, ball securely in socket, pulling down the back. Their backs and torsos locked like their guns. From that locked and ready base, the hands get to hang, not passive 
but waiting, anticipating, ready. In the suspended hands of the gunslinger, we see his keen sense, his superiority, his all-knowing ability to work a saloon room, work a gunfight, work on anything, all to his benefit and success. He trusts no one, or very few, but he does trust his hands, for they know. One hand slips down towards his gun holster. In this steady slip, the other, and we, know he is ready, he is serious, he will shoot. But he doesn't-his hands will know when it's the right time. His hands read the diegetic space, and we read and trust them. His hips may shift, his weight need not be static, pushing against his gun holster, but his hands are unerring in their attention, in their focus. His eyes squint, but the hands do the real looking. His hands see the hands of the other and know when to react. Here is a gestural exchange in the diegesis: mano a mano.

The viewer apprehends mythological and ideological meanings from their kinesthetic reception of these gestures. In the spiraling spine of the last girl, we read the constant possibility of horror and violence inflicted against women; in the transversal chin and eyes of the chick flick's leading lady we read the promise of happiness and fulfillment in heterosexual romance; in the steady hands of the cowboy, we read the confident and arrogant enterprise of white men on a new frontier. Reading the mythological meaning of genre films is accomplished by reading its gestures. This "reading" however, is not simply specular, but rather embodied, affected and empathetic. Apprehension of gesture, and thus apprehension of genre, is a kinesthetic practice enacted by the spectator.

\section{Embodied Spectatorship and Affects of the Generic Gesture}

The body is both the persistent site of self-recognition and the thing that always betrays us.

—Kathleen Stewart, Ordinary Affects, 114.

In its affects, kinesthetic recognition, critique and empathy with filmic gestures, the spectator's body co-produces genre. Framing the kinesthetic response and affects of film viewers not as effects of film but rather as participants in the choreographic performance and production of genre, reconsiders genrefication as an affective, and kinesthetic exchange. It suggests that genre production is enacted, and made possible, by the body's status as moving and move-able, affected and affecting. The repetition of these generic gestures across films enables their easy recognition by the spectator. Indeed, while film theorists have emphasized the discernibility of visual iconography, these gestures, while apprehended by the vision of the viewer, are recognized even more fully by the body of the viewer.

As theorists like Linda Williams and Vivian Sobchack have emphasized, the viewer must be acknowledged as embodied and somatically agentive. ${ }^{28}$ This viewer thus literally feels the moves of a film and makes sense of the film through her body and senses. As Vivian Sobchack precisely articulates in her formulation of the "cinesthetic 
subject" for whom cinema is "somatically intelligible," "the film experience is meaningful not to the side of my body, but because of my body." ${ }^{29}$ These embodied accounts of spectatorship that do not neglect the body's sensorium as a site of knowledge make way for an understanding of the role of the spectator's body in genre production. Brannigan notes how attention to such theories of embodiment have produced a greater consideration of the kinesthesis of film viewers: "through a focus on the physical activities of the actors, many new writings on screen performance inevitably conclude with what Ross Gibson calls 'a somatic response' on the part of the audience." ${ }^{30}$ Embodiment need not be theorized only as a spectatorial state that allows for affects and "somatic responses" as effects, but as a condition that enables these affects to participate in and co-produce the very meaning of the texts conceptualized as producing those effects. As such, it is the body's embodied apprehension of generic gestures that endows the gestures themselves as generically significant and signifying. As the body apprehends and is moved by the gestures of a genre, it produces the generic.

We might thus clarify that, more than recognize or respond, film viewers empathize, kinesthetically, with the gestures they see in genre films. I borrow Susan Foster's notion of kinesthetic empathy but extend it beyond the dance viewer whom she discusses. Susan Foster's compelling notion of kinesthetic empathy suggests that "perception simulates action ... The viewer, watching a dance, is literally dancing along." ${ }^{31}$ Due partially to the operation of mirror neurons, the body empathizes with the movements of those bodies it sees moving. Viewers, of all cinematic forms, thus dance along with film gestures; they enact genre in their moves. However, I would argue that this "dancing along" is also critical-a body can reject or revise these gestures and their accompanying ideologies in their own kinesthetic apprehension and articulation of them. Empathy need not be situated as a non-critical acceptance of movement. Brannigan expands upon Susan Foster's notion by looking to the work of John Martin. Martin posits that corporeal screen presence produces particular affects that include "the inherent contagion of bodily movement, which makes the onlooker feel sympathetically in his own musculature." 32 The kinesthetic empathy of viewers for the repeated gestures of genre films further reiterates and produces genre while linking genre production to the kinesthetic subjectivity of viewers. As such, the viewer's experience of their "own musculature" engages in the production of genre alongside other productive elements. As such, we might consider film genre as it is enacted by its gestures, as what dance scholar Janet Adshead-Lansdale calls a "dancing text," in which "the reader is not, then, a parasite upon a fixed object, sucking its life blood, but a co-creator of a mobile text, breathing new life into (it)." 33

Colloquial expressions referring to spectators' apprehension of films gesture towards the affective impact of such films. Film "move" and "touch" us; we claim to "take in a movie" (as in the expression "it was a lot to take in"). More than films just producing 
"somatic responses," they are taken in-possessed-by our bodies. Deleuze suggests this corporeal or kinesthetic incorporation of films with his theorizing of the movement-image in which:

There is inevitably a part of external movements that we 'absorb,' that we refract, and which does not transform itself into either objects of perception or acts of the subject; rather they mark the coincidence of the subject and the object in a pure quality. This is the final avatar of the movement-image: the affection image. ${ }^{34}$

While Deleuze's subject is not exclusively a spectator, the way in which he absorbs external movements that do not transfer themselves into actions or objects helps to articulate the way in which the spectator experiences generic gestures and participates in their genre. Brannigan articulates saliently the response of the spectator to the gesture in her analysis of dancefilm:

We are asked to provide for the occasion, or occurring of the actus, an unpremeditated, extemporaneous reaction that makes critical response a challenge. With nothing to hang onto but the potential of the gesture-as Lyotard describes it-we are left to our resources, compelled by these strange, summoning gestures to find a way to meet them. Beyond succumbing and indulging, we are put to work by the gestural dancefilm to produce an appropriate returning gesture. This is the impetus of such films: to produce, yield, bring out something exterior, yet akin to itself. We are called upon to improvise our response as we follow a trace of movements that we will never quite master, a choreography that will elude us each time despite the replay option. ${ }^{35}$

While Brannigan is addressing gestures within dancefilm, rather than genre films that include movement that might not be considered "dance" by many, the way in which she describes the viewer as being put to work to "produce an appropriate returning gesture," is akin to the response of the genre film viewer who also feels the "potential of the gesture" and is called upon to trace it and find a response. In this way, the genre film viewer is subjectified by the generic gesture and their body made a site in which genre plays out.

We carry genre with us, producing it in our bodies in their constant ability to reiterate and recall film gestures. Our muscles and skeletons carry traces of film genres and the potential of their gestures, and charge the very spaces in which we move. As Kathleen Stewart writes of affect, "the potential stored in ordinary things is a network of transfers and relays. Fleeting and amorphous, it lives as a residue or resonance in an emergent assemblage of disparate forms and realms of life." ${ }^{136}$ We might therefore look to locate genre in the residue-animate potential-its moves leave in the moving 
bodies of its spectators. ${ }^{37}$ It is here-in the moving and moved body-that screendance studies can best intervene in our theorizations of film genre.

\section{Biography}

Sarah Friedland is a filmmaker and choreographer working at the intersection of moving images and moving bodies. She received her BA in Modern Culture and Media from Brown University and studied under the mentorship and collaboration of dancefilm scholar Erin Brannigan at UNSW. She is currently in New York City working on a new dance film involving the textural manipulation of skin, fat and light.

Email: sarahmfriedland@gmail.com

Website: www.motionandpictures.com

\section{Notes}

${ }^{1}$ Erin Brannigan, Dancefilm, 7.

${ }^{2}$ My interdisciplinary approach to filmic movement models that established by Erin Brannigan, a dancefilm scholar whose work on dancefilm has been critical in the emergence of dancefilm studies.

${ }^{3}$ Adam Kendon, Gesture, 82.

${ }^{4}$ Rick Altman writes that "genre itself is typically thought of as a corpus of films." Film/Genre, 24.

${ }^{5}$ Barry Grant, Film Genre, 9.

${ }^{6}$ Grant, Film Genre Reader IX, xx.

${ }^{7}$ Altman, 84.

${ }^{8}$ Grant, Film Genre, 10.

${ }^{9}$ Idem., 34.

${ }^{10}$ Altman, 84.

11 Jacques Derrida, "The Law of Genre," 211.

${ }^{12}$ Steve Neale, Genre and Hollywood, 48.

${ }^{13}$ Roland Barthes, Mythologies, 114.

${ }^{14}$ Ibid.

${ }^{15}$ Idem., 117.

${ }^{16}$ Grant, Film Genre, 143. 
${ }^{17}$ Barthes, Mythologies in Ibid.

${ }^{18}$ Brian Massumi, Parables for the Virtual, 4.

${ }^{19}$ Barthes, 18.

20 Idem., 20.

21 "The gestural parameters of a given performer become a kind of performative domain that unifies a character, a film, and bodies of work. The gestural parameters, performative domain, or corporeal specificity of the dance start will be referred to as the performer's idiogest: their gestural idiolect." Brannigan, 142.

22 Idem., 172.

${ }^{23}$ Derrida, 204.

24 Idem., 41.

${ }^{25}$ Barthes, 130.

${ }^{26}$ Altman, 84.

${ }^{27}$ From Andrew Tudor, Theories of Film. Quoted in Neale, 18.

${ }^{28}$ See Vivian Sobchack, Carnal Thoughts, and Linda Williams, "Film Bodies."

${ }^{29}$ Sobchack, "What My Fingers Knew," original emphasis.

${ }^{30}$ Brannigan, 13.

31 Susan Foster, Choreographing Empathy, 123.

32 Brannigan, 12.

33 Janet Landsdale, Dancing Texts, 21.

${ }^{34}$ Gilles Deleuze, Cinema 1, 65.

${ }^{35}$ Brannigan, 178.

${ }^{36}$ Kathleen Stewart, Ordinary Affects, 21.

${ }^{37}$ It should be noted that my approach here, unlike my initial reference to Massumi, is inconsistent with his understanding of affect which "is unqualified... it is not ownable or recognizable, and is thus resistant to critique" (Massumi, "Autonomy of Affect," 88). I am, here, opening up affect to critique. However, my use of Stewart's "residue" is consistent with Massumi's notion of incipience, a term he substitutes for affect: "The body doesn't just absorb pulses or discrete stimulations; it infolds contexts, it infolds volitions and cognitions that are nothing if not situated. Intensity is asocial, but not presocial-it includes social elements, but mixes them with elements belonging to other levels of functioning, and combines them according to different logic. How could this be so? Only if the trace of past actions including a trace of their contexts were conserved in the brain and in the flesh, but out of mind and out of body understood as qualifiable interiorities, active and passive respectively, directive spirit and dumb matter. Only if past actions and contexts were conserved and repeated, autonomically reactivated, but not accomplished; begun, but not completed. Intensity is incipience, incipient action and expression. Intensity is not only incipience, but the incipience of mutually exclusive pathways of action and expression that are then reduced, inhibited, prevented from actualizing themselves completely-all but one. Since the crowd of pretenders to actualization are tending toward completion in a new context, their incipience cannot just be a conservation and reactivation. They are tendencies-in other words, pastnesses opening onto a future, but with no present to speak of... This 
requires a reworking of how we think about the body. Something that happens too quickly to have happened, actually, is virtual. The body is as immediately virtual as it is actual. The virtual, the pressing crowd of incipiencies and tendencies, is a realm of potential." Massumi, "Autonomy of Affect," 223-224.

\section{References}

Adshead-Lansdale, Janet. Dancing Texts: Intertextuality in Interpretation. London: Dance Books, 1999.

Altman, Rick. Film/Genre. London: British Film Institute, 1999.

Barthes, Roland. Mythologies. New York: Macmillan, 1972.

Brannigan, Erin. Dancefilm: Choreography and the Moving Image. Oxford: Oxford University Press, 2011. http://dx.doi.org/10.1093/acprof:oso/9780195367232.001.0001

Deleuze, Gilles. Cinema 1: The Movement Image. Translated by Hugh Tomlinson and Barbara Habberjam. Minneapolis: University of Minnesota Press, 1986.

Derrida, Jacques, and Avital Ronell. "The Law of Genre." Critical Inquiry (1980): 55-81. http://dx.doi.org/10.1086/448088

Foster, Susan Leigh. Choreographing Empathy: Kinesthesia in Performance. New York: Routledge, 2010.

Grant, Barry Keith. Film Genre Reader IV. University of Texas Press, 2012. . Film Genre: From Iconography to Ideology. London: Wallflower Press, 2007.

Kendon, Adam. Gesture: Visible Action as Utterance. Cambridge: Cambridge University Press, 2004. http://dx.doi.org/10.1017/CBO9780511807572

Lyotard, Jean-François. "Gesture and Commentary." Translated by Stephen Adam Schwartz. Iyyun, The Jerusalem Philosophical Quarterly 42 (1993): 37-48.

Massumi, Brian. "The Autonomy of Affect." Cultural Critique (1995): 83-83. http://dx.doi.org/10.2307/1354446

Massumi, Brian. Parables for the Virtual: Movement, Affect, Sensation. Durham: Duke University Press, 2002. http://dx.doi.org/10.1215/9780822383574 
Neale, Steve. Genre and Hollywood. London: Routledge, 2000.

Sobchack, Vivian. "What My Fingers Knew, The Cinesthetic Subject, or Vision in the Flesh." Senses of Cinema 5 (2000). http://sensesofcinema.com/2000/conferencespecial-effects-special-affects/fingers/

. Carnal Thoughts: Embodiment and Moving Image Culture. Berkeley: University of California Press, 2004.

Stewart, Kathleen. Ordinary Affects. Durham: Duke University Press, 2007. http://dx.doi.org/10.1215/9780822390404

Tudor, Andrew. Theories of Film. London, Secker and Warburg, 1974.

Williams, Linda. "Film Bodies: Gender, Genre, and Excess." Film Quarterly 44.4 (1991): 213. http://dx.doi.org/10.2307/1212758 


\title{
A Dance Between Chaos and Complexity: Choreographing the Spasm in Music Videos ${ }^{1}$
}

Melissa Blanco Borelli, Royal Holloway University of London

\begin{abstract}
This article analyzes the use of the spasm as a choreographic tool in the following music videos: The Talking Heads' "Once in a Lifetime" (1981), Radiohead's "Lotus Flower" (2011), and Atoms for Peace's "Ingenue" (2013). I read the choreography in these videos as representations of the spasm (as defined by Franco 'Bifo' Berardi) which can ultimately become a chaoide (as defined by Gilles Deleuze and Félix Guattari) when deployed in specific ways by specific bodies. My analysis of these videos suggests opportunities for thinking about how the corporeal labor of the spasm-especially its contingent sweat alongside (un)successful moments of corporeal fluidity-mark bodies as agents capable of negotiating how they might control their own embodied relationship to semiocapitalism and its privileging of speed and productivity.
\end{abstract}

Keywords: spasm, chaoide, chaosmosis, dance in music videos, semiocapitalism

This article engages with the concepts of the spasm (Franco 'Bifo' Berardi) and the chaoide (Gilles Deleuze and Félix Guattari) to analyze the dancing in three music videos curated in order to demonstrate the progression of the spasm as a corporeal gesture brought upon by neoliberal semiocapitalism: The Talking Heads' "Once in a Lifetime" (1981), Radiohead's "Lotus Flower" (2011) and Atoms for Peace's "Ingenue" (2013). My understanding of neoliberalism comes from David Harvey in A Brief History of Neoliberalism (2005) where he argues that neoliberalism is "in the first instance a theory of political economic practices that proposes that human well-being can best be advanced by liberating individual entrepreneurial freedoms and skills within an institutional framework characterized by strong private property rights, free markets, and free trade." ${ }^{2}$ Beginning in the late 1970s and gaining traction by late $80 \mathrm{~s}$ and $90 \mathrm{~s}$, neoliberalism, in order to keep the market moving, accumulating and creating more capital, established a new speed of exchange. Technological developments continue to facilitate this increase in speed. 
I add further nuance to Harvey's definition of neoliberalism through the use of Berardi's idea of semiocapitalism, which focuses on what actually gets produced within capitalism. For Berardi, semiocapital "is not about the production of material goods, but about the production of psychic stimulation. The mental environment is saturated by signs that create a sort of continuous excitation, a permanent electrocution, which leads the individual mind as well as the collective mind to a state of collapse. ${ }^{\prime \prime}$ Berardi sums up the current psychic-physiological situation as follows:

While info-technologies are provoking an acceleration of the rhythm of information and experience, simultaneously the space for physical movement is shrinking and the resources for economic expansion are becoming exhausted. I call this double process of acceleration and exhaustion: the spasm. ${ }^{4}$

The speed of semiocapitalism and its inexorable endurance and exhaustion leads us to emotional depression since, as some critical theorists argue, we lack the ability to grow accustomed to this constant change in speed/rhythm. ${ }^{5}$ Berardi claims that depression is so widespread today because "the contemporary organization of production of surplus-value is founded on the phenomenon-the accumulation-of speed." ${ }^{16}$ If becoming a subject requires contemplation, care and practice, the socially imposed requirement of speed creates a tense situation for said subject. This tension between fast and slow is what brings about the condition of the "spasm." Berardi continues his observations by stating that "today's social/political problem" due to the "compulsive acceleration of daily rhythms" is the spasm, which "stems from economics of competition." According to Berardi, this spasm is a condition where "the body is less able to live and breathe in harmony with other bodies" because of the "precarisation (continuous competition between bodies) of work and daily life." ${ }^{7}$ In his more recent publication, Heroes: Mass Murder and Suicide, Berardi defines the spasm as a "sudden, abnormal, involuntary muscular contractions and relaxations." ${ }^{8}$ It is also "a sudden, brief spell of energy and an abnormal, painful intensification of the bodily nervous vibration." ${ }^{\prime 9}$ Clearly Berardi subsumes the corporeal experience into a universal presumably first world body, but how neoliberal semiocapitalism and its demands for speed, consumption and competition affects bodies choreographically is of concern here. The spasm interrupts the flow of semiocapitalist time, an efficient teleological progression, by highlighting the tension inherent in adhering to such ordering of time. Yet, I ask, how might the spasm be a productive corporeal interruption? What does the physicalized battle between being in and out of control at the same time look like when represented through popular screen dance choreography?

The aestheticization of the spasm could be said to function as what Guattari calls chaosmosis, "the creation of a new (more complex) order (syntony, and sympathy) emerging from the present chaos." ${ }^{10}$ This new order is about "the sharing of a sympathetic mindset." 11 In order to be able to find this new order, Guattari states we 
need a "chaoide," a living decoder of chaos that manages to avoid absorbing the negative psychological effects of chaos. ${ }^{12}$ Berardi adamantly calls for "us" (his readers presumably) "to produce and circulate chaoides ... tools for the conceptual elaboration both of the surrounding and of the internalized chaos. A chaoide is a form of enunciation (artistic, poetic, political, scientific) which is able to open the linguistic flows to different rhythms to different frames of interpretation." ${ }^{13}$ I read the choreography in these videos as representations of the spasm leading to the chaoide. My analysis of these videos suggests opportunities for thinking about how the corporeal labor of the spasm-especially its contingent sweat alongside (un)successful moments of corporeal fluidity-mark bodies as agents capable of negotiating how they might control their own embodied relationship to semiocapitalism.

Minoritarian discourses have allowed for women, queers, and people of color (and all intersectionalities within) to act, react, and contest the histories of subjugation, violence, and erasure these bodies have encountered. Furthermore, a strong case exists to suggest they have been living longer with the conditions that produce the spasm. I wonder how a theoretical contestation against the spasm might play out when the bodies doing or performing the spasm, i.e. white males, benefit from an ideological system that grants them privilege. In the videos I analyze, the music industry (as a mode of production) regulates the types of aesthetic and cultural capital recording artists have in order to generate economic capital. Thus, the novelty of a white male band, not known for choreographic display, showcasing its lead singer as an embodied subject or 'dancer' prompts me to wonder what types of neoliberal choreographies of white masculinities circulate in the music video genre. Although these three videos feature white male bodies dancing, I do not wish to imply that they are the only bodies capable of feeling the effects of semiocapitalism. Nor am I discounting the work of queer and women of color feminist theories that necessarily foreground the instability inherent in all masculine identities. ${ }^{14}$ Instead, I focus on how reading their bodies alongside the development of neoliberal semiocapitalism offers ways to both experience and exploit the corporeal effects of economics, politics, and technology. I hope to entertain a dialogue between masculinity studies and dance-a conversation often addressed in terms of men's roles in concert dance, cultural appropriation, and the white male body or spectatorship/the male gaze. It seems crucial now more than ever to assert what late social theorist and dance scholar Randy Martin wrote in Critical Moves, that "dance generates a sense of being in the midst of a crisis, a break, a rupture, even a loss and a prospect at the same time." 15

The white male body dancing in popular culture and the cultural implication this term contains sets up a possible contention to this essay. In setting these videos alongside one another, I do not attempt a taxonomy of white masculinity. Instead, I consider how the spasm as both a corporeal condition and a choreographic strategy functions 
in music videos as a way to watch how white masculinity reconfigures itself choreographically in the wake of a rather cataclysmic economic downturn brought about by the economic hubris of said first world white masculinity. Clearly, white masculinity arrives with its sets of privileges (even the privilege of using the spasm as an aesthetic/choreographic choice), but I want to draw our attention to how the spasm develops and emerges alongside the progression of neoliberalism, and how perhaps it can lead us to see its potential as a chaoide. The development of the discomfort, corporeal shock, (re)adjustment or spasm, I posit, can be traced progressively through these videos from the rigid, puppet-like contortions of David Byrne to the fidgets, wriggles, and the jittery posturings of Thom Yorke. If the spasm as chaoide can exist as a tactic to interrupt the smooth flow of semiocapitalism rather than as an uncomfortable corporeal modus operandi, then how might choreographers (particularly working within music video/popular screen) engage with its aesthetics to draw our attention to the urgency of such tactics for psychic-physiological survival?

Although I am specifically looking at representations of neoliberal white masculinities, I do not want to couch all of my analysis within the concept of hegemonic masculinity because it receives much scholarly criticism. Yet, as Connell and Messerschmidt state, "the pattern of embodiment involved in hegemony has not been convincingly theorized." ${ }^{16}$ They advocate for a continued interrogation and reconceptualization of hegemonic masculinity particularly through the significance of embodiment and its relationship to social context. Dance scholars welcome this call to arms (pardon the pun). Connell declares that in order to "understand embodiment and hegemony, we need to understand that bodies are both objects of social practice and agents in social practice." ${ }^{17}$ As both objects and agents, they respond to and resist institutional, economic, political, and social relations. Sometimes this response synchronizes well with the rhythms of life; other times it moves awkwardly out of time, out of synch, creating moments of tension, control, chaos, release and, for our purposes, spasms. In the case of hetero-masculinity and the white male bodies in the following analysis, the corporeal negotiations of the spasm, in other words, being in control and in synch versus displaying an apparent loss of control, becomes an identifying factor. Overall, my analysis marks a way to invite further interrogations about the relationship between corporeality, the corporeal discomforts of semiocapitalism, and how dance in music video often becomes a rich site for such discourses.

\section{Up in Arms: Talking Heads, “Once in a Lifetime" (1981)}

David Byrne appears to be stuck on an imaginary Ferris wheel that he himself must operate in the first images of the video for "Once in a Lifetime" directed by choreographer Toni Basil. It is as if this wheel represents the daily grind of the capitalist workplace, or, more precisely, serves as a metaphor for the labor all bodies must endure in order to maintain their gendered corporeality. Byrne exhales deeply, his 
cheeks expand outwards to demonstrate the laborious nature of his task. After what seems like the last circulation of his ride on this unseen wheel, Byrne jerkily stops and stands to face the camera. His body lies framed in mid-shot from his waist upwards. One hand rests below his sternum, while the other arm bends at the elbow in mid-air as if getting ready to swear to an oath.
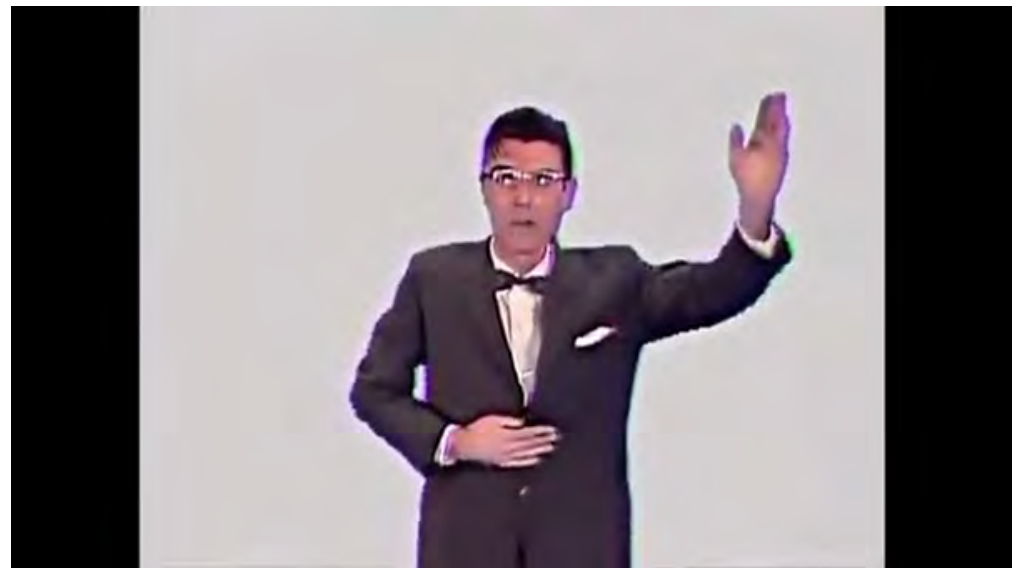

Screenshot, "Once in a Lifetime." Byrne begins his choreography with the proselytizer pose.

Dressed in a tan suit, bowtie, and glasses, Byrne could also be a great proselytizer, preparing to invite novices into his world of ideas. Austerlitz describes Byrne's appearance in this video as "part televangelist, part limbo dancer, and part children's show host, all bathed in the flop sweat of nerdy exertion." ${ }^{18}$ It is the sweat that interests me here. The labor of dancing, of having to follow a piece of choreography, might be alien to his body since Byrne is a singer/songwriter/musician, not a dancer. Yet, why draw attention to his sweat? His heavy breathing and sweaty brow instantiate the framework of the spasm, since "semiocapital arouses and mobilizes expression up to the point of a hyper-expressivity." ${ }^{19}$ He appears over-exerted, overexaggerated and over-worked, and the video has only just begun. Although semiocapitalism was arguably at its inception at the time of the filming, Byrne's character struggles with demands imposed on his body by the choreography and the narrative of the song's lyrics. The lyrics attest to an existential dissatisfaction he faces once he possesses material goods (e.g., beautiful automobile, beautiful house, beautiful wife) that exist as criteria for success within semiocapitalism. The emotional, physical, and cognitive labor required to 'succeed' literally trickles down from Byrne's brow as sweat. His inability to consistently stay within the ordered progression of neoliberal time (as evidenced by the constant self-reflexive questioning of the lyrics) creates small spasms, moments that demonstrate a loss of control and, perhaps worse, a total failure in executing the 'right' kind of corporeality -white, hyper-masculine, and economically viable-for neoliberalism. In this historical moment the 'right' kind of body was the "hard body" ${ }^{20}$ manufactured by the Ronald Reagan ideology.

Ronald Reagan was inaugurated as 40th US President in January 1981. Talking Heads' (USA) "Once in A Lifetime" single was released on 2 February 1981 and became a 
heavy rotation video on MTV after its broadcast debut in August 1981. Reagan's economic policies included his infamous "trickle down economics," or Reaganomics, which argued that tax cuts to corporations and the wealthy would result in a top down movement of capital that would improve the economy for all. Other economic policies during the Reagan administration included changes in the tax code, an explosion of military spending, a massive increase in the federal deficit, and a wholesale deregulation of industry that reinforced class divisions and led to an upward redistribution of wealth. ${ }^{21}$ However, this was not yet the reality in 1981. Reagan had only been in power for eight months when this video aired. Nevertheless, Byrne offers a sharp contrast to the corporeal bravado of Ronald Reagan. In Hard Bodies: Hollywood Masculinity in the Reagan Era, Susan Jeffords argues that the normative body set up was one that "enveloped strength, labor, determination, loyalty and couragethe"hard body" - the body that was, like Reagan's own, male and white." ${ }^{22}$ This "hardened male form" stood in as the synecdoche of the Reagan presidency, a form that Byrne's stiff and unregulated body undermines. ${ }^{23}$

Byrne seems like a harmless, effete nerd-boy in comparison to the Reagan ideal. ${ }^{24} \mathrm{His}$ sweat is evidence of his struggle to try to successfully em-body the "hard body" that can withstand anything. Byrne's stiffness is the wrong kind of hard. His body looks uncomfortably rigid, it falls to the front or side, and it cannot maintain its balance. In fact, it is hardly filmed facing forward-whether stably or comfortably. Instead, it moves chaotically, spasms with difficulty, and creates more and more sweat. Sweat that generates the Reaganesque strong, supple, upright body, is permissible; sweat from corporeal inefficiency is not. Byrne's body does not respond to the rhythm of the song, and any close-up of his body, particularly his face, displays the wrong kind of sweat. His arms seem listless without direction, needing external forces to engage them into action. In fact, when the second verse of the song begins, he is shot in full frame while his shoulders alternate in jerky spasms backwards, as if something, or an imaginary someone, is poking him violently each time his shoulders go back (and his arms flail backwards).
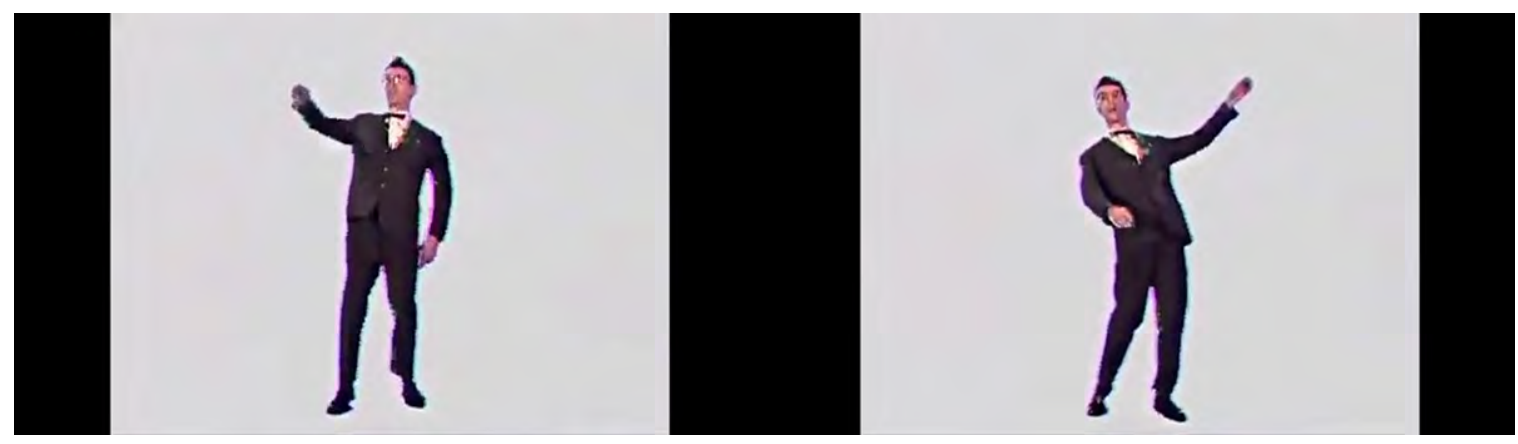

Screenshots, "Once in a Lifetime." Byrne lacks stability and balance. 
I read this inability to maintain composure and firm resistance as further confirmation of Byrne's failure to be a "hard body," for as Jeffords writes, "such bodies exist in the confirmation of this mastery by themselves refusing to be 'messy' or 'confusing,' but having hard edges, determinate lines of action, and clear boundaries for their own decision making" (my emphasis). ${ }^{25}$ His lack of "hard edges" contributes to his "messy" and "confusing" spasms. He is not in control since some-thing else forces his body to re-act, not enact.

Behind Byrne, a full body shot shows ethnographic footage of women of color kneeling close to the floor and pulsing their arms rhythmically in gestures mimetic of female domestic labor or possibly even of ecstatic spiritual worship. Byrne, in contrast, kneels and pulses his arms downwards with his palms flat, further instantiating his "soft body." Choreographer/director Toni Basil's interest in dances from the global South (an interest I am familiar with, having taken Afro Cuban dance classes with her in Los Angeles) may have been the catalyst for the use of ethnographic film footage and the appropriation of the choreographies within them. Basil explains that:

He [Byrne] wanted to research movement, but he wanted to research movement more as an actor, as does David Bowie, as does Mick Jagger. They come to movement in another way, not as a trained dancer. Or not really interested in dance steps. He wanted to research people in trancesdifferent trances in church and different trances with snakes. So we went over to UCLA and USC, and we viewed a lot of footage of documentaries on that subject. And then he took the ideas, and he "physicalized" the ideas from the documentary-style films. ${ }^{26}$

This physicalizing stems from the politics of appropriation and mass consumption that began to swell in the 1980s. It could also be read alongside the Reagan Doctrine's foreign policy particularly its influence in the so-called Third World as a way to combat the threat of the Soviet Union in that area of the world during the last decade of the Cold War. The mining of global South choreographies for source material points to the privileged and possibly self-serving agenda of US imperialism, but it also highlights how Byrne opted for embodiment outside of the early 1980s neoliberal hard masculine form. The tension produced by his inability to execute either a successful "hard body" or a "soft" feminine othered body (as portrayed by the choreography of the brown women in the ethnographic video) creates the spasms that riddle his body. The experience of neoliberal time by the subjects in the footage and Byrne himself is decidedly different, further demonstrating how bodies find ways to be in or out of control, causing them to spasm ... or not.

The song's chorus and its corresponding choreography features many Byrnes moving across the screen like cogs in the capitalist machine with arms in aggressive posturing, preparing for a pugilistic encounter with those Cold War enemies the Reagan Doctrine 
was keen on disarming. That Byrne in his nerdish guise appears ready to fight the good fight in honor of patriotism and deference to the Reagan Administration is laughable considering his criticism of said administration in his film True Stories (1986). ${ }^{27}$ However, his body's performance in the video attests to its attempt at incorpo-rating itself into Reaganomics; an unsettling, uncomfortable task full of agitation, instability, and spasms.
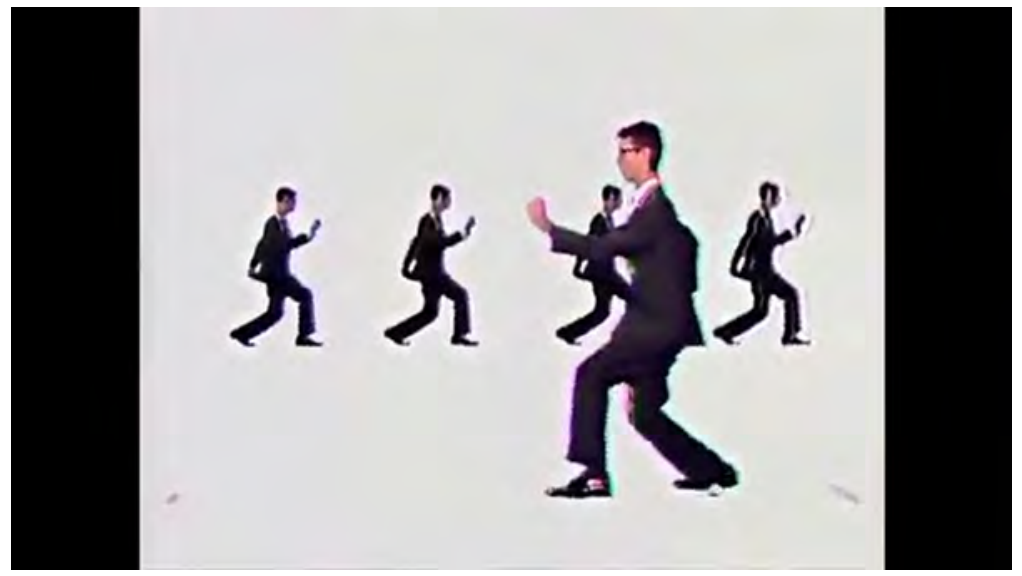

Screenshot, "Once in a Lifetime." Byrne as pugilistic cog in the machine.

As the video progresses, more ethnographic footage appears, this time of hands crossing on top of one another. Like before, Byrne imitates these as part of his choreographic score and he appears to be in time with the footage. Yet, when the chorus returns, his body spasms uncontrollably and he is no longer in control. It jerks, quivers and shakes while repeating arrhythmic motions that shift in intensity from slow and sustained to bound and fast. Basil had Byrne study epileptic seizure victims in order to learn how to spasm for the choreography. ${ }^{28}$ Here, the commodification of pain and illness for art/consumption belongs to the greater narrative of commodity culture and neoliberalism, those things that I consider as entities that Byrne's nerd boy contests. As the camera comes in for a close-up of his sweaty face, damp hair, and discombobulated gaze, he spasms so much that it appears as if outside hands (not his own) grab him on each side of his face to try to steady his shaking. He bends forward, rotates his torso around from the waist while the arms adjust on either side or move above his head as he comes back up during his rotation. This movement motif gets repeated later, rotations that call to mind the hands of a clock moving erratically and laboriously to tell time. These unsteady, uneasy, and perturbed corporeal spasms appear as if someone or something might be controlling his body. Although his attire suggests a Yuppie aesthetic, the young urban professional that emerged because of Reaganomics, Byrne's nerdish alter ego's discomfort with such an aesthetic manifests through the spasms. His is a white male body in conflict with the outside forces of Reaganesque hegemonic neoliberal masculinity. That someone/something must try to stop his spasms suggests the precarious nature of conformity especially during an era where conformity equaled success. Furthermore, Byrne appears in a different iteration of himself momentarily during this version of the chorus and jarringly breaks the 
distinction between Byrne as the out-of-control marionette and Byrne as the recording artist who appears settled, seated, and in control in the final moments of the video. I shall return to this still and non-sweaty Byrne shortly.

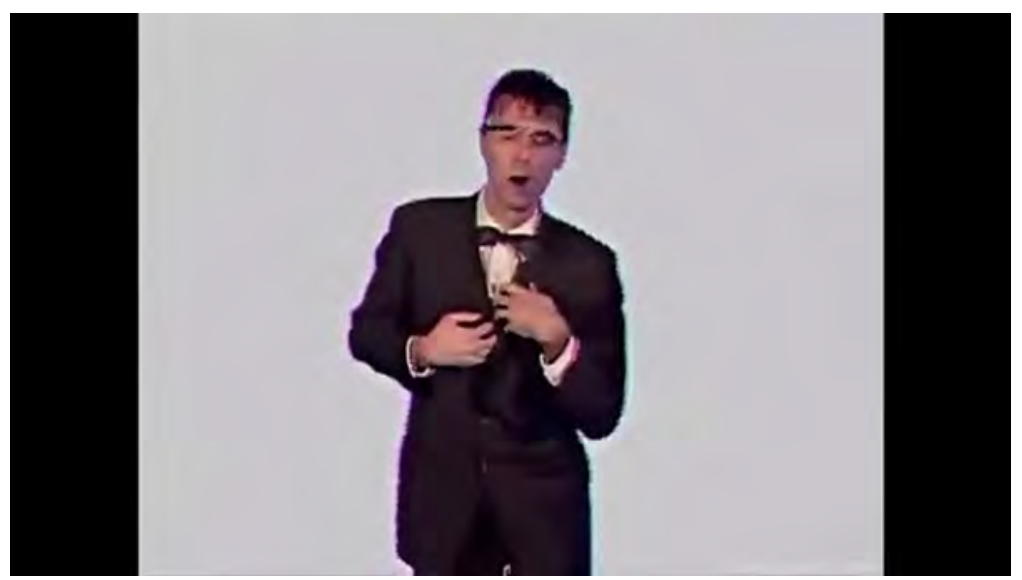

Screenshot, "Once in a Lifetime." Byrne in the middle of his spasms.

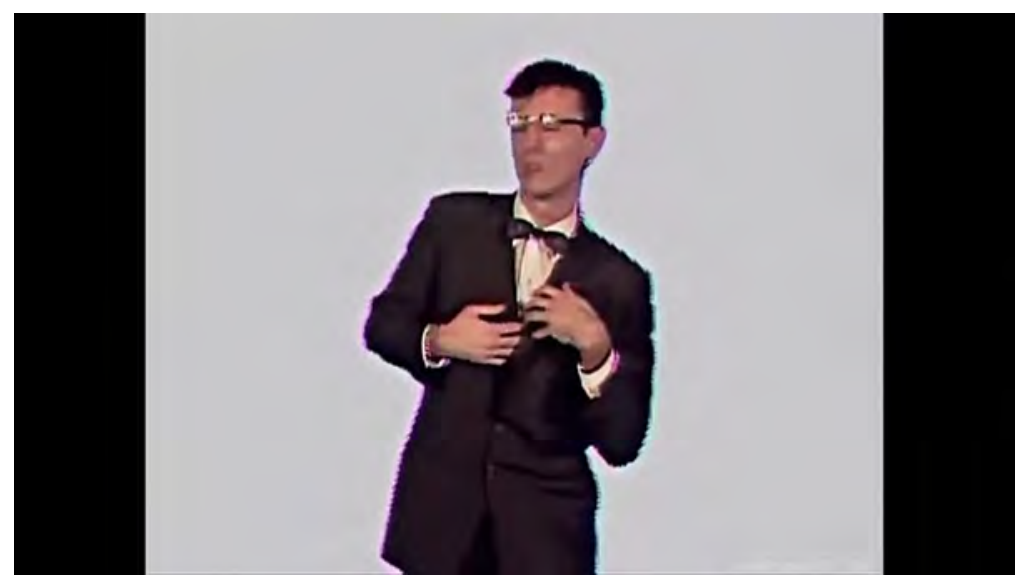

Screenshot, "Once in a Lifetime." Byrne continues to spasm.
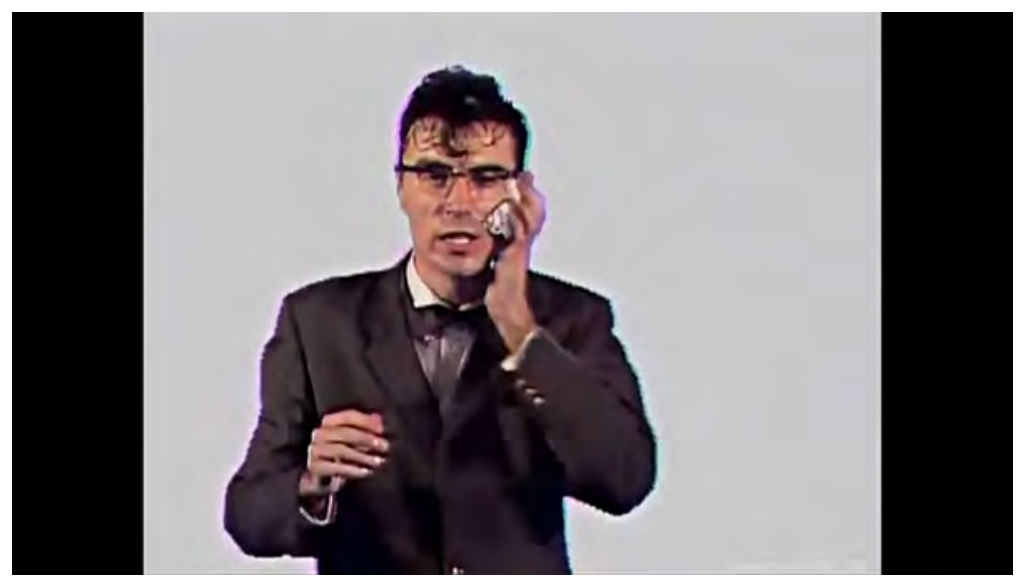

Screenshot, "Once in a Lifetime." Byrne wipes his sweat while trying to remain in control. 


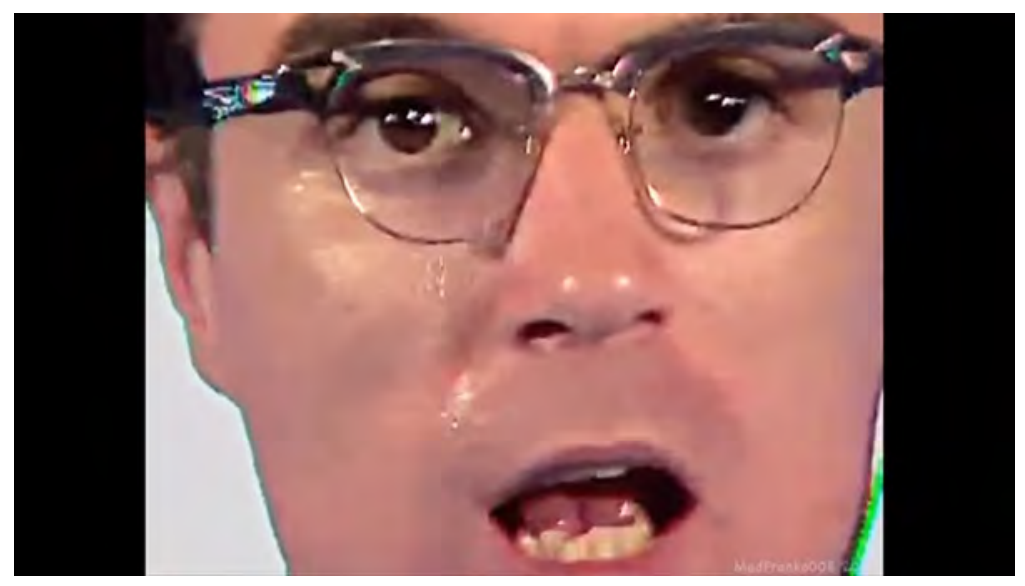

Screenshot, "Once in a Lifetime." A sweaty Byrne repeats "same as it ever was."

While the nerd Byrne spasms himself into the blue oblivion of the background, this other Byrne, who calmly lip synchs showing no signs of sweaty excess or discomfort, maintains a steady gaze with those of us behind and beyond the camera.

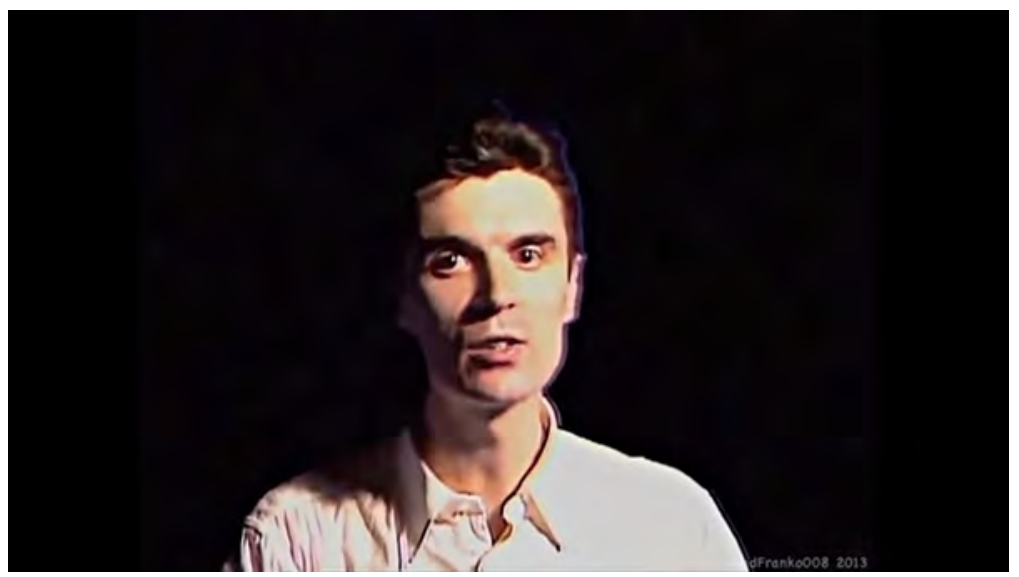

Screenshot, "Once in a Lifetime." Byrne the "rock star" stays in control without visible sweat.

As he repeats "same as it ever was" we are reminded that perhaps no matter how white male bodies resist and respond to and against socio-economic or cultural impositions, those that conform and uphold the "same" can continue to shape patriarchal capitalism in their own interest so that it indeed can be "same as it ever was." Those who cannot, must eventually spasm in order to endure.

\section{Dis-Arming the Spasm: Radiohead, "Lotus Flower" (2011) and Atoms for Peace, “Ingenue" (2013)}

"Lotus Flower" provides an aesthetics of austerity to parallel the economic slump that US/UK/EU faced after the 2008 financial banking crisis. In this video, with its stylized lighting, stark black and white cinematography and a black bowler hat, Thom Yorke of the UK band Radiohead spasms and contorts in ways that, I posit, mirror Berardi's precarization of work and daily life. Thirty years have passed since the "Once in a Lifetime" video first aired on MTV and "Lotus Flower," airing first on the Internet via 
VeVo and YouTube, engages with new modes of distribution and dissemination of the music video form. In examining the over thirty-year history of the music video form, media scholar Carol Vernallis writes, "Music video has since undergone shifts in technologies, platforms, periods of intense cross-pollination with other media, financial booms and busts, and changing levels of audience engagement. While music videos hit a low point in the [20]00s as budgets dried up, they have reemerged as a key driver of popular culture." ${ }^{29}$

Aesthetic requirements and styles may have shifted given the ways in which music videos are distributed today in contrast to the 1980s, when MTV had a board of 10 vetters who cleared material before it went to the Standards and Practices division. ${ }^{30}$ Now, many music videos for the major music conglomerates (and their high profile pop stars) compete not just for the attention of the viewer given our oversaturated image market, but for product placements and the most hits on YouTube. While it is difficult to qualitatively ascertain what material will receive more hits/views/circulation and why, in the case of the following two videos, it is the novelty of watching Thom Yorke, lead singer of Radiohead, dance that may have drawn over 35 million viewers (as of February 2016 on YouTube) to the "Lotus Flower" video.

As the music for "Lotus Flower" begins, Yorke dances in a frustrated fashion. His choreographer is Wayne McGregor. ${ }^{31}$ Yorke moves his arms and torso while his legs/feet stay in one place. He wriggles, swivels, and shifts from side to side. He sinks his torso inwards in concave fashion and has his hands shoved into his pockets in a gesture of nonchalance. He finds his way to one pose-left arm outstretched horizontally while the right arm is almost parallel but bent and stays closer to his torso. He pulses in this pose, repeating it as if on a digital loop, each repetition increasing in intensity until he makes a final sharp articulation of it and pauses. He acknowledges our gaze (the camera) and then abruptly shifts into spasmodic gestures that make him lose his balance as he jerks quickly backwards.

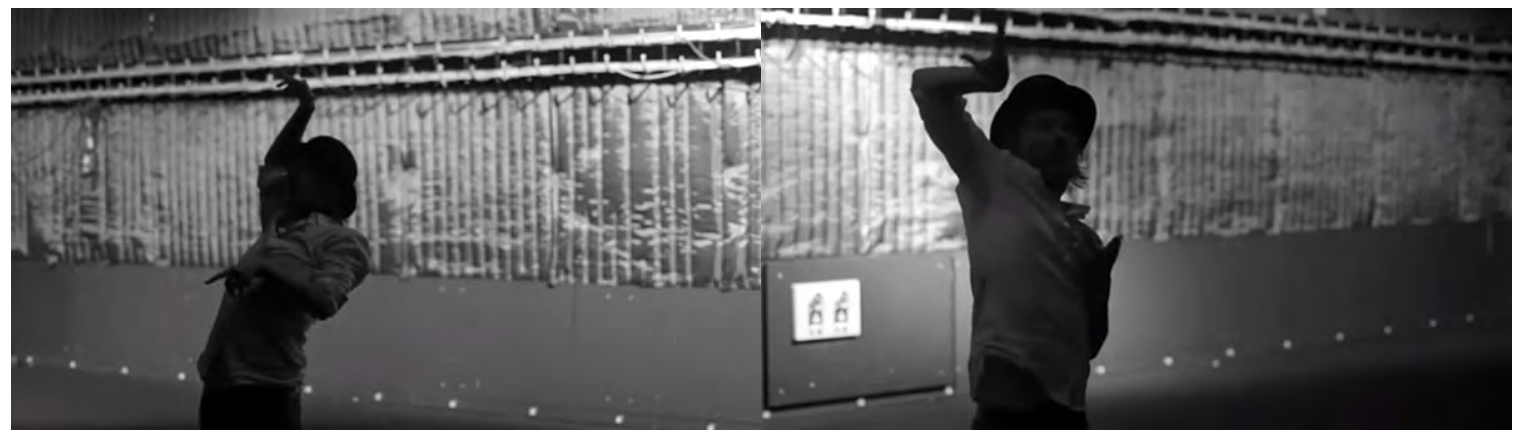

Screenshots, "Lotus Flower." Yorke stretches, writhes and wriggles. 


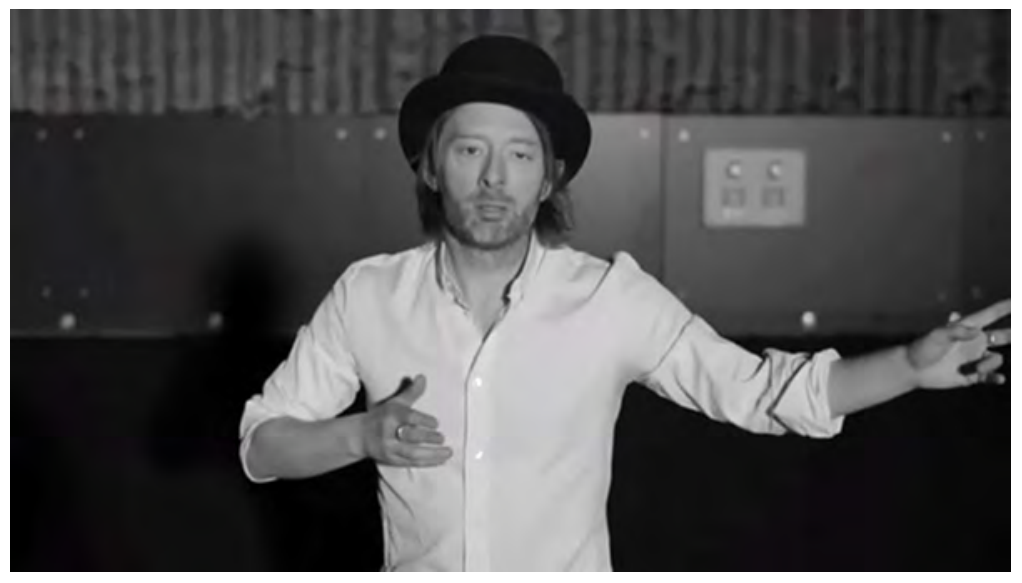

Screenshot, "Lotus Flower." Yorke finishes his intense repetition and acknowledges the camera's gaze.

Berardi writes that the "spasm emerges as an effect of a violent penetration of capitalist exploitation into the field of info-technologies which acts on the sphere of cognition, of sensibility, and the unconscious." 32 The stark warehouse, the even starker black and white cinematography and the stark imagery in the lyrics ("empty space inside my heart," "moon on a stick," "I dance around the pit / darkness is beneath") contrast with the active physicalizations of Yorke's body. It is as if his out-of-control limbs are "violently penetrating" the aestheticized tabula rasa of the backstage surroundings. Like Byrne before him, he physically struggles, caught between chaos/spasm and something else. Guattari would call this something else "complexity." Guattari develops the terms chaosmosis in order to re-define subjectivity. For him, chaosmosis is a "dance of chaos and complexity" 33 that individuals within neoliberalism (or semiocapitalism) must attune themselves to. As such, Yorke's chaotic spasms enact the chaosmosis of his austere surroundings and the austerity that riddled the world financial markets when the video was produced. In contrast to Byrne's nerd boy who was unable to embody the masculine "hard body" of his historical moment, Yorke's spasms demonstrate a new struggle after the economic downturn post 2008. It is not so much a struggle to become more masculine, rugged, or powerful, but rather an engagement in a metaphoric struggle with how to regain balance after so much economic and psychic-social upheaval.

Yorke finds his physical balance again by running in place until that movement transforms into arms reaching forward, grabbing at intangible objects. He circles around in a running pattern again which leads to a quick edit showing him standing still in a full body shot. He appears mesmerized by his left palm as he looks over at it and slowly begins to raise his hands over his face. The camera zooms in to a medium shot and his gaze moves from the left palm to the right hand/arm lifted high above his head. His eyes look up, he removes the bowler hat from his head and we see damp hair, a sweaty forehead, and a large sweat spot at his armpit. 


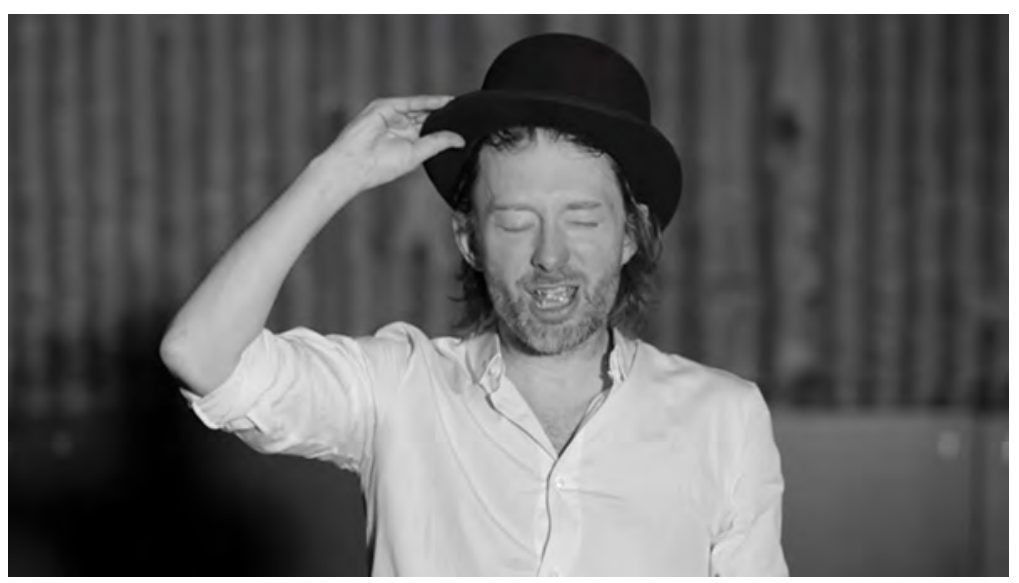

Screenshots, "Lotus Flower." Yorke takes a break from his spasms to remove his hat.
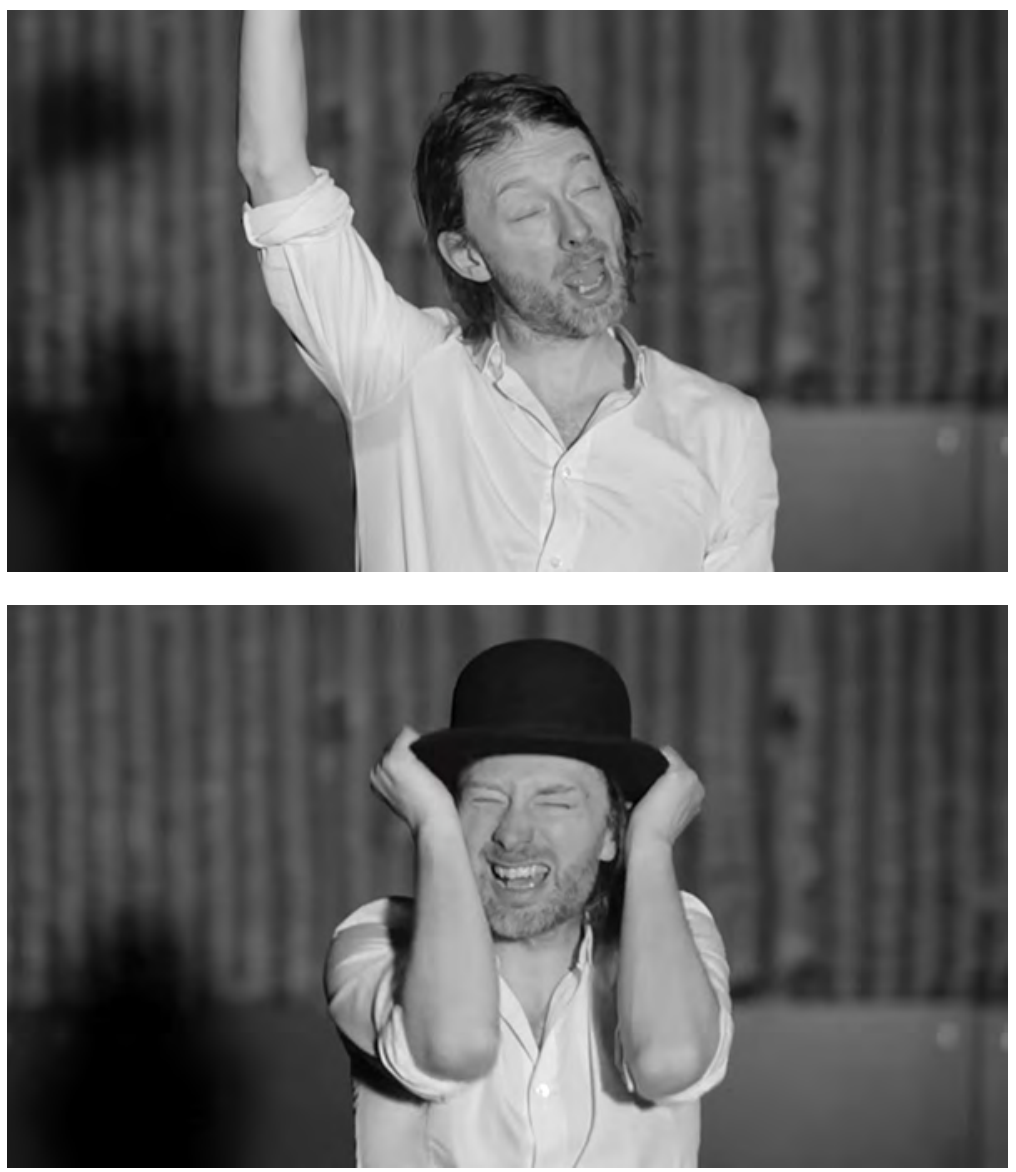

This short, almost languorous gesture of ecstasy meets a spasmodic end as by the time he brings his arm down and replaces the hat on his head, he breaks into jerky, quivering spasms while he runs in place. As Berardi explains, "the spasm is the panic effect of the accelerated stimulation of the organism." ${ }^{34}$ The spasm has caused his body to sweat, become unruly and to labor inefficiently. He runs, yet he doesn't go anywhere, representing the futility of corporeal labor during neoliberal austerity. He 
remains stuck in a push-pull between moments of slowness and ease with other moments of twitching and trembling dis-ease.

For the second verse, the same choreographic idea of gestures in intensified repetition returns. This time the camera changes location. It is set up higher and at a different side-ways angle. He continues to balter about, moving between losing his balance and trying hard to regain it. He kneels, claps, and loses his balance as if the ground can no longer offer stability in a clear choreographic metaphor of the experience of the financial crisis and its ensuing austerity measures. The close-up returns after this moment of imbalance. Yorke has a look of contemplative consideration with hands in what appears like a prayer position. He removes his hat once more before the jiggles, wriggles, and jerks return. His shoulders lift up and down, his legs flail and kick around, his torso cannot find proper alignment. There is no stability for him here. For the final 44 seconds of the video, Yorke is in a constant state of spasm.

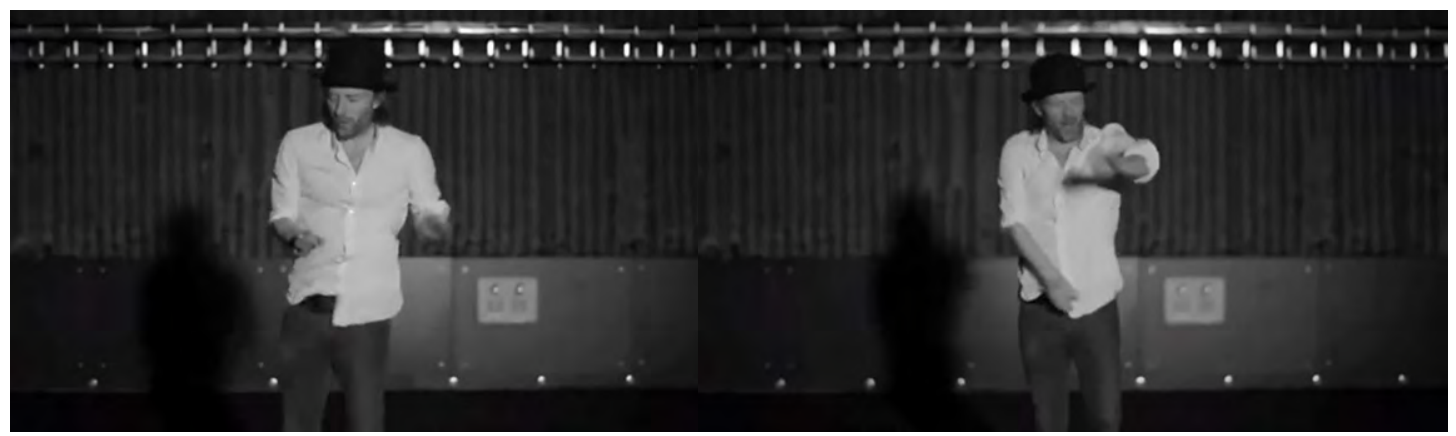

Screenshots, "Lotus Flower." Yorke continues to spasm as the music video draws to a close.

"What should we do when we are in a situation of spasm?" asks Berardi. ${ }^{35}$ In Yorke's case, it involves giving into it somewhat, not with defiant recalcitrance (that may create more spasms), but with cautious practice since, as a white male body marked with privilege, discomfort and spasm is a new precarious embodiment to learn.

Wayne McGregor continued his collaboration with Thom Yorke with Atoms for Peace, a collaborative project between Yorke, Flea (of Red Hot Chili Peppers) and other indie rock musicians. In "Ingenue," a tweed-suited Yorke mirrors choreography begun by dancer Fukiko Takase, a member of McGregor's Random Dance company. This is a fun video to watch in terms of the noticeable differences between their two distinctively articulate bodies executing the same movements. More importantly, both genders wrestle with the spasm in this video. The contrast in their bodies goes further: his whiteness, her Asianness, his untrained body, her dance-trained one. Evidence of competition could be read within the video: both do the same movements, both are dressed alike, calling to mind the equal compensation objective for women in the corporate workplace, something that began in 1980s. 
"Ingenue" begins on a dance theater stage. A white screen comes down while Takase, dressed in a brown tweed three-piece suit, stands still, eyes closed. The camera changes and comes closer (in similar fashion to "Lotus Flower") and we now see her from the side, off-center. The choreography begins. It features an over-exaggerated walk in place with knees raised high, arms swinging forward and backward like lazy pendulums, and her body weight is slightly backwards. She appears to be walking up an imaginary hill.

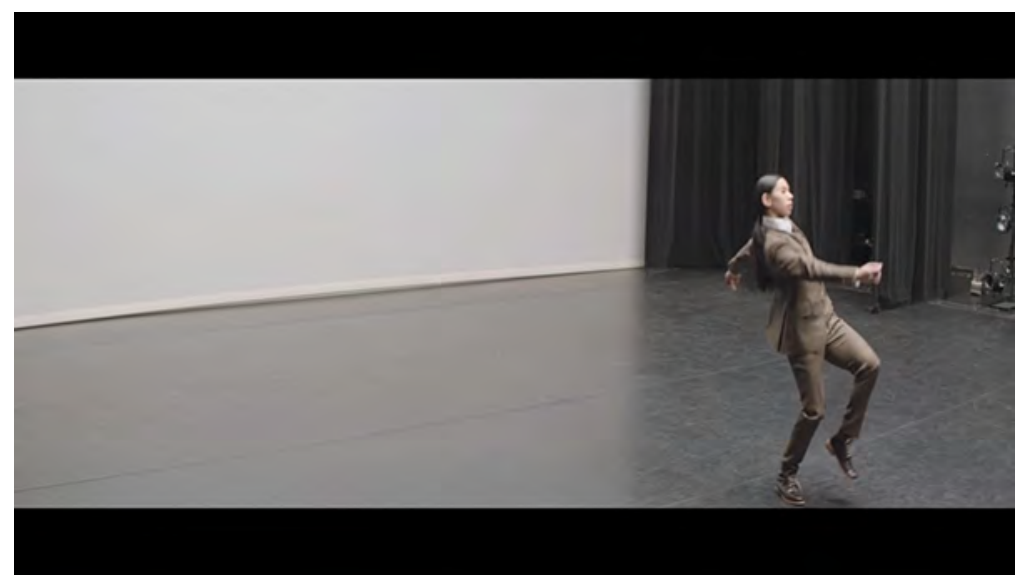

Screenshot, "Ingenue." Takase in the middle of her exaggerated walk.

When she turns to circle in place, a sharp edit makes Yorke appear in her place, doing the same choreography ... slightly differently. His movements are not as fluid nor as expansive as hers. Yet, their partnering could be read as a new order emerging from chaosmosis, with order "understood as harmony between mind and the semioenvironment, and also a sharing of the same mind-set: sympathy as common perception. ${ }^{36}$ While Berardi (and Guattari) privilege the mind here, I prefer to see the harmony in bodies, particularly in the harmoniously edited shift between Yorke and Takase's performances of similar choreographic phrases.

She kneels and thrusts her torso bending forwards while covering her head with the blazer's coattails. He does the same. The editing keeps jumping from her to him as if one starts the choreographic phrase while the other continues or ends it. This shared choreographic labor occurs until she suddenly jumps out from behind him while he rests in a pose with his arms up and across in an L-shaped formation.

They begin to dance together, mirroring one another. Their partner work includes side-to-side movements, level changes, and tracing uneven lines in space with their bodies. It is as if they are each trapped inside a plastic bag and trying to feel their way out by bending, writhing, and flicking their limbs in asymmetrical patterns. 


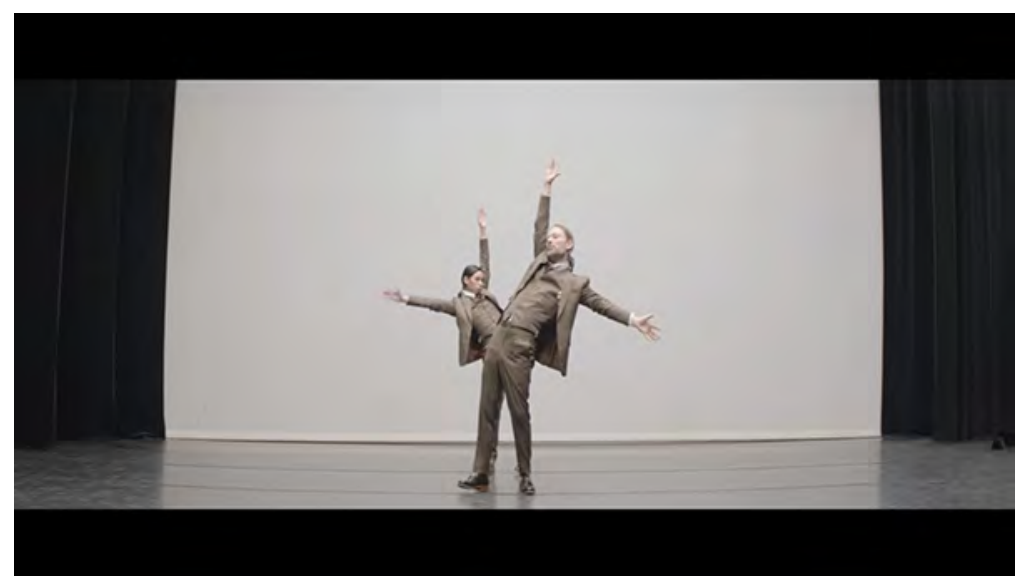

Screenshot, "Ingenue." Yorke and Takase occupy the stage space together for the first time.

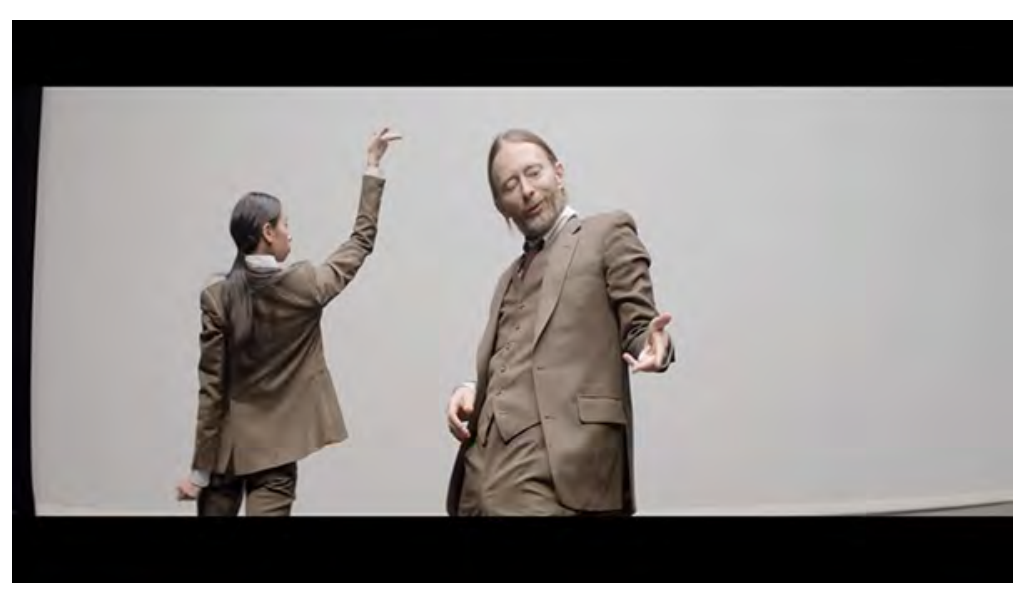

Screenshot, "Ingenue." Together they engage in stylistic, spasmodic phrases.

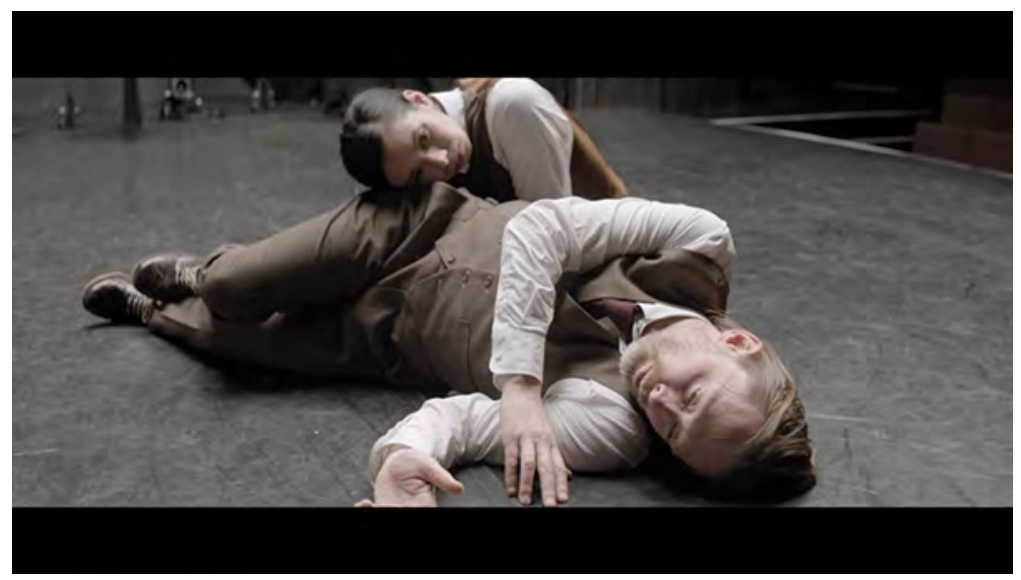

Screenshot, "Ingenue." Takase and Yorke enjoy a brief moment of stillness.

They eventually find a moment of respite from their twitching postures and gestures and they lie on the floor. At one point, Yorke lies sideways and Takase rests her head on his hip. The unexpected rhythmic variation between the intense jerks and the slow, almost still poses materializes the variability of neoliberal time.

As Deleuze and Guattari write in What Is Philosophy?, "This is the instant of which we do not know whether it is too long or too short for time. We receive sudden jolts that beat like arteries. We constantly lose our ideas." ${ }^{37}$ This shift from chaos to stillness 
could also be read as what Guattari articulates as "an initial chaosmotic folding [which] consists in making the powers of chaos co-exist with those of highest complexity." ${ }^{38}$ It is this moment of slowness, of stillness, or more specifically of temporal complexity that begins to shift the spasms in this video from mere representations of lack of control, inefficiency and messiness to the possibility of seeing them as chaoides; especially since Takase demonstrates such corporeal elegance and fluidity in her embodiment of them.

Interestingly, these two videos rely on full-body shots for the majority of the time. Only at decisive moments in the songs does the camera offer a close-up of each of their faces. They contort their faces similarly: eyes tucked upwards into their lids, features slightly twisted, an un-self-conscious reflection into what dancing or the music might offer: unbridled release from the social inscriptions that write the body. I am reminded of what cultural geographer David Harvey writes: "a body is not a closed and sealed entity but a relational 'thing' that is created, bounded, sustained, and ultimately dissolved in a spatiotemporal flux of multiple processes." ${ }^{\prime 39}$ These close-ups might be short moments where their choreographed bodies offer ways to dismantle or disturb the apparent chaos of the spasm. They are chaoides, "the living decoders of chaos that manage to avoid absorbing the negative psychological effects of chaos" by learning how to manage the struggle through corporeal fluidity.

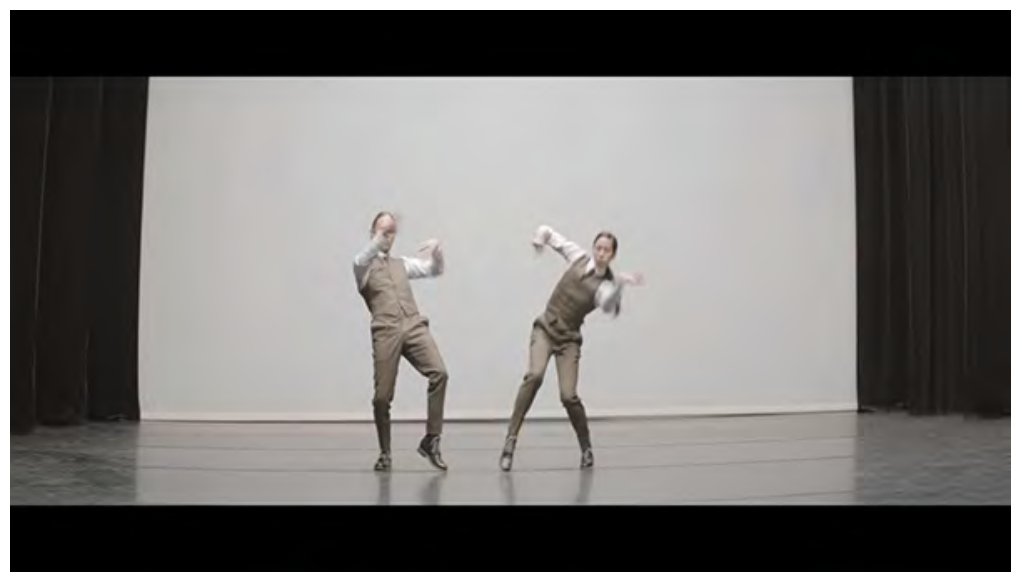

Screenshot, "Ingenue." The final spasms they perform together.

"Ingenue" concludes with both Yorke and Takase jerking and spasming uncontrollably after their brief, sympathetic respite on the floor. They flail, flounce and jostle. Limbs askew, feet in place, gaze directed forwards or upwards. Eventually, she moves behind him, disappearing from view as the camera pulls out and shows a solo Yorke, standing still, slowly lowering his bent arms. Their visible embodied differences highlight the need to work in synchrony and sympathy with others in order to materialize Guattari's chaoides, particularly in this historical moment that privileges competition and individual success. Perhaps the only way to endure the spasm is through embodied exchanges, especially with bodies (such as Takase's) that are practiced in skillfully enunciating their chaos and complexity within and outside of semiocapitalist time. 


\section{Biography}

Dr. Melissa Blanco Borelli is Senior Lecturer in the department of Drama and Theatre (soon to be Drama, Theatre, and Dance) at Royal Holloway, University of London. Her publications include She is Cuba: A Genealogy of The Mulata Body (Oxford University Press, 2015) and The Oxford Handbook of Dance and the Popular Screen (OUP, 2014). Chapters and journal articles appear in Women and Performance: a journal of feminist theory, Zizek and Performance (Palgrave, 2015), Black Performance Theory (Duke UP, 2015), and The Oxford Handbook of Screendance (forthcoming). Currently, she is on the lookout for a new book project.

Email: Melissa.Blanco@rhul.ac.uk

\section{Notes}

${ }^{1}$ I would like to thank Sherril Dodds for her comments to a very rough draft version of this essay. Derek Burrill suggested some of the books I consulted and was on hand for preliminary conversations. I would like to thank PoP Moves conference participants at UEL where I presented the first draft of this essay. My anonymous readers at IJSD were brilliant in their criticisms. Harmony Bench helped me focus theoretically and pare down what began as an overly ambitious hodge-podge of critical theory, music video analysis, and very long dance descriptions. Thank you Harmony and Simon Ellis for your patience. Lastly, I'd like to thank Nadine George-Graves who attended the panel where I presented a working draft at SDHS Conference in Trondheim, Norway. Her comments were very helpful especially since she was not initially convinced by the ideas. Trying to convince a skeptic always makes you work just a little bit harder, so thank you, Nadine.

${ }^{2}$ David Harvey, Neoliberalism, 2.

${ }^{3}$ Franco Berardi, Precarious Rhapsody, 45.

${ }^{4}$ Berardi, Heroes, 216.

${ }^{5}$ See Elizabeth Povinelli, Economies of Abandonment. Povinelli proposes the ideas of endurance and exhaustion as related to capitalism in late liberalism (neoliberalism). I am drawn to this combination because endurance and exhaustion relate to time, rhythm, and the event of a social project.

${ }^{6}$ Berardi, Heroes, 10.

${ }^{7}$ Berardi, CalArts TedX.

${ }^{8}$ Berardi, Heroes, 217.

${ }^{9}$ Ibid. 
${ }^{10}$ Félix Guattari qtd. in Berardi Heroes, 220.

${ }^{11}$ Ibid.

12 Idem., 222.

${ }^{13}$ Ibid.

14 As R. W. Connell and James W. Messerschmidt helpfully gloss in Hegemonic Masculinity, "Feminist theories of patriarchy include works by Goode (1982) and Snodgrass (1977). Maxine Baca Zinn (1982), Angela Davis (1983) and bell hooks (1984) articulate the race bias when it comes to speaking about sex difference, while Broker (1976) and Plummer (1981) examined 'gay men's ambivalent relationships to patriarchy and conventional masculinity"' (832). Eve Kosofsky Sedgwick's "Gosh, Boy George" usefully removes the association of masculinity with men to complicate the social enactments of gender.

${ }^{15}$ Randy Martin, Critical Moves, 1.

${ }^{16}$ Connell and Messerschmidt, Hegemonic Masculinity, 851.

17 Ibid.

${ }^{18}$ Saul Austerlitz, Money for Nothing, 55.

${ }^{19}$ Berardi, Chaosmic Spasm, 186.

${ }^{20}$ See Susan Jeffords, Hard Bodies.

${ }^{21}$ David Savran, Taking it Like a Man, 164.

22 Jeffords, Hard Bodies, 25.

${ }^{23}$ Ibid.

${ }^{24}$ Jeffords traces how masculinity was constructed during the Reagan Administration in the USA, linking Reagan's own Hollywood screen history to his presidential persona and the types of male characters that emerged in Hollywood action films.

${ }^{25}$ Idem., 27.

${ }^{26}$ Greg Prato, 2011 qtd in Songfacts.

27 True Stories (1986) directed by Byrne which fuses satire, documentary, and music to tell the story of a fictional small town in Texas preparing to celebrate its $150^{\text {th }}$ anniversary. As a "window" into 1980s Americana, the film subtly critiques Reagan era cultural ideologies.

${ }^{28}$ See Songfacts.

${ }^{29}$ Vernallis, Unruly Media, 207.

${ }^{30}$ Idem., 208.

${ }^{31}$ Wayne McGregor Random Dance received a 29\% increase in Arts Council funding for 2012-something interesting to note given the budget cuts affecting UK artists during the Tory austerity measures. (London Dance)

32 Berardi, Chaosmic Spasm, 184.

${ }^{33}$ Guattari, Chaosmosis, 88.

${ }^{34}$ Berardi, Chaosmic Spasm, 187.

${ }^{35}$ Idem., 184.

${ }^{36}$ Idem., 187.

${ }^{37}$ Gilles Deleuze and Félix Guattari, What Is Philosophy?, 201. 
${ }^{38}$ Guattari, Chaosmosis, 110.

${ }^{39}$ Harvey, Spaces of Hope, 98.

\section{References}

Austerlitz, Saul. Money for Nothing: A History of the Music Video from the Beatles to the White Stripes. New York: Continuum International Publishing Group, 2007.

Berardi, Franco 'Bifo.' Precarious Rhapsody: Semiocapitalism and the Pathologies of the Post-Alpha Generation. London: Minor Compositions, 2009.

. CalArts TedX:Performance, Body and Presence. 9 March 2013.

http://tedxcalarts.org/livestream/

. "Chaosmic Spasm and the Educational Chaoide" in Deleuze and Guattari Politics and Education: For People-Yet-To-Come. Edited by Matthew Carlin and Jason Wallin. London: Bloomsbury Press, 2014.

. Heroes: Mass Murder and Suicide. London: Verso Books, 2015.

Connell, R.W. and James W. Messerschmidt. "Hegemonic Masculinity: Rethinking the Concept" Gender \& Society December 2005 19: 829-859.

http://dx.doi.org/10.1177/0891243205278639

Deleuze, Gilles and Félix Guattari. What is Philosophy? New York: Columbia University Press, 1994.

Guattari, Félix. Chaosmosis: An Ethico-Aesthetic Paradigm. Bloomington: Indiana University Press, 1992.

Harvey, David. Spaces of Hope. Berkeley: University of California Press, 2000.

. A Brief History of Neoliberalism. New York: Oxford University Press, 2005.

"Ingenue." Dir. Garth Jennings. Atoms for Peace. 2013. YouTube.

https://www.youtube.com/watch?v=DpVfF4U75B8

Jeffords, Susan. Hard Bodies: Hollywood Masculinity in the Reagan Era, New Brunswick:

Rutgers University Press, 1994.

“Lotus Flower." Dir. Garth Jennings. Radiohead. 2011. Vimeo.

https://vimeo.com/20751513 
London Dance. "News: Arts Council funding announcements." 30 March 2011. Accessed 18 Feb. 2016. http://londondance.com/articles/news/arts-council-fundingannouncements/.

Martin, Randy. Critical Moves: Dance Studies in Theory and Politics. Durham: Duke University Press, 1998.

“Once In A Lifetime." Dir. Toni Basil. The Talking Heads. 1981. Vimeo.

https://vimeo.com/97541390

Povinelli, Elizabeth. Economies of Abandonment: Social Belonging and Endurance in Late Liberalism. Durham: Duke University Press, 2011.

http://dx.doi.org/10.1215/9780822394570

Prato, Greg. MTV Ruled The World: The Early Years of Music Video. Self-Published, 2011.

Savran, David. Taking it Like a Man: White Masculinity, Masochism, and Contemporary American Culture. Princeton: Princeton University Press, 1998.

http://dx.doi.org/10.1515/9781400822461

Sedgwick, Eve Kosofsky. "Gosh, Boy George, You Must Be Awfully Secure in Your Masculinity." Constructing Masculinity. Ed. Maurice Berger. New York: Routledge, 1995. 11-19.

Songfacts. "Once In A Lifetime by Talking Heads." The Top 13. Retrieved 13 Aug. 2011. Accessed 6 Nov. 2015. http://www.songfacts.com/detail.php?id=1867

Vernallis, Carol. Experiencing Music Video: Aesthetics and Cultural Context. New York: Columbia University Press, 2004.

Vernallis, Carol. Unruly Media: YouTube, Music Video and the New Digital Cinema. New York: Oxford University Press, 2013.

http://dx.doi.org/10.1093/acprof:oso/9780199766994.001.0001 


\title{
Ghanaian Screendance Perspectives: The Nuance of 'Sankofaism' as Emerging Aesthetics and Rejection of Orthodoxy
}

Samuel Benagr, Department of Theatre Arts, University of Ghana

Terry B.K. Ofosu, Department of Dance Studies, University of Ghana

\begin{abstract}
Screendance is a hybrid art in which choreographic and film techniques are necessary for creating texts where the body dialogues with camera. Ghanaian dance film is best understood within the context of postmodern discourse. This article argues that indigenous and foreign cultural practices are convoluted by morality and hegemonic influence of western culture. Moving from orthodoxy, the Ghanaian dance film recontextualizes dance practice and film techniques into a composite construct with a tinge of Afrocentrism. Framed by critical sankofaism, screendances in Ghana are discussed as being influenced by individual musician's ideas with western biases. Dances for television are shaped by institutional guidelines gleaned from Ghanaian culture. Using Heyba and screendance at TV3 Network and GTV, this article discusses dance films as an emerging aesthetic that re-interprets the function of bodies, their relationships with the camera, and concludes that more than being a hybrid site, screendance in Ghana is a 'polybrid'.
\end{abstract}

Keywords: Screendance, 'sankofaism,' morality, Afrocentrism, aesthetics, hegemony

Africa's contribution, place, and voice in global discourse is quite often obscured and masked. To counteract this tendency, Afrocentrism, as a cultural ideology and worldview, seeks to celebrate the history and achievement of black people. It offers the space for Africans and people of African descent to respond and rewrite their story from the perspective of Africans with the objective of putting right the inaccurate accounts (often imbued with racist connotations) about Africans by non-Africans. Afrocentrism provides an ideological and cultural focus, and agency for selfdetermination. This essay explores Afrocentrism through the notion of 'sankofaism,' which represents a return to beneficial African knowledge systems and cultural practices, including understandings of morality, interwoven with Western cultural influences. In particular, we examine music videos and dance on television as critical 
sites for Ghanaian screendance and the development of 'critical sankofaism,' as an aesthetic.

Dancers, musicians, actors, and artists play important roles in national economic development. For example, a Centre for Economics and Business Research (Cebr) report for Arts Council England, published in July 2015 showed that the arts and culture industry in the U.K. contributed $£ 7.7$ billion as gross value added (GVA) to the British economy. ${ }^{1}$ In Africa, dance performances are often undertaken with a communal spirit, ${ }^{2}$ invariably evincing the voice of the people or that of institutions such as royal, religious, warrior, political and governmental groups. The values, norms and sanctions in African dances are socially constructed and are, for the most part, adhered to by its members. Africa has a youthful population and is usually described as the world's youngest continent. Statistics from the International Year of Youth August 2010-2011 report indicate that in 2010, young people (35 years and below) constituted $70 \%$ of the continent's population. ${ }^{3}$ These youth, including artists, contribute to the economic growth of the continent. Over the years, mostly young and ambitious artists have sought success and fame, and their ambition helps to develop local cultural landscapes that, according to Halifu Osumare, "resist expectations, offer counter-narratives, and amass sociocultural and economic power against social norms of the older generation." 4

In Ghana, screendance is one such form that ambitious musicians and performing artists use to explore their imaginations and creativity. In this paper we use the term screendance to describe the platforms offered to Ghanaian dancers to interact with the camera, often by musicians and television stations, in music videos, and music/dance productions respectively. Music video in this sense refers to a videotaped performance of an electronically recorded popular song usually accompanied by dancing and visual images to interpret the lyrics. Music/dance productions, on the other hand, refer to a live music performance with dancers or a strict dance performance or contest recorded for television. Ghanaian music videos are mostly influenced by the individual musician's ideas, and generally reflect a strong Western influence. Dances for television, on the other hand, are often shaped by institutional guidelines, usually buried in moral or puritanical principles gleaned from the general Ghanaian culture. What defines both artistic approaches are the interwoven Ghanaian identity, normally captured either in the quotidian social movements, or the Afrocentric costumes and scenery. Using the dance film Heyba and screendance on TV3 Network and GTV (Ghana Television), this article discusses the growing phenomenon of dance films in Ghana.

The Ghanaian dance and film landscape underwent slow development until the rise of globalization. In the 1960 s to 1980 s, the Ghanaian film industry was almost entirely state-owned and therefore standards were measured through the moral gaze of Ghanaian society. As shall be discussed in subsequent argument this measurement of 
standards via the moral gaze of the Ghanaian society still pertains. Kwame Gyekye describes the moral gaze as patterns of conduct that are considered most worthwhile and thus cherished by a society, which include principles of behavior and goals of social and individual action. ${ }^{5}$ Broadcasted moving images adhered to strict artistic moral conduct; invariably giving TV stations authority over artworks. Artists whose works were not screened on state-owned televisions were disenfranchised and denied equity. Speaking of the function of media among Western audiences, Rosalind Krauss decries such authority as "disastrous" because the media platforms are "...virtually the only means of verifying its existence as art." ${ }^{\prime 6}$ Despite such criticism of the media, it continues to remain resilient and is arguably one of the most significant sites where humans and the arts interact. ${ }^{7}$

Capitalism was the driving economic ideology during the Ghanaian president John Agyekum Kufuor's government, from 2000-2008, Characterized by privatization, the youth took advantage and perpetuated the capitalist agenda through popular culture, thereby "positioning hiplife ${ }^{8}$ music and style as a primary tool for competing corporate interests." 9 The ability of the newly created artistic product to achieve economic success is dependent on how the artwork appeals to its audiences, the message that it carries and how that is communicated to audiences. As explained by ethnographer Jesse Weaver Shipley, "the affinity between salesmanship and effective lyrical performance marks how hiplife aligns with entrepreneurship." ${ }^{10}$ In parts of the world where poverty is rife, the extent to which an artistic product can be sold underscores its value in society, meaning the economic value of the work can help to combat artistic poverty. This is where private individuals in the arts are vociferous, by making available their appealing and most engaging products.. Paul du Gay et al. in their discussion of advertising make similar observations. They state that as an economic and representational practice, the aim of advertising,

is to make people buy the product, to increase sales and maximize profits. But it is also a cultural practice because, in order to sell, it must first appeal; and in order to appeal, it must engage with the meanings which the product has accumulated and it must try to construct an identification between us - the consumers - and those meanings. ${ }^{11}$

New screendances become both an economic, and culturally representational practice. By this assertion, screendance can be conceived as some form of advertising material for the musician and by extension the television networks.

\section{The Arts in Ghana and the Theories of Local and Global}

Today, globalization has exposed Ghanaians to various media technologies, equipment, and screen-based images. This exposure tempers the orthodox Ghanaian aesthetic consumption, paving the way for the creation of new aesthetics that is best 
explained by what Terry Sprague describes as the "mediazation and aesthetic of consumerism" that characterize contemporary screendance. ${ }^{12}$ The media arouses desires and needs of consumers that they never imagined they had, including for locally produced arts and cultural practices. The central tenet of Ghanaian society with moral conduct as its base - is at a crossroads. There are the (mostly older) lawmakers and money-spinners who uphold the strict moral values as dictates of social behavior, and the youth who embrace the sub-cultural influences of the global village (and who make up the middle and lower class and therefore on the receiving end of the policies). The situation invariably creates two opposing ideologies as theorized by John Collins. He claims that hegemony of the Ghanaian tradition and that of the ruling group is a "repressive" or "centripetal" approach, and the tendency of free expression and creation by the youth as "emancipatory" and/or "centrifugal."13

In Ghana, the arts, and more specifically film and dance, promote indigenous philosophical and ideological perspectives that are given national credence in so far as the various ethnicities contribute to an image of Ghana as a nation. Kwame Gyekye refers to such indigenous philosophies as national orientation or public philosophy, which represent the body of knowledge of a people. ${ }^{14}$ The identity of Ghanaians will therefore be informed by the different cultural practices of the various ethnic groups contributing to the development of national cultural values. Gyekye describes these cultural values as "forms of behavior, practice or thought that are nurtured by a culture and held, cherished and maintained by the users of the culture as most worthwhile and desirable, as having sufficient importance and relevance for their lives." ${ }^{15}$

Ghana has shaped its national identity in part through the representations of some dances, dramas, songs, symbols, maxims, beliefs, and values. ${ }^{16}$ Katharina Schramm explains how after Ghana's independence in 1957, Kwame Nkrumah and his ruling government worked tirelessly to implement new national and cultural policies, to decolonize and reorient independent Ghanaians to embrace a general national identity instead of particular ethnic identities. Schramm further highlights the formation of the Ashanti Cultural Centre and the Institute of African Studies, which played significant roles in Nkrumah's agenda, eventually culminating in the formation of the Ghana Dance Ensemble-a national dance group with members from the different ethnic groups, created to learn and perform the various Ghanaian ethnic dances. ${ }^{17}$ These dances were represented as equally valuable, all adding to the richness and diversity of the new Ghanaian culture and contributing to the creation of a national identity.

The inclusion of maxims, beliefs, and value systems as markers of identity by Nkrumah's government was strategic in facilitating Ghana's decolonization. The Ghanaian local landscape is therefore deeply enmeshed in Ghana's social values, epitomized by its moral values. As part of the Ghanaian ethos, teenagers in the past were required to be sexually ignorant until their initiation rites were performed. ${ }^{18}$ It 
was common knowledge in Ghana that semi-nude pictures and sexually explicit songs and movement were culturally deviant and unacceptable ${ }^{19}$. According to Brigid M. Sackey, however, African "encounters with other cultures, particularly Western, have influenced people to do away with the respect for moral order." 20 This therefore prepares the ground for a cultural collision between the Ghanaian youth and adults.

The result of this collision is what Kwame Gyekye refers to as cultural globalization. Cultural globalization deals with the integration of communities of the world through local cultural activities in a new global village. ${ }^{21}$ Globalization through technological advancement has seemingly brought nations across the world closer together. Different cultures of the world are inadvertently under siege especially from Western capitalism, and it is only the cautious and purposeful countries that can retain their national identities in the convoluted global mix. For the Ghanaian lawmakers, who prefer to adhere to strict regimes of social conduct, the semi-nudity-which Osumare refers to as "deleterious American hip-hop representations" 22 -in many Western pop music videos and films, mostly watched by young people, are problematic. If the Ghanaian youth imbibe some of these 'negative' consumerist artistic approaches, they will transmit them into the new Ghanaian music videos. The comingling of the global and the local has produced various views and taxonomies. Osumare refers to this mix as "internalized structures" or "faces of indigenization" 23 and in similar analysis various scholars have referred to the phenomenon as hybridity, syncretism and appropriation. These taxonomies above are encapsulated in Rolland Robertson's nomenclature "glocalization," ${ }^{24}$ which represents the fusion of new global practices and local antecedents.

Our argument in this article relies on what Gyekye refers to as "critical sankofaism," which is the retrieval of specific old practices to blend with contemporary approaches to new oeuvres. It is distinctive from "naïve sankofaism," which Gyekye defines as "a wholesale revival of the cultural past, irrespective of the functionality or moral worth of particular elements of our (Ghanaian) cultural heritage." ${ }^{25}$ The following section analyzes the different levels of 'sankofaistic' blending that characterize individual 'images of dancing on TV' such as music videos and those produced by television institutions. In what follows, we discuss the music video Heyba (You Are Not on My Level), by the dancehall artist Edem, and Dance Fever Reality Contest by TV3, a private television station in Ghana, as well as GTV's (Ghana's national television station established by former president Kwame Nkrumah) approach to screening dance.

\section{The Heyba Video}

The music video Heyba premièred on 10 November 2012 on the Cine Afrik channel on Multi TV in Ghana. The music video is about the artist's achievement and rise to stardom, and his zeal to conquer and dominate the global music (video) 'territory'. The film has an African-centered presence, a fact reinforced by the artist himself when he 
says "the elements of the song Heyba are actually African." ${ }^{26}$ The wearing of African masks and headdresses together with elaborate cloth and fiber costume play pivotal roles in rituals, such as purification, initiation, exorcism, and others. Apart from shielding the wearer's identity, the spirit is called up to inhabit the mask and then transfer its supernatural potency to the wearer of the mask. ${ }^{27}$ Taking the foregoing view into account, the mise-en-scène in Heyba establishes the connection between the contemporary and traditional, where the two situations co-exist to produce that all-conquering and domineering force characteristic of the might of a tsunami.

In the opening sequence of Heyba, notions of territory, conquest, and dominance are evoked before we see the musician, Edem. The subsequent shot of a female dancer in raffia skirt sets the tone and context for this music video. New technology is democratic in nature. It engenders creative abilities and aids the conceptualization and production values of dance films. Ghanaian youths (typically 18-25) therefore have a platform with which they can express as well as assert themselves. This is demonstrated by this film, for example, in images such as female traditional priests in raffia skirts, muscular men with make-up that is stereotypical of African warriors, and others like the mask, which represents the embodiment of the ancestral spirits and gods of the African continent. We propose that the encounter in the initial sequences portrays Edem's aspirations toward cultural dominance through his strategic combination of creative and artistic abilities with Afrocentric symbolism.

Through shot composition as well as the narrative and lyrical structure, Edem takes center frame. The way the shots are filmed, the story of the music video, and the arrangement of imagery through editing all point toward a contest of some sort. For example, there is an image of Edem on the clouds ${ }^{28}$ which echoes the view expressed in part of the title of the music video; You Are Not On My Level. What competition is being alluded to here? Who is Edem's competition with? And what is the focus and purpose of the competition? Is it for recognition, dominance, or both? An image of a surge of force, power, and strength is seen here that alludes to a "tsunami," 29 the force of which is comparable to the power that resides in this youthful group to impact Ghanaian culture.

The primary visual references in the film include African artistic, literary, and performative elements. Analyzed through a lens of sankofaism, the mask, facial decoration, and bodily ornaments suggest that the emerging Africa is making good use of its cultural heritage to achieve territorial conquest and dominance as suggested at the start of Heyba. Edem's competition for space within the global music market is representative of Africa's quest for recognition and eventual conquest of the same market. In order to "reach for the heavens," as the lyrics suggest, Ghana requires a talented, creative, ingenuous, and capable population. Therefore when we look at the film, we recognize the symbolism of the sequence and movement involving strong and well-built young men and women. Their physical attributes reflect the strength 
that is found in the nation, which must be harnessed in order for it to further develop. Similarly, the priestess dressed in a raffia skirt ${ }^{30}$ with angelic wings is an example of how women in the predominantly patriarchal and Christian Ghanaian society might assert themselves. As a priestess, she is listened to and accorded the respect that her male counterparts take as a given. Edem uses such images symbolically to demonstrate the complementary contributions of females in contemporary Ghana.

The framing of the musician is significant. He is placed mostly at the center of the screen. In the same way, most of the medium and close-up shots in the music video are centered, and, the centered subjects are Afrocentric in essence. This echoes the centrality of African-centered and African-inspired approaches to Africa's quest for dominance in the wider world. The quest and clamor to be "reaching for the heavens" 31 must be perpetuated by Afrocentric ideals and values. But in pursuing the agenda of reaching the desired heights of success, as implied in the music video, creative and enterprising youth, as exemplified by Edem, occupy a middle ground by borrowing and mixing cultures in a typical postmodern approach. Therefore Ghanaian orthodoxy ceases to be the sole bearer of meaning.

In the entire music video, we find only four direct references to Western culture: the microphone at the end of the film, the Absolut Vodka bottle, the speaker, and the Italian wine. The Heyba music video also has indirect references to hip-hop, which in itself has Afrocentric roots. With these references come the workings of hybridity and globalization - selecting what is useful from other (Western) cultures to enhance and advance one's course and mission. Such references make it possible to apply the concept of 'critical sankofaism' in the global world. Indigenous African theories and paradigms, such as the use of masks and body ornaments to evoke strength and power, interface with Western ones, highlighting their hybridity. The minimal use of these foreign codes, sharply contrasted with the dominance of African imagery in the music video, does not undermine the value of this hybridity. Edem's lyric about getting better with time correlates with the Italian wine reference, but also corresponds to an African worldview. Experience and old age is indispensable - note the relevance of the sage old lady in the film. In as much as the youth, exemplified in the music video, have new approaches to improving their conditions and by extension the nation, there is still the need to recognize that in the African cultural setting, wisdom, good counsel, and the experiences of the elderly are indispensable.

The predominance of African percussion instruments in the film strongly aligns with the national policy of Ghana's sitting government for citizens to use products made in Ghana, to improve the nation's efforts towards sustainable economic development. This approach is not a novel concept. It echoes similar calls made in the 1960s by Ghana's first president, Kwame Nkrumah when he said, 
let us begin to look inwards into the African continent for all aspects of its development. Our communications were devised under colonial rule to stretch outwards towards Europe and elsewhere, instead of developing internally between our cities and states. ${ }^{32}$

By extension therefore, the prevalence of African instruments in the video represents the adoption of made-in-Africa solutions for African problems. The importance of socalled homegrown solutions and self-reliance were reinforced during the global financial crisis in 2008. Because Africa was not fully integrated into the global financial system, it was less affected by the economic downturn. ${ }^{33}$ Consequently, the region became one of the fastest growing areas of the world.

The music video seems to suggest that there is energy, power, and vitality in the African mode of life. Furthermore, its dominant Afrocentric imagery coupled with the lyrics can be viewed as a desire for growth. The clip in which the women turn their back to camera ${ }^{34}$ is especially noteworthy. It uses a montage editing technique, and is followed by the image of the speaker to make a strong ideological statement. In keeping with Gyekye's notion of 'sankofaism,' we suggest that the ladies are embarking on a journey to recover their heritage in order to engineer economic growth. They literally turn their backs on practices that are not local and go back to their roots to retrieve the valuable practices that will open the door to higher aspirations. The combination of youthful energy, wisdom of the old, and traditional cultural values enables the African to be victorious on the world stage.

\section{Screendance at TV3 Network and GTV}

In this section we turn our attention to the second platform for screendance in Ghana: the television institution's TV3 Network, which is a private organization, and GTV (Ghana Television), which is a state owned public service. Our interest is in their diverse programming in current trends, traditions, and dance contests. As a public service broadcaster, GTV has a mandate to create programs with cultural, intellectual, or educational merit..$^{35}$ Though both are institutions, TV3 Network is more flexible and able to accommodate morally questionable artworks, ${ }^{36}$ as measured by the Ghanaian adult/government moral perspectives, while GTV is more rigid and therefore censors artistic materials that do not conform to the Ghanaian moral gaze.

In a lecture during the Ghana Broadcasting Corporation's golden jubilee celebrations, communications scholar P. A. V. Ansah asserted that while cultural pluralism is desirable, "it is essential that people should be initially and basically nurtured on their own cultural values so that inevitable external borrowings do not have undue alienating effect." ${ }^{137}$ Recommendations like Ansah's invariably represent the Ghanaian adult/government viewpoints that characterize GTV's censorship approach. This approach by GTV can be appreciated in the context of it being a trustee for national 
interest and therefore broadcasts state-driven representations of culture. ${ }^{38}$ Perhaps inevitably, GTV's audience ratings have decreased over time, and it continues to be bereft of innovative programs that are needed to revitalize the station. In a recent article in the Daily Graphic, Charles Wereko-Brobbey stated: "Sadly, the GBC [GTV] has abandoned its role as a public broadcaster in its attempt to retain its relevance and retain the audiences who are deserting it in droves to the independent alternatives." ${ }^{39}$ GTV's cameramen and editors are set to a very strict code of ethics, conduct, and regime, which does not allow for the wider aesthetic possibilities available in the private sector. ${ }^{40}$ Ansah alludes to this strict control in his lecture: "the effect of this tight control is that objectivity is sacrificed by broadcasters for their survival, and their professionalism is stifled." ${ }^{41}$

In contrast to GTV, we argue that the TV3 Network practices 'critical sankofaism'. TV3 is one of the most patronized television stations in Ghana, which according to Anangfio Jnr. is due to their innovation:

in their quest to give factual meaning to their slogan 'Best In Entertainment', TV3 Network has always come up with entertainment programmes such as Music Music, Hitz Video, Spot Light, Bands Alive, Dance Fever, TV3 Carnival, The Battle and the just ended Ghana's Most Beautiful on its network. They have secured success with those programmes. ${ }^{42}$

Though they allow for creativity with the dancers, musicians, and curators, TV3 still exercises some form of control over their product, ensuring some level of moral scrutiny. ${ }^{43}$ Just like any Ghanaian institution, TV3 is influenced by the moral gaze of society, but being private also allows for some flexibility in its operations. To a large extent, the form and content are all examined to ascertain their moral soundness before they are aired. TV3 Network has a strict rehearsal regime that allows for guidance, orientation, and some level of scrutiny of most artistic presentations before they are staged. ${ }^{44}$ It is at this platform that artists' acts are fine-tuned. However, as a private organization, TV3 Network's scrutiny of dance programs is more relaxed than GTV's:

If you think TV3 has run out of juice after putting together 'Mentor', 'Looking for love' and 'Ghana's Most Beautiful', think again! They are just about to roll out yet another offering for dancers. ${ }^{45}$

Though the above statement may sound like a marketing hype, TV3's success is acknowledged nationwide; in fact the famous Ghanaian footballer Godfred Yeboah was nicknamed TV3 as a result of his on-field brilliance.

Dance Fever is one of the most innovative dance programs of TV3. Ghanaians watched movement from various dance genres, coupled with surprising camera angles and 
shots (through the use of cranes and jibs) that reflected Western approaches. TV3's success seems to be based on innovations exhibited in the coverage and introduction of new programs, which culminates in its popularity nationwide. In fact, months after the completion of Dance Fever, fans still demanded its revival as indicated by Anangfio Jnr.:

If TV3 can revisit their slogan 'Best in Entertainment' then Boogie Down should be taken off air or something really needs to be done about it, I know the concept is just brilliant but the execution is just wrong, it needs more planning. Paa Kwesi Ackom, we are still waiting for Dance Fever. ${ }^{46}$

The above statement is Anangfio's message of displeasure to the producer of Boogie Down Paa Kwasi Ackom, who happens to be the producer of Dance Fever. Ackom, a middle-aged man and a former producer at TV3 Network started most of the new TV shows. By virtue of his age and knowledge in film he was able to blend the old and new schools of thought. He was technically the innovator of TV3 Network and therefore a household name amongst the television fraternity as evidenced in Anangfio's account:

seeing the director of "Music Music" Paa Kwesi Ackom, I was more fired up and listened attentively. I was thrilled seeing him, because the success story of TV3 "Best In Entertainment" slogan will not be written without him. ... this guy is a tough guy for the records. He has the penchant for good productions, when you talk of Music Music, one thing that comes to mind immediately is Paa Kwesi Ackom, and he has brought diversity to the show. ${ }^{47}$

During his tenure as producer, Ackom epitomized the very concept of 'critical sankofaism'. He ensured that any young artist who had to dialogue with his cameras and audiences exhibited a blend of Ghanaian identity and new trends. His approach was recognized and he was nominated for Best Television Producer in the maiden Radio and Television Personality awards in $2011^{48}$ in Ghana.

In a personal interview during Dance Fever, the producer intimated that his influence comes to bear on the production during rehearsals for the show:

We make sure to give the contestants good orientation. Firstly, on their identity as Ghanaians and therefore Africans and insist that it must show in their choreographies. And secondly, that they belong to a global world so they must be current and very innovative. ${ }^{49}$

Ackom's words and approach ring true for the Dance Fever production because it was a 'polybrid' production that had African, Western, and even Latin artistic approaches. In the maiden production the choice of dances reflected the producer's intention to have a global mix. According to TV3's Public Relations Manager Janet Carboo 
Danquah, "Certain dances like ballroom, salsa, the twist and even highlife - the young ones don't know how to really dance. So we are going to teach them how to do it." These many dance genres depicted in the Dance Fever contest show how the global is conflated with the local and how old and new interact: youth learn the local Ghanaian highlife alongside the global ballroom, salsa, and twist dances, and the young dancers also learn old dances.

It is the negotiation of the virtuosic dancing body between intrinsic Ghanaian/Afrocentric colorings, fused with global artistic ideas, which are manipulated by screen technology that makes dancing for the screen in TV3 Network unique. The station has some equipment such as jibs, cranes, lights, and a scenic shop, which offers opportunities for creativity and follows the conventions of television. One of the strengths of TV3 Network is the composition of its mise-en-scène in dance productions. The producers are able to creatively organize elements such as setting, lights, costumes, and figure expression and movements. ${ }^{51}$ The lighting team uses lights to compose shots that delineate African from Western dance movements. They accentuate the texture of the rounded, curvy, and earthy Afrocentrism of contemporary Ghanaian dances, contrasting then with the sharp angular Western postmodern popular dances. It is during programs such as Dance Fever that Ghanaians are able to fathom their unique contributions to global culture.

\section{Conclusion}

As a developing nation, Ghana lacks the sophistication and luxury of Western technology to create screendances purposefully for appreciation. In this article we have argued that screendance in Ghana is constituted by dances in music videos and those performed in television institutions. We have also argued that globalization has introduced technological advancement and other foreign cultures, more specifically Western culture that sometimes subverts some Ghanaian indigenous moral codes. We have argued how the application of 'critical sankofaism' in various measures by institutions such as TV3, GTV, and individual musicians such as Edem, bring the Ghanaian moral order and identity in the complex global mix.

The paper also postulates that the interface of Western and Ghanaian culture has resulted in the abandoning of the old orthodox approach. The creation of new aesthetics re-contextualizes Ghanaian screendance as part of the Afrocentric approaches into what can largely be referred to as cultural globalization. The Africanthrough 'critical sankofaism' - is able to connect local culture to the 'polybrid' global culture. It is at this stage that the notion of Afrocentrism comingles with the global cultures. 


\section{Biographies}

Dr Samuel Benagr is a lecturer at the School of Performing Arts, University of Ghana, Legon-Accra. Benagr teaches courses in Media Arts and Theatre Arts at undergraduate and graduate levels. Benagr's research interests are in the area of cinema and new technologies and identity construction, with emphasis on West African video filmmaking. He is a contributing author of Directory of World Cinema - Africa. Some ongoing research works include re-reading early Ghanaian video film practice in the context of neorealism, Ghanaian 2012 elections; the aftermath and lessons going forward, the performing arts and peace building in Ghana.

Email: sbenagr@ug.edu.gh

Terry Bright Kweku Ofosu is an assistant lecturer at the Department of Dance Studies, School of Performing Arts, University of Ghana, Legon-Accra, where he has been teaching since 2011. Ofosu is currently a PhD student at the Institute of African Studies at the same university, with special interest in popular dance narratives within the Ghanaian socio-political landscape. As a choreographer and videographer (director and editor), Ofosu's passion is in researching within/across both terrains. Ofosu presently awaits a research publication on globalization and hip-hop dance cypher, with Oxford University Press.

Email: terryofosu@yahoo.com

\section{Notes}

${ }^{1}$ Cebr report, Contribution of the Arts and Culture.

${ }^{2}$ Gloria Fiero, The Humanistic Tradition, 100.

${ }^{3}$ International Year of Youth.

${ }^{4}$ Halifu Osumare, The Hiplife in Ghana, 83.

${ }^{5}$ Kwame Gyekye, African Cultural Values, 55.

${ }^{6}$ Rosalind Krauss, "Video: The Aesthetics of Narcissism," 59.

7 P. A. V. Ansah, Ghana Broadcasting Corporation, 28.

${ }^{8}$ Hiplife is a hybrid music genre of hip-hop and Ghanaian highlife.

${ }^{9}$ Osumare, 120.

${ }^{10}$ Jesse Weaver Shipley, "Aesthetic of the Entrepreneur," 642.

${ }^{11}$ Du Gay et al, Doing Cultural Studies, 25.

${ }^{12}$ Terry Sprague, "Screendance: Aesthetics of Media and Consumer Visual Culture," 61.

13 John Collins, "One Hundred Years of Censorship in Ghanaian Popular Music," 171. 
${ }^{14}$ Gyekye, Philosophy, Culture and Vision, 159.

${ }^{15}$ Ibid.

${ }^{16}$ Francis Nii-Yartey, "Performing Arts: Identity and the New Social Paradigm," 284-289.

${ }^{17}$ Katharina Schramm, "The Politics of Dance," 343

${ }^{18}$ Peter Sarpong, Ghana in Retrospect, 69.

${ }^{19}$ Paschal Yao Young, Music and Dance Traditions of Ghana, 162.

${ }^{20}$ Brigid M. Sackey. "African Worldviews," 160.

${ }^{21}$ Kwame Gyekye, Origins of Globalization, 126.

${ }^{22}$ Osumare, 15.

${ }^{23} \mathrm{Ibid}$.

${ }^{24}$ Ronald Robertson, "Glocalisation," 26.

${ }^{25}$ Kwame Gyekye, Philosophy, Culture and Vision, 159.

${ }^{26}$ Ernest Dela Aglanu, "No Video Released This Year Can Match My Heyba - Edem."

${ }^{27}$ See Fiero.

28 "Heyba" music video, 00:02:15

${ }^{29}$ Idem., lyric 00:00:26 to 00:00:27

${ }^{30}$ Idem., from 00:00:26 to 00:01:10

${ }^{31}$ Idem., lyric 00:01:21 to 00:01:22

${ }^{32}$ Kwame Nkrumah, Africa Must Unite, 219.

${ }^{33}$ John, Katunga (Regional Technical Advisor, CRS East Africa Regional Office) made this declaration during at a training workshop organized by the CRS Institute for Peace in Africa at GIMPA in Accra, Ghana. The theme of the workshop was "Equipping The Youth To Be The Leaders And Champions For Peace, Reconciliation And Good Governance In Africa." From 23 - 28 June, 2014.

34 "Heyba" music video, from 00:02:31 to 00:02:32

${ }^{35}$ Ansah, Ghana Broadcasting Corporation, 8.

${ }^{36}$ Birgit Meyer, Sensational Movies, 7.

${ }^{37}$ Idem., 31

${ }^{38}$ Ibid.

${ }^{39}$ Charles Wereko-Brobbey, "Suspend TV License Fee; It is a Bad Law," 44.

${ }^{40}$ Meyer, 6.

${ }^{41}$ Ansah, 26.

${ }^{42}$ Ebenezer Anagfio Jnr., "TV3, What is Boogie Down all about." 19 August 2009. http://www.ghanacelebrities.com.

${ }^{43}$ Paa Kwesi Ackom qtd. in Terry B. Ofosu, "Interview at TV3."

${ }^{44} \mathrm{Ibid}$.

${ }^{45}$ Jive, "Dance fever."

${ }^{46}$ Ibid.

${ }^{47}$ Ibid.

${ }^{48}$ Ernest Dela Aglanu, "Multi media others to receive honorary awards."

${ }^{49}$ Paa Kwesi Ackom qtd. in Ofosu

50 Jive.

${ }^{51}$ Michael Rabiger. Directing the Documentary, 589. 


\section{References}

Aglanu, Ernest Dela. "Multi media others to receive honorary awards." Posted 15 August 2011. http://entertainment.myjoyonline.com/pages/news/201103/62753.php. “No Video Released This Year Can Match My Heyba - Edem." Posted 9 November 2012. http://entertainment.myjoyonline.com/pages/news/201211/96999.php.

Anagfio Jnr., Ebenezer. "TV3, What is Boogie Down all about.” Posted 19 August 2009. http://www.ghanacelebrities.com.

Ansah, P.A.V. Ghana Broadcasting Corporation: Golden Jubilee Lectures, Accra: Ghana Broadcasting Corporation, 1989.

Cebr Report for Arts Council England. "Contribution of the arts and culture industry to the national economy." London: Cebr, 2015.

Collins, John. "One Hundred Years of Censorship in Ghanaian Popular Music." Popular Music Censorship in Africa. Eds. Michael Drewett and Martin Cloonan. Hampshire: Ashgate Publishing Limited, 2006.

Du Gay, Paul, Stuart Hall, Linda Janes, Hugh Mackay, Keith Negus. Doing Cultural Studies: the Story of the Sony Walkman. London: Thousand Oaks, Sage Publications, 1997.

Fiero, K. Gloria. The Humanistic Tradition: the European Renaissance, the Reformation, and Global Encounter. New York: McGraw Hill Publishers, 2002.

Gyekye, Kwame. African Cultural Values: An Introduction. Accra: Sub-Saharan Publishers, 2013.

. "Understanding Globalization." Globalization. Accra: Ghana Academy of Arts and Sciences (GAAS), 2006. 111-131.

. Philosophy Culture and Vision: African Perspectives. Accra: Sub-Saharan Publishers, 2013.

"Heyba." Dir. GYO Gyimah. Edem. 2012. YouTube.

https://www.youtube.com/watch?v=rrLsW4yzwQI.

International Year of Youth: Dialogue and Mutual Understanding. "Regional Overview: Youth in Africa." 2010. http://social.un.org/youthyear/launch.html. 
Jive. "Dance fever: Another TV reality show." Posted 25 April 2007. http://www.modernghana.com/music/4374/3/dance-fever-another-tv-realityshow.html.

Krauss, Rosalind. "Video: The Aesthetics of Narcissism." October 1 (1976): 50-64.

Meyer, Birgit. Sensational Movies: Video, Vision, and Christianity in Ghana. California: University of California Press, 2015.

Nii-Yartey, Francis. "Performing Arts: Identity and the New Social Paradigm" Identity Meets Nationality: Voices of the Humanities, Eds. Helen Lauer, Nana A.A.Amfo and Jemima A. Anderson. Accra: Sub Saharan Publishers, 2011. 282-297.

Nkrumah, Kwame. Africa Must Unite. London: Panaf, 1963.

Ofosu, Terry B.K. Interview at TV3 with Paa Kwesi Ackom, 20 January 2009.

Osumare, Halifu. The Hiplife in Ghana: West African Indigenization of Hip-Hop. New York: Palgrave Macmillan, 2012. http://dx.doi.org/10.1057/9781137021656

Rabiger, Michael. Directing the Documentary. Oxford: Elsevier/ Focal Press, 2004.

Robertson, Ronald. "Glocalization: Time-Space and Homogeneity-Heterogeneity," Global Modernities. Eds. Mike Featherstone, Scot Lash, and Ronald Robertson. London: Sage Publications, 1995. http://dx.doi.org/10.4135/9781446250563.n2

Sackey M.Brigid. "African Worldviews" Africa in Contemporary Perspective: A Textbook for Undergraduate Students. Eds. Takyiwaa Manuh and Esi Sutherland-Addy. Accra: SubSaharan Publishers, 2013. 151-164.

Sarpong, Peter. Ghana in Retrospect: Some Aspects of Ghanaian culture. Accra: Ghana Publishing Corporation, 1974.

Schramm, Katharina. "The Politics of Dance: Changing Representation of the Nation in Ghana." Spectrum Africa. 35.3 (2000): 339-358.

Shipley, Jesse W. "Aesthetic of the Entrepreneur: Afro-Cosmopolitan Rap and Moral Circulation in Accra, Ghana' Anthropological Quarterly. 82(3) (2009): 631-668. http://dx.doi.org/10.1353/anq.0.0074

Sprague, Terry. "Screendance: Aesthetics of Media and Consumer Visual Culture". The International Journal of Screendance. 2 (2012): 61-63

Taylor, Lisa. and Andrews Willis. Media Studies: Texts Institutions and Audiences. Oxford: Blackwell Publishers Limited, 1999. 
Wereko-Brobbey. "Suspend TV licence fee; it is a bad law." Daily Graphic: No. 19824. Tuesday, July 21, 2015.

Young, Y. Paschal. Music and Dance Traditions of Ghana: History Performance and Teaching. North Carolina: McFarland \& Company Inc. Publishers, 2011. 


\title{
New Materials: Natural Elements and the Body in Screendance
}

Sylvie Vitaglione, New York University

\begin{abstract}
This article explores the practice of shooting on location in screendance advocating for a practice that explores the concept of material specificity in order to create grounded conceptual works. In order to metaphorically and literally ground the dancing body, this article examines the crucial dichotomy between intervention in sites and integration of sites in order to understand exactly what stance screendance takes on its settings. In other words, what do artists take from the site and what do they bring to it? I begin by examining various definitions of site-specificity. By surveying theories and practices surrounding the artistic treatments of locations, my aim is to highlight the choreographic and cinematic techniques that connect the dancing body to the environment. I argue that through the use of natural elements these films articulate a version of site-specificity deeply connected to the materiality of each location rather than to its geography or history.
\end{abstract}

Keywords: site-specificity, land art, material specificity, location shooting, screendance

Screendance is concerned with the body. As the exploration of the friction between the corporeal and the technological, between the live and the recorded, between the still and the mobile continues, in recent years the practice has shifted to new grounds: screendance has become concerned with space. ${ }^{1}$ The camera and its accompanying gear have pushed dancing bodies outside to explore sites and surfaces beyond the studio and the stage. Our sprung wood floors and smooth Marley now quasi-obsolete onscreen, the screendance body takes root outdoors. ${ }^{2}$ Shooting on-location has not only become a possibility, it has become the default option. The vast majority of films in circulation at festivals take place outside and most film synopses begin with a description of a physical location. While landscapes seem to offer a practical solution to finding large spaces to fit tight budgets, the recurrence of particular types of natural spaces without a conceptual backbone becomes cliché. After all, what does that beautiful sunset on the beach have to do with grand-jetés? 
In her article analyzing the films of Thierry de Mey, Sophie Walon claims that "the cinematic possibility of relocating theatrical works to original sites appears to be one of the most efficient ways of enabling screendance artists to make a creative dance film that is emancipated from being a mere dance recording." ${ }^{3}$ While it is true that the use of sites has generated a number of creative and memorable films, the simple relocation of a dance does not in itself suffice to create an original work with integrity. Screendance utilizes sites in different ways and not every film shot on location can be called site-specific. Numerous films treat landscapes as visual backdrops, much like in a fashion photo-shoot, because it "looks cool." The outdoor location provides ample space for movement and adds depth to the typically frontal staging but overall its use remains within a theatrical tradition. The camera stays put while the dancers face it, much like they would an audience. For example, in Luc Riolon's Aunis (1994), Jacques Garnier's choreography is set on a beach in Normandy where three men dance on a thin white stage set in the sand. While their costumes move in the wind and the waves in the background add movement to the film, the piece could very well be set anywhere with a flat surface and sunlight. Landscape here provides a background for the body while the camera alternates between three safe medium shots. Choreography in such cases does not aim to relate to the site but rather lands on it, in a sort of "Plop Art" as Noémie Lafrance would say. ${ }^{4}$

In order to metaphorically and literally ground the dancing body, this article explores the crucial dichotomy between intervention in sites and integration of sites in order to understand exactly what stance screendance takes on its settings. In other words, what do artists take from the site and what do they bring to it? I begin by examining various definitions of site-specificity. By providing a survey of the theories and practices surrounding the artistic treatments of locations, my aim is to highlight the choreographic and cinematic techniques that connect the dancing body to the environment. I argue that through the use of natural elements these films articulate a version of site-specificity deeply connected to the materiality of each location rather than to its geography or history.

Screendance makers are familiar with the term site-specific yet the numerous variations on it suggest that the scope of possibilities when shooting on-location is broader than we might expect. In her seminal book Dance on Screen, Sherril Dodds observes that these choices of location typically demonstrate a sparse background with minimal set design so as to keep the attention on the dancing body. She notices that the "video dance body is often situated in unexpected locations, but also, in several cases, it is presented within circumstances that are illogical and peculiar." ${ }^{5}$ For Dodds, the lure of the landscape is primarily a way to focus on the body by reducing the clutter in the frame and seeking open spaces to move in. While visually the result can be striking, conceptually the lack of narrative connections between the dance and the site can make films weak due to incongruous choreography. 
The rapport between site, body, and camera lens is often referred to as a dialogue, one where the artist should be prepared to listen, respond, and improvise. For Heike Salzer "shooting dance on sites has an exciting side effect, it is uncontrollable; the weather changes, animals or objects [...] appear. These unexpected moments offer the chance for a dialogue between the environment, the dancers, and the filmmaker." ${ }^{\prime 6}$ The presence of uncontrollable factors in the environment has the benefit of literally pushing artists out of their comfort zone and potentially generating a productive collaboration. Ana Baer speaks of "situational screendances" where the narrative develops out of the situation encountered in the location. ${ }^{7}$ Both of these approaches to shooting on-site stress the need to be ready to catch something as it comes, filming almost in a documentary-style and turning movement-making into an exercise in improvisation. What Baer and Salzer fail to explain is the way through which the link between the body and its surroundings is established; beyond simply being in the right place at the right time, how does a dance filmmaker make a piece site-specific?

Kyra Norman has brought to our attention several choreographers for whom work is born out of "sincere attention to place in the moment of recording" and suggests that by being "in and out of place," these artists manage to stay physically engaged with space while making screendance. ${ }^{8}$ She distinguishes between inhabiting and occupying a place suggesting that a traditional film crew will simply take hold of the space around them and temporarily occupy it. Inhabiting a place for Norman is to "engage space directly through the body," to focus "attention to active vision and responsiveness to place." ${ }^{\prime 9}$ The distinction she makes underlines the importance of spending time on the site in order to find a way to relate to it and to respond to it. However, the concept of "engaging space through the body" remains vague and open to many interpretations. Again we must ask, how does one occupy place?

In her manual Making Video Dance, Katrina McPherson addresses the selection of locations in dance films as though shooting outdoors is a given. She warns about the incompatibility between dance and filming on location and urges filmmakers not to forget about the dance: "frequently, whilst featuring interesting locations, the work seems to lack any really significant choreographic content."10 She emphasizes the importance of creating a dance that seems appropriate for the space, so that bodies do not seem "out of place" and suggests strategies for integrating the landscape into the choreography. ${ }^{11}$ For example, she proposes that by "having the dancer move around and through, and even touch objects, you will create the feeling that their actions belong in the location." ${ }^{12}$ McPherson's suggestion to have the dancer physically come in contact with the setting is by far the most practical and approachable, emphasizing the need for the viewer to not only see a connection between the dancer and the space but to feel the environment and to relate to it through the performer's body. For McPherson rendering touch creates a dance "in place." With what "objects" might a dancer come into contact with and what might 
they signify within the film? Does touch suffice to create site-specificity for screendance?

None of the authors above explicitly utilize the label site-specific yet they are all theorizing ways of engaging with location in screendance. While the term is by no means foreign to the field, it remains somewhat difficult to apply simultaneously to the contexts of both dance and film. My purpose here is to first clarify conceptions of site-specificity as originally articulated in relation to Land Art, and second, to propose a new concept that emphasizes materiality in order to theorize screendance shot on location.

\section{Defining Site-Specificity}

The term site-specific emerged in the early 1970s in the US and was adopted in Europe in the 1980s. While numerous US-based choreographers such as Trisha Brown, Anna Halprin, and Meredith Monk had taken dance outdoors in the 1960s, the term sitespecific was hardly in circulation in the dance world. Instead it came from the world of visual arts, combining the fashion for minimalism with large-scale sculpture. 1968 marks the year of shifting attitudes toward environmental issues as presented in the Earthworks exhibition in New York. Land Art emerged as a type of sculptural practice drawing from architecture and landscape design, often utilizing photography and film to record the traces left in distant locations. As an attempt to de-materialize the art object within the institution of the gallery, these works presented a variety of ways for art to "take place" in the landscape.

In her 1979 essay "Sculpture in the Expanded Field," art critic and theorist Rosalind Krauss questions the validity of the term "sculpture" for these works. While she does not adopt the term Land Art she does coin "marked sites" to describe Robert Smithson's Spiral Jetty (1970) and Michael Heizer's Double Negative (1969) in addition to work by Richard Serra, Robert Morris, Carl Andre, Dennis Oppenheim, Nancy Holt, and George Trakis. She stipulates that "in addition to actual physical manipulations of sites, this term also refers to other forms of marking. These might operate through the application of impermanent marks-Heizer's Depressions, Oppenheim's Time Lines, or De Maria's Mile Long Drawing, for example-or through the use of photography." ${ }^{13}$ This mention of the temporality of the mark and the need to document it through a visual medium comes close to the considerations of ephemerality and permanence often encountered in screendance.

In this sense, one definition of site-specific art equals a piece which is created and installed on-site and typically necessitates the presence of the viewer in order to fully experience the materiality of the work. Art historian Miwon Kwon explains that "sitespecific work in its earliest formation, then, focused on establishing an inextricable, indivisible relationship between the work and its site, and demanded the physical 
presence of the viewer for the work's completion." ${ }^{14}$ Of course this would only be possible if the viewer had the means and foreknowledge to be in the right place at the right time. Therefore, through the use of photographs and films, as well as materials such as rocks, twigs, and dirt collected on-site, artists found ways to bring traces of the landscape back to the gallery.

If Land Art aims to de-materialize itself as an art object, to produce works in nature that are not available for purchase, what type of imprint do they aim to leave on the land? As sculpture, one would assume a certain weight and fixity in place, but as works in nature these alterations are necessarily subject to weathering and the movement already present in the site. Writing in 1989, Richard Serra explains:

Site-specific works deal with the environmental components of given places. The scale, size, and location of site-specific works are determined by the topography of the site, whether it be urban or landscape or architectural enclosure. The works become part of the site and restructure both conceptually and perceptually the organization of the site. ${ }^{15}$

Serra's definition does not mention how permanent this restructuring of the site is, and yet his most notorious claim in reference to his piece Tilted Arc (1981) in New York City is that "to remove the work is to destroy it." In a similar vein, curator Michael Lailach in his definition of site-specificity in Land Art suggests that "the artists conceive the works for particular settings and create them on site. Thereby they alter the location's surface, structure, and materiality, and inscribe themselves in its memory." ${ }^{16}$ Once more, while Lailach points to the modification of the surface of the site and the inscription of the piece into the site's history, he does not consider how this physical impact shifts over time, how nature might re-write this dent made on its surface.

According to Ben Tufnell, Land Art "encompasses the scarring of the landscape, the ecological reclamation of industrially devastated terrain, an impulse towards change and permanence and an attitude of respect, a desire to "leave no trace."'17 This spectrum presents a more diverse picture as it highlights the many possible stances towards landscape within the umbrella term "Land Art." It also suggests a shift in the term's scope, the label "specific" now expanding to mean much more (or less as is sometimes the case). Kwon suggests that the original rootedness of site-specific art in the 1960s and 1970s has now given way to more mobile and unhinged work. In other words, whereas site-specific art used to mean that the tangible physical work could not exist in any other place and would risk being destroyed if moved (as in the sculptures of Richard Serra and Robert Smithson's Spiral Jetty), its definition has since shifted towards "site as predominantly an intertextually coordinated, multiply located, discursive field of operation." ${ }^{18}$ What Kwon calls an intertextual relationship is in fact a complex, at times less visible, link to landscape. She informs us that in "art practices of the past thirty years the operative definition of the site has been transformed from a 
physical location-grounded, fixed, actual-to a discursive vector-ungrounded, fluid, virtual." ${ }^{19}$ Rather than a concrete physical relationship between land and art, the new model is "not a map but an itinerary, a fragmentary sequence of events and actions through spaces, that is, a nomadic narrative whose path is articulated by the passage of the artist." ${ }^{20}$ Whereas once viewers "had to be there" to experience the work and the work itself actually physically "had to be there" to exist, site now filters through in many ways in this more complicated, more "fluid" form of marking the landscape.

This looser application of the term site-specific explains its current presence across multiple artistic disciplines as a label much like "environmentally friendly": often encountered but worthy of skepticism. Within the dance world, the term picked up popularity in the 1980s to refer simply to work not on a proscenium stage, and now constitutes an asset in funding applications. I argue that there is a difference between choreography developed on-site, which could not exist anywhere else, and dance simply located on a site for the sake of a change of scenery. Screendance artists avoid the physical constraints of live performance by producing films, however as they relocate to the outdoors, often to remote locales, they create a temporary imprint on the land with their crew and dancers. In addition, I argue that the recording of movement in space generates a trace in and of the landscape that is inscribed on the image. The ephemeral presence of the dancing bodies is therefore rendered material and semi-permanent through cinema.

The notion of site-specificity in screendance is complicated. Most of the films I consider in this article do not acknowledge their actual location within the film: the setting remains nameless, detached from any particular geographic location. The body is not permanently attached to any particular site and its movement leaves only a temporary trace on the ground. The articulation of site-specificity in these cases has to do more with the connection between the body's movement and the physical attributes of the location: we are in fact speaking of a material-specificity. The film's choreography and cinematography represent the landscape's materiality while the site remains anonymous, its history a deep one to be found somewhere in the dirt, the dust, the rock, and the plants.

\section{Material Specificity}

To determine the intimate beauty of materials: their mass of hidden assets, all this affective space concentrated inside things.

- Gaston Bachelard ${ }^{21}$

Screendance, like Land Art, is concerned with materials in space. As filmmakers move outdoors they are confronted with the environment: its scale, sounds, densities, textures, and temperatures are now brought in front of the lens and against the body. 
These new materials not only trigger new choreography that challenges the dancing body, but when captured on camera they reveal what Walon calls a "new particular world which can only exist in the screendance medium." ${ }^{22}$ Rich textures fill the frame in close-ups while the sounds of wind, water, leaves, and the dancers' breath are heard on the soundtrack.

In order to create material-specific screendance, choreographers and filmmakers need to begin with a material, the way a sculptor does before he/she begins to chisel away at it. From a choreographic standpoint, by starting with a tangible, textured substance, and designing movement for it, one shifts from creating shapes that will register visually to developing motion that comes from a base of sensations. By imagining materials first, the choreographer considers the impact of the material on the range of motion. The choice of costume becomes important to decide whether or not the body should be protected, whether the skin or fabric can take it. New materials push the dancer's abilities and endurance, and can impact the pace and weight shifting of the choreography. Based on the texture's density and give, one may confront the limits of motion within that environment: can one walk in the sand in stilettos, run in knee-high water, crawl naked in gravel or breakdance in the mud?

A material-specific approach to designing screendance would not only generate new types of sensation-based movement but it would also create original haptic films. From the filmmaker's standpoint, in order to render the materiality of the site palpable, the film should include numerous close-ups and medium or long shots of the site without a performer in it. Direct sound with sparse music captures the sense of texture and weight of different materials. Placing the microphone near points of contact between the surface and the dancer helps convey the physical nature of the interaction. Shots that show the environment's impact on the body, the mark it leaves on the skin, the fabric or hair also aid in representing the qualities of the site and give the audience a sense of what it is like to be there. Longer takes and slower editing allow the viewer time to look beyond the body in the frame and take in the textures and temperatures of the space.

The aim of adopting a term like material-specificity is not to neglect the overall properties or history of the site itself, but rather to establish a tangible link between the body and the location. In order to develop screendance that is rich in cinematic sensations and choreographies that are intricately linked to the ground, I propose this shift in focus. If a dance created for a beach can be lifted and re-set on a different beach, it is not adhering to the original meaning of the word site-specific. What we are witnessing is a dance that one could call material-specific, one where the dialogue between sand and dancer produces a narrative that will be captured by the camera.

In the following selection of films, natural materials such as light, sand, dust, salt, moss, snow, and water become sources for movement and catch the eye of the camera. In 
the tradition of Body Art and Butoh, building off of the work of such artists as Ana Mendieta (Silueta Series 1973-1980), Eiko and Koma, Amy Greenfield, and Anna Halprin, the following films integrate natural materials into their choreography, relishing this newfound textural richness. As we move from hard to soft grounds, from more stagelike surfaces to liquid settings, we observe how the camera zooms in on details making bare skin appear vulnerable. Bodies give into the horizontality of landscapes and embrace the contours of the ground, while the camera looks for that point of collision between surfaces.

\section{Horizons of Exile (2007) - Between Sand and Salt}

Spanish-British artist Isabel Rocamora shot her 2007 film in the Atacama desert in Chile, one of the most arid places on Earth. Looking for a timeless desert landscape, she chose a location with geysers, a salt marsh, sand dunes, and a sharp horizon line. Despite working at very high temperatures and with blinding sunlight, Rocamora manages to convey a soothing, open landscape. The film, described on her website as "loaded with affect," "presents its politics through a sparse dialogue between human and landscape." ${ }^{23}$ Two veiled women dressed in black roll, walk, and rest on the ground. The vast space around them implies they have nowhere to go, matching the film's theme of exile. Deborah Jowitt in her review of the film in the Village Voice sees these women "slowly rolling and twisting in the barrenness ... express with great economy both the pain of leaving and the pain of staying." ${ }^{24}$ The emotional content of the film is carried primarily via excerpts of interviews of exiled Iraqi and Kurdish women, which are layered onto the desert scene. The pain we hear on the soundtrack matches the material roughness of the ground. As the women cross the hot, dry, and coarse space in a slow and steady manner, the emotional and physical weight becomes heavy.

While the physical space serves as a metaphor for exile, the choice of geographic location is puzzling. The connections between the Chilean desert, the veiled dancers, the displaced Iraqi voices, and the Armenian duduk flute on the soundtrack are not immediately evident and create tension within the work that serves to dislocate the site. ${ }^{25}$ For journalist Ferran Mateo, the Chilean location is "the most obvious estrangement in the work, in the contextualizing of dancers with place." He explains that it "emerged as an imperative following the Lebanon/lsrael conflict and the instability of the region post 9/11. As a work funded by the Arts Council of England, the ministry of culture advised the artists to move the film's production away from Petra (the original shoot location), making a virtue of necessity. ${ }^{26}$ If the film uproots the location to accommodate the practicalities of the shoot, the connection between these powerful narratives, their choreographic embodiment and their setting becomes compromised. Therefore, in this film, as the artist herself states,"the location looses its identity and becomes a stage, a hypothesis, fiction, poetry, metaphor...." ${ }^{127}$ 
The site-specificity of the film remains to be found in its material connection between the women's clothed bodies and the harsh terrain.

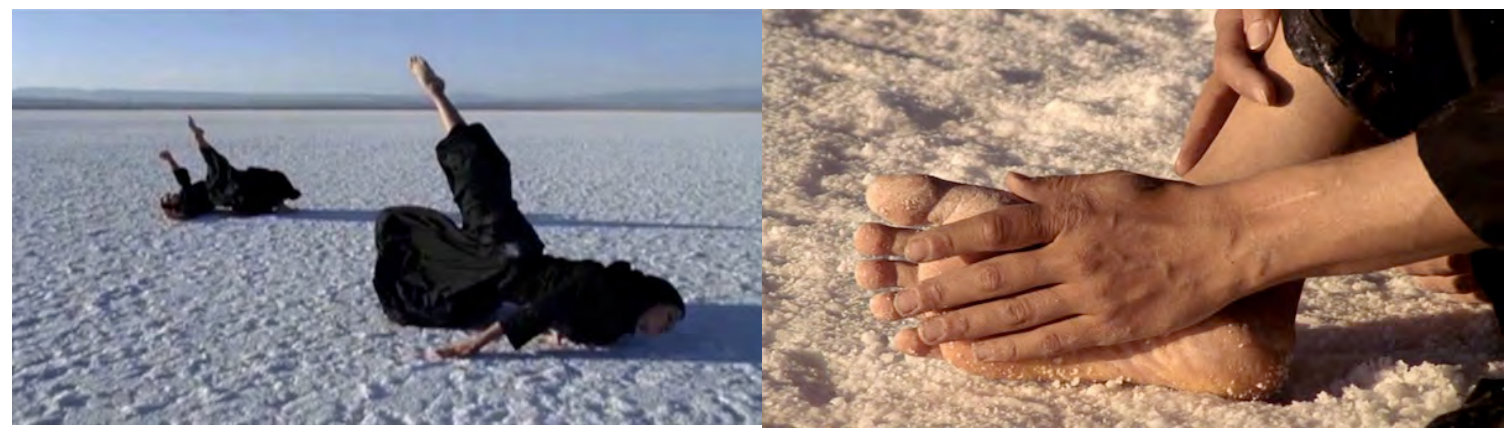

Connecting the body to the ground; screenshot from Horizons of Exile.
Coarse ground against the extremities; screenshot from Horizons of Exile.

\section{Prélude à la Mer (2009) - From Water to Dust}

Shot in October 2009 in the Aral Sea in Kazakhstan, Thierry de Mey's film takes place in a former lake, now dried up due to climate change. Featuring the choreography of Anne Teresa De Keersmaeker set to Claude Debussy's Prélude à l'après-midi d'un faune, two dancers seem lost in the desert, encountering only each other and the dryness of the ground. In the wide-open space, the sharp contours of the dancers' bodies create a jarring contrast. Camille Guynemer describes how the inescapable horizon line and the vastness and stillness of the space create a type of hyper-visibility of the dancing bodies. ${ }^{28}$ Similarly, Walon suggests that the endless tracking shots showcase this "lack of landmarks, and the boundless, empty horizon provokes a feeling of disorientation and a sort of lateral, spatial vertigo." ${ }^{29}$ The viewer gets lost in the proportions and scale of the site, expecting to find not only narrative in the dancing bodies, but also spatial anchors.

Amidst the immensity of the location, and the overwhelmingly powerful music, de Mey manages to create a sense of texture and intimacy through moments of stillness and silence captured in visual and aural close-ups of the body as it meets the ground. ${ }^{30}$ For Walon, the fact that "the dancers-who represent two fauns-are solidly grounded on the floor as they walk on all-fours, roll-up, and rub their bodies on the sandy expanse, suggests, especially through the sounds produced by these contacts, the roughness and dryness of the site." ${ }^{131}$ As their limbs scrape the salty and dusty surface of the land the camera catches the tension through frequent close-ups. The blinding light casts sharp shadows marking the soil with another trace of their incongruous bodies. This is a no-man's land par excellence. Where there once was a sea, there now are these two bodies skimming the soil like fish out of water. This 
environmental story of disappearance is found in the tactile link between skin and dust: the water has gone and soon, too, the bodies will vanish.

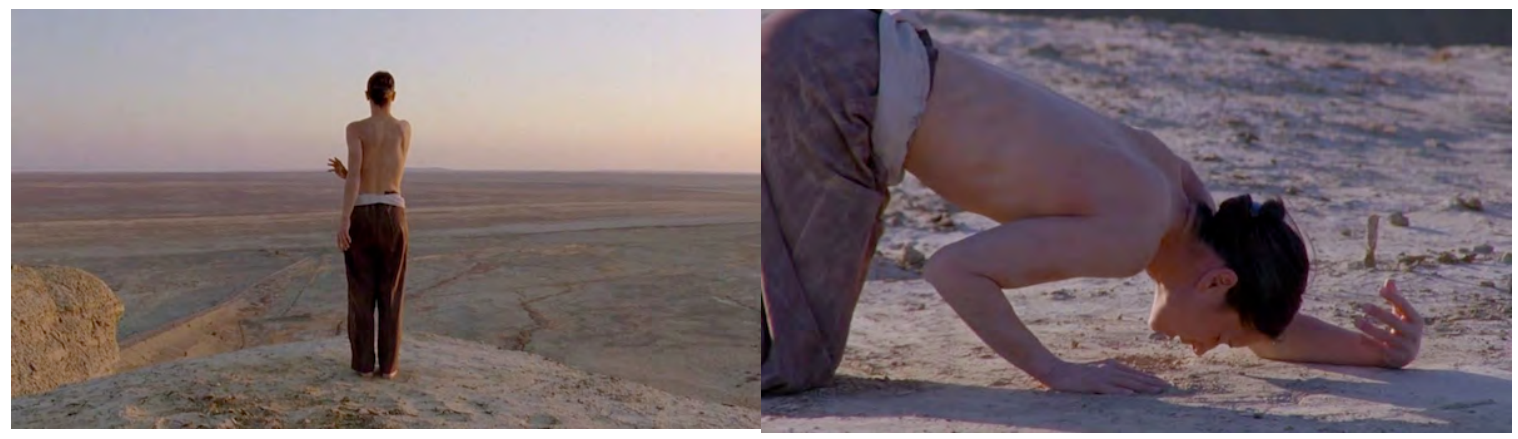

Silhouette against horizon line; screenshot from Prélude à la Mer.

Skin against dust; screenshot from Prélude à la Mer.

Menuett (2011) - Moss

Set in a peat marsh in Malax, Finland, Jukka Rajala-Granstubbon's film begins with an inter-title that explains that when the traditional French minuet arrived in Finland it suited the Finish "forest" people well though it allowed only the hands to touch. The text draws our attention to tactility before we discover any images. The film opens on a close-up of moss and two bare feet step into it gently. The material comes first, the body second. A leg extends into the frame and leads us into this landscape filled with rich textures. The face of a female performer appears from behind a tree branch, keeping nature in the frame as much as the human body.

Four dancers come together to perform a modified minuet. This wild setting immediately seems unusual for such a formal dance yet it incorporates the local textures through close-ups of bare feet sinking into the ground. The two couples playfully dance, at times letting themselves fall backwards into the soft moss, their linen costumes becoming damp. The sounds of the squishy ground and the visible traces of its moisture on the costumes of the dancers draw the viewer's attention to the substance: through its material properties this landscape absorbs the dance. Mia Wiik's choreography incorporates frequent moments of touch between the dancers, moving beyond the boundaries of the traditional minuet, as if the invigorating setting triggered tactile explorations. Heads lean against each other, hands meet, and shoulder blades rest on their partner's back. On this spongy earth the body can fall without harm, feet sink in with joy and the "forest" people seem at home. By transposing a minuet to a peat bog the film pushes the choreography to exploit the new absorbent ground and develop a dance with a material that triggers a sense of tactile freedom and lets the body move with ease. 


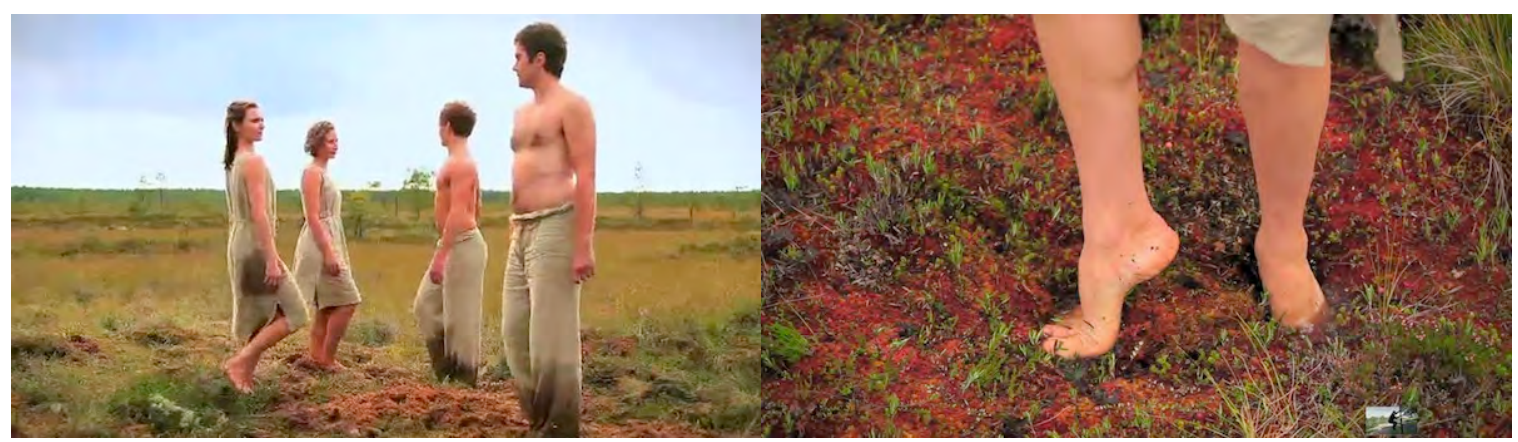

Wet clothes and traces of the ground on the body; Textures for tactile exploration; screenshot from screenshot from Menuett. Menuett.

\section{1/6 D'après Obvie (2010) - Snow}

Out of the series of six solos choreographed by Cindy Van Acker turned into six films by Orsola Valenti, the most material-specific is 1/6 d'après Obvie, set in a snowy field in the mountains of Switzerland. The opening shot is blurry, the falling snow makes the sky almost indistinguishable from the ground. Against this white background, a body clad in black snow gear rolls slowly on the ground, appearing hyper-visible in this monochromatic environment. In this sea of white, our only anchor is the dancing body. As if rolling down a hill, the performer immerses her body in the material, like a child making snow angels. The choreography resembles a floor warm-up routine where the body slowly grows out of the floor, lifting sometimes a leg, sometimes an arm. As she moves slowly and continuously across this powdery texture, the snow clings to her clothes, accumulating in the folds of the fabric, creasing audibly. The use of direct sound captures the crunch that her body makes when it touches the ground and penetrates the material. An establishing shot reveals the solitary body in the landscape while a series of tighter close-ups focus on the imprint of her body on the snow. Rolling around in place, she marks the ground with her pelvis and back, creating a temporary dent in the thick substance. The falling snow flakes remind us that her trace will soon be covered, and the landscape will regain its pristine appearance.

The dancer rolls onscreen from left to right, as the camera alternates between long, medium, and close-up shots, producing the illusion of accelerated movement on a flat surface. She covers ground and the ground covers her in snow. The faint string music washes over the image in a continuous drone, smoothing over the editing cuts. The high pitched sound gives her limbs lightness against the heavy bulk of the snow. The image fades to white and returns to the same site this time with the performer in close-up quasi-naked, wearing only nude underwear. This dreamlike scene works like an $\mathrm{x}$-ray: it reveals the sensations of the body, making the same movements as before appear vulnerable and restrained. As the dancer rolls with apprehension, her bare skin 
slowly touching the frozen snow, each weight shift generates tension in the viewer. The body seems delicate and fragile in this climate: her exposed face, arms, inner thighs and breasts come in contact with the snow and make us cringe. In this scene, the haptic image renders temperature first and texture second. The dancer, whether clothed or not, always stays flat on the ground, never coming off entirely until the end when she gets up and walks into the distance, her dark silhouette blending with the dark greens of a distant pine forest. By rooting the choreography on the ground, the dance becomes about snow. The body never leaves the material and embraces it despite its temperature.

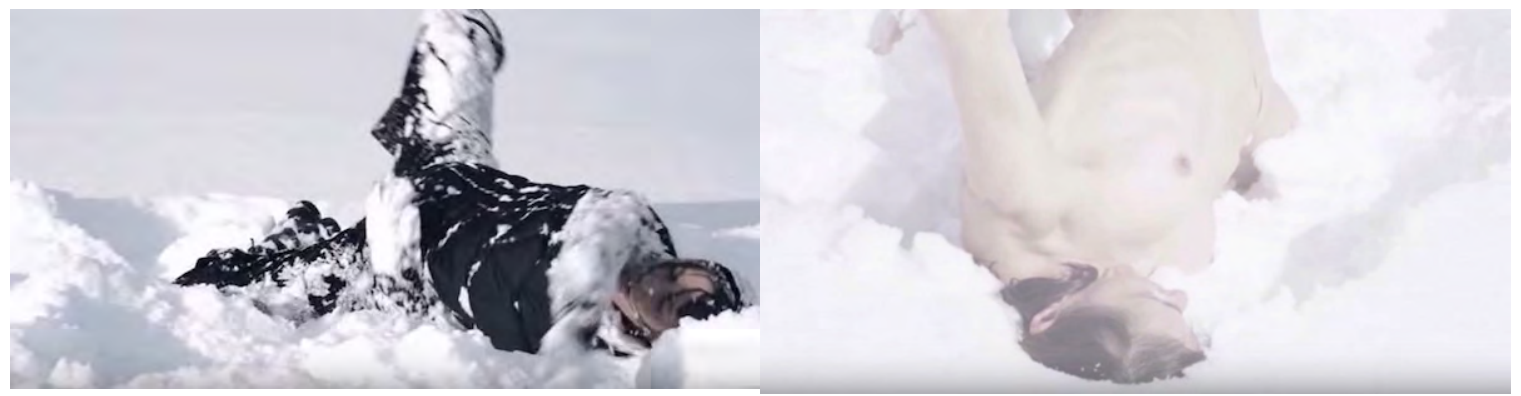

Snow clings to clothes and adds texture and sound Cold material makes skin seem vulnerable; to the body in motion; screenshot from $1 / 6$. screenshot from $1 / 6$.

\section{Blush (2004) - Water}

Shot off of the coast of Corsica, France, and in the back-alleys of Brussels, Blush by Belgian filmmaker and choreographer Wim Vandekeybus, stiches together two territories to create a wild, frenetic, sexual, rock-music scored film that pushes dancers to their limits, especially outdoors. Among other materials, Blush makes explicit use of water, pioneering the use of underwater cinematography in screendance. Several scenes in the film use water to disburse the energy of the choreography. As a group of dancers perform highly energetic partnering sequences in a clearing between dry Mediterranean trees, the filmmaker intercuts shots of other dancers jumping into the nearby ocean. Elsewhere, a group of women dip into a nearby river, and come out to dance on its sandy bank, soaking wet, the sand clinging to their bare legs. Near a small waterfall, a female dancer squats like an animal at a watering hole. An extended sequence shot underwater shows women swimming like mermaids, their skin glistening in the sun. A couple dressed in bright red dance together in the sand in a sort of aggressive swing dance, until the female dancer is flung into the ocean, where she floats face down momentarily until another man comes to snatch her back out. A woman wearing a long white dress walks on the edge of a cliff, before falling into the water. She is later shown walking through the water, near the shore, the fabric of her clothes now transparent, seemingly struggling to stand, and falling back into the waves. 
Throughout the film, each time a sequence takes place on the ground, Vandekeybus cuts back to the water. It is as if the materiality of the water serves to diffuse the high energy of the overall choreography and fast-paced editing. Incorporating long shots of cliffs, close-ups of the surface of the splashing water and underwater cinematography, this film exploits the power and beauty of the material. Absorbing the weight of these hyper-active bodies, the surface of the ocean coaxes the dancers into its depths. When jumping back out and darting across the land, their skin remains wet and their costumes clings to their bodies. The wetness appears invigorating, as the dancers move fearlessly through the different settings. Without water Blush would lack balance. Vandekeybus's incorporation of it in his choreography demonstrates the potential of screendance to work with new materials. The body landing with a splash and the shimmer of water left on the skin give the film a texture to showcase, a temperature to convey, and a sound to record that gives the body weight and substance.

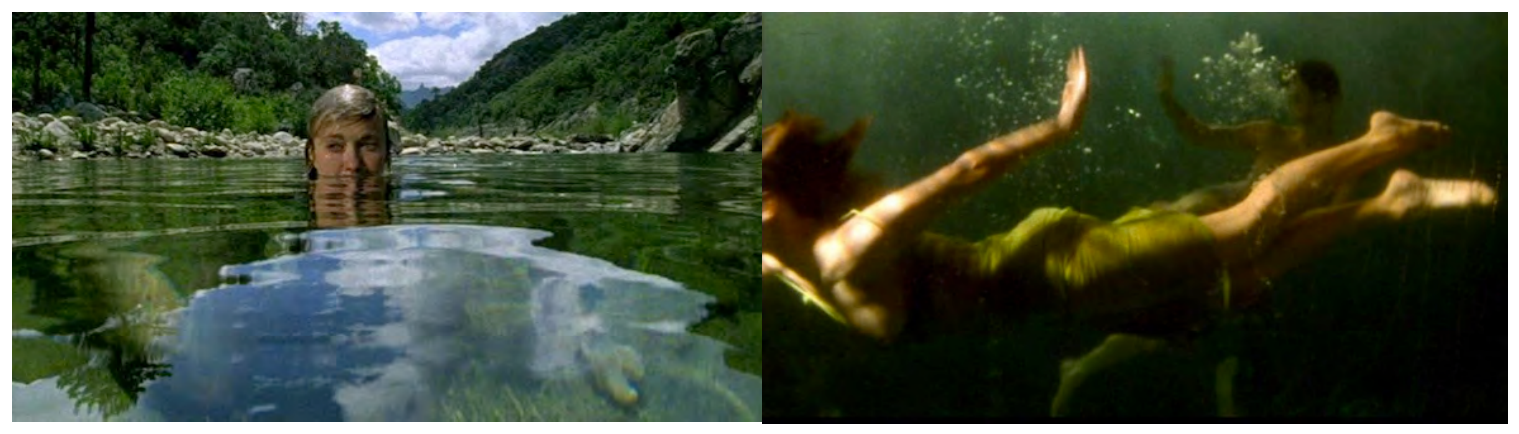

Dancers emerge from the water, giving importance Shooting underwater and its impact on movement; to its surface; screenshot from Blush. screenshot from Blush.

\section{Conclusion}

Whenever I quiet this persistent chatter of words within my head, I find this silent or wordless dance always already going on - this improvised duet between my animal body and the fluid, breathing landscape that it inhabits.

- David Abram ${ }^{32}$

By shifting our focus from site-specificity to material-specificity this article proposes new strategies for listening to space in order to avoid taking the locations in screendance for granted. Different artistic approaches exist to ground the body in space, to make site more than a backdrop, and the one proposed here has been to make material-specific screendance. This concept urges us to dig deeper into the nuances between different theories of site-specificity in the arts. Its application aligns 
screendance with other visual and performance art forms that are based in the manipulation of raw materials such as painting, sculpture, Land Art, installation art, or architecture. The limited scope of this article prevents me from developing this material catalogue further but one could begin to curate, teach, or design films around the concept of a specific material. Could one imagine a screendance for clay, wax, JellO or Styrofoam? Curating a series of films designed for snow, for example, would not only give an audience the opportunity to explore the range of motion possible within a chosen environment, but also the scope of choreographic strategies created by the artists.

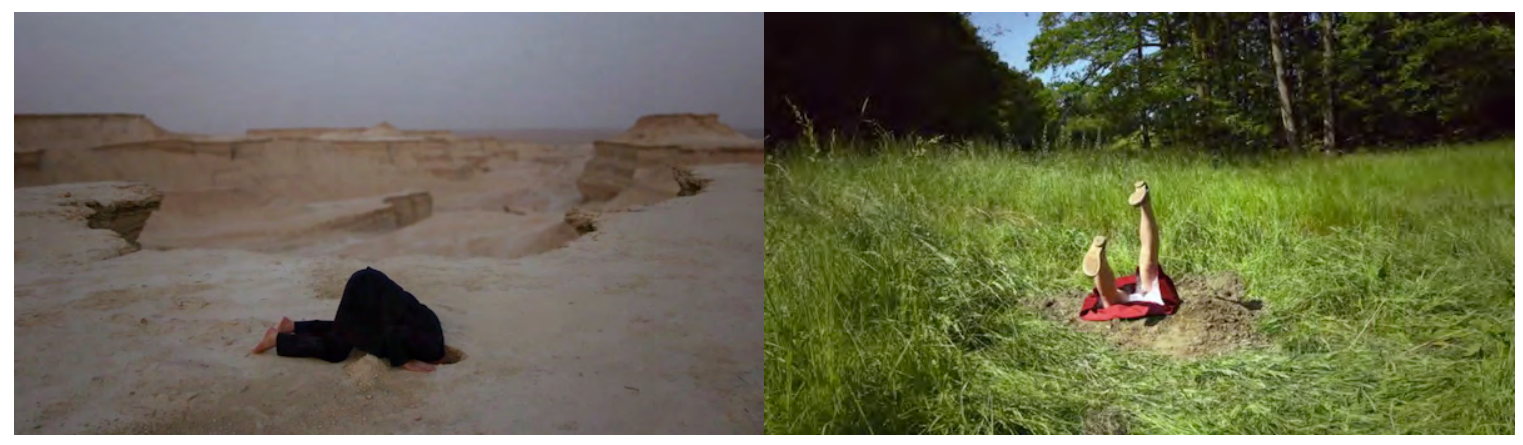

Digging in; screenshot from Nation for two.

Finding meaning and movement in the materials; screenshot from Nation for Two.

In practice, the concept of material-specificity exploits what makes screendance shot on location so different than work made for the stage or studio, namely its ability to incorporate natural materials in order to connect the body to its surroundings. The recent film Nation for Two by Nir Nadler and Chaja Hertog (2012) does precisely this by creating a stop-motion film that begins with two bodies digging their way into the ground towards each other. The film does away with bodies for a while, capturing only a supposed trace underground as they move through different landscapes, freely crossing geographic borders. Each shot presents a different material and as the film cuts from grass and dust to water and sand via bricks, leaves, concrete, salt, and rock, viewers become enraptured in this journey across textures, in these haptic images full of touch and ruffling sounds. As screendance continues to explore this dialogue between the (animal) body and the (breathing) landscape it inhabits, as David Abram would say, I look forward to films that experiment with ambient sound, sparse music, voiceover, or dialogue as well as shots without bodies. I am eager to see screendance resist the urge to fictionalize the landscape. After all what impact on the land does the screendance community wish to have? What do we take from it, but especially what do we bring to it? 


\section{Biography}

Sylvie Vitaglione is a PhD candidate in the Department of Cinema Studies at New York University. Her chapter "Surface Tension: Experimental Dance Films And The Undoing Of Urban Space" is forthcoming in May 2016 in the anthology Imaging the City: Art, Creative Practices and Media Speculations, with Intellect Books. Vitaglione has been an adjunct professor at New York University, The New School, Queens College and the College of Staten Island. She has taught Film History, Film Theory, and seminar classes on Choreography and the Moving Image, Music Videos and Agnès Varda. She has programmed screenings, panel discussions and workshops on the Tiny House movement, definitions of experimental film, Chantal Akerman's film "One Day Pina Asked" and dance and documentary form for New York University, Gibney Dance Center and Dance Films Association in New York. She trained in ballet and contemporary dance in Monaco, San Francisco, London and New York, and is a certified yoga instructor.

Email: smv259@nyu.edu

\section{Notes}

${ }^{1}$ For discussions of the body in screendance see for example Sherill Dodds, Dance on Screen, 29-36 and 126-169; Douglas Rosenberg, Screendance, 33-73; and Erin Brannigan, Dancefilm, 39-62 and 172-197. Valerie Briginshaw additionally analyzes dance films through their use of public space as a means of discussing the constructions of gendered subjectivities in Dance, Space, Subjectivity.

${ }^{2}$ Bob Lockyer pointed out this new ground when he suggested that "dance made for camera has given choreographers another place to dance. The sprung floor can now give way to a beach, a bar, a school hall, or even a field." He does not explain why one would move outside by rather asks "why not?" See Bob Lockyer. "A New Place for Dancing," 160.

3 Sophie Walon. "Poetic Phenomenology," 30.

${ }^{4}$ Noemie Lafrance has used this term in keynote talks at Experimental Film Virginia in relation to working on site.

${ }^{5}$ Dodds, 123.

${ }^{6}$ Heike Salzer and Ana Baer, "Being a Video-Choreographer," 106.

${ }^{7}$ Salzer and Baer, 106.

${ }^{8}$ Kyra Norman, "In and Out of Place," 14.

${ }^{9}$ Norman, 19. 
${ }^{10}$ Katrina McPherson, Making Video Dance, 67.

${ }^{11}$ Idem., 64.

${ }^{12}$ Idem., 68.

${ }^{13}$ Rosalind Krauss, "Sculpture in the Expanded Field," 41.

${ }^{14}$ Miwon Kwon. "One Place After Another," 86.

${ }^{15}$ Richard Serra, "Tilted Arc Destroyed," 34-47.

${ }^{16}$ Michael Lailach, Land Art, 11.

${ }^{17}$ Ben Tufnell. Land Art, 13.

${ }^{18}$ Kwon, 159.

${ }^{19}$ Idem., 95.

${ }^{20}$ Ibid.

21 "déterminer la beauté intime des matières; leur masse d'attraits cachés, tout cet espace affectif concentré à l'intérieur des choses." Translation my own. Gaston Bachelard. La Terre et les rêveries de la volonté, 9.

${ }^{22}$ Walon, 30.

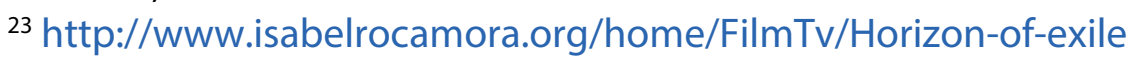

${ }^{24}$ Deborah Jowitt. "Images on the Move," http://www.villagevoice.com/2008-0101/dance/images-on-the-move-for-dance-on-camera-2008/

${ }^{25}$ The Armenian duduk is an woodwind flute that sounds like a cross between a clarinet and an oboe.

${ }^{26}$ Ferran Mateo. "La danza de la liberación" (the dance of liberation). La Vanguardia (Culture Magazine - Screens), 25 February 2009.

${ }^{27}$ Isabel Rocamora, in María Céron. "El gesto humano," 242.

28 "Sur l'horizontalité infinie du sol craquelé de sécheresse, les phrases développées par les danseurs atteignent une lisibilité fulgurante. Cet espace libre, démesurément fixe, démultiplie l'impact de ce qui bouge. Nous ne sommes plus là dans une plongée en son cœur, nous sommes dans un hyper-rayonnement du mouvement". Translation and paraphrase my own. Camille Guynemer in Jean Marc Adolphe, "Thierry de Mey," 5. ${ }^{29}$ Walon, 39.

${ }^{30} \mathrm{I} \mathrm{am}$ using the term aural close-up here to refer to moments when the sound recording moves the microphone in close to capture a sound in greater detail.

${ }^{31}$ Walon, 39.

${ }^{32}$ David Abram. The Spell of the Sensuous, 53.

\section{References}

1/6 D'apres Obvie. Dir. Orsola Valenti, chor. Cindy Van Acker. Switzerland, 16 min, color, sound. 2010. 
Abram, David. The Spell of the Sensuous: Perception in a More-Than-Human World. New York: Random House, 1996.

Adolphe, Jean Marc (ed.). "Cahier Special: Thierry de Mey." Mouvement. (April-June 2011).

Aunis. Dir. Luc Riolon, chor. Jacques Garnier. France, 13 min, color, sound. 1993.

Bachelard, Gaston. La Terre et les rêveries de la volonté. Paris: Jose Corti, 1948.

Blush. Dir. and chor. Wim Vandekeybus. Belgium, 52 min, color, sound. 2004.

Branningan, Erin. Dancefilm: Choreography and the Moving Image. New York: Oxford University Press, 2011. http://dx.doi.org/10.1093/acprof:oso/9780195367232.001.0001

Briginshaw, Valerie. Dance, Space and Subjectivity. New York: Palgrave Macmillan, 2001. http://dx.doi.org/10.1057/9780230508538

Candelerio, Rosemary. "Bodies, Camera, Screen: Eiko \& Koma's Immersive Media Dances." International Journal of Screendance 4 (2014): 80-92.

http://dx.doi.org/10.18061/ijsd.v4i0.4522

Cerón, María. "El gesto humano en lo fílmico. Entrevista a Isabel Rocamora". Arte y políticas de identidad - Revista de investigación. Vol 9, Ediciones Universidad de Murcia, Spain, 2013.

Dodds, Sherill. Dance on Screen: Genres and media from Hollywood to Experimental Art. New York, Palgrave, 2001. http://dx.doi.org/10.1057/9780230509580

Jowitt, Deborah. "Images on the Move For Dance on Camera 2008". The Village Voice. Tue, Jan 1, 2008. http://www.villagevoice.com/2008-01-01/dance/images-on-themove-for-dance-on-camera-2008/

Horizons of Exile. Dir. \& chor. Isabel Rocamora. UK/Spain, 21 min, color, sound. 2007. Kloetzel, Melanie and Carolyn Pavlik (eds). Site Dance: Choreographers and the Lure of Alternative Spaces. Gainesville, FL: University Press of Florida, 2009.

Krauss, Rosalind. "Sculpture in the Expanded Field." October. 8 (1979): 30-44.

Kwon, Miwon. "One Place After Another: Notes on Site Specificity". October. 80 (1997): $85-110$.

. One Place after Another: Site-Specific Art and Locational Identity. Cambridge: MIT Press, 2004.

Lailach, Michael. Land Art. Koln: Taschen, 2007. 
Lockyer, Bob. "A New Place for Dancing." In Envisioning Dance and Film on Video, eds. Judy Mitoma and Elizabeth Zimmer, 156-162. New York: Routledge, 2002.

Mateo, Fernando. "La danza de la liberación" (the dance of liberation). La Vanguardia (Culture Magazine - Screens), 25 February 2009.

McPherson, Katrina. Making Video Dance: A step-by-step guide to creating dance for the screen. London: Routledge, 2006.

Menuett. Dir. Jukka Rajala-Granstubb, chor. Mia Wiik. Finland, 6 min, color, sound. 2011.

Mitoma, Judy (ed.). Envisioning Dance and Film on Video. New York: Routledge, 2002.

Nation for Two. Dir. and chor. Nir Nadler and Chaja Hertog. Netherlands, 15 min, color, sound. 2012.

Norman, Kyra. "In and Out of Place: Site-based Screendance." The International Journal of Screendance. 1 (2010): 13-20.

Prélude à la Mer. Dir. Thierry de Mey, chor. Anne Teresa de Keersmaker. Belgium, 19 min, color, sound. 2009.

Rosenberg, Douglas. Screendance: Inscribing the Ephemeral Image. New York: Oxford University Press, 2012. http://dx.doi.org/10.1093/acprof:oso/9780199772612.001.0001

Salzer, Heike and Ana Baer. "Being a Video-Choreographer: Describing the Multifaceted Role of the Choreographer Creating Screendance." International Journal of Screendance 5 (2015): 102-115. http://dx.doi.org/10.18061/ijsd.v5i0.4446

Serra, Richard. "Tilted Arc Destroyed." Art in America 77.5 (1989): 34-47.

Tufnell, Ben. Land Art. London: Tate Publishing, 2006.

Walon, Sophie. "Poetic Phenomenology in Thierry de Mey's Screendances: Open Corporealities, Responsive Spaces, and Embodied Experiences." International Journal of Screendance. 4 (2014): 28-43. http://dx.doi.org/10.18061/ijsd.v4i0.4529 


\title{
Imagined Archaeology and Enlivening the Proximate Senses in the construction of Blind Torrent - An Interdisciplinary Screendance Project
}

Ruth Way, Plymouth University

Russell Frampton, Plymouth College of Art

\begin{abstract}
The screendance project Blind Torrent, is the result of an ongoing collaborative and interdisciplinary film making process between visual artist Russell Frampton and choreographer and somatic movement practitioner Ruth Way. The article will provide an analysis of the creative processes and insights, which informed Blind Torrent. Anthropological and phenomenological theory will be drawn upon with the aim to reveal how the construction of 'filmic ritual landscapes' unearthed connections between site, artifact, temporality and embodied choreographic response. Connections between this screendance practice and the genres of land art and sitespecific art will be discussed and inform the contextual analysis. The article will principally examine how the creation of empathic movement responses to the landscape developed a phenomenological interface between the body and landscape to enhance the proximate senses in the construction of Blind Torrent.
\end{abstract}

Keywords: imagined archaeology, landscape, proximate senses, somatic movement, ritual

This article will present a detailed contextual analysis of the creative processes and insights, which informed the screendance project Blind Torrent. ${ }^{1}$ Blind Torrent is the result of an ongoing collaborative and interdisciplinary film making process between visual artist Russell Frampton and choreographer and somatic movement practitioner Ruth Way. In this co-authored article, the analysis of the film is presented jointly in respect of this collaboration and where appropriate, will provide specific information and personal insight from our disciplinary perspectives.

To view the film prior to reading this article, Blind Torrent can be accessed at: https://www.youtube.com/watch?v=Z6V9Nbrb2hg 
The analysis explores how the construction of 'filmic ritual landscapes' unearthed connections between site, artifact, temporality and embodied choreographic response. It discusses how these connections served to realize the sensorial potential in digitally layered and scenographically enhanced interior and exterior landscapes. In reference to our disciplinary perspectives and collaboration, the article examines the creation of empathic movement responses to the landscape and the development of a phenomenological interface between the body and landscape to enhance the proximate senses. We use the term 'proximate' to refer to the haptic, aural, visual and olfactory senses and in the film where the body is in a process of transformation as it absorbs the qualities, sounds and textures in these landscapes. We draw on anthropological and phenomenological theory to both critically frame and investigate our artistic intention in the making of Blind Torrent to "return perception to the fullness of its encounter with its environment." ${ }^{2}$ This conceptual framework aims to offer an intimate perceptual lens and a means to remain attentive to the creative processes and the connections arising between imagination, somatic memory and the perceptual senses within our screendance practice.

Blind Torrent engages in processes of unfolding and forming, where intention is constantly being redefined and where, "the relationship between the unexpressed but intended and the unintentionally expressed, ${ }^{\prime 3}$ is kept alive. Similarly our analysis does not attempt to prove or substantiate findings but rather concerns itself with developing a critical praxis, one which provided us with an imaginative and analytical mode of operation to search for and 'unearth' the connections between landscape, body and constructed artifacts. We propose that this method of searching represents our practical research, and those creative processes that lead to, and uncover, a critical and analytical framework and inform our creative decision-making.

As practical scholars we move between the intuitive development of the work and our position as reflexive practitioners, critically engaging with potential new directions, insights and ideas. We describe our creative process as open, fluid and nonpremeditated and propose that this enables the work to retain a focus on immediacy. Rather than employing preparatory story boarding and set choreographic sequences, intuitive artistic responses take precedence over more logical and pre-determined processes. In this writing we discuss the main thematic territories explored in Blind Torrent, and how these themes informed the construction of what we describe as an 'imagined archaeology' and its associated visual environments.

Blind Torrent is a screendance film, distilled from over 20 hours of filming, shot on location in the agricultural hillsides of Mid Devon and in the studio at Plymouth University. Filming took place from March 2011 - January 2012, to capture the landscape in different seasonal states. The title Blind Torrent refers to the unstoppable surge of a torrent, a torrent of information, an overflowing, flooding force, but a force that has no fixed outcome or destination. The concept of the torrent in this dance film 
acts as a metaphor for the evolution of both human consciousness and the increasing degrees of social and cultural complexity.

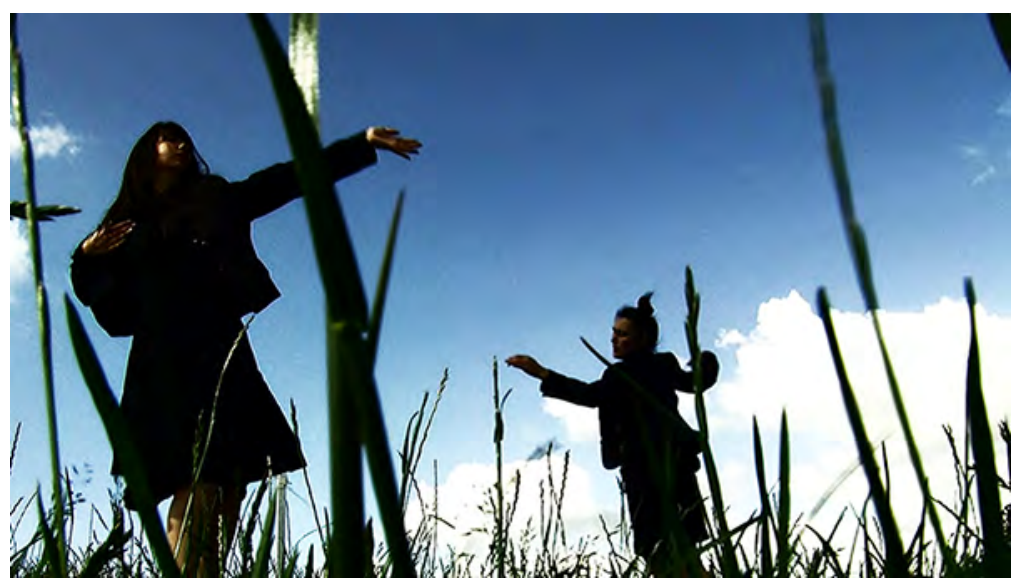

Blind Torrent (2011). Courtesy of Russell Frampton.

Our conceptual locus underpinning the thematic content is in close alignment with performance theorists André Lepecki's and Sally Banes's proposal, "that performance practices become privileged means to investigate processes where history and body create unsuspected sensorial-perceptual realms, alternative modes for life to be lived." 4 We share their argument for a "performative power of the senses," ${ }^{5}$ in both the generation of our film material and the crafting of the final edit. Engaging with phenomenological studies and specifically leading phenomenologist Merleau-Ponty's consideration of the reciprocal relationship between the body and the world ${ }^{6}$ one of the key philosophical imperatives was to challenge the idea of a fixed perceptual field and to focus on the body as a fluid organism, which has the potential to remain open to change and acknowledge the intelligence of the body and its systems. Central to our creative concerns was dance scholar Sondra Fraleigh's observation that somatic movement is interpreted by perceptual phenomena and that "perception does not refer to sight alone, but to all the senses." ${ }^{7}$ Working with this principle, the performers demonstrated self-awareness and a form of relational seeing, a term referred to by dance artist and educator Alison East as "sensory seeing" which she proposes that "there is another way of seeing into things, a sense of seeing that occurs at a deeply cellular level...that comes from deep in our"subterranean" consciousness and facilitates a merging with place or object." ${ }^{18} \mathrm{~A}$ state of 'awakening,' referenced in the film draws the viewer's attention to the somatic and cultural reverberations occurring in the relationship between the body and landscape. Blind Torrent attempts to evoke a reminder of the capacity of our bodies have to be in a closer relationship with landscape through engaging the proximate senses.

\section{Unfolding Textualities and Thematic Territories}

As screendance practitioners we are conscious of being at the intersection of a complex series of multiple narratives, temporalities and trajectories. How we apply 
perception to unlock these creative possibilities shapes our practice. This reservoir of potential lies at the core of our creative activity and provides a conduit to access past histories and mythologies. One of the initial generative ideas for the film explored issues concerning the volume of information available today. The prevalence of this predominately internet based repository, and our relationship with ways of accessing and processing its content, differs fundamentally from an embodied, practical form of knowledge, one learnt through direct bodily experience. Dance researcher Anna Pakes draws our attention to Aristotle's reference to practical wisdom, and how this knowledge is "associated with the domain of praxis ... the moral domain in which, as human beings, we try to live and act in ways beneficial to ourselves and the social group."

A formative anthropological imperative of most societies is the construction of a collective mythology. Social anthropologist James Frazer's The Golden Bough (1993) provides a compendium of research and description of the global and historical nature of this phenomena. The purpose of this mythological worldview is to create a context where individuals can experience a world with edges, or mutually verifiable parameters. This form of communal, often religious belief system is based on the transmission of knowledge and ancestral worship, and as Frazer describes, is specifically linked to the development of agrarian communities. Creation myths and the pantheon of deities, representative of human traits and natural phenomena serve to mythologize knowledge and to encode archetypes that have practical and spiritual relevance. The codified framework of mythology, physical terrain, flora and fauna, seasonal cycles and astronomy, served to create a sensorium of perception. The recent field of sensory ecology ${ }^{10}$ seeks to understand the interpretative processes that evolve from a proximal ecological environment; that being the immediate physical space an organism has direct contact with and experience of. Crucially this field of study provides an understanding of affordances between objects encountered in the environment and the actions they perform. In the making of Blind Torrent the affordances between props, locations and performers are explored through processes of imagination, intuition and the kinesthetic proprioceptive sense of movement.

One strategy that pre-historic cultures applied to manifest and nurture this sensorium of perception was the construction and enactment of ritual. Ritualistic activity can be seen as a way to gain a beneficial degree of control over the external forces impacting on the survival of an individual or community. Some rituals seek to link those enacting them to a deity, who represents the personified form of a specific series of traits, characteristics or perceived governance over aspects of that society. This process of a culture distilling attributes into iconic representations is closely tied to Jungian theories of the archetype. An archetype is a primitive mental image or construct, often inherited from very early human populations, that Jung postulates is present in the collective human unconscious. Jung specifically states that the notion of 'archetypes' 
refers to, "archaic or primordial types, that is with universal images that have existed since the remotest times."11 This idea was key to the development of central characters or personas within Blind Torrent, such as the 'corn mother' and the 'white girl' or 'acolyte,' and offered not an explanation or clarification of their specific role or reason to be, but rather an iconographic "intimation of meaningfulness." 12 These atavistic reversions were sought out and used to form the core of the visual imagery, where they present forms of polarity and an implied hierarchical order. Examples include the division between underground/ground, chromatic opposites of black and white and master/acolyte, mother/daughter relationships. Throughout the construction of Blind Torrent the creative potential of the socio-historic lineage of the landscape was explored through our direct experience and knowledge of the proximal landscape where the film was located. We sought to re-imagine the rhythms of a range of localized human activities, such as work and play, and specifically agricultural labor. This allowed us to reconfigure a form of ritualized response to these locations through the medium of screendance. In Blind Torrent our personal connection with the landscape of Mid Devon provided a formative base of familiarity, where the experience of markers and signifiers of a place build up over many years of deep scrutiny, casual play, and genuine co-existence. As Pearson and Shanks discuss in Theatre and Archeology, "The square mile, the intimate landscape of one's childhood, the patch of ground we know in a detail we can never know again." ${ }^{13}$ Thus it was the primal understanding of an immediate landscape, which provided the foundation for the film.

\section{Development of An Imagined Archaeology}

As a visual artist Frampton approaches film with an emphasis on color, texture and composition, and through the development of props or three-dimensional sculptural forms. Many of the structures used in the film were developed from studio based manipulation of materials, which themselves were informed by the aura of ancient artifacts. His recent work has explored processes of stratification and deposition, which mimic the process of layering the complex surface of a painting. Frampton includes frequent references to historical presence within the contemporary landscape, encoded in personalized pictograms and encryptions within the paintings. This process has informed the development of an 'imagined archaeology' within the film. As philosopher Mark Johnson points out, "without imagination, nothing in the world could be meaningful. Without imagination, we could never make sense of our experience". ${ }^{14}$ Artifacts were made in the categories of costume, scenography and held objects, all of which sought to combine surface qualities such as patina, texture and coloring, and the minute detailing of surface pattern. In a sense there is a direct connection to the landscape itself, as structures are often made from localized materials and found objects. These artifacts served to create forms whose physical 
properties were shaped by the land and mediated through the artist, examples being the ritual posts and the collar [see second and fourth images].

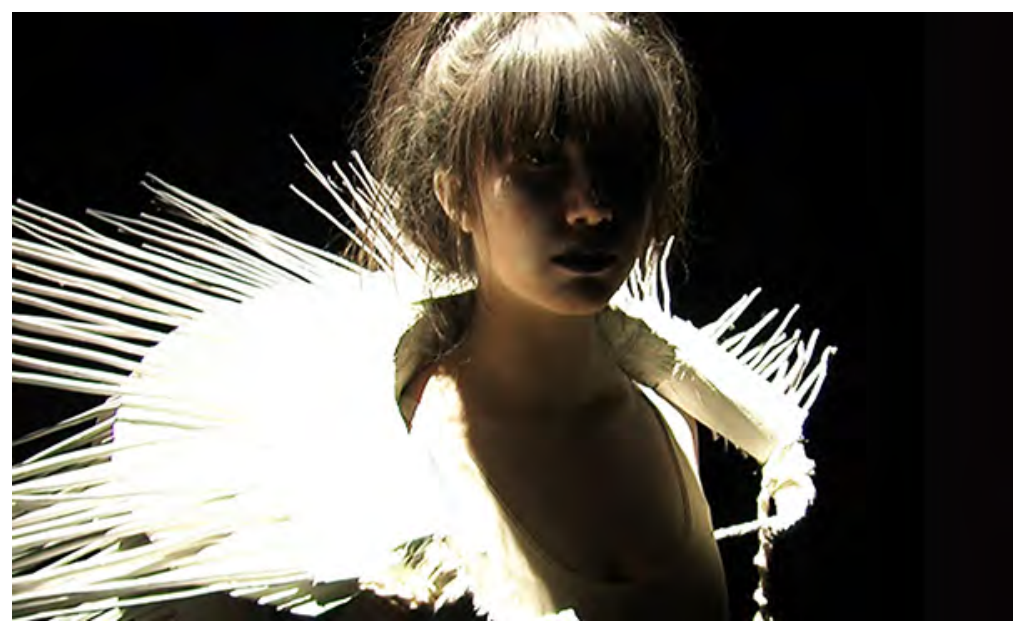

The collar, costume, Blind Torrent (2011). Courtesy of Russell Frampton.

When these artifacts were constructed, the creative aesthetic informing their appearance was painterly, but also tried to invest qualities of a regressive nature to give these artifacts a sense of their archaeo-ritualistic functionality. It is this functionality that gave these reconfigured artifacts the potential for generating movement responses. Central to this proposition of an 'imagined archaeology,' was an awareness that the vast majority of the socio-historical presence within the landscape took place prior to the development of written records. These histories are real, though un-documented, forming a speculative continuum of human ceremonial response from rites to ritual, which encompasses the cultural articulation of awareness of sentience and existence.

There are clear connections between this screendance practice and the genres of land art and site-specific art. External locations were meticulously surveyed and historically researched by the film-makers. Anecdote and localized knowledge informed central components of the final work, this understanding was gained from conversations with farm workers discussing specific geographical peculiarities and weather conditions. Land artist Robert Smithson's comparable approach to the historiographical development of Spiral Jetty (1970) Great Salt Lake, Utah USA, through discussions with locals of the lore of the region, fostered the creation of multiple, almost serendipitous overtones of meaning. Roberts elaborates on this idea stating, "Historical details refuse to remain bound to a limited, nominalist register. They have a fantastical or eerily coincidental aspect about them that suggests their connections to other scales and resonances of meaning." ${ }^{15}$ These are the details that impart uniqueness of site and profound complexity to how Spiral Jetty is experienced. Within the context of Blind Torrent we incorporated these historical details into the work through our specific knowledge of people and place and through research into the local historical land usage and agricultural practices. 


\section{The Visual Environments of Blind Torrent. The Seasons}

The primary locations of the film are subdivided into four areas, each representative of a season. This alludes to repetitive natural cycles, and is a layer within the film that orders implied ritual activity and creates a distinctive cosmological structuring. The first environment created for the film was the 'sanctuary of bones,' representative of winter, a time of reflecting, taking stock and of preparation. The recurrent transitions into this space mark a descent from sky, to horizon and to land, where a slow descent into the 'underground' represents a sinking, a dropping down into an abyss. Victor Turner's explanation of the terms 'byss' and 'abyss' has pertinence in our attempt to describe the qualities residing in this environment, "Ritual, in other words, is not only complex and many-layered; it has an abyss in it." "16 Turner describes 'byss' as being deep and 'abyss' as beyond all depth and writes, "Many definitions of ritual contain the notion of depth, but few of infinite depth."

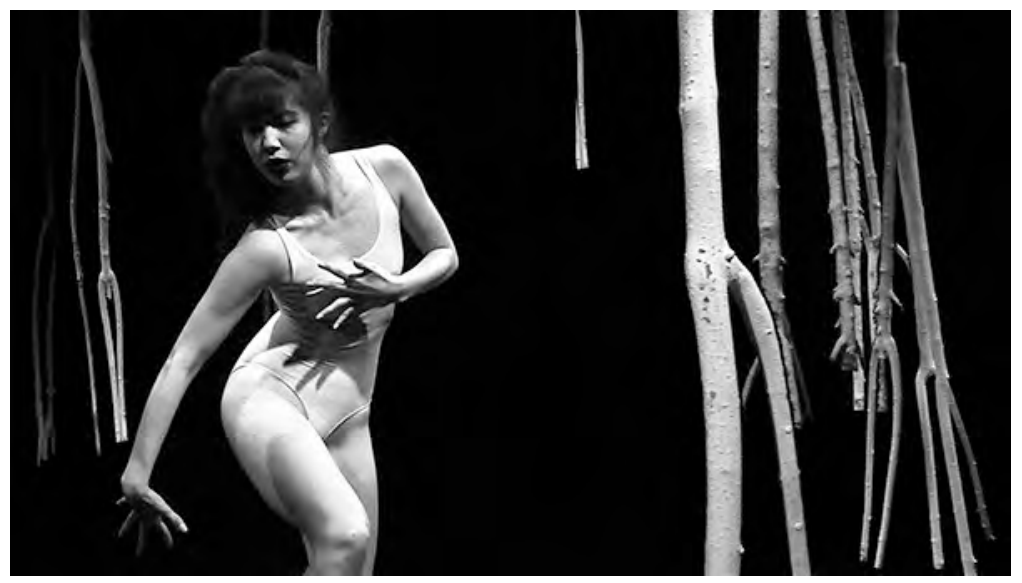

The sanctuary of bones. Blind Torrent (2011). Courtesy of Russell Frampton.

The scenography for this section involved the suspension of inverted lengths of forked branches, bleached white, each possessing distinctive 'bone-like' characteristics. At staged intervals these suspended forms were set in motion and allowed to slowly revolve. The implied significance of this scenography was threefold. First to represent a repository of ancestral mythic knowledge and identity, imparting a sense of belonging and continuity. Second as a visual metaphor, the suspended branches reaching to the ground corresponding to the strength in the hands and the fingers searching to feel, to have connection, to reunite. Finally the branches as bones, suggesting the remains of generations stripped back to their core physical structure. It also referred to an internal state, a psychological space, a vestigial memory buried on the far edges of our humanity. The dancers in this environment worked with a growing awareness of just how 'alive' our bones are, and how energy is directed through our skeletal form to create and direct movement. These 'bones' inhabiting the space were an attempt to remind us of our ancient core, and of their capacity to endure and reveal an intuitive physical awareness. 
The external scenography of the five white post structures was in stark juxtaposition to the branch-filled, darkened interior spaces. These carved and painted forms were developed as sculptural responses to the demarcated post-holes on diagrammatic drawings of archeological sites, which paradoxically signify both location and absence. The subsequent re-imagining of sculpted posts to fill these spaces led to the development of a series of related structures that possess both stylistic commonality and a form of personified individuality. The constructional lineage of these posts drew from ethnic totem structures, the slender white painted series of wooden carvings produced by artist Louise Bourgeois ${ }^{17}$ and weathered anthropomorphic beach posts found in North West Brittany.

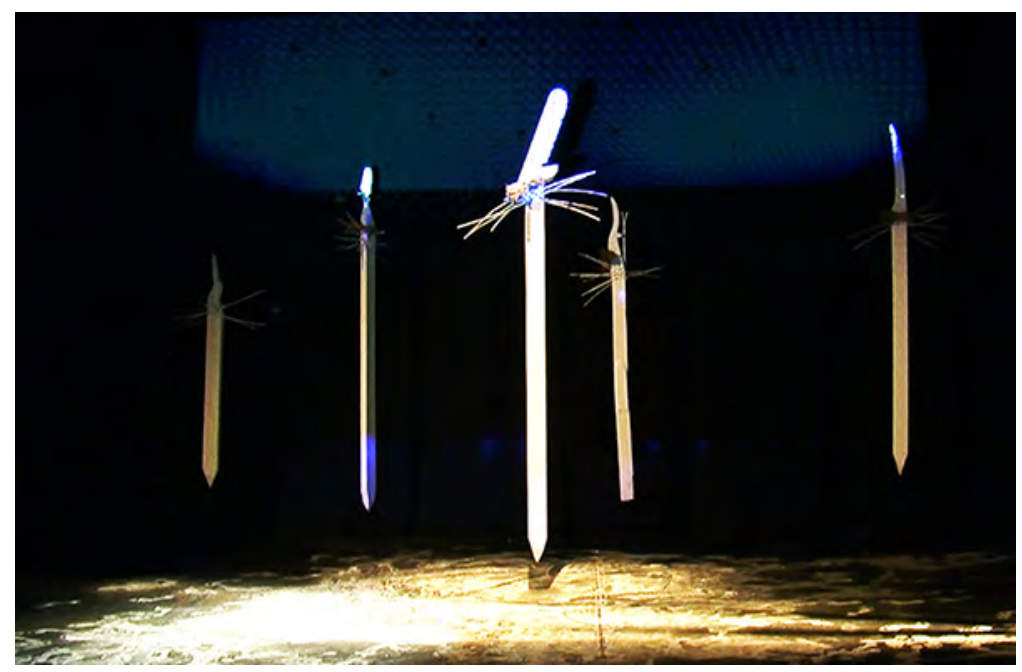

The white posts. Blind Torrent (2011). Courtesy of Russell Frampton.

The posts incorporated materials from the actual sites, found objects, twigs and branches, and were arranged across a hillside to form a structure, transforming the physical space, and by implication serving to ritualize the landscape. This process of demarcation created the spatial framework of the film and much of the potential for performative action; the posts provided nodes to punctuate the filmic and actual landscape. The filming of the post sequences took place in early May and their location on verdant grassland, teeming with insect life firmly placed this environment in spring.

During summer, the ripening cornfields of Mid Devon are striking. Their glowing golden presence, combined with their inherent structural and spatial aesthetic provided a compelling filmic environment. Corn mythology permeates the world's earliest religions and belief systems, linking agriculture, growth, fertility, rebirth and the seasons in complex ritualized interrelationships. ${ }^{18}$ Cornfields are managed landscapes and within them resides a sense of collective security, an investment in the future. They are areas of provision, which tie communities together through common effort, and are places that exclude the unmanageable, the wild and the unproductive. 
The decision to use this evocative and symbolically rich space led to the development of two distinct movement sequences, the 'ritual walk' and the 'transference,' both choreographic responses to the physically limiting, localized terrain of the cornfields. The 'ritual walk' sequence deals with the processional aspect of ritualization, and is symbolic of the process of learning, of following and of the rote aspect of remembering. The 'transference' sequence involves the two figures digitally mirrored and superimposed, as if to merge their identities and embodied histories. Paradoxically this device also places the emphasis on the performers' individualities, as the contours of their faces, ages, expressions and distinct ways of performing the actions are amplified. This sequence visually articulates the notion of an exchange of cultural knowledge and empathic understanding of the continuum of lives lived.

The toil section in Blind Torrent illustrates the repetitive actions required to work the land, and symbolized the preparation of the land for sowing. Movement improvisation in this environment with a range of agricultural tools, informed a series of repetitive actions, which rhythmically scored the land, with a forceful, almost compulsive work ethic. The use of split screens and out of sync looping emphasizes the extended temporality of the agricultural work cycles. The use of poly vision, split screen editing techniques created temporal and spatial juxtapositions, which elicited a more direct apprehension of the material. Specifically the audio of the edging tool, which in one section moves progressively towards the viewer with increased amplitude on one half of the screen. This is in direct opposition to the second screen where the live audio is minimized, creating a choreographically spatial and rhythmic counterpoint through the expressive use of the tool. The creation of these dual sections enhanced the potential for formal compositional elements to be explored, and served to reinforce the recurrent visual motif within the film of the inter-relationship between the two female characters.. The implied ambiguity of distinctive identity was reinforced by similar attire and appearance, which offered multiple interpretations, such as mother/daughter, older self/younger self, master/acolyte. Stylistically the use of this technique references Andy Warhol's art house film, Chelsea Girls (1966) a film that also lacks a formal narrative structure and through juxtaposed clips builds a compelling and disjointed sensorial experience. A second major influence on this sequence was Alexander Dovzhenko's epic film Earth (1930), a silent masterpiece of early Soviet revolutionary cinema. This film idealized aspects of Stalin's program of industrial collectivism and features poetic sequences of work on the land in the Ukraine, referencing the cyclical nature of agriculturalism, and the nobility of the worker. 


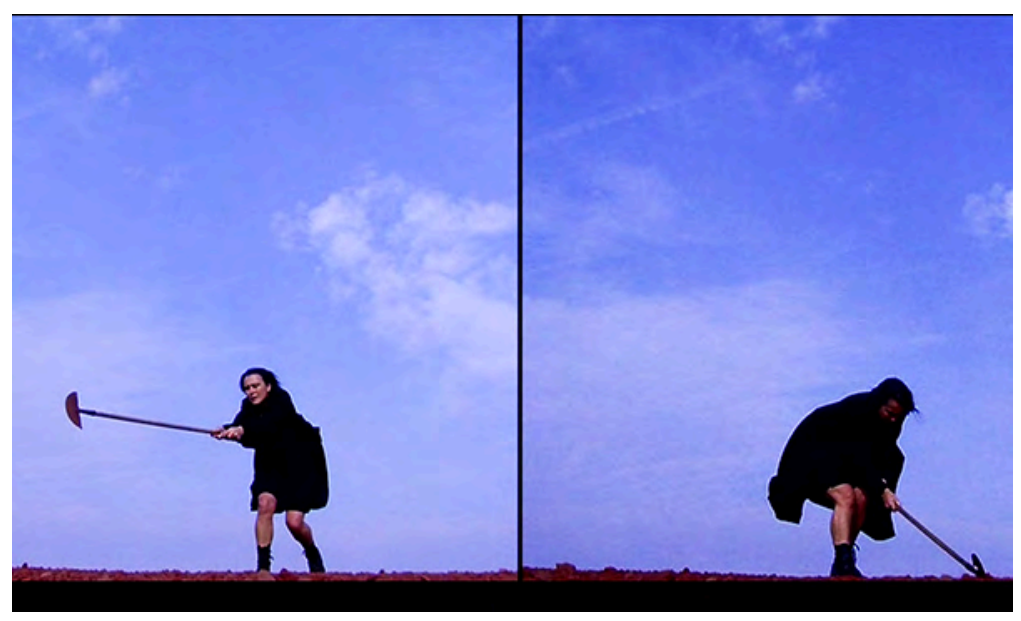

The work/toil section, Blind Torrent (2011). Courtesy of Russell Frampton.

\section{Somatic Memory and the Impact of Stillness}

We recall formative memories; how as children, through a process of unfettered play within environments such as cornfields, the sheer joy of lying in the corn looking at the sky was experienced, providing a feeling of being protected and 'wrapped' in the land. This childlike apprehension is receptive to the proximate sensorium experienced in this landscape, imprinting a fundamental initial response, a somatic memory. A memory formed by its embodied schema and awakening perceptional phenomena, such as how the body experienced the texture and smell of the corn. This form of somatic memory surfaces within the film when a performer is seen lying in the cornfield. These filmic images represented a sleeping state or meditative repose, and a process of entering into an altered state of consciousness; the hollow created in the corn representing a portal linking the levels of sky, earth and underground.

Standing still in this landscape with an awareness of breath and alignment, Way recalls how her attention shifted from being quite passive to actively engaging all of her senses. This shift enabled a heightened receptivity to the qualities residing in the land and her place within it, and can be described as a somatic mode of attention. It facilitated a slowing and opening of her perceptual field, allowing the choreographic and movement responses to become receptive to these meditative and transformational states. Linda Hartley, a dance movement therapist offers further insight about this relationship when she writes, "today we are beginning to recognize again what ancient cultures have always known - that altered states of consciousness are vital for individual and collective health, and are fundamental to spiritual experience." ${ }^{19}$

In ongoing conversation with our performers, there is an increased awareness acknowledged, of developing strategies to avoid always feeling compelled to include kinetic representation in their performance and in the choreographic edit. Including strategies such as improvisational movement scores, working with visual imagery and 
stillness, assisted in the interruption of automatic and habitual movement responses. André Lepecki in his book Exhausting Dance (2006) draws our attention to German philosopher Peter Sloterdijk's premise that modernity's ontology is a pure "beingtoward-movement" ${ }^{20}$ and informs the analysis of this film. Lepecki writes, "the mode of performance that occasions the self-enclosure of subjectivity within representation as an entrapment in spectacular compulsive mobility is the one that early modernity invents and gives a proper name: choreography." ${ }^{21}$ These moments of 'standing still' in Blind Torrent, where the performers stand in front of the posts strive to claim a different mode of being from "being-toward-movement." ${ }^{22}$ The performers deliberately stand outside of this form of representation in order to be in relationship to their environment through a different ontological grounding. These bodies in this landscape remain defiant through their sentient presence as women who can stand 'to be' and thus avoid representation of the body "as a sign to be consumed by the audience as a representation of flexibility, mobility, youth, athleticism, strength and economic power." ${ }^{23}$ Movement material generated by sensing and feeling the other in close proximity and apart achieved a strong mutuality between the performers. This more intimate dialogue developed an empathic movement relationship between the dancers and their environment. There was no requirement, cause or need for any representation of virtuosic acts in this work.

\section{Walking the Land}

As the performers walk through the cornfield with a repetitive and ritualized gestural sequence, it appears as if they are attempting to assert their presence and call us to attention. Hand gestures chart the space through a pattern of spatial punctuation points as if they are mapping out this experience of walking, observing and sensing in the landscape. Walking has its own rhythm, its own pace and tempo and it is this repetitive reinforcement that informs the ritualized cornfield sequences. Contemporary performance theorist Deirdre Heddon, who writes about relationships between performance and environments, refers to the art of walking. She draws our attention to phenomenologist Edmund Husserl's theories and states:

the body is always, no matter where we are, 'here', present; moving through place, our body nevertheless, serves as an anchor ... this phenomenological quality of walking is one that stressed: we 'know' the world through our physical, bodily experience of it and our literal contact of body and environment is thought to provide a privileged mode of knowledge. ${ }^{24}$

Walking through a landscape, experiencing it from the shifting perspective of motion and the direct physical contact of the body with the land forged an empathic relationship, which informed the search for a kinesthetic understanding of place and the subsequent creation of these embodied movement responses. Mike Pearson, who 
has written extensively on site-specific performance proposes that "walking is then a spatial acting out, a kind of narrative, and the paths and places direct the choreography." ${ }^{25}$ Walking can fulfill many functions, we walk to search for an answer, to process ideas and mull things over, we walk to empty ourselves and just reconnect with the world on an instinctual level. Our experience of landscape as we pass through it is one of constant shifting, horizons change imperceptibly, the immediate landscape moving past us, turning from sharp focus to peripheral vision, a liminal zone where the fleeting glimpse is caught from the corner of our eye.

When walking we experience an implicit duality, with both an inner dialogue and an external awareness of the spatial flux of the environment. The subtle gradients of the path, the texture and firmness of the ground beneath our feet, the curvature of the hills, the sun and wind on our face; all these sensations connect us directly to the place we have evolved to inhabit.

\section{The Proximal Landscape}

Within the disciplines of landscape painting and somatic movement practice, great attention is focused on the closest of observations of the subtle forms, colors, and textures and movement occurring in the natural environment. This artistic sensibility creates an indelible network of the meaning of a place, in much the same way a proximal landscape is imprinted on the receptive spatial and sensorial receptors of a child. The idea that both performance and archeological sites constitute sensoria, and that they are "apprehended as a complex manifold of simultaneous impressions of which any account will be inevitably embodied, subjective and poetic," ${ }^{26}$ underpins our working methodologies. Intuitive movement responses and the nature of the physical terrain allowed ritualized, gestural sequences to evolve, which developed a specific affinity to location, creating charged liminal spaces. All these elements within the film are tautly interrelated and exist to communicate a vision of our perceptual experience. This process was applied to distill meaning, which can paradoxically be seen as both indeterminate but also possessing meaningfulness. Philosopher Max Van Manen writes, "It is important to remember that the phenomenological determination of meaning is itself always indeterminate, always tentative, always incomplete, always inclined to question assumptions by returning again and again to lived experience itself." ${ }^{27}$

A central concept within our screendance practice is a creative awareness of multiple temporalities, the use of which allow the work to enter a form of liminal space of past, present and future. Blind Torrent displays a sense of convoluted temporality, one that is, "neither a linear or a slice through time; it is convoluted. Memories, pasts, continuities, present aspirations and designs are assembled and recontextualized in a work that is both performance and archaeology. ${ }^{\prime 28}$ Merleau-Ponty implies that there is, 
a relationship, between beings who are both embodied and limited and an enigmatic world of which we catch a glimpse, but only ever from points of view that hide as much as they reveal. ${ }^{29}$

Within the film we strive to create these glimpses by being attentive to the historical and sensorial potential located at the very edges of actual anthropology, entering into a liminal space of imagined ritual and artifacts.

We imagine that Blind Torrent creates an environment where "history is experienced as contemporaneous, where the past still operates on the present" ${ }^{\prime 30}$ and where the landscape becomes a palimpsest, marked, named and overwritten by the actions of ancestors. The landscape in this context can be seen as the same original document but layered with the barely discernible traces of past lives and cultures, and acting as prompts to unearth and re-imagine. During the filming process this framework allowed for new work and new understandings to surface as we began to sense the rhythm of these actions and the journeys taken within these landscapes. In Deidre Sklar's chapter "Unearthing Kinesthesia: Groping Among Cross-Cultural Modes of the Senses in Performance" (2007), she draws our attention to how people think in different representational systems and how an individual will "rely on one sensory modality to 'go after' information (visually searching, aurally questioning, kinesthetically groping)." ${ }^{31}$ Sklar's insight describes how we applied these different modalities in our interaction with the landscape. We also draw on Sklar's proposal that, "not reason but imagination is the essential meaning making operation," ${ }^{32}$ and Johnson's argument that imagination, "works not merely reproductively to duplicate or reflect experience but productively, as an ongoing activity that structures experience by organizing perceptions, figuratively, into patterns." ${ }^{33}$

Both Johnson and Sklar's insights have significance in relation to how this creative practice functioned during the making of Blind Torrent and how our 'imagining' in these landscapes was therefore inevitably inter-subjective. Anthropologist Thomas Csordas states, "to attend to a bodily sensation is not to attend to the body as an isolated object, but to attend to the body's situation in the world." ${ }^{\prime 4}$ Through the various ways of seeing, thinking, embodying, visualizing, and generating artifacts and performance we drew on these different modalities to search for strands of information we would describe as sensed cultural knowledge.

The final 'torrent' sequence was composed of a series of rapidly flashing single frame edits of stills from the film, featuring the props, material and footage, both used and unused in the final edit. This filmic condensation offered glimpses of a hidden lineage of embodied historical experience, where artifacts, enacted ritual and ritualized landscapes become compressed into a stream of filmic images, images that can be accessed subliminally. It allows the viewer the opportunity to experience not only the implied meaning of the work, but also the work's construction, the out takes, the 
unused locations, its stages of experimentation and choreographic processes. This is actually the film's embodied history and intrinsically links the process of making with the film's resolution.

The multiplicity of perceptual and sensorial strands within the work, the absence of a linear narrative and the fusion of ritualized movement and archetypal references within the landscape, led to the creation of a pluralistic reality in the film. This reality sought to re-imagine potentialities existing in the creative relationship between the performers and the landscape. John Wylie, who draws our attention to phenomenological approaches to develop understanding of the relationships between people and land, culture and nature writes in Landscape (2007), "Body and environment fold into and co-construct each other through a series of practices and relations." $^{35}$ The Russian filmmaker Andrei Tarkovsky expands on this idea by proposing that film, "is an emotional reality, and that is how the audience receives it as a second reality." ${ }^{36}$ Tarkovsky further holds the belief that film is, "among the immediate art forms since they need no mediating language, cinema allows for an utterly direct, emotional, sensuous perception of the work." ${ }^{37}$ This sentiment grounds our creative methods and aims, and reminds us that our methods of searching and articulating these research insights necessitates a fluid exchange between critical thinking and practical, embodied understanding.

\section{Biographies}

Ruth Way is Associate Head of School for Performing Arts at Plymouth University and Subject Head for the Theatre and Performance Department. She is Programme Leader for BA (Hons) Dance Theatre and ResM Dance. Specialist teaching and research areas are in screendance, performance training and somatic movement practice. Ruth has performed with Earthfall and Lusty Juventus Physical Theatre and has presented her practice as research through articles, screenings and performances internationally. She is co-director of Enclave Productions with visual artist Russell Frampton and their dance films have been selected for major festivals in Europe, Australia and USA. Ruth is a registered somatic movement educator, her chapter "Somatic Awakenings" was published in Sondra Fraleigh's book Moving Consciously (2015). Ruth acts regularly as a mentor for emerging dance artists and is a member of the board of Directors for Plymouth Dance.

Email: R.Way@plymouth.ac.uk 
Russell Frampton is a visual artist and film-maker. He is a lecturer in painting at Plymouth College of Art and associate lecturer at Plymouth University, teaching screendance and digital dance practices. Russell is an established visual artist exhibiting his paintings internationally and is represented by Store Street Gallery and Highgate Contemporary Art London, Bell Fine Art, Winchester and Smelik \& Stokking The Hague, Netherlands. In 2004 he formed 'Enclave Productions' with Ruth Way, dance artist and choreographer to extend his work into the arena of multimedia, film and collaborative practice. His dance films have been screened at major festivals in Australia, Europe and USA and he has presented his research through international screenings, conference papers and published articles. He has devised both film and digital scenography for dance artists and theatre companies and regularly composes sound scores for film.

Email: rframpton@pca.ac.uk

\section{Notes}

1 Dance film Blind Torrent (2012) directed and produced by Russell Frampton and Ruth Way explores the rural landscape of Devon from the perspective of an imagined archaeology and ritualized movement, performers Catarina Lau and Ruth Way.

${ }^{2}$ Stanton Garner, Bodied Spaces, 2.

${ }^{3}$ Marcel Duchamp, in Freeman, Blood Sweat \& Theory, 180.

${ }^{4}$ Sally Banes and André Lepecki, The Senses in Performance, 1.

${ }^{5}$ Idem., 3.

${ }^{6}$ In Phenomenology and Perception, 239, Merleau-Ponty writes, "by thus remaking contact with the body and with the world, we shall also rediscover ourself, since, perceiving as we do with our body, the body is a natural self and, as it were, the subject of perception."

${ }^{7}$ Sondra Fraleigh, Moving Consciously, xxi-xxii.

${ }^{8}$ Alison East, "Performing Body as Nature," 171. East, a contributor to Fraleigh's book Moving Consciously, talks about her growing awareness of a relationship to the world beyond herself.

9 Anna Pakes, "Knowing Through Dance-Making," 18. Pakes discusses the philosophical implications of choreography as practice as research to consider practical knowledge as being distinct from theoretical understanding. Pakes refers to Aristotle's mode of practical knowledge phronesis, to highlight how phronesis referred to as practical wisdom has the ability to be sensitive and attuned to the particularities of different situations and experiences. 
10 Sensory ecology is a recent field of study that investigates how organisms acquire process and use information gained from their environment, specifically how sense organs capture this information and how the significance of this information is processed to make decisions.

${ }^{11}$ Carl Jung, The Archetypes and the Collective Unconscious, 4-5.

12 Max Van Manen, Phenomenology Online. Van Manen refers to eidetic reduction, which differs from concept analysis by offering iconic images of phenomenon, paradoxically opening up ambiguity and indeterminacy.

${ }^{13}$ Mike Pearson and Michel Shanks, Theatre/Archaeology, 54.

${ }^{14}$ Mark Johnson, The Body in the Mind, ix. Mark Johnson developed a theory of image schema, maintaining that image schema, are regularly embodied patterns of experience. His research in the role of bodily schema in cognition and language proposes how aesthetic aspects of experience structure every aspect of our experience and understanding.

15 Jennifer Roberts, "The Taste of Time: Salt and Spiral Jetty," 97.

${ }^{16}$ Victor Turner, From Ritual To Theatre: The Human Seriousness of Play, 82.

${ }^{17}$ Between 1946-1955 Louise Bourgeois created a series of totem like structures, which she called "personages."

18 James Frazer's The Golden Bough, 399-463, deals with the evolution of the cornmother and corn-maiden and expands on the prevalence of corn mythology in primitive culture.

${ }^{19}$ Linda Hartley, Somatic Psychology Body, Mind and Meaning, 107.

20 Lepecki's analysis of dance's political ontology draws on Sloterdijk's premise that modernity's ontology is a pure being toward movement and also his proposal that modernity's project is fundamentally kinetic. Lepecki constructs an argument that acts of stillness in choreography can stand in opposition to totalitarian political systems and ideologies. Blind Torrent explores a slower ontology to enable the performers to focus on their sentient presence and develop self-agency.

${ }^{21}$ Lepecki, Exhausting Dance, 58.

${ }^{22}$ Peter Sloterdijk, in Lepecki, 7.

${ }^{23}$ Gerald Siegmund, in Lepecki, 58.

${ }^{24}$ Heddon, Autobiography and Performance, 105.

${ }^{25}$ Pearson, Site-Specific Performance, 95.

${ }^{26}$ Idem., 54.

27 Van Manen, "Eidetic Reduction: edios" Van Manen's work focused on developing phenomenology as a qualitative research method and developed research models aligned to practice as research such as textual construction with the practice of writing.

${ }^{28}$ Pearson and Shanks, Theatre/Archaeology, 55.

${ }^{29}$ Merleau- Ponty, The World of Perception, 54.

${ }^{30}$ Pearson and Shanks, Theatre/Archaeology: Disciplinary Dialogues, 139.

${ }^{31}$ Sklar, "Unearthing Kinesthesia," 38.

32 Ibid. 
${ }^{33}$ Johns in Sklar, "Unearthing Kinesthesia: Groping Among Cross-Cultural Modes of the Senses in Performance," 38-39.

${ }^{34}$ Csordas, "Somatic Modes of Attention," 138.

${ }^{35}$ Wylie, Landscape, 144. John Wylie lectures in cultural geography, in the section 'Landscape Phenomenology' he draws on Smithson's analysis of the Spiral Jetty referring to Smithson's words and the material form of Spiral Jetty as developing phenomenological approaches to understanding landscape and describes these relations as being active, embodied and dynamic.

${ }^{36}$ Tarkovsky, Sculpting in Time, 176.

${ }^{37}$ Ibid.

\section{References}

Banes, Sally and André Lepecki. "Introduction: the performance of the senses". Eds. Sally Banes and André Lepecki. The Senses in Performance. New York; Abingdon, Oxon: Routledge, 2007.

Blind Torrent (2012). Dir. Russell Frampton and Ruth Way. Plymouth, 2012. DVD.

Bourgeois, Louise. Personages Series. Carved wood. London: Tate Modern, 2007.

Chelsea Girls (1966). Dir. Andy Warhol and Paul Morrissey. Rome: Mustang/RaroVideo, 2004. DVD.

Csordas, Tom. "Somatic Modes of Attention." Cultural Anthropology 8.4 (1993): 135-

156. http://dx.doi.org/10.1525/can.1993.8.2.02a00010

Earth (1930). Dir. Alexander Dovzhenko. New York City: Kino International Corporation, 1991. DVD.

Freeman, John. Blood Sweat \& Theory. UK: Libri Publishing, 2010.

East, Alison. "Performing Body in Nature." Moving Consciously Somatic Transformations Through Dance, Yoga, and Touch. Ed. Sondra Fraleigh. Urbana, Chicago, and Springfield: University of Illinois Press, 2015. 164-179.

Fraleigh, Sondra. Dancing Identity: Metaphysics in Motion. Pittsburgh PA: University of Pittsburg Press, 2004. 
_. "Prologue on Somatic Contexts." Moving Consciously Somatic Transformations Through Dance, Yoga, and Touch. Ed. Sondra Fraleigh. Urbana, Chicago, and Springfield: University of Illinois Press, 2015. xxi-xxii.

Frazer, James. The Golden Bough. Ware, Hartfordshire: Wordsworth Editions Limited, 1993.

Garner Jr., Stanton B. Bodied Spaces: Phenomenology and Performance in Contemporary Drama, New York: Cornell University Press, 1994.

Hartley, Linda. Somatic Psychology Body, Mind and Meaning, London: Whurr, 2004.

Heddon, Deirdre. Autobiography and Performance, Basingstoke: Palgrave Macmillan, 2008.

Johnson, Mark. The Body in Mind, The Bodily Basis of Meaning, Imagination, and Reason, Chicago and London: University of Chicago Press, 1987.

Jung, Carl Gustav. The Archetypes and the Collective Unconscious, Princetown, N.J.:

Princetown University Press, 2nd ed. 1968.

Lepecki, André. Exhausting Dance, New York: Routledge, 2006.

Merleau-Ponty, Maurice. Phenomenology of Perception. Trans. Colin Smith. London and New York: Routledge, 2002.

. The World of Perception. Trans. Oliver Davis. Abingdon, Oxon: Routledge, 2004.

Pakes, Anna. "Knowing Through Dance Making." Contemporary Choreography A Critical Reader. Eds. Jo Butterworth and Liesbeth Wildschut. Abingdon, Oxon: Routledge, 2009. 10-22.

Pearson, Mike. Site-Specific Performance. Basingstoke: Palgrave Macmillan, 2010.

Pearson, Mike and Michael Shanks, Theatre/Archaeology: Disciplinary Dialogues, Abingdon, Oxon: Routledge, 2001.

Roberts, Jennifer. (2004), "The Taste of Time: Salt and Spiral Jetty," Robert Smithson. Eds. Eugenie Tsai with Cornelia Butler. Museum of Contemporary Art, Berkley: University of California Press, 2004. 97-103.

Siegmund, Gerald. "Strategies of Avoidance: Dance in the Age of the Mass Culture of the Body." Performance Research 8.2 (2003): 82 - 90.

http://dx.doi.org/10.1080/13528165.2003.10871931 
Sklar, Deidre. "Unearthing Kinesthesia: Groping Among Cross-Cultural Modes of the Senses in Performance." The Senses in Performance. Eds. Sally Banes and André Lepecki. New York and Abingdon, Oxon: Routledge, 2007. 38-46.

Tarkovsky, Andrei. Sculpting in Time. Austin: University of Texas Press, 1986.

Turner, Victor. From Ritual To Theatre: The Humans Seriousness of Play. New York: PAJ Publications, 1982.

Van Manen, Max. "The Eidetic Reduction: Edios." Phenomenology Online. Posted 2011. http://www.phenomenologyonline.com/inquiry/methodology/reductio/eideticreduction/

Wylie, John. Landscape, Abingdon, Oxon: Routledge, 2007. 


\title{
The Camera-Dancer. A Dyadic Approach to Improvisation
}

Jennifer Nikolai, Auckland University of Technology

\begin{abstract}
How can the light-weight video camera in the hands of the improvising dancer, enhance compositional choices in moment-to-moment or retrospective decisionmaking in studio? I propose that the camera in the hands of the dancer moving and passing the camera between dancing subjects/objects is a form of improvisational investigation. I refer to this dyadic approach as camera-dancer, distinct from the tradition of the camera as archival instrument, in multimedia or interactive performance. The camera-dancer as instigator/provocateur opens perspectives towards composition otherwise not considered. In this paper I highlight approaches that moving image pioneers Maya Deren and Dziga Vertov held towards the camera and how this has informed studio improvisations myself and dance collaborators apply. Perhaps it is how we as dancing operators react to moments before, discoveries in the moment, a retrospective 'camera consciousness,' that enhances compositional openings as a form of camera dramaturgy.
\end{abstract}

Keywords: provocation, improvisation, camera-dancer, camera dramaturgy, motion capture

\section{Introduction}

The advent of inexpensive digital video and post-production tools has opened an array of potential pathways for exploration in the making processes of screendance. The accessibility and ease of use of cameras can stimulate artistic approaches that harness the immediacy of the technology as a reflective and iterative tool for the dancer and choreographer. ${ }^{1}$ The historical landscape of moving image includes a vibrant narrative of dance on screen, dance film, and dance for camera, which highlight the similarities between choreographic and cinematic practices. ${ }^{2}$ As a dancer, choreographer, researcher, and dance lecturer, I am interested in the shift in compositional inquiry that emerges when video cameras are introduced into dance improvisations in the studio. 
My studio practice embraces a dyadic relationship between moving dancers with handheld cameras. ${ }^{3}$ My studio practice extends from the use of the hand-held camera to motion capture in order to interrogate dance improvisation and digital technology. I observe emergent approaches to problem-finding as dancers improvise with each other and with cameras. ${ }^{4} \mathrm{I}$ allow for playfulness in our process, informed by Dziga Vertov's dynamic and experimental use and theorizing of the camera. ${ }^{5}$ A sense of naivety is encouraged between the dancers and cameras; this naivety arises from improvising with the technology as non-trained operators. Such dilettante-like treatment of the handheld recorders by dancers resembles Maya Deren's application of the amateur as a user of handheld cameras in her works. ${ }^{6}$ The playfulness and the naivety applied within my studio processes are grounded by Deren's essay, "Amateur versus Professional," and Vertov's notion of the kino-eye, which celebrates how the film camera surpasses the capabilities of the human eye. These filmmakers/theorists motivate the choreographic experimentation that has and continues to inform my practice. ${ }^{7}$ This article contextualizes theories on the moving camera that support the practice and position I present. Combining moving image history and theory alongside a discussion of my studio practice I propose that the camera in the hands of the improvising dancer is supported by a lineage of moving-image pioneers. I discuss my approach to working with hand-held cameras and motion capture technology, and turn to dramaturgical inquiry in order to catalyze the dyadic possibilities when camera and dancer meet.

\section{Movement and time, tracing dance and the camera}

For Henri Bergson, movement in time is distinct from the space that it occupies. Space covered is past, while movement is the present act of covering. ${ }^{8}$ Bergson's thesis on movement instants or positions, which he expounds in his book Creative Evolution, distinguishes between the dissolution of the pose (ancient movement), versus movement-as-flux (modern movement). ${ }^{9}$ Bergson attributes the position or pose to space, and the "whole that changes," to time. ${ }^{10}$ I propose that moving image dance can be considered an activity of transformation from the pose towards an uninterrupted flow as flux. In the text Dancefilm Erin Brannigan synthesizes the emergence of cinema and modern dance in motion pictures, in relation to Bergson's theories on movement.

Developments in turn-of-the-century technologies for film in 1895, as well as shifts in the practice of American modern dance, occurred concurrently with Bergson's development of theories on movement. ${ }^{11}$ As Eadweard Muybridge and Étienne-Jules Marey were first experimenting with motion studies, the fascination with how still frames could become moving images shifted technologies in the field and led to the emergence of cinema and motion capture (mocap) technologies. In early explorations of motion on camera, the subjects included animals, athletes, and dancers. In his early 
experiments in the 1890s-1900s, Thomas Edison used dancers to test his equipment. Likewise, Georges Méliès used dance pieces in his film sequences. As Douglas Rosenberg has observed, "Technologies of the moving image as developed in the early 1900 s enabled artists to explore multiple frames of reference and take advantage of the fluidity of cinematic time." ${ }^{12}$ With the conception of modern dance (less so than with traditional styles such as ballet), an emphasis on fluid movement qualities inspired changes to the photographic reproduction of dance. ${ }^{13}$ The two most prominent modern dance pioneers in this regard were Isadora Duncan and Loïe Fuller, who contributed to "popular entertainment technologies [producing] a 'moving image' that calls for a rechoreographing of the history of the moving image." ${ }^{\prime 14}$ Fuller utilized then-contemporary technology of motion picture and lighting implements, and her movement vocabulary and quality were ones of "flow" and of "flux" as opposed to poses and gestures. ${ }^{15}$ The combination of Fuller's use of popular entertainment technologies and her continuous movement quality produced a "moving image" that advanced the capture of movement in cinema.

As recording technologies developed and film became a dominant form of popular entertainment, Hollywood absorbed dance practices from vaudeville. Having begun his career on the vaudeville stage, Fred Astaire duplicated this perspective in his films, creating a cinematic experience that paralleled the proscenium experience for stage audiences. He insisted on full framing of the dancer's movements with no cutting away from the body. In contrast, Gene Kelly initiated an approach to camera work that favored the dancer while utilizing cinematic devices, including slow motion and the use of multiple perspectives, to enhance the gestures and drama that were being played out. ${ }^{16}$ The commercial interests of Hollywood filmmakers were orientated towards sound as opposed to modern dance and experimental approaches, such as those of Maya Deren who operated in the avant-garde space outside of American cinema. Deren contributed to a cinema that characterizes the instrument, the camera. ${ }^{17}$ Dance has informed cinematic practices with considerations of time, space, and form, just as the camera apparatus pushed the boundaries of what was recorded. It is no coincidence that the history of the moving image and the history of modern dance collide and align.

\section{Pioneers Deren and Vertov: their philosophies towards the camera}

In their respective practices, Maya Deren and Dziga Vertov exemplified philosophies towards the camera I have applied to develop the camera-dancer. Both pioneers were experimental in their own practice and wrote of the possibilities inherent in the use of mobile cameras. They were similarly intrigued by the potential of the untethered moving camera in terms of how it could, through its mechanics, see and record the kinetic vibrancy of the world in ways that were not possible with the human eye. Vertov, in particular, was invested in the notion of a camera that could capture the 
'unawares' of daily life. His concept of the kino-eye is understood as "that which the eye doesn't see." ${ }^{18}$ One characteristic of Vertov's kino-eye was to avoid "filming 'unawares' for its own sake, but to show people without masks, without makeup; to catch them with the camera's eye in a moment of nonacting. To read their thoughts, laid bare by kino-eye." ${ }^{19}$

Deren argued for the value of a camera held by the amateur. ${ }^{20}$ Her 1959 essay "Amateur versus Professional" provides a point of reference for the role of the camera alongside the "mobile body" and "imaginative mind" of the dancer:

Cameras do not make films; filmmakers make films. Improve your films not by adding more equipment and personnel but by using what you have to its fullest capacity. The most important part of your equipment is yourself: your mobile body, your imaginative mind, and your freedom to use both. Make sure that you do use them. ${ }^{21}$

Deren's writing emphasized the experimental, amateur filmmaker, and the use of the camera to enhance cinematic potential, even to enhance dance. Although Deren did not always place the camera in the hands of the dancers she collaborated with, her camera work has been cited as an innovating art form, and is referred to as 'choreocinema. ${ }^{22}$ Rosenberg echoes Deren's sentiment in his call for a camera that "catalyzes a reverence for the dance and focuses the act of seeing in a way that is quite different than the perceptual act that one might practice as a matter of habit." ${ }^{23}$ He refers to "camera-looking" as "an active performance that frames an event and elevates it while 'screening out' all other information." ${ }^{24}$ Dancers holding cameras while moving can choose to look at what they are shooting as they are shooting, or, alternately, footage can be viewed later. Either approach provides opportunities for immediate or retrospective viewpoints on improvised choices - on movement within the frame. Deren's sentiment and Rosenberg's suggestions lean towards the purposeful act of camera-looking. ${ }^{25}$ The camera operator dancing with the dancer(s) in the frame "is an act of reverence for that which is framed" choosing "essential and non-essential" therefore "presupposes the editing process." 26 The intimate relationship between capturing in the space, within the frame, parallels the camera to the prosthetic, a "vision-prosthetic." ${ }^{27}$

Vertov made films during the early Soviet silent era, which is known for its application of montage techniques and graphic camera framing. ${ }^{28}$ As Steve Dixon observes, in Vertov's film Man with a Movie Camera (1929), "the camera is mounted in unusual and often extreme high angles and on moving automobiles." ${ }^{29}$ In one of the film's final sequences, Vertov shows the camera sitting on its tripod without a camera operator. It moves with a stilted walk, no joints in the lower limbs, implying it has done its job for the day. This anthropomorphic construction is a playful metaphor. In the film the human eye is repeatedly superimposed on the camera lens. "The film ends as it begins 
- with the camera - but the final point of view is attributed to the human eye, which continues to stare at the viewer, even after the iris completes its contraction." ${ }^{30}$ Vertov's camera implies a camera with a character, with enhanced capabilities. ${ }^{31}$ The appeal of Vertov's camera-consciousness is that he did not use hidden camera photography, "but makes a clear distinction between filming people off-guard and filming them with a hidden camera." ${ }^{32}$

The mobile camera gives us camera moves and camera angles - rhythm within the frame in the first instance. Deleuze writes that the moving camera is to be used only when it is essential to track, pan, and dolly in order to inform the work or image being seen. ${ }^{33}$ His notions of time go beyond the fascination of the composition within a fixed frame or a locked-off camera. Qualities of the moving camera reveal abstractions in movement. Deleuze's perspective on the mobile camera is that it does not just describe space through events, but also opens perception. For Deleuze, movement lives in montage. There is montage within the frame, across the shot, and in the linking of shots as the expression of unity in multiplicity throughout the system of the film. According to Deleuze:

In Vertov the interval of movement is perception, the glance, the eye. But the eye is not the too-immobile human eye; it is the eye of the camera, that is the eye in matter, a perception such as it is in matter, as it extends from a point where an action begins to the limit of the reaction, as it fills the interval between the two, crossing the universe and beating in time to its intervals. ${ }^{34}$

In human perception of matter, the interval is a delay between an action and a reaction that measures the infinite potentials and unforseeability of the reaction. ${ }^{35}$ In Vertov's montage theory, the interval no longer simply marks the distance between two consecutive images. The kino-eye is an objective perception, that which "couples together any point whatsoever of the universe in any temporal order whatsoever." ${ }^{36}$ Vertov's theory that intervals align any two points in the universe whatsoever became a point of departure for my improvisation approaches with hand-held cameras. I simultaneously identified parallels in digital capture, coupling together any points whatsoever through marker-based motion capture.

\section{Contextualizing the camera-dancer process}

I started the creation process for the camera-dancer in 2007 by using handheld (Flip) cameras as a pedagogical tool for tertiary dance students in composition studio classes. In 2009, I participated in Deakin Motion.Lab, a motion capture boot camp at Deakin University in Melbourne. The work at Deakin helped me to develop research into capturing digital movement data to use in non-digital settings (i.e. improvisations in the studio). I integrated into my practice a number of concepts embedded in 
motion capture technology. Firstly, the concept of the Omniscient Frame stems from the lack of a proscenium-like orientation to the subject, as the array of cameras within the capture volume are not fixed and not determined by shot type. ${ }^{37}$ Secondly, one can attach a virtual camera to any still object or moving object marker inside the capture volume area. This can enable the tethered camera to move with and as a response to the moving body. A camera can be 'virtually' mounted anywhere on the moving body or within the capture space during post-production. To do so, the motion that has been embedded as motion capture data in 3D virtual space-a virtual camera-generates a dancer inside the screendance itself.

\section{Tethered cameras}

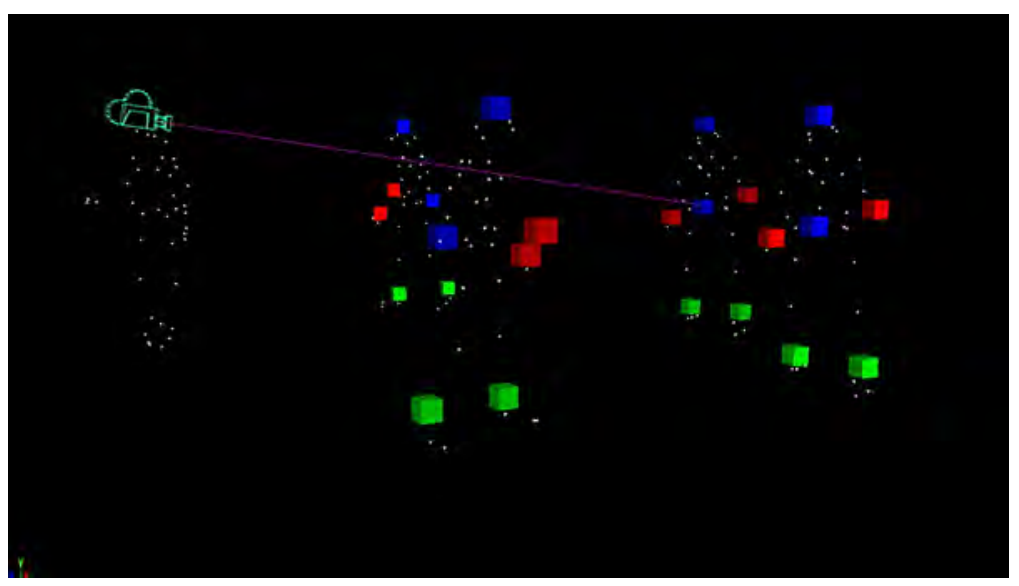

Motion Capture visualization; camera tethered to Dancer 1 head marker.

During my creative process, a key question that emerged was: how might an accessible video camera placed in the hands of, or tethered to, the body of the dancer, motivate dancers' movements, based on such variables as the moving dancers' point of view (POV), camera placement (held by the dancer or shooting the dancer), or what the dancer encounters in the frame (the viewfinder)?

Months later in a studio workshop with six dancers and four video cameras, we set provocations for improvisations. We used a green Thera-band ${ }^{38}$ to tie two cameras together, and we set a task for the two cameras (bound together) to be passed between two operators. The dancers being shot would later shoot. This gave the dancers the opportunity to improvise for and with the cameras, and established conditions for what would become a task we called Bound Together. 


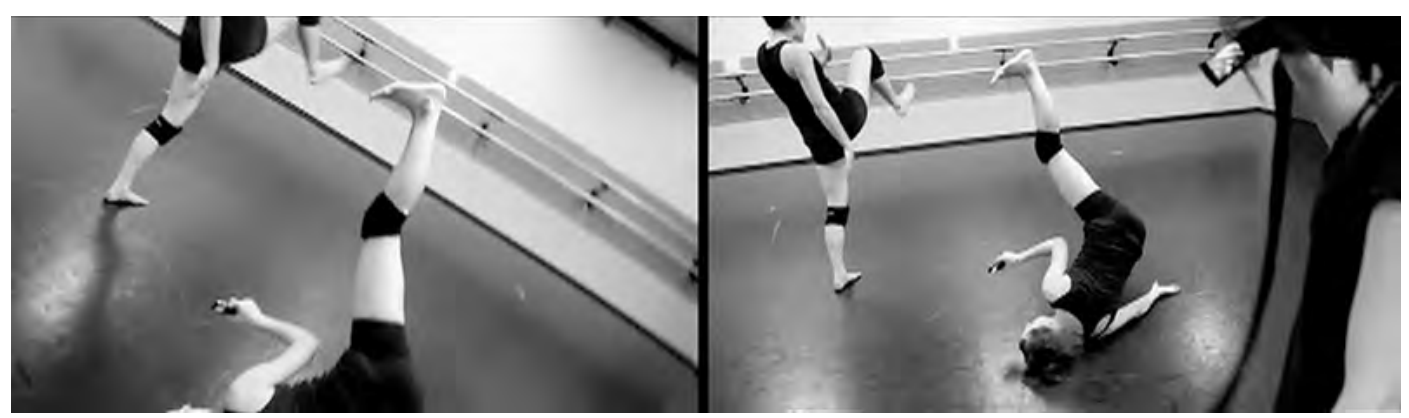

Dancers Xinia Alderson, Jane Carter and Aya Nakamura studio footage; Thera-band bound to two Flip cameras connecting two dancers holding tethered cameras.

In Bound Together, two dancers, holding cameras restricted by the band that attached them, moved in tandem. The pair had the freedom to travel amongst the other dancers (who were not operating cameras). The attached, resistant fabric simultaneously restricted and subtly directed their choices. The tension was not only between the cameras bound by resistant fabric, but also the potentially conflicting pathways the dancing operators wished to travel in. ${ }^{39}$

The forced relationship between cameras and dancers afforded multiple perspectives, and restricted movement pathways and dynamics between the improvising dancers. The camera-operators bound together offered a compositional vantage point. They could dance and see through their eyes, through their own viewfinder, or through the other operator's viewfinder.

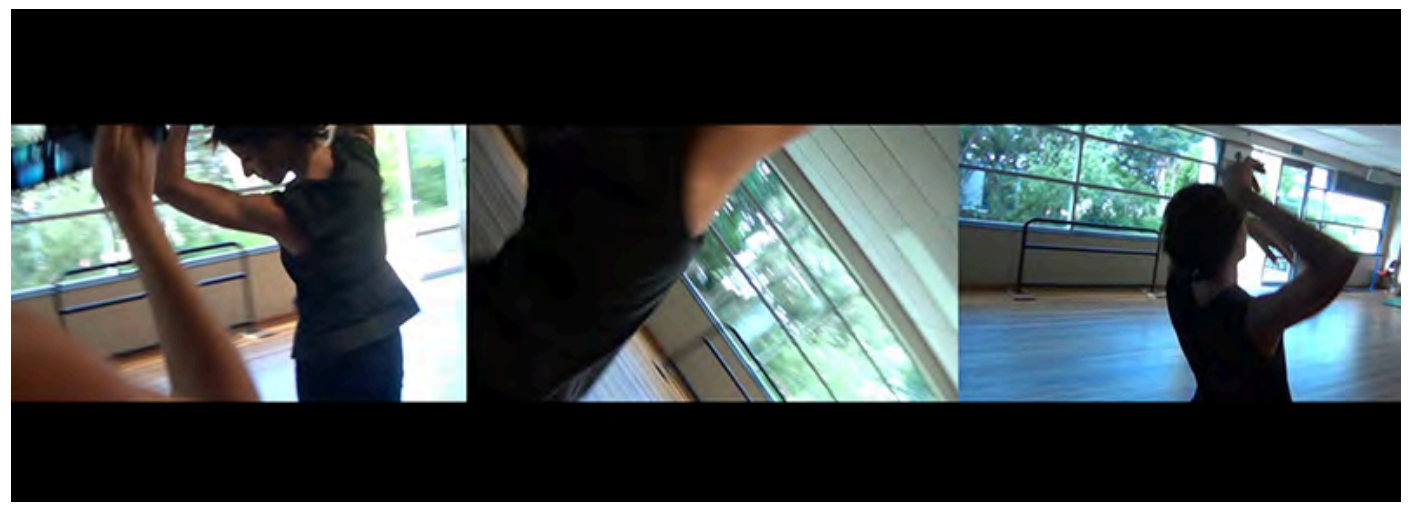

Dancer Jennifer Nikolai; captured by three untethered handheld cameras in a studio improvisation.

The camera-dancer became an observer, a participant, a partner, and an instigator, distinct from the conventional camera as archival machine in performance and rehearsal. The role of the camera-dancer shifts the dynamic between camera and mover in multiple ways. It asks a camera-dancer to be dramaturgical, in that it uses moving image capture (of moment-to-moment decisions) to inform or respond to improvisational decision-making. In an improvisation, the dancer can make an immediate decision to align an action experienced live with an action captured on 
camera (seen through the viewfinder), in order to deliberately frame a moment or movement. When retrospectively reviewing footage of an improvisation, dancers may find connections or contrasts between two seemingly distant moments. Improvisers can parallel or juxtapose movement quality, spacing, or timing, or align to what they think the operators might shoot in the improvisation. In looking at the footage retrospectively, two seemingly distal or proximal images can inform a specific choice for the next improvisation. This option to look through the viewfinder is significant as a tool while improvising with a capture apparatus, because it encourages immediacy and supports reflection.

The camera offers perspectives as it pans, zooms, frames, and reveals openings for the improviser to work with. As cameras are passed between operators, movers without cameras cannot entirely anticipate what will be shot within the improvisation. The improvisers holding cameras therefore respond to one another's compositional choices such as depth of field, POV, or framing. ${ }^{40}$ The dyadic relationship between the dancing and operating opens emergent compositional opportunities to dancers and camera-dancers, otherwise not apparent.

\section{Dramaturgical intentions in camera perspectives and structuring}

Choreographic processes using moving image do not always begin with a predetermined structure, but rather, structures emerge in concert with the shaping of ideas. ${ }^{41}$ Through dramaturgical approaches that involve trial and error, collaboration and shared facilitation, a decentering of established hierarchies in the roles of production takes place. ${ }^{42}$ My approach to dramaturgy as a form of live and digital dialog occurs within improvisation as integrative and emergent. It involves an interactive expansion of shared processes. It opens awareness to possibilities and trajectories revealed by shared forms (live and digital). I refer to dramaturgy as sensitive to the dynamics that emerge within the creative process through experimentation. The integrative character of my practice blends theoretical with physical exploration from a range of sources and perspectives that in a cumulative decision-making process create emergent trajectories. The interactive element of my practice involves the physical, intellectual, and imaginative engagement of makers throughout the process, who in turn transform physical and conceptual ideas into material. ${ }^{43}$ These characteristics guide dramaturgical intention towards improvisational inquiry with cameras.

While improvising as a camera-dancer propositions that emerge become themes, possibilities, juxtapositions, and trajectories for further provocations. The term 'provocation' in this context is taken from Edward De Bono's methods of lateral thinking adapted to re-arrange information (e.g. camera-dancer improvised material), in order to "bring new features into existence" in an emergent process. ${ }^{44}$ Provocations led by the camera-dancer dyad emerge through the improvisations, and through 
viewing footage in real-time or retrospectively. All the unknown spaces, the gaps in between dancing and looking or not looking, close-up or wide-shot, but holding and negotiating between camera and mover, these are the moments of provocation. Moments may be small, subtle, and unpredictable. Provocations lead us to "where to next?" when investigating compositional and dramaturgical possibilities.

Hilary Preston proposes that we expand choreographic potential to include the elements of camera operation and composition. ${ }^{45} \mathrm{Her}$ thinking has been a catalyst for my practice and experimentation of parallel compositional principles with a dramaturgical approach. Preston suggests that choreography and camera work are symbiotic. ${ }^{46}$ The choices that are available to the moving camera operator to question POV, angles, and camera movement, allow him/her to manipulate spatial relationships within and outside of the frame, further informing decision-making while improvising. With a camera in hand, the dancer can shape with or around bodies in space, in order to consider how the role of the frame helps to develop dance 'looking' and camera composition. Further,

the unique relationship that is created between the dancer and his or her environment by the single viewpoint of the film camera can enable this spatial precision to be substantially developed - either through the interpretation of existing choreography by careful camera positioning, aspect ratio and filming site selection or, more excitingly, through the creation of choreography specifically designed to exploit the film medium in this way. ${ }^{47}$

A key advantage offered by the Flip cameras for camera-dancers was that the open viewfinder/screen enabled the dancer to refer to the frame or to disregard it while improvising. Wide, medium, and close-up framing allowed for selection or delegation of what existed within or outside of the frame. Brannigan situates the close-up as being significant in the history of dancefilm, as it has provided a "new cinechoreographic terrain." ${ }^{48}$ In focusing on body parts, body gestures, or facial expressions, dancefilm has the capacity to investigate micro-choreographies on screen. ${ }^{49}$ Rosenberg discusses how: "A gesture that on stage may seem small and insignificant may become, when viewed through the lens, grand and poetic, while the dancer's breath and footfalls may become a focal point of the work." ${ }^{50}$ These nuances are experienced by the dancer in the intimate, shared space of the improvisation. The close-up allows the fellow improviser as well as spectators to engage with microchoreography, and invites a focused respect for the micro-the nuance, the slow breath-unheard, to be seen. 


\section{Framings and re-framings: Deleuze and the mobile camera}

Deleuze attributes the subjective camera to those camera actions that enhance more than just the act of following a character's movements (description of space) subordinated to the function of thought. The subjective camera in this instance allows the camera to engage with the indiscernible, in its array of functions, moving towards camera-consciousness.

a camera-consciousness, which would no longer be defined by the movements it is able to follow or make, but by the mental connections it is able to enter into. And it becomes questioning, responding, objecting, provoking, theorematising, hypothesising, experimenting, in accordance with the open list of logical conjunctions ('or', 'therefore', 'if', 'because', 'actually', 'although'). ${ }^{51}$

According to Daniel Frampton, Deleuze recognizes Alfred Hitchcock as introducing what he refers to as the mental image into cinema. This is where the film image "is able to catch the mechanisms of thought, while the camera takes on various functions strictly comparable to propositional functions. ${ }^{152}$ Can the camera-dancer therefore be advantaged by pushing the mobility of the camera,"hypothesizing" while moving as/with the subjective camera? ${ }^{53}$ This camera-consciousness is not solely held by the apparatus, or the performing body - it is in the space, indiscernible, subjective, between and amidst. The perception of space and of space moving, as chosen by the camera-dancer, opens possibilities for improvisational approaches responding to space, between and amidst. Deleuze also proposes that

the fixity of the camera does not represent the only alternative to movement. Even when it is mobile, the camera is no longer content sometimes to follow the characters' movement, sometimes itself to undertake movements of which they are merely the object, but in every case it subordinates description of a space to the functions of thought. ${ }^{54}$

Deleuze's reference to the "fixity of the camera" is not simply a distinction between a subjective and objective camera; rather, he points to the indiscernibility between the subjective and objective, which"endow the camera with a rich array of functions," and in this regard, provide "a new conception of the frame and reframings." ${ }^{55}$ This speaks to the interchange between subjective and objective perspectives proposed by the camera-dancer.

\section{What next? The camera/dancer dyad in practice}

Maya Deren described "the incalculable and uncategorised kinds of movements possible with the handheld camera in direct relationship to the body. ${ }^{\prime \prime 6}$ In her work 
and writings, she recognized that the camera can be utilized as a creative instrument in the process of making:

to think of the mechanism of the cinema as an extension of human faculties is to deny the advantage of the machine. The entire excitement of working with a machine as a creative instrument rests, on the contrary, in the recognition of its capacity for a qualitatively different dimension of projection. $^{57}$

Deren describes her model of cinema as a vertical structure as opposed to a horizontal structure. ${ }^{58}$ Verticality lends itself to a more poetic structure, whereas the horizontal is associated with drama, moving action, and circumstance, one into the other. In an improvisational provocation with a handheld camera, the camera's relationship to the body in space, with multiple and diverse perspectives, allows the viewer to empathize without narrative structure.

Such an approach to constructing empathy appears in Hilary Harris's film Nine Variations on a Dance Theme (1966). The dance phrase, which Bettie de Jong performs repeatedly, recalls Talley Beatty's movement in Deren's A Study In Choreography For Camera (1945). A main focus of Nine Variations is the role of the camera in shaping the space of the dancer. When the film begins, De Jong is seen dancing from a distance; by the end of the film, we have travelled through mid-shots to extreme close-ups from multiple angles. Further, as the film progresses, a shift occurs; the camera starts to move in opposition to the dancer as her movement phrase rotates in place. De Jong executes a long, languid movement phrase commencing from the floor, spiraling in a controlled sequence to a standing extension. Then, she returns to the floor to finish in the same position she began in. The phrase is looped nine times, and the movement remains consistent. It is movement of the camera that is used to construct nine variations of the phrase by never repeating its position or spatial pathways. In this film, the compositional considerations are in the hands of the mobile camera operator. I suggest that as a viewer I become increasingly empathetic by experiencing poetic variations, abstractions not otherwise possible through live performance or a proscenium documentation of the recorded phrase. The initial real-time pace of the shots reveals the full dance phrase, her movement quality, and her relationship to the studio space. The edited sequence, varied, later accelerates, punctuating segments of De Jong's body in motion. With fast cuts and framed fragments of the dancing body natural light in the studio illuminates parts of her torso. We still recognize her, her qualities and experience a shift in tone as we retain the vision of the full movement phrase. A Deleuzian perception of space moving is not determined by the dancer holding the camera here, but by the camera that dances amidst her. So in this instance, the piece presents the leading possibility of what a dancing operator could offer if the framed phrases were formed by the mover. The spatial and temporal 
variations open the viewer to kinesthetic empathy as if we move alongside and sense that space and light and textures, with De Jong. ${ }^{59}$

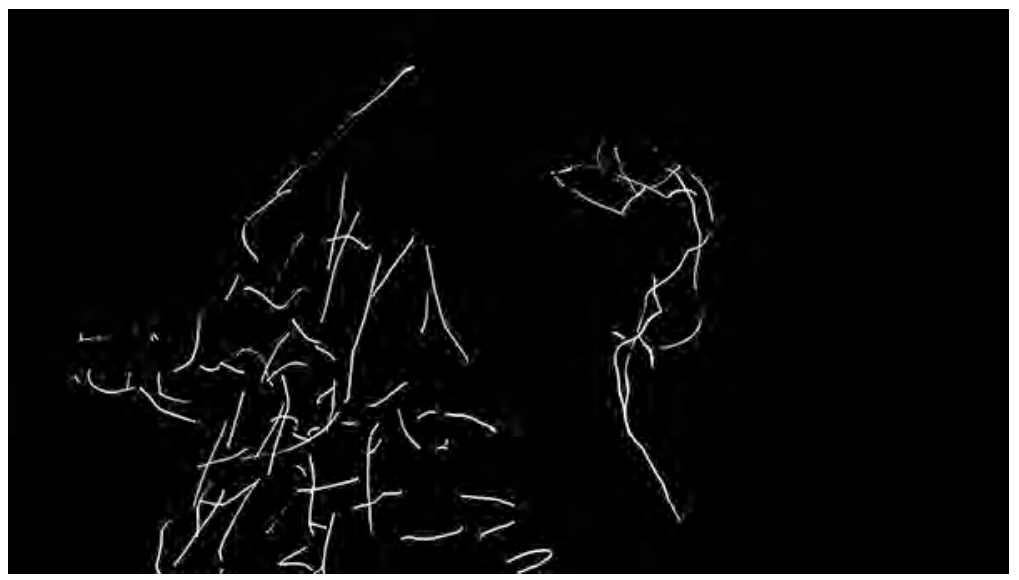

Study \#1 still with dancer Jennifer Nikolai and cloth simulation.

In my recent practice (2015), I have returned to motion capture technology and the resulting data as a form of camera dramaturgy. In studio improvisations through to post-production, an inquisitive and reflective camera-consciousness emerges from making and viewing the motion capture data. Study \#1 is a co-choreography with animation artist Gregory Bennett. The studio improvisations, as well as the data capture, visualization, and post-production decision-making processes were collaborative and iterative. ${ }^{60} \mathrm{~A}$ series of virtual cameras were created in postproduction and choreographed around the improvised performance. Each iteration occurred as trial-and-error through dialog and reflection, during which we made adjustments and choices before embarking on the next iteration. ${ }^{61}$ Our collaboration has continued with Study \#2, currently in post-production, in which we have returned to the tethered camera as a catalyst for capturing the moving body from perspectives not otherwise considered.

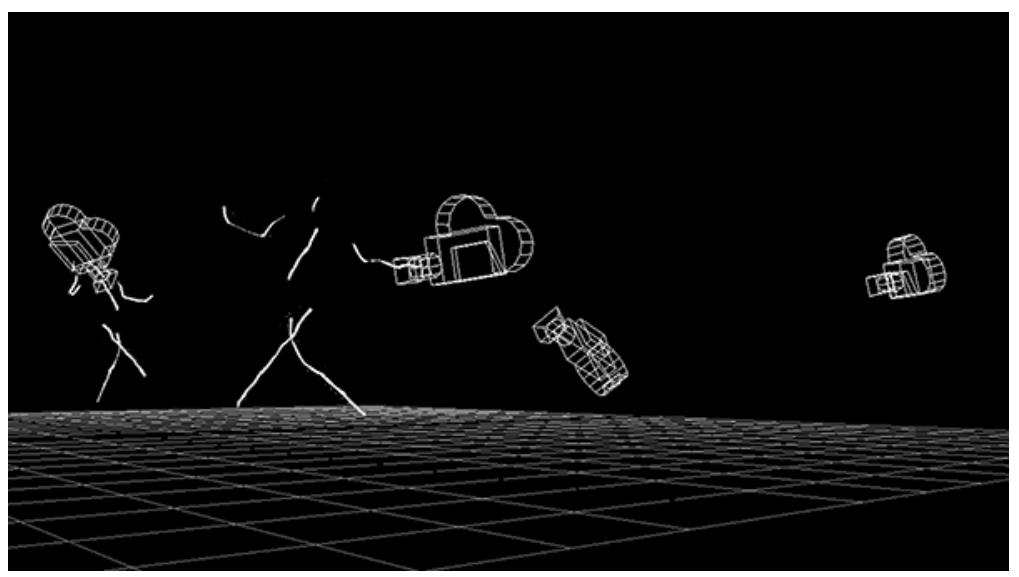

Study \#2 multiple tethered cameras to one dancer (duplicated).

In this work with Gregory, I am drawing inspiration from Deren's film The Very Eye of Night (1958). Deren's film is an example of freeing dancers from gravity via the postproduction film technique of optical printing. The process of filming with a hand-held 
camera on a dolly combined with optical printing in post-production created the effect of dancers floating like stars in space. Deren's untethered camera generated raw footage that was further manipulated in post-production and editing by combining and re-combining layers of dancers against a constellation. Her dancing subjects were superimposed on a black background so the effect of the floating dancer mirrored that of the stars within the constellation. ${ }^{62}$

There are interesting parallels between optical printing and motion capture. In both techniques, the cameras are untethered: a virtual camera can be created at any point in space and anywhere in the capture volume. The virtual camera can move at any point in that $x, y, z$ space. With motion capture data, the floor is not recorded as such. Only the movement data of the dancers is captured. In motion capture, cameras are mounted from any angle anywhere and this enables greater flexibility than in Deren's time. Thus, we have a wealth of options while still creating an illusion of moving flexibly through 3D space.

Study \#2 as an iteration from Study \#1 has similar provocations in the process of creation, capture, and post-production decisions. These options also extend to the 3D visualization of the "large" camera. The difference in Study \#2 is that the dancers' captured movement is used to directly drive the camera visualization by virtually tethering the camera to markers on the digital dancers' bodies.

The camera in Study \#2 moves through a 3D geometric map with pathways that resemble a dancer in a jump, mid-turn, or inverted - because it is a dancer with a camera visualization..$^{63}$ The camera is attached to her body. The camera in this piece, as in The Very Eye of Night, cajoles with degravitation not amidst the constellation, but amidst fellow performers. The multiplication of dancers in Study \#2 is simultaneously a post-production choice to replicate the one moving figure, caught in an improvisation. This dancer is duplicated to be tethered to herself, as well as virtual cameras tethered to her duplicated body. That moving dancer is my duplicated avatar, in my improvisation.

Dramaturgical thinking in dance, involving technologies and interactive designs from the conceptual starting point, requires a different environment for its evolution. ${ }^{64}$ In my practice, the inquisitive and interactive characteristics of camera-dancer improvisation, with dramaturgical intention opens a recurring relationship between dancers and their cameras. These are the cameras that we hold and shoot. They improvise with us as subjects and objects. Taken to motion capture, these cameras enable myriad possibilities between dancer and camera, and facilitate an iterative, generative process of inquiry. 


\section{Biography}

Jennifer Nikolai (PhD) is a contemporary dance practitioner, researcher, and Senior Lecturer. Her studio-based, emergent methodology informs live and digital interactivity in performance making and staging. Her research spans mobile camera improvisation, motion capture and VR and the practice of pedagogical critique across a range of tertiary teaching contexts. She conducts research in Canada and New Zealand, her country of origin and her country of residence, respectfully. Jennifer lectures and supervises postgraduate research students in the School of Sport and Recreation and in the School of Art and Design at Auckland University of Technology in Auckland, New Zealand.

Email:jnikolai@aut.ac.nz

\section{Notes}

${ }^{1}$ Approaches to using the camera as a pedagogical tool are discussed further in a paper presented to the International Conference on Dance Education. See: Jennifer Nikolai, "Camera Dramaturgy," forthcoming.

${ }^{2} \mathrm{~A}$ range of discussions and critiques arose as video cameras became more accessible and affordable. Suggestions such as Douglas Rosenberg's did enlighten audiences and makers that "Since the advent of film...cinema and dance have engaged in an almost unbroken courtship, each appropriating techniques and styles from the object of affection" ("Video Space," 275). To follow were 'definitions' encompassing dance and cinema in complimentary forms, including Noël Carroll's shaping of the term "movingpicture dance" in "Toward a Definition," as well as Hillary Preston's writing on "how dance for the camera extends the conceptual boundaries of dance" in "Choreographing the frame." The response that resulted is in the form of endless interdisciplinary works and outcomes between live and digital forms. In this article, I am most interested in early experiments and their lasting impact. I have identified examples including early moving image experiments in Deren's works A Study in Choreography for Camera (1945) and The Very Eye of Night (1958) as well as Harris's Nine Variations on a Dance Theme (1966).

${ }^{3}$ The initial emphasis was placed on how to 'compose,' considering the elements and devices surrounding camera-based provocation. Initial exercises developed an awareness of trust and partnership, sharing space, traveling through space (range of levels, dynamics, pathways) and sharing focus while holding the camera and dancing with 'other' dancers and cameras. I also proposed exercises that questioned the notion 
of clock time (stillness and temporal transitions) and how holding cameras while dancing occupied 'time,' and focus.

4 Problem-finding refers to studio 'making' approaches in a process that is collaborative and emergent as in Keith Sawyer, "Improvisation and the Creative Process."

${ }^{5}$ See Annette Michelson, Kino-Eye.

${ }^{6}$ See Bruce R. McPherson, Essential Deren.

${ }^{7}$ It was within my PhD candidacy at AUT (Auckland, New Zealand) that I conducted five years of work-shopping dancers with handheld cameras.

${ }^{8}$ Gilles Deleuze, Cinema 1, 1.

${ }^{9}$ A concept articulated through Deleuze in Cinema 1, and in Brannigan, Dancefilm, 22.

${ }^{10}$ The whole that changes in Deleuze's time-image is developed and contextualized alongside Deleuze's movement-image, within Cinema 2.

${ }^{11}$ As outlined in Deirdre Towers' description of the gap in moving image technology and dancing subjects in "Inventions and Conventions."

${ }^{12}$ Rosenberg, Screendance, 58.

${ }^{13}$ See Erin Brannigan's recapitulation of American dance historian Nancy Lee Chalfa Ruyter's identification of the shift in physical culture from a private and amateur activity, to movement as choreographic, outside of the institution of ballet (and the pose). Dancefilm, 22.

${ }^{14}$ See Brannigan, 22.

${ }^{15}$ Idem., 38. Brannigan develops a detailed description, and suggests that Fuller's dance was composed of her moving arms, with a circle of silk panels from her neck to her arms, to create flow in her dance through the fabric. This material (silk panels) surrounded the dancer, creating fluid movement in constant transformation. The transformative, moving fabric was coupled with multiple colored lighting effects to create a magical, theatrical dance spectacle captured by motion picture, distributed by Edison Manufacturing Company in 1895. The kinetic range in these large, upper body movements exemplifies the abstract, continuous flow and enlarged gestures, in contrast, for example, to balletic gestures repeated as traditional in origin and recognizable to dance audiences.

${ }^{16}$ See for example the slow motion dream sequence in Carefree (1933), the dancing shadows in Swing Time (1936), and the mobile camera and a range of camera angles in Singin' in the Rain (1952). Beth Genné, "Dancin' in the Rain," 73.

${ }^{17}$ Brannigan, 103.

${ }^{18}$ Michelson, 41.

${ }^{19}$ Idem., 132.

${ }^{20}$ Maya Deren worked with minimal resources when she began filmmaking and she continued to ask questions of the camera that pushed her practice.

${ }^{21}$ Katrina McPherson, Making Video Dance, 18.

${ }^{22}$ Sherril Dodds, Dance on Screen, 7.

${ }^{23}$ Rosenberg, Screendance, 69.

${ }^{24}$ Rosenberg, "Proposing a Theory of Screendance," 14. 
${ }^{25}$ Rosenberg, Screendance, 69.

${ }^{26}$ Ibid.

${ }^{27}$ Ibid.

${ }^{28}$ See Deleuze, Cinema 1, 33 - 42, chapter section on "The Soviet school."

${ }^{29}$ Steve Dixon, Digital Performance, 66.

${ }^{30}$ Vlada Petric, Constructivism in Film, 127. Although this and other films are located within historical, Soviet political objectives, I refer to Dziga Vertov as an influential practitioner and writer, on his "kino-eye," the eye of the camera that accentuated the capabilities of the camera improving on the human eye's perceptive capabilities.

${ }^{31}$ Vertov operated with an enthusiasm for the playfulness of the motion picture camera and its capacity to inform and augment as it played, coerced, and cajoled with the games and industry of everyday spectators and participants.

32 Jeremy Hicks, Dziga Vertov: Defining Documentary Film, 24.

${ }^{33}$ Deleuze, Cinema 1, 25-26.

${ }^{34}$ Idem., 41.

${ }^{35}$ D. N. Rodowick, Gilles Deleuze's Time Machine, 60.

${ }^{36}$ Vertov, "Articles, journaux, projets de Dziga Vertov," 126-127.

${ }^{37}$ See Matt Delbridge, Motion Capture in Performance.

${ }^{38}$ A Thera-band is an elastic fabric often used for rehabilitation or strength and conditioning purposes for dancers. The color of the band determines the factor of resistance. A green Thera-band provides minimal but ample resistance and is strong enough not to break easily.

${ }^{39}$ Partnered cameras shot either a different perspective of the dancers in the space, or a slight variation of the image recorded by the camera hovering nearby. The resulting footage therefore revealed both massive variations on the dance material shot in the space, or the slight variations of the non-operating dancers and the other dancing operator, attached.

${ }^{40}$ These three examples are compositional offerings a camera has to offer to a dancer, which parallel the choreographic compositional considerations implicit in the dancer's body practice, also offered through her training and her relationship to space.

${ }^{41}$ See Synne Behrndt, "Dance, Dramaturgy and Dramaturgical Thinking."

42 Jean-Marc Adolphe, "Dramaturgy of Movement," 27.

${ }^{43}$ See David Williams, "Geographies of requiredness."

${ }^{44}$ Ed Hagood, Legacy in Dance Education, 203.

${ }^{45}$ Preston, Choreographing the frame.

${ }^{46} \mathrm{Ibid}$., 75.

${ }^{47}$ Billy Cowie, "Framing the Body," 38.

${ }^{48}$ Brannigan, 39.

${ }^{49}$ Idem., 45-46.

${ }^{50}$ Rosenberg, "Video Space," 277.

${ }^{51}$ Deleuze, Cinema 2, 23.

${ }^{52}$ Daniel Frampton, Filmosophy, 63. 
${ }^{53}$ Refers to Frampton's writing on Hitchcock's camera-consciousness combined with my links to Deleuze (Cinema 2, 23) and the potential in the camera-dancer.

${ }^{54}$ Deleuze, Cinema 2, 23.

55 Ibid.

${ }^{56}$ Amy Greenfield, "The Kinesthetics of Avant-Garde Dance Film," 26.

${ }^{57}$ McPherson, Essential Deren, 25.

${ }^{58}$ Brannigan, 104-105.

${ }^{59}$ Kinesthetic empathy in this context refers to Karen Wood's loose definition of the term as the sensation for the screendance viewer, of moving while viewing. See Wood, "Audience as Community," 29.

60 Study \#1 is a dance and motion capture collaboration by Gregory Bennett and Jennifer Nikolai. The piece explores choreographic prompts and improvisation utilizing 3D digital motion capture technology. The live dancer is inscribed into a 3D visualization, which references both drawing practices such as the sketch, and experimental animation, particularly Len Lye and Norman McLaren and their studies in moving image and sound. Iterations from studio generated material were taken to post-production. The sequencing of outcomes in post-production determined what prompts we then took back to studio. As an iterative process, this sequencing determined in the final stage, when we would set our decisions, towards reaching our final outcome; a screendance piece.

${ }^{61}$ Study \#1 trailer: https://vimeo.com/133319833. Study \# 1 has been screened in the International Screendance Festival 2015 (North Carolina), the Edmonton International Film Festival 2015 (Edmonton, Canada), the Tempo Dance Festival 2015 (Auckland, NZ) and in the Dance on Camera Festival (New York) 2016.

${ }^{62}$ See OK Hee Jong, Reflections.

${ }^{63}$ Study \#2 test: https://vimeo.com/157387789, password: dance

${ }^{64}$ Johannes Birringer, "Dance and Interactivity," 89.

\section{References}

"A Study in Choreography for Camera." Maya Deren. 3 min. USA, 1945.

Adolphe, Jean-Marc. “Dramaturgy of movement" Ballet International 6 (1998): 29-27.

Behrndt, Synne K. "Dance, Dramaturgy and Dramaturgical Thinking." Contemporary Theatre Review 20.2 (2010): 185-196. http://dx.doi.org/10.1080/10486801003682393

Bergson, Henri. Creative Evolution. Translated by Arthur Mitchell. Westport, Connecticut: Greenwood Press, Publishers, 1944. 
Birringer, Johannes. "Dance and Interactivity." Dance Research Journal 35.2-36.1 (2004): 88-111.

Brannigan, Erin. Dancefilm; Choreography and the Moving Image. New York: Oxford University Press, 2011. http://dx.doi.org/10.1093/acprof:oso/9780195367232.001.0001

Carroll, Noël. "Toward a Definition of Moving-Picture Dance." Dance Research Journal 33.1 (Summer 2001): 46 - 61. http://dx.doi.org/10.2307/1478856

Cowie, Billy. "Framing the Body." Paper read at Screendance: The State of the Art at Duke University, Durham, NC. 2006.

Delbridge, Matt. Motion Capture in Performance: An Introduction. Basingstoke, Hampshire: Palgrave Pivot, 2015. http://dx.doi.org/10.1057/9781137505811

Deleuze, Gilles. 1986. Cinema 1: The Movement-Image. Translated by Hugh Tomlinson and Barbara Habberjam. London, New York: The Athlone Press. Original edition, 1983.

. Cinema 2: The Time-Image. Minnesota: University of Minnesota Press, 1989.

Dixon, Steve. Digital Performance: A History of New Media in Theatre, Dance Performance Art and Installation. Cambridge: The MIT Press, 2007.

Dodds, Sherril. Dance on Screen; Genres and Media from Hollywood to Experimental Art. Hampshire, New York: Palgrave MacMillan, 2004.

Frampton, Daniel. Filmosophy. London \& New York: Wallflower Press, 2006.

Genné, Beth. "Dancin' in the Rain: Gene Kelly's Musical Films." In Envisaging Dance on Film and Video. Edited by Judy Mitoma. New York and London: Routledge, 2002. 71-77.

Greenfield, Amy. 2002. "The Kinesthetics of Avant-Garde Dance Film: Deren and Harris." In Envisaging Dance on Film and Video. Edited by Judy Mitoma. New York and London: Routledge, 2002. 21-26.

Hagood, Ed Thomas K., ed. Legacy in Dance Education; Essays and Interviews on Values, Practices, and People. Amherst, New York USA: Cambria Press, 2008.

Hee Jong, OK. "Reflections on Maya Deren's Forgotten Film, The Very Eye of Night." Dance Chronicle. 32.3 (2009): 412-441. http://dx.doi.org/10.1080/01472520903276750

Hicks, Jeremy. Dziga Vertov: Defining Documentary Film. London, New York: I.B. Taurus \& Co Ltd, 2007.

McCarren, Felicia. Dancing Machines: Choreographies of the Age of Mechanical Reproduction. Stanford, California: Stanford University Press, 2003. 
McPherson, Bruce R. ed. Essential Deren; Collected Writings on Film by Maya Deren. Kingston, New York: McPherson \& Company, 2005.

McPherson, Katrina. Making Video Dance; A step-by-step guide to creating dance for the screen. London and New York: Routledge, 2006.

Michelson, Annette. Kino-Eye: The Writings of Dziga Vertov. Berkeley, Los Angeles, London: University of California Press, 1984.

Nikolai, Jennifer. The Camera-Dancer Dyad: A critical, practical dialogue of virtual and live studio methodologies. Doctoral Thesis, AUT University, Auckland, NZ. 2014.

- Camera Dramaturgy: A critical, practical dialog between dance and camera studio methodologies, International Conference on Dance Education (ICONDE). Kuala Lumpur, Malaysia 2014. Publication of the conference proceedings will be forthcoming in 2016.

Nikolai, Jennifer, and Gregory Bennett. "Stillness, Breath and the Spine - Dance Performance Enhancement Catalysed by the Interplay between 3D Motion Capture Technology in a Collaborative Improvisational Choreographic Process." Performance Enhancement \& Health 4 (2016): 55-66. http://dx.doi.org/10.1016/j.peh.2015.11.003

“Nine Variations on a Dance Theme.” Dir. Hilary Harris. 13 min. USA, 1966/67.

Petric, Vlada. Constructivism in Film: The Man with the Movie Camera: A Cinematic Analysis. Cambridge: Cambridge University Press, 1987.

Preston, Hilary. "Choreographing the frame: a critical investigation into how dance for the camera extends the conceptual and artistic boundaries of dance." Research in Dance Education 7.1 (2006): 75-87. http://dx.doi.org/10.1080/14617890600610752

Rodowick, D.N. Gilles Deleuze's Time Machine. Durham and London: Duke University Press, 2003.

Rosenberg, Douglas. "Video Space: A Site for Choreography." LEONARDO 33.4 (2000): 275-280. http://dx.doi.org/10.1162/002409400552658

. "Proposing a Theory of Screendance." Paper read at Screendance: The State of the Art at Duke University, Durham, NC, 2006.

. Screendance: Inscribing the Ephemeral Image. New York: Oxford University Press, 2012. Sawyer, Keith. "Improvisation and the Creative Process." The Journal of Aesthetics and Art Criticism 58.2 (2000): 149-161. http://dx.doi.org/10.1093/acprof:oso/9780199772612.001.0001

"The Very Eye of Night." Dir. Maya Deren. 15 min. USA, 1958. 
Towers, Deirdre. "Inventions and Conventions." Paper read at Screendance: The State of the Art at Duke University, Durham, NC, 2006.

Vertov, Dziga. Man with a Movie Camera. Blackhawk Films Collection. Image Entertainment, 1929, DVD 1998.

. Articles, journaux, projets de Dziga Vertov. Paris: Union générale d'éditions, 1972.

Williams, David. "Geographies of requiredness: Notes on the dramaturg in collaborative devising." Contemporary Theatre Review 20.2 (2010): 197-202. http://dx.doi.org/10.1080/10486801003682401

Wood, Karen. "Audience as Community: Corporeal Knowledge and Empathetic Viewing." The International Journal of Screendance 4 (2015): 29-42.

http://dx.doi.org/10.18061/ijsd.v5i0.4518 


\section{PROVOCATIONS AND VIEWPOINTS}





\section{Watch films, watch dance films, watch more dance films}

Katrina McPherson, Independent Artist, Scotland

Keywords: screendance, Internet, on-line viewing, curation, contextulization

Whatever your relationship to screendance-whether making, curating, or writing about the genre, or coming across it for the first time-accessing a wide range of work represents an essential aspect of engagement with the medium. Whereas screendance makers and audiences previously depended on relatively rare public screenings in theaters and infrequent television broadcasts, and the shipping or schlepping of VHS tapes/DVDs across continents was par for the course, nowadays the Internet provides an always-on, global site for the dissemination and discovery of screendance works.

However, knowing what exists on the Internet and how to find it presents its own challenges and so the curating and contextualization of new and historic screendance available through the Web would seem to be a useful, if not essential accompaniment to this expanded platform. With that in mind, I was pleased to be invited by the editors of this journal to take a personal 'frolic' through screendance available to view on the Internet and to write about it here.

My exploration started with where things kicked off for me 30 years ago, and that was with a film documentation of Yvonne Rainer performing her seminal postmodern work Trio A, captured in this film produced by Sally Banes in 1978. The frame remains wide throughout, showing the whole of Rainer's body as she performs the five minute long choreography for the camera on a studio stage, then certain details are repeated in closer shots, giving more information about specific phrases of movement. This single camera documentation was pretty much the only piece of filmed postmodern-or indeed modern-dance available on VHS in the library at Laban when I was a student there in the mid-1980s. I viewed it again and again in those days, intrigued and inspired by the simplicity of the image and the non-virtuosic concept behind Rainer's dead-pan performance.

When I search for the Trio $A$ film online today, I find it and also a new discovery from a decade before, which is Yvonne Rainer's short Hand Movie (1966). This was the first film that Rainer herself made, the result of being immobilized in a hospital after major surgery. Here the camera takes the role of a neutral witness, a single shot framing

The International Journal of Screendance 6 (2016). 
Rainer's hand as it bends and points and smooths in a series of uninflected everyday gestures, resonant of the whole body movement sequences of her better known stage work and echoed here in this simple filmic treatment.

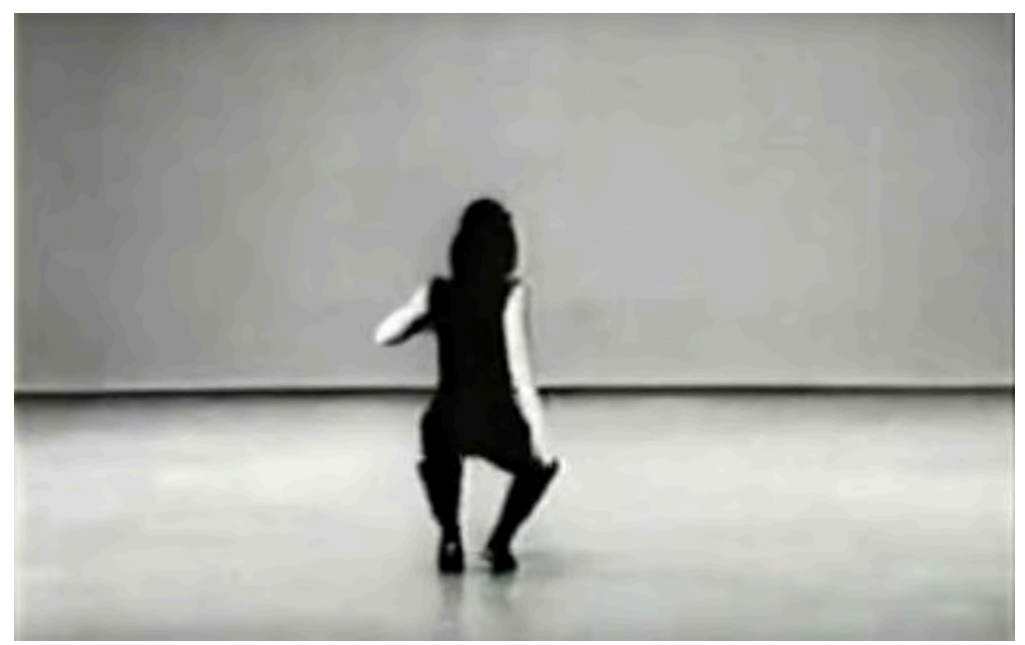

Screenshot. Trio A Chor. and Perf. Yvonne Rainer. Cinematogr. Robert Alexander Prod. Sally Banes. 1978. 16mm.

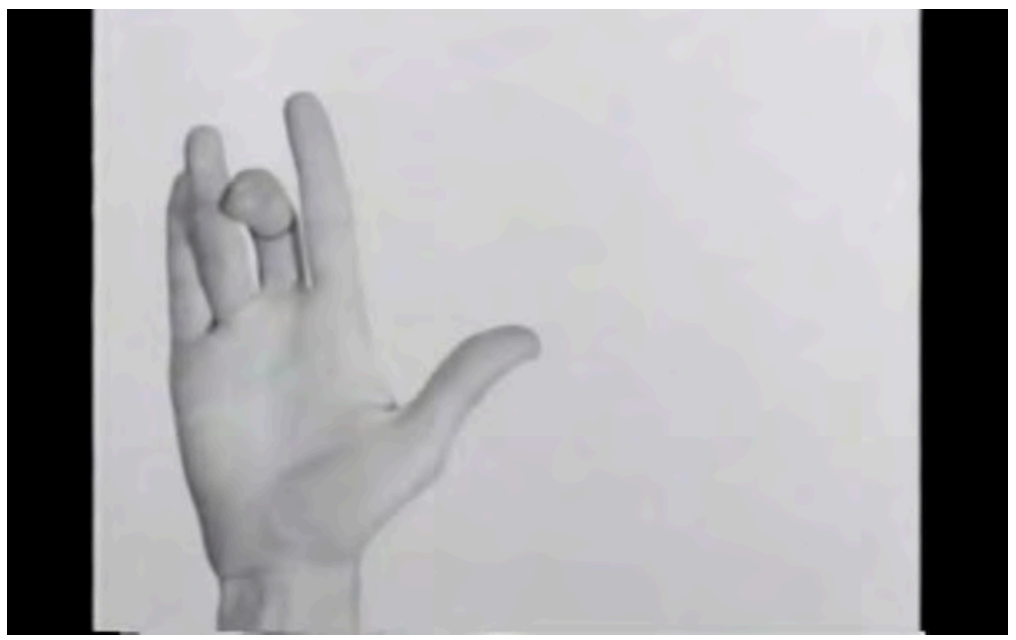

Screenshot. Hand Movie. Chor. and Perf. Yvonne Rainer. Cinematogr. William Davis. 1966. $16 \mathrm{~mm}$.

In a public forum recently, artist and scholar Douglas Rosenberg made the following observation: "For some of us, we can mark a definitive point of origin; a moment when 'screendance' as we know it began." ${ }^{1}$ Reflecting on this notion, I can pinpoint exactly when that moment was for me. Or, perhaps more accurately, the moment when my gut instinct about the potential of the collaboration between dance and the moving image became recognizable in a definable art-form, even if its name remained fluid for a good while longer. Around 1990, having worked pretty much in isolation for five years, and having had very little exposure to screendance other than my own, I attended IMZ Dance Screen Festival in Frankfurt. It was there that the moment of definition happened for me, and the work that triggered it was Roseland (1990).

Directed by Walter Verdin, Octavio Iturbe, and Wim Vandekeybus, the film is made from the material of Belgian dance artist Vandekeybus's first three live works for his 
company Ultima Vez, resetting the choreography in the atmospheric location of a deserted Brussels cinema. On its release, Roseland received the Dance Screen Award for "transforming the theatrical energy of the stage choreography into a dynamic screen experience, using a full range of cinematic techniques." ${ }^{2}$ In doing so, it set the bar for the next decades of screendance making.

Online, I find an excerpt of Roseland lasting just over seven minutes. It is the thrilling stones section, full of shifting relationships and split-second timing. Returning to the work today, I am as captivated as ever. The relaxed use of handheld camera, the rhythmic editing leading from wide images that situate the choreography in the architecture to close up details of body parts-a hand gripping an arm, faces looking outward-Roseland utilizes all the elements that contribute to creating a dynamic and engaging screendance work. It displays an understanding by the artists of the different types of shots and how these can frame the human body, the ability of the camera to bind us to the heart of the action, the rhythmic construction through editing of time and space that is unique to the screen work, and which draws us with it, through variations of pace and flow. All this is contained in Roseland and, 25 years after it was made, it can still teach much about making dance for the screen.

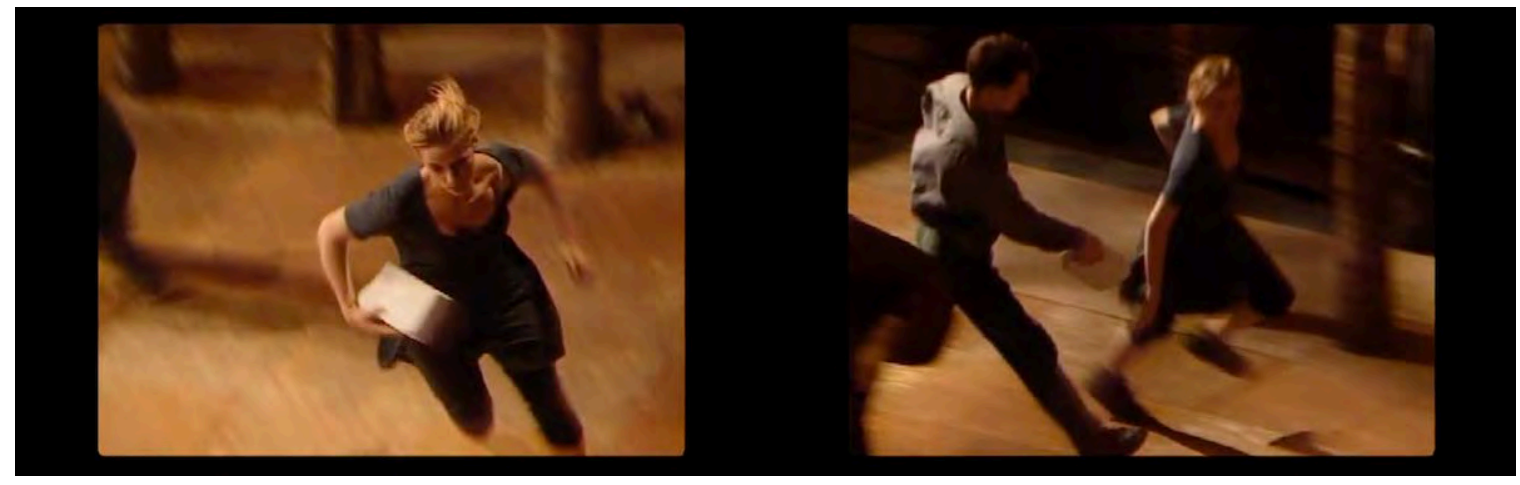

Screenshots. Roseland. Dir. Walter Verdin \& Wim Vandekeybus Chor. Wim Vandekeybus Comp. Thierry de Mey and Peter Vermeersch Perf. Ultima Vez. 1990.

A series of links lead me to another screendance work based on dance made for live performance. This time, it is the short 10 Men, which features choreography by the UK dance artist Nigel Charnock, captured in rehearsal by filmmaker Graham ClaytonChance. Here, largely observational monochrome images are presented to create a raw, yet unified aesthetic, edited to a poppy bossa nova music track.

What speaks so eloquently are the performances: Clayton-Chance's handheld lens captures the infectious, sweaty exuberance of the ten men as they rehearse Nigel Charnock's quick-footed, witty choreography. It's quite an ensemble, each performer is distinctly individual, yet all come across as ordinary blokes, and fun-looking ones at that. Viewers familiar with Nigel Charnock's memorable on-screen roles, most notably in David Hinton's DV8 films, can perhaps detect echoes of his performances in the 
choreography, as embodied in this eclectic group of dancers. That Charnock is no longer living makes these men's lively and committed dancing all the more poignant.

This is such a simple film, yet there is a joyful immediacy that feels important, not least as a record of-and a subtly flamboyant tribute to-the legacy of a brilliant dance artist whose work might otherwise be lost. Sometimes this aspect of screendance is overlooked - that it can provide cherished traces of moments and people now gone.

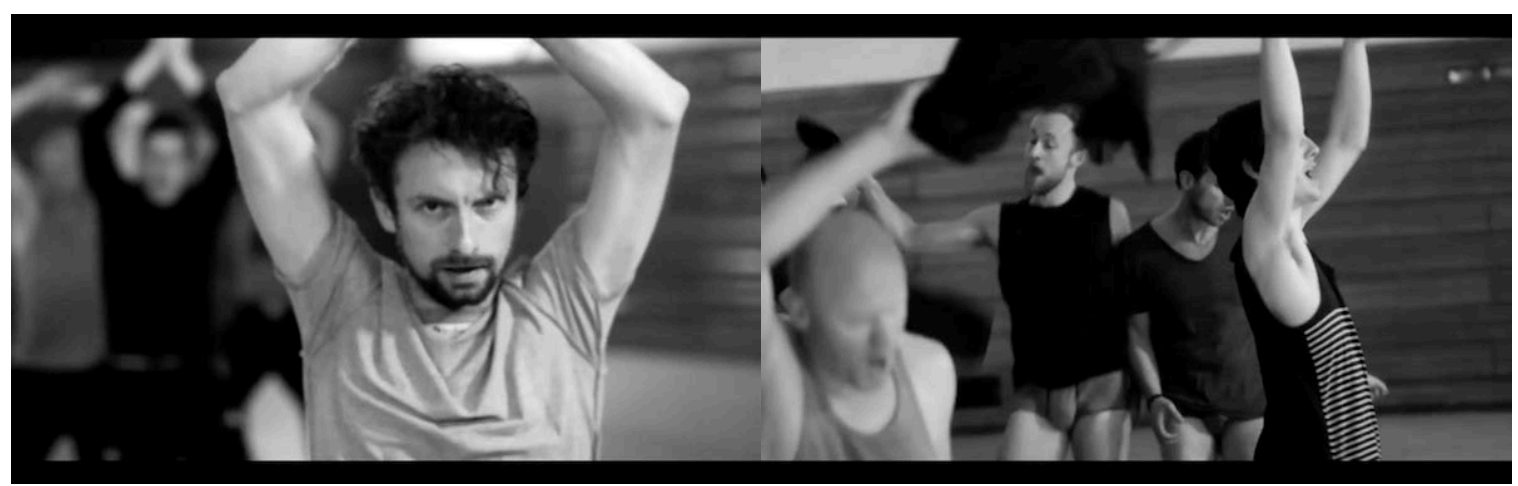

Screenshots. 10 Men. Dir. Graham Clayton-Chance. Chor. Nigel Charnock. Perf. The Nigel Charnock Company. 2012.

While talking of performance, I want to mention a series of micro-films by the influential video artist Joan Logue, available on YouTube. Produced mainly in the 1980s, Logue's 30 second Spots: TV Commercials for Artists originate from a period when artists working in the medium of video often made work that commented on the nature of television. This series of fake advertisements features seminal artists from the later decades of the 20th century. Perhaps stretching the definition of 'screendance' a step too far by including it here, in Logue's work there is a simplicity of concept, carried through with intelligent humor, that can inspire us all as we work with performance on screen.

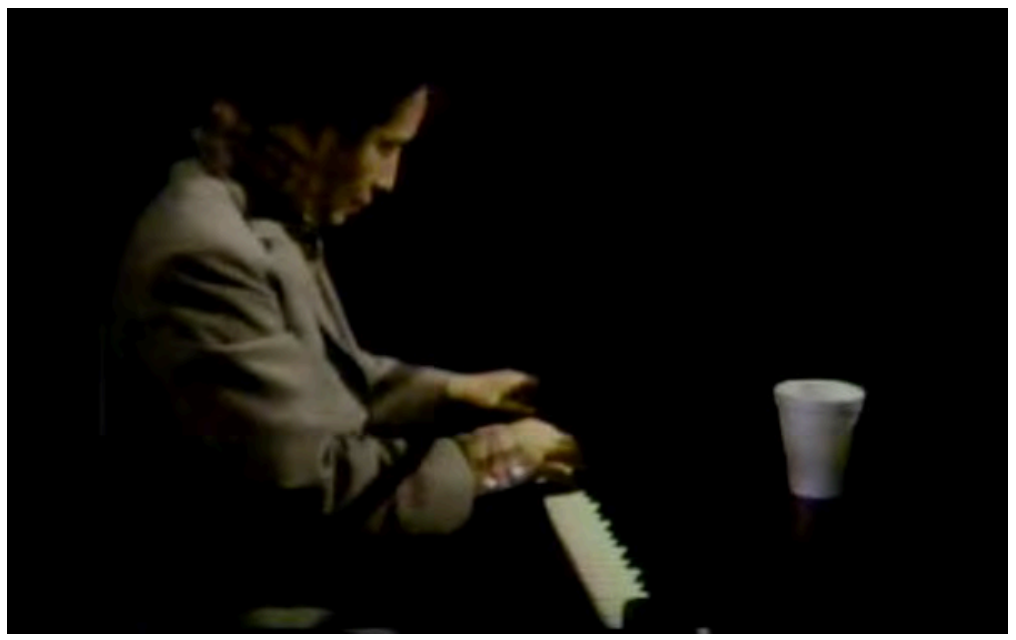

Screenshot. 30 Second Spots: TV Commercials for Artists. Dir: Joan Logue. 1982-83. Nam June Paik. 
A single still wide shot frames Nam June Paik as he takes his place at the piano. He places his Styrofoam cup deliberately on the top of the piano, sits down and hesitates, before crashing his head onto the keyboard. Steve Reich's 'advertisement' features intercut close up shots of two pairs of clapping hands creating a texture of polyrhythmic images. Laurie Anderson is represented playing percussion on her body, with head, mouth, and hands all involved. My favorite is a piece delivered to camera by John Cage, whose measured, gentle voice tells us sweetly and solemnly how his father told him that "Your mother is right ... even when she is wrong." Brilliant!

The Internet is increasingly providing us with the opportunity to watch dance films from across the last century, as more archival work is made available. I am very happy to re-discover Shirley Clarke's Bridges Go Round on YouTube, a film which is often programmed within the screendance canon, and rightly so. Part of an avant-garde of independent film-making in America in the 1950s, Shirley Clark's background was as a dancer and choreographer before studying film and she brings a kinaesthetic sensibility to her short films. A number of Clarke's early films featured modern dancemakers such as Daniel Nagrin (Dance In the Sun, 1953) and Anna Sokolow (Bullfight, 1955). At present, I can't find either of these films to view on the Internet, however Bridges Go Round offers us an important insight into Clarke's contribution to the evolution of screendance, as camera movement, montage, and super-imposition fuse to create an exquisite cine-choreography of the inanimate and iconic Brooklyn Bridge. The film exists with two different soundtracks, added at the time of production, to be seen one after another. Teo Macero's evocative jazz sound score contrasts Louis \& Bebe Barron's haunting electronic score and it is both enlightening and educational to compare the effect of the different soundtracks on the experience of watching the film.

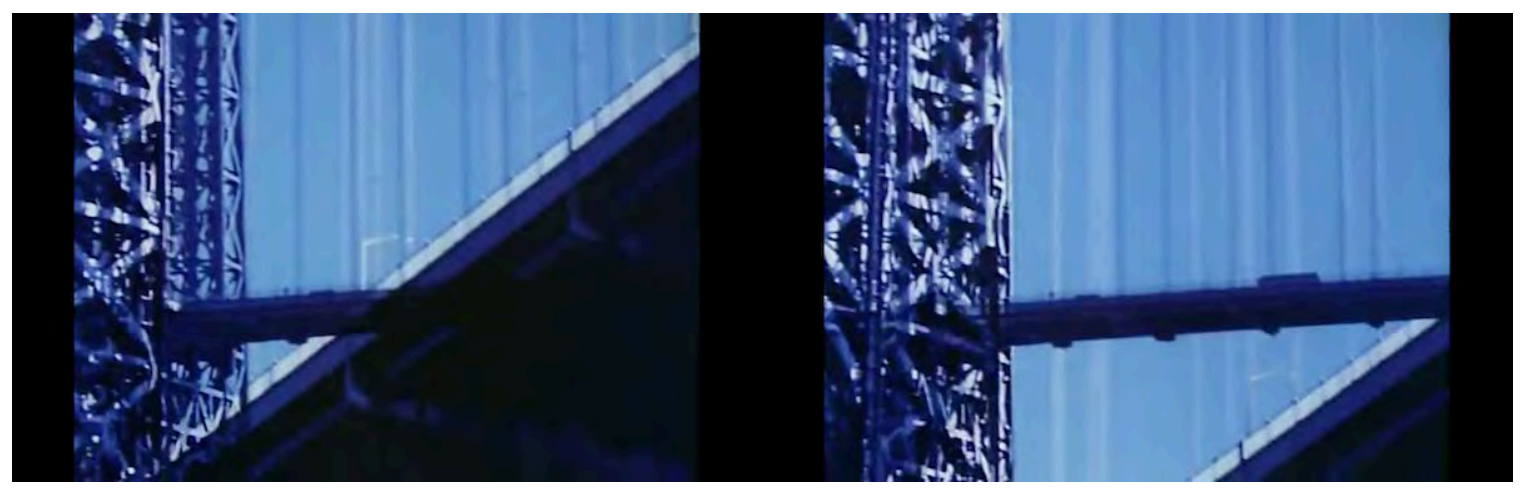

Screenshots. Bridges Go Round. Dir. Shirley Clarke. Comp. Teo Macero/ Louis \& Bebe Barron. 1958. 16 $\mathrm{mm}$.

Developments in technology often capture the imagination of artists, typically resulting in shifting paradigms of production. Lately, super high definition cameras (such as the Phantom) have invited a new exploration of slow motion. In amongst the 
examples of cheetahs running very, very fast, slowed down to very, very slow, on the Internet we can find some screendance artists who have been inspired by the very same technological possibilities and apply the techniques and related concepts to their work.

Sabroso is the work of The Performing Kitchen, a collaborative platform for research and creation on dance and performance, coordinated by Marcos Moraes. Utilizing the razor-sharp images of high definition and played out entirely in slow motion, here is a narrative involving a collection of individuals who appear to have gathered to create a celebration feast. According to the collective's own publicity material, available on their website, the concept behind the work is part inspired by the activities of Gordon Matta-Clark and his cohorts in 1970s, whose New York café, called Food was an artistic gesture. However, with its richness of tone, the colorful performed scenario and filmed against a black background, Sabroso is also reminiscent of Dutch still life painting from the 1600 s and the films of Peter Greenaway come to mind too. In Sabroso, the scene is rich, the actions simple and the extreme slow motion serves to amplify the emotion inherent in the fragments of action that we see, whether that is a gesture, a look or a physical intervention.

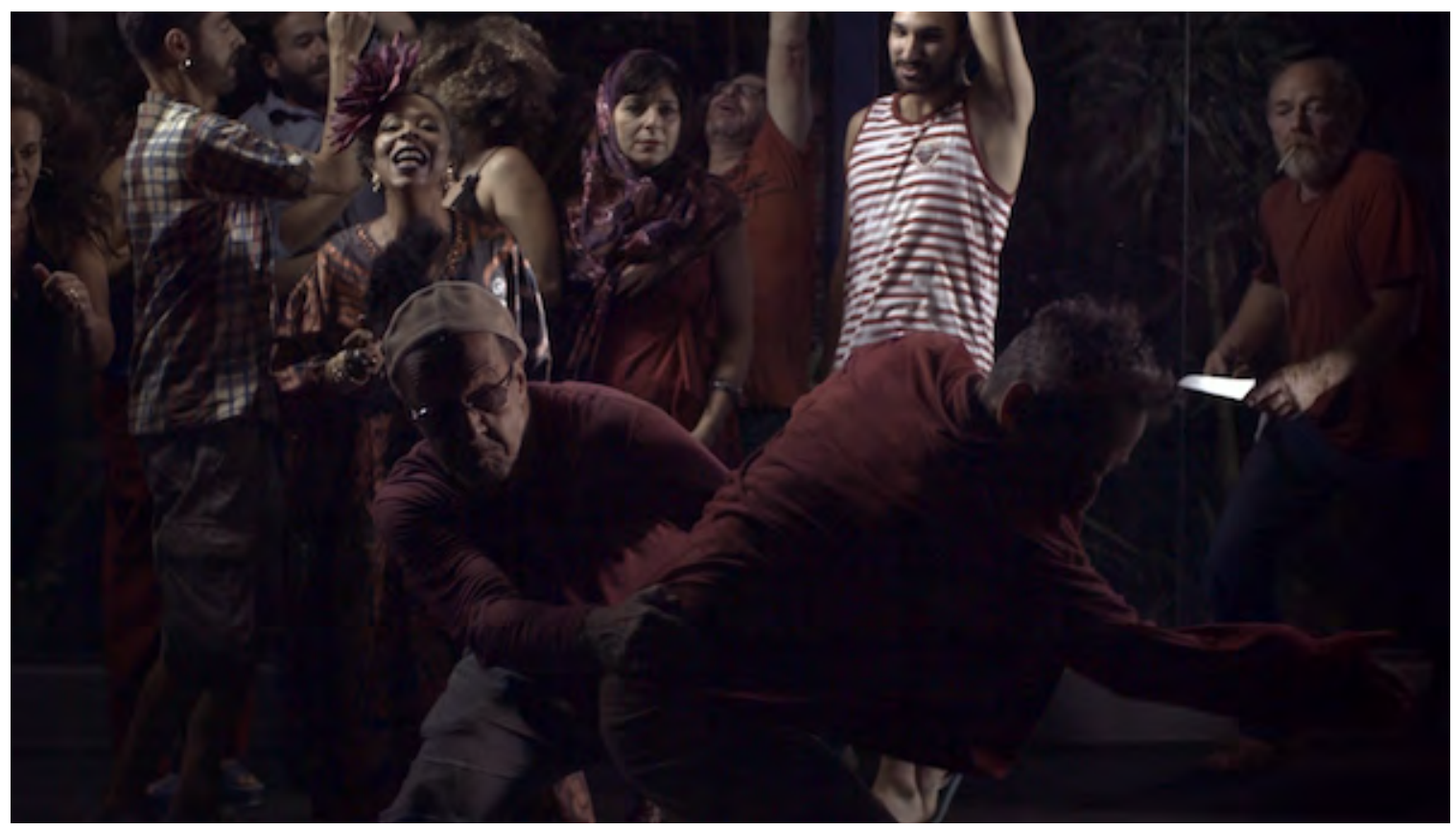

Film Still. Sabroso. Dir. Osmar Zampieri. Chor. Marcos Moraes. Comp. Aricia Mess. Perf. The Performing Kitchen. 2015. HDV. Image courtesy of the artists.

Also filmed in high definition, and slowed right down, in SAMBA \#2 (password: samba) the collaborative team chameckilerner (choreographers and filmmakers Rosane Chamecki and Andrea Lerner) present a single silent shot that frames the hips of a female samba dancer. As the artists themselves point out, this is a copy of a shot 
frequently used in the filming of samba for Brazilian television and, by presenting it in this heightened way, they encourage a rare scrutiny of the image.

The close up view of the woman's hips as she twists and turns, with scant jeweled underwear barely concealing her sex, might hardly register in the flow of images of the televised dancing spectacular. But here, the artists invite us to question our reaction to the image. On watching, fascination turns to disbelief and then selfscrutiny as the dancing flesh behaves in unfamiliar, uncomfortable ways.

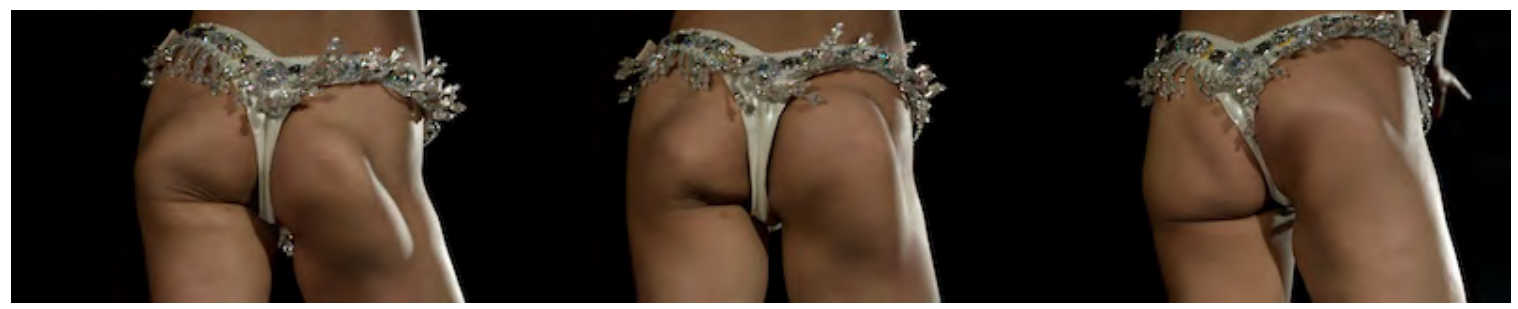

Film still sequence. SAMBA \#2. Dir. and Chor. chameckilerner (Rosane Chamecki \& Andrea Lerner). 2014. Images courtesy of the artists.

Rewind 25 years and screendance artists were using comparable techniques to enhance the impact of filmed dance movement. L'Entreinte is the ultimate romantic screendance love duet in which the physical interaction between the couple is played out in slow motion. Made in 1988 by the influential and innovative French choreographers Joelle Bouvier and Regis Obadia, this exquisite dance film is one of three films that they made around that time with their company L'Esquisse.

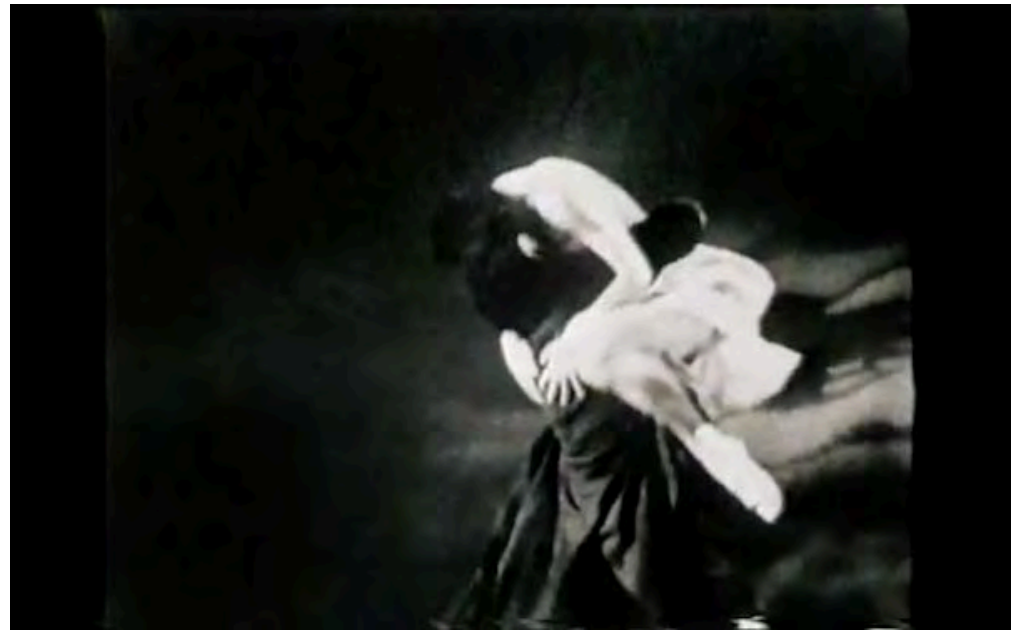

Screenshot. L'Entreinte. Dir. and Chor. Joelle Bouvier \& Regis Obadia. Comp. A. Vivaldi. Perf. Bernadette Doneux \& Eric Affergan/L'Esquisse. 1988. $16 \mathrm{~mm}$.

Whereas Sabroso and Samba \# 2 communicate through crystal clear high definition, here the images have been captured on film, probably $16 \mathrm{~mm}$, and in monochrome. The image is blurred and opaque, and this painterly quality is enhanced by the slow motion, each element adding to the timelessness of the scene. A man and a woman, dressed in evening clothes, are in a space, which is empty apart from a bed. The couple is in the throes of a passionate relationship. We cannot know if this is the 
beginning or the end, desire or rejection, as they repeatedly fall together, pull apart, break free and run, one grasping, the other pushing away, then roles reversing. Initially, the music is of romantic strings, then the booming sound of the slow motion movement fades in, emphasizing the intense physicality of the slowed dance.

Also presented in monochrome and featuring a couple repeatedly falling and getting up again, Montreal screendance dance artists Priscilla Guy and Catherine Lavoie Marcus's Singeries presents a refreshingly simple concept that is packed with knowing. Two women stand opposite each other in a neutral space. They are wearing professional, everyday office clothes and they appear to be interacting, when suddenly they fall to the ground, as though shot, or felled, or simply unable to stand any more. The image cuts to the women standing again, then they fall again and so begins a series of rhythmic, repetitive edits, the choreographic structure of the work enhanced by the use of the echoing synch sound. The neutral gaze of the camera as witness to the quotidian movement brings to mind the Yvonne Rainer films, whereas the filmic treatment of monochrome and the use of slowed down sound recall L'Entreinte. In this short excerpt here, Guy and Marcus offer a contemporary reflection of female relationship and failing to remain upright in the world.

Film still. Singeries. Dir., Chor., and Perf. Priscilla Guy \&

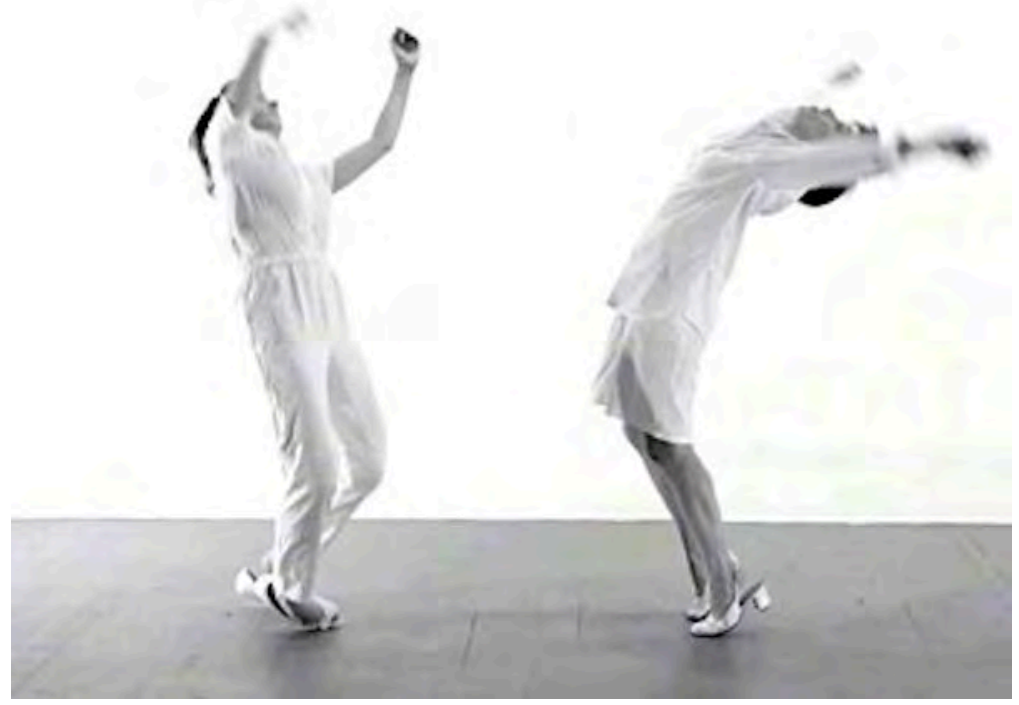
Catherine Lavoie Marcus. 2015. Image courtesy of the artists.

Another recent discovery for me is the work of US/German performance artist and filmmaker Julia Metzger-Traber, who, like many independent screendance artists, makes her work available online. For example, her poetic dance documentary film Rhizophora, which features the startling and moving improvised movement performance by young residents of the Friendship Village in Vietnam, who are living with disabilities caused by their grandparents' exposure to the deadly Agent Orange. 
In another of Metzger-Traber's short films viewable on the Internet, Die Weiten Wege, the simple and playful narrative which follows a pair of fingers as they walk through a world of close up textures and micro environments becomes a meditation on body image. Our acceptance of index and middle finger as the inquisitive legs of a 'handperson' questions assumptions about the type of body we expect, or perhaps are comfortable seeing on screen, as did the lens of Rhizophora.

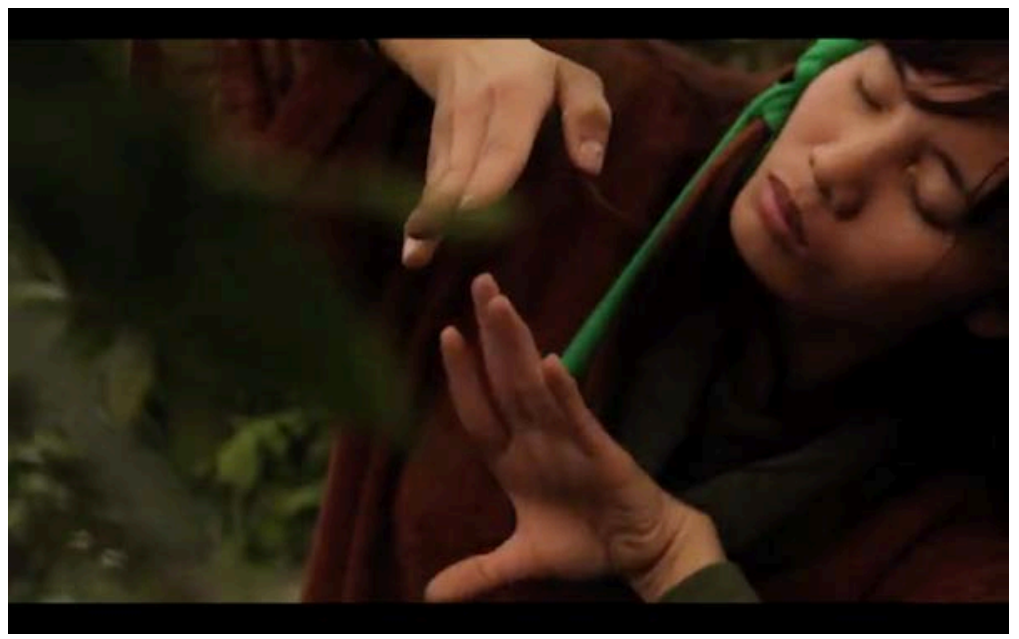

Screenshot. Rhizophora. Dir. and Chor. Julia Metzger-Traber \& Davide De Lillis. Comp. Barnaby Tree. Perf. Residents of the Friendship Village, Vietnam. 2015. Video.

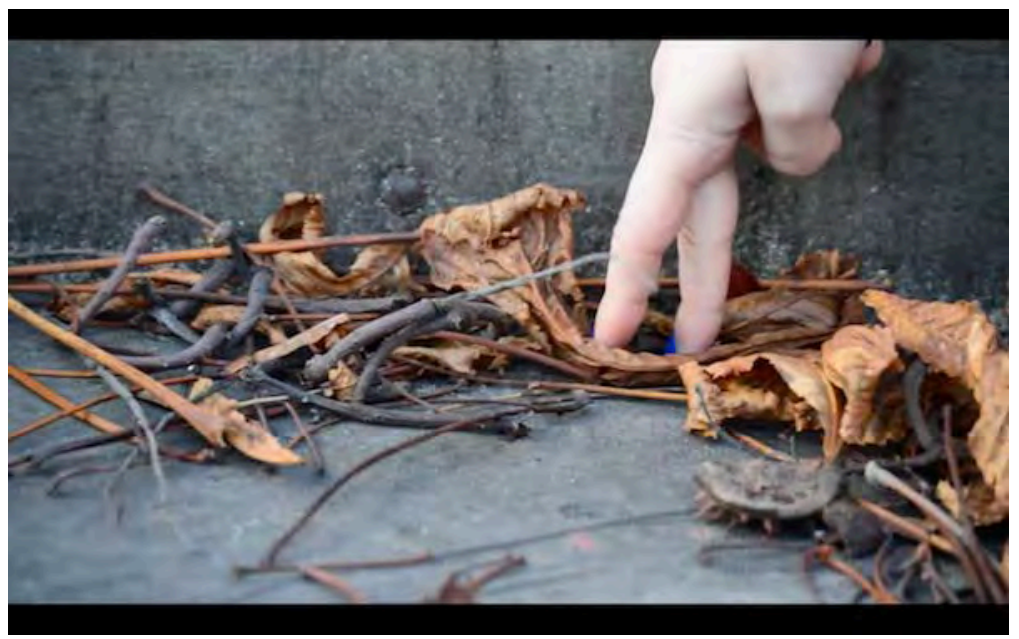

Screenshot. Die Wieten Wege. Dir. and Chor. Julia MetzgerTraber. Comp. Fourtet. 2014.

Films like those made by Julia Metzger-Traber, Priscilla Guy, and chameckilerner are evidence that the art form continues to be in good hands. Amongst others, these artists show that the form can be political, personal, inclusive, disturbing, generous, and beautiful. Moreover, these artists are using the Internet to disseminate their work, no longer dependent on the preferences of a broadcaster or distributer, nor even the festival programmer, as was the case not much more than a decade ago.

There are many stories waiting to be told and screendance continues to offer the potential to communicate across verbal language barriers, to an increasingly visually literate world, with thoughtfulness and integrity. The Internet provides an invaluable 
platform on which to share this work with as wide an audience as possible. As we have seen even within the framework of this article, there already exists a rich and varied program of screendance available online. However, despite its obvious rewards, an increasing reliance on the Internet as a platform for viewing work can also be fraught with problems. For example:

You do need good access to the Internet, which is certainly not a given in many parts of the world. In order to watch material for this article, I had to drive back and forth a number of times between where I live (with slow broadband) and a local café (with a super fast connection).

Watching work online does not necessarily provide the rich visual and acoustic experience that the artists might plan for, nor the shared engagement of a theatrical screening that public events can offer. The curating of festival programs remains in constant need of attention to bring it up to the level of expectation we have for the art form and a similar urgent requirement exists for the internet, to assist the online audience's navigation through-and understanding of-the ever-expanding catalogue of work available on the Internet.

Bound up with this is the notion of free access on the Internet, and of course this impacts an artist's ability to forge a sustainable life. Although there are systems in place for 'pay-to-view' screendance, most work is made available without charge and, as an audience, we have come to expect that we can watch work for no payment. While much is made of the increasing accessibility of technology, no material or time is without cost, and presumably this affects who has the means to make and distribute work, while also being able to earn a living.

It is a dilemma that has long existed: as makers we want our work to be seen and yet rarely receive payment for screenings or viewings, whether that be in a curated show, a festival, or now online. Moreover, as artists and producers, we may feel uncomfortable with putting in place the obstacle of online pay-per-view which may deter the curious Internet explorer. It is beyond the scope of this article to unpack the issues of arts funding, other than perhaps to make an observation that the international screendance community does seem to be made up of a particularly committed and generous group of people, for whom making work and sharing it, along with the knowledge that surrounds it, is central to engagement with the art form.

The ability to distribute work on the Internet supports a belief that what can be expressed through dance and the moving image is important and should be shared. Although sometimes at significant personal cost, those that sense its value look for ways in which to sustain a life and make work, and to create related activities, that demand a commitment that goes well beyond monetary compensation. 
Furthermore, in some ranks the screendance community is becoming increasingly aware of the need to develop and articulate a pedagogy for the art form and part of this is the realisation that, as artists, teachers and scholars working in the field, we must be well-versed in our chosen art form, both past and present. There is a continuing need to identify and share the existing and evolving works that speak to an understanding of screendance and increasingly the Internet plays a role here. The exercise of curating the growing list of works-both historic and contemporary-that are available to view online is central to this and will provide a rich seam of knowledge, essential for the continued healthy development of the art form.

\section{Biography}

Katrina McPherson is an award-winning filmmaker and screendance artist, whose creative, academic, and educational work is at the forefront of the international field. She is the sole author of the workbook Making Video Dance (Routledge, 2006) and has taught dance film and related subjects all over the world. Most recently, Katrina has devised and presented the Symposium for Teachers of Screendance with Douglas Rosenberg at the American Dance Festival in North Carolina and at the Dance on Camera Festival in New York, USA.

Email: katrinamcpherson@mac.com

Email: www.makingvideodance.com

\section{Notes}

${ }^{1}$ Douglas Rosenberg in a group email communication dated 12/26/15.

${ }^{2}$ http://www.ultimavez.com/en/films/roseland 


\section{References}

10 Men. Dir. Graham Clayton-Chance. Chor. Nigel Charnock. Perf. The Nigel Charnock Company. 2012. https://vimeo.com/36006586

30 Second Spots: TV Commercials for Artists - Nam June Paik. Dir. Joan Logue. Perf. Nam June Paik. 1982-83. https://www.youtube.com/watch?v=cGnDrJu-Xf4

30 Second Spots: TV Commercials for Artists - Steve Reich. Dir. Joan Logue. Perf. Steve Reich. 1982-83. https://www.youtube.com/watch?v=JE2tGJyQEeo

30 Second Spots: TV Commercials for Artists - Laurie Anderson Dir. Joan Logue. Perf. Laurie Anderson. 1982-83. https://www.youtube.com/watch?v=Qt_zQbu3dFA

30 Second Spots: TV Commercials for Artists - John Cage Dir. Joan Logue. Perf. John Cage. 1982-83. https://www.youtube.com/watch?v=nXAHrinbDNg

Bridges Go Round. Dir. Shirley Clarke. Comp. Teo Macero/ Louis \& Bebe Barron. 1958. 16 $\mathrm{mm}$. https://www.youtube.com/watch?v=2gxX74iGRTc

Hand Movie. Chor. Yvonne Rainer. Cinamatogr. William Davis. 1966. 16mm.

https://www.youtube.com/watch?v=CuArqL7r1WQ

L'Entreinte. Dir. and Chor. Joelle Bouvier \& Regis Obadia. Comp. A. Vivaldi. Perf.

Bernadette Doneux \& Eric Affergan/L'Esquisse. 1988. 16mm.

https://www.youtube.com/watch?v=XqwWk-PmxG0

Rhizophora. Dir. and Chor. Julia Metzger-Traber \& Davide De Lillis. Comp. Barnaby Tree. Perf. Residents of the Friendship Village, Vietnam. 2015. Video.

http://www.cheneso.com/Rhizophora (trailer) https://vimeo.com/123498557 (excerpt)

Roseland. Dir. Walter Verdin \& Wim Vandekeybus Chor. Wim Vandekeybus Comp.

Thierry de Mey and Peter Vermeersch Perf. Ultima Vez. 1990

Sabroso. Dir. Osmar Zampieri. Chor. Marcos Moraes. Comp. Aricia Mess. Perf. The Performing Kitchen. 2015. HDV.

http://www.acozinhaperformatica.com/\#!sabroso/kmctd

SAMBA \#2. Dir. and Chor. chameckilerner (Rosane Chamecki \& Andrea Lerner). 2014. https://vimeo.com/119779106. pw: samba

Singeries. Dir., Chor., and Perf. Priscilla Guy \& Catherine Lavoie Marcus. 2015.

https://vimeo.com/146858193 
Trio A. Chor. and Perf. Yvonne Rainer. Cinematogr. Robert Alexander Prod. Sally Banes. 1978. 16mm. https://www.youtube.com/watch?v=qZwj1NMEE-8

Die Wieten Wege. Dir. and Chor. Julia Metzger-Traber. Comp. Fourtet. 2014. https://vimeo.com/114092307 


\section{Testing ground: evolving screendance practices and theories and the Leeds International Film Festival Screendance Competition}

Kyra Norman, University of Falmouth, UK

Keywords: Leeds International Film Festival Screendance Competition, hybridity, nomenclature, epistemology, boundaries

\section{Context}

In 2014, artist Andy Wood and regional art form agency, Yorkshire Dance, began a collaboration with the Leeds International Film Festival (LIFF) to present a Screendance Competition within the Festival's program. LIFF, now in its thirtieth year, is a wellestablished event on the international film circuit. Following film festival convention, the Screendance Competition makes an annual open call for submissions, from which a shortlist of films is then drawn up by the organizers. These selected works are then rated and debated by a panel of expert judges, with all 10 shortlisted films then presented at a public screening during LIFF, after which the winning film is announced and awarded £500. The audience also have the opportunity to vote for their favorite film, which is announced as one of five LIFF Short Film Audience Award winners, drawn from across the festival's screenings.

In its first two years, LIFF SDC has brought together a number of key international artists, curators, and writers engaged in dance and moving image to shortlist, select, present, and discuss the work, including Gitta Wigro, Simon Fildes, Marisa C. Hayes, Claudia Kappenberg, Silvina Szperling, Liz Aggiss, and Leonel Brum.

Following the Screendance Competition at the Leeds International Film Festival in 2015, I was struck by the ways in which this event makes visible, and actively engages with, several issues that seem to define current discourse around screendance. If I review recent writing on screendance, three key questions emerge:

- How might we (screendance artists, curators, audiences and researchers) draw on the separate knowledges and ways of seeing that varied dance and moving 
image practices bring to this hybrid form?

- How might we frame what it is that we are doing in ways that might be useful to audiences?

- How might we establish greater specificity in our discussions of screendance works in ways that might be useful to artists?

Looking into each of these questions offers the potential to change our perceptions of what we are doing and discussing. Here, I begin to trace the ways in which the programming strategies and thinking going on behind the scenes at the LIFF Screendance Competition actively work through and respond to each of these questions.

Chirstinn Whyte has reviewed the 2014 and 2015 LIFF SDC events, and her writing provides a useful summary and thoughtful reflection on the screened films. ${ }^{1}$ Drawing on her work, I have developed a 'review' of the form of the event, rather than the content - a critically engaged response to the context being created, rather than the works screened. My response is intentionally open-ended, indicating the sorts of directions in which our thinking and making might open out from the proposals inherent in this particular event, and across the wider fields of dance and moving image research, practice and presentation.

In their introduction to the 2015 issue of this journal, "Community and Screendance" editors Simon Ellis and Harmony Bench also begin with three questions, focusing on "the networks and support structures that enable each of us to do our work," the "communities [that] we draw from creatively and intellectually," and the "audiences and interlocutors for our work." ${ }^{2}$ It is from this perspective that I reflect on the LIFF Screendance Competition: focusing on ideas of networks, communities, and audiences. I consider the event as a structure supporting artists and researchers to do our work; as a means of engaging creatively and intellectually with different communities, and balancing their needs and desires; and as a project working to engage its audiences in ongoing conversations on the possibilities and potential of screendance. I am interested to reveal the underlying ethos that shapes the event, and to recognize that this ethos is evolving in response to: a) the works submitted; b) ongoing critical discourse; and c) wider questions about life, the universe, and everything which artists ask through making screendance, and audiences ask in response.

This writing is structured around three sets of ideas that emerge from the questions outlined above. First, considering how we bring together dance and screen knowledges, I discuss the implication of positioning screendance in an explicitly 'screen' context, that of a film festival. Second, in relation to how we frame 
screendance, I look at the way that LIFF SDC both works with and against definitions of dance, moving image, and screendance. Third, in terms of how we can find greater specificity in talking about screendance, I consider the judges' statement identifying two distinctive approaches in the works submitted, and trace some connections between this proposition and ongoing discussions around genre and sub-genre in screendance, in particular contributions to the conversation made by Douglas Rosenberg, Noel Carroll, and Anna Heighway.

\section{Screendance in a 'screen' context}

As screendance artist Katrina McPherson writes in Making Video Dance, one attraction for dance artists moving from working in a live to a screen context is the possibility of reaching wider, more diverse audiences than those typically attending contemporary dance performances in contemporary dance spaces. ${ }^{3}$ But, while screendance is widely available online, and occasionally seen on TV, it is still the case that screendance events tend to be presented in dedicated dance spaces - whether venues, festivals, or conferences-and are attended by dance enthusiasts.

The LIFF Screendance Competition's placing of screendance into an event associated with 'screen' rather than 'dance' offers rich potential and a refreshed perspective. The film festival context encourages us to see the films through the lens of screen-related theories and practices, and places screendance in direct comparison with other moving image forms, as opposed to the usual comparisons with live dance. For example, one recurrent issue in relation to how audiences experience screendance work is whether works that lack a visible dancing presence on screen are read as 'dance.' Another area of research into how audiences engage with screendance has focused on kinesthetic empathy: the embodied response of the viewer watching movement on screen. ${ }^{4}$ When considering questions of framing screendance and audience experience at LIFF, I wondered how we might present dance thinking, rather than the doing of dance, on screen. Placing the works within a film context also brought to mind film theorist David Bordwell's discussion of analytical and constructive editing, and the work of Lev Kuleshov: an approach to making work for the screen which recognizes, in Bordwell's pithy summary, that "what happens between shots happens between your ears." ${ }^{5}$ This idea, that the audience for a screen work plays an active role in making connections from shot-to-shot, is a mainstay of Hollywood editing, as well as an established principle motivating avant garde filmmaking. It also seems to be particularly relevant in discussions about audience experiences of screendance. I enjoy the idea that this interpretation of where in your body a film occurs might give us a new perspective on how the audience receives information through watching screendance - distinguishing dance that takes place 'between our ears,' in relation to that which occurs 'before our eyes.' 
In "Toward a Theory of Screendance" Douglas Rosenberg makes a strong case for the inclusion of theories and perspectives from all of the other forms with which screendance intersects-including visual art, film, video, performance-alongside dance, in order to better understand our medium. ${ }^{6}$ Events such as the 2010 What If ... festival, curated by Lucy Cash, Gill Clarke, Becky Edmunds, Claudia Kappenberg, and Chirstinn Whyte and hosted by Siobhan Davies Studios, in London have demonstrated the possibilities of this approach in practice, bringing together a curated program of works from dance, film, live art and performance and contributing a rich mix of perspectives and propositions. ${ }^{7}$ My hope is that LIFF SDC will continue to develop as part of this proactive conversation, situating screendance within film conventions and narratives, and reminding us that, as Rosenberg contends, "screendance is contingent on, but is not, generically, dance."

\section{Framing screendance practice, engaging with different perspectives and possibilities}

The idea that screendance is not simply 'dance,' but a complex hybrid form, is one that has been championed by many artists, producers, and curators over the last fifteen years at least, and in that time there have been many attempts to define the parameters of the field, in order to emphasize this idea. In a paper first presented in 2000, film critic Noël Carroll suggests that debates on what should, or shouldn't, be classified, positioned, or presented as screendance had already become a staple of screendance events, observing that:

Whenever festivals of this sort are held, it is very likely that at one time or another almost everyone present will be tempted to say that some of the work doesn't really belong on the program. Everyone complains about labeling, but sooner or later most people feel compelled to invoke some favorite definition of their own. For human beings, categorizations are unavoidable, even if we like to pretend indifference to them. And most of us can feign indifference only so long; most of us have a breaking point." ${ }^{\prime 9}$

From a UK perspective, commissioning bodies such as ACE, BBC, Channel 4, and organizations that hosted screendance festivals, such as South East Dance and the Place, played an important role in defining the form by determining what works were not eligible for inclusion; for example, documentaries of live performances. Artists such as Becky Edmunds, Simon Aeppli, and Magali Charrier have since worked over and into what Edmunds has described as "the enjoyable gap"10 created by this complicated positioning of 'documentary' and 'screendance.' LIFF's original call for submissions alludes to the creative possibilities of dance documentary, whilst also cautioning against submitting straight-up documentation: "We are not looking for 
documentations of live performance, though we will consider live work creatively reinterpreted specifically for the screen." ${ }^{11}$

LIFF SDC intentionally welcomes hard-to-categorize and innovative work that challenges our perception of how interrelations of 'dance' and 'screen' can play out. To do this, the event both embraces categorization-it is, after all, a 'Screendance Competition'-and also invites the widest possible interpretation of what 'screendance' might be:

This competition seeks out innovative short films that explore the intersection of choreography and cinematography. This could be screenbased work that features dance, or it may have a specific choreographic element in the edit itself; it may use new technologies, animation or webbased work.... How radically the entries interpret choreography on a screen is up to the artists and we invite them to challenge our expectations and surprise us with their imagination! (my emphasis). ${ }^{12}$

Whilst we can assume that all the artists who submitted films felt that their work fell within these purposefully wide boundaries, audience reaction suggests that some present had reached the sort of 'breaking point' that Carroll discusses: the point where what we are seeing no longer accords with our understanding of the form. Erin Brannigan has discussed the long history of dance that "challenges the parameters of human perception"13 and the resultant attraction dance has held for avant garde filmmakers, tracing a history from early cinema, through Surrealism and Dada to the present day. From this perspective it is clear that dance's engagement with experimental moving images practices is long-standing, and that LIFF aims to keep this spirit alive. However, the traditional view of dance and moving image remains that of dancer-as-object represented through moving image, and presenting screendance works outside the usual dance-centerd venues makes clear how far this perception persists. In both 2014 and 2015, heated debate at the screening has been followed by audience members taking to social media to debate and contest the judges' decisions and selections, principally on the grounds of whether the winning work 'is dance.' In response to debates in 2014, a post-show discussion was added to 2015's program in order to give more room to these discussions. In this way the Competition's programming strategies encourage debate in two key ways: through the audience vote mechanism, and also in making room within the event for public debate. Also, by running an open submissions program, LIFF SDC is well-positioned to provide a snapshot of the extent to which artists are currently pushing screendance's parameters.

By intentionally inviting works that challenge our preconceptions of screendance and what it can be, LIFF SDC is part of a wider curatorial/programming movement, visible in dance and moving image as separate forms, to question art form boundaries and to 
provoke debate and discussion. By bringing the work to a wider 'non-dance' audience, new voices and perspectives enter the conversation.

\section{Establishing greater specificity in screendance discourse}

When we talk about 'screendance': what do we mean? And how can we take account of different approaches, priorities, knowledges, and histories? This is a line of enquiry that runs through screendance discourse, and may be traced back through previous issues of the International Journal of Screendance, for example from Douglas Rosenberg's writing on excavating genres within screendance and Carroll's essay, discussed above, in volume 1, through Adam Roberts' "Notes of Filming Dance" in volume 2, and most recently taken up by Anna Heighway in her discussion of "Radical Screendance" in volume 4 . The drive to speak with specificity is not purely academic, since it also allows us to discuss and respond to works in appropriate, direct, and specific ways.

In their closing comments at this year's event, the LIFF Screendance Competition judges (Liz Aggiss, Leonel Brum, and Marisa C. Hayes) acknowledged a particular challenge in this area. Among the diverse works submitted, they had identified two very different approaches to making screendance and they "didn't want their final choice to be read as endorsing one approach over another." 14 The judges saw a clear divide between "works of choreography for human dancers, in partnership with the camera and a site-specific environment," and works that construct choreography from materials and processes, in this case Mariam Eqbal's "Choreography for the Scanner," a film constructed using a still image and a flatbed scanner, creating a simple choreography through repetition, referencing early photographic and cinematic explorations of moving bodies. Might we consider, returning to Bordwell, above, that Eqbal's choreography takes place 'between your ears': that the connection between her activity and the idea of 'dance' takes place in our minds, rather than before our eyes?

In highlighting and finding ways to describe the two distinct approaches, the LIFF Screendance Competition judges feed into ongoing discussions around genres and sub-genres in screendance, a topic on which Douglas Rosenberg has written extensively, urging us to "counter the narrative of screendance as monolithic and without distinction as to genres, medium specificity, or identifiable differences that flow from formal or substantive approaches and concerns..." 15 Rosenberg proposes that "the discourse around screendance would be made stronger by excavating and identifying its generic sources, which would in turn push screendance into a broader and more vital interdisciplinary dialog." ${ }^{16}$ I understand such vitality to be equally important to artists writers and researchers, enabling more appropriate and complex discussions of our work. 
Given the LIFF SDC judges' comments, two pieces of writing seem relevant to consider understand seemingly disparate definitions of screendance: Noël Carroll's paper "Toward a definition of Moving-Picture Dance," and Anna Heighway's essay "Understanding the 'Dance' in Radical Screendance."

Carroll's paper was initially presented at the "Dance for the Camera Symposium" at the University of Wisconsin Madison in 2000, and subsequently published in the Summer 2001 issue of Dance Research Journal, before being reprinted in the first issue of the International Journal of Screendance in 2010. His insistence on accuracy in naming, and his considered refutation of many possible terms is provocative. For example, he argues against then prevalent, medium-specific labels such as cine-dance or dancefilm, and also against the term 'screendance' as an overarching categorization, on the grounds that TV, for example, isn't a screen in the sense of a surface onto which the image is projected, but a means of creating and presenting an image. I find this distinction particularly interesting in that it suggests a shift in the common usage of the word 'screen' in the last 15 years, as we now routinely refer to TV, computers, and smartphones as having screens, independent of any means of projection. The prevalence of terms such as 'screen media' and 'screen time' underline this change. Nevertheless, Carroll opts for 'moving-picture dance' and, again, is very precise in selecting 'moving-picture' over 'moving image,' proposing that where an image can be abstract, a picture offers a recognizable form:

[T] he term moving-picture dance narrows the field to visualizations of recognizable things, specifically to dances, which, it would seem, are necessarily composed literally of humans and human movement, or personifications thereof. So, at least according to me, when I claim that the concept of moving-picture dance describes our field of interest, I am saying that something belongs in our area if and only if it is a moving visual array of recognizably human movement or stillness (or a personification thereof) drawn from an identifiable existing dance vocabulary or a descendent therefrom. Or, more simply but less accurately: a moving-picture dance is a moving picture of dance movement. ${ }^{17}$

Heighway poses the question: "what is the 'dance' in screendance now that the human body has left center stage?" and, a related query, whether audiences are equipped to "identify and appreciate works that have outgrown traditional models." 18 She considers how viewers might access screendance today, both literally and conceptually, and offers an analysis of "works that lie at screendance's outermost edges," which she calls "Radical Screendance." 19

For Heighway, traditional screendance is that which uses the screen to present the dancing body. Radical screendance is that which uses screen practices to explore the nature of dance itself. In traditional screendance, "[t]he 'dance's may have taken the 
shape of formal vocabulary or a looser interpretation of movement as dance, but common to either approach would have been the sight of humans in motion." ${ }^{\prime 20}$ In radical screendance, artists explore a"paradigm in which the 'dance' in screendance need not be 'dance' movement, nor human motion, but anything kinetically driven, full stop." ${ }^{21}$ Heighway's rehearses a history of traditional screendance that begins with Thomas Edison's "Annabelle the Dancer" (1894-95)—which brought together dance and the nascent cinema-and then diverges into two pathways, one mainstream (e.g. Busby Berkeley), one avant garde (e.g. Maya Deren). She then proposes that radical screendance begins from a different premise: looking to the work of Eadweard Muybridge and Étienne-Jules Marey, and then tracing an alternative history of the exploration of movement through screen practices and technologies. For Heighway, laying claim to this alternative history has opened up an expansive range of works to re-consideration, and potential re-classification, considering 'non-dance' works through a choreographic lens.

Both Carroll and Heighway identify a number of subcategories within their main categories. Carroll proposes that 'moving-picture dance' be considered a sort of genus, within which we can then identify species such as "moving-picture dance documentations, moving-picture dance reconstructions, and moving-picture dance constructions," ${ }^{22}$ this last sub-category including all work made specifically for 'moving-picture' presentation. Within her formulation of 'radical screendance,' Heighway identifies four approaches, each arising from different proposals aboutand positionings of-contemporary dance practice. First, she discusses a broad interpretation of 'dance as movement,' which opens up the possibility of working with non-dance movement material to create a screendance, whether that be movement in front of, or by the camera. Second, she considers 'dance as metaphor,' where:

in the absence of 'recognizable' dance content, the 'conceptual links' that must be made in order that we perceive dance nonetheless become consciously embedded into the work by the filmmaker. The intentionality of filmmakers in devising and articulating metaphors, as well as our act of deciphering them, is central to an audience's understanding of dance's significance within these works. ${ }^{23}$

Third, Heighway identifies a 'choreographic' approach to moving image work, where choreography is seen as separable from the act of dancing, and so can be applied as a means of structuring in other areas such as filmmaking. Finally, she delineates a 'somatic' approach, where dance-trained artists utilize physical thinking to approach the process of filmmaking from an embodied perspective. For each of these approaches, Heighway argues that the artists "[do] not ask that we abandon our conventional notions of dance, but rather that we use these as a reference point from which to engage our imaginative understandings of the concept." ${ }^{24}$ 
Heighway's thinking is useful in relation to discussions at LIFF and other screenings and events: the idea of using our sense of what dance 'is' as a point of imaginative departure rather than the endpoint. To return to LIFF, the Screendance Competition demonstrates how an awareness of debates in screendance theory, such as those outlined above, can inform screendance programming strategies in practice. As a form, screendance proceeds and develops through a reflexive interplay of making and thinking, practice and theory. As Claudia Kappenberg and Douglas Roseberg have noted, we are working "at a time when there is an increasing fluidity between theory and practice; when those who 'make' are also those who think beyond the edges of practice, and whose contributions to the field are often sharply defined by [verbal] language." ${ }^{25}$ The LIFF Screendance Competition is one example of the ways in which people engaged in sharing and circulating screendance practice are beginning to use words in particular ways to engage diverse audiences, and draw out responses informed by different reading of the works shown. These perspectives can, in turn, feed back into our understanding of the ways in which screendance is perceived. I believe that such feedback loops, and the informal sharing of ideas, are central to screendance's development. As Bench and Ellis observe: "human beings seek to identify, connect, and converse with others" and accordingly the ways that we communicate our thinking around "why we work together in screendance and the ways in which we work together are key." ${ }^{26}$ However, as they discuss, with fewer festivals and screenings in the UK, screendance artists, here at least, increasingly connect and communicate through virtual means rather than in person. Those contributing to the LIFF Screendance Competition do rely on virtual communications, in order to coordinate international judging panels for example, but, significantly, they are also generating an opportunity for physically getting together and watching and discussing work: and this opens up the conversation to passers-by as well as those already involved in the form.

My key impressions of the LIFF Screendance Competition are of a considered opportunity to bring people, ideas, and practices together: local audiences and international artists, writers, and curators; dance and screen practices and theories; and diverse approaches to creating and conceptualizing relations of dance and moving image. By highlighting some of the ways in which this is happening, and placing a commentary on this evolving event in the context of the International Journal of Screendance, I hope to extend the range and scope of conversations and methods from the event, and others, out into the wider realms of discourse - to make visible to a wider audience the efforts of this event "to incite curiosity and debate about the very nature of the art form." ${ }^{27}$ 


\section{Biography}

Kyra Norman is a dance artist based in Cornwall, UK. She has been following her curiosity as to what, and where, choreography can be for over 15 years: working across dance, theatre and film as a maker, curator, writer and teacher. Kyra is on the Editorial Board of the International Journal of Screendance and an Associate Lecturer at Falmouth University. In 2015, she completed her PhD, exploring the screen as a site for choreographic practice, at the University of Bristol.

\section{Notes}

${ }^{1}$ Chirstinn Whyte, "Leeds International Film Festival."

2 Harmony Bench and Simon Ellis, "Editors' Note," 1.

${ }^{3}$ Katrina McPherson, Making Video Dance, xxvii.

${ }^{4}$ See for example "Watching Dance: Kinesthetic Empathy,"

http://www.watchingdance.org/

${ }^{5}$ David Bordwell, "What happens between shots...."

${ }^{6}$ Douglas Rosenberg, Screendance, 176.

${ }^{7}$ The website for this event is no longer available online, but for an insight into some of the works screened and curatorial strategies, see Chirstinn Whyte's "What If... 2010 Catalogue Essay."

${ }^{8}$ Rosenberg, Screendance, 177.

${ }^{9}$ Noel Carroll, "Toward a Definition of Moving-Picture Dance," 111.

${ }^{10}$ Becky Edmunds, A work of art from a work of art.

${ }^{11}$ LIFF 2015 Call for Submissions.

12 Ibid. My emphasis added.

${ }^{13}$ Erin Brannigan. Dance Film, 125.

${ }^{14}$ LIFF 2015 Jury statements.

${ }^{15}$ Douglas Rosenberg, "Excavating Genres," 63.

${ }^{16}$ lbid.

${ }^{17}$ Noël Carroll, "Toward a Definition of Moving-Picture Dance," 118.

${ }^{18}$ Anna Heighway. "Understanding the 'Dance' in Radical Screendance," 44.

${ }^{19}$ Ibid.

20 lbid.

${ }^{21}$ Idem., 45.

${ }^{22}$ Carroll, 119.

${ }^{23}$ Heighway, 50.

${ }^{24}$ Idem., 51. 
${ }^{25}$ Claudia Kappenberg and Douglas Rosenberg, "Editorial," 7.

${ }^{26}$ Bench and Ellis, 3.

${ }^{27}$ Kappenberg and Rosenberg, “Editorial," 8.

\section{References}

Bench, Harmony and Simon Ellis. "Editors' Note: On Community, Collaboration, and Difference." The International Journal of Screendance. 5 (2015): 1-8.

http://dx.doi.org/10.18061/ijsd.v5i0.4866

Bordwell, David. "What happens between shots happens between your ears." 2008. http://www.davidbordwell.net/blog/2008/02/04/what-happens-between-shotshappens-between-your-ears/

Carroll, Noel. "Toward a Definition of Moving-Picture Dance." The International Journal of Screendance. 1 (2010): 111-125.

Edmunds, Becky. A work of art from a work of art. http://beckyedmunds.com/\#/ondocumentation/4531976852

Heighway, Anna. "Understanding the 'Dance' in Radical Screendance." The International Journal of Screendance. 4 (2014): 44-62.

http://dx.doi.org/10.18061/ijsd.v4i0.4530

Kappenberg, Claudia and Douglas Rosenberg. "Editorial." The International Journal of Screendance. 4 (2014): 5-9. http://dx.doi.org/10.18061/ijsd.v4i0.4560

LIFF 2015 Call for Submissions.

https://www.facebook.com/events/1479975602296764/

LIFF 2015 Jury Statements.

https://www.facebook.com/events/1492156104432642/permalink/151990341499124 4/

McPherson, Katrina. Making Video Dance. Abingdon and New York: Routledge, 2006.

Roberts, Adam. "Notes on Filming Dance." The International Journal of Screendance. 2 (2012): 107-113. 
Rosenberg, Douglas. Screendance: Inscribing the Ephemeral Image. Oxford, New York: Oxford University Press, 2012.

http://dx.doi.org/10.1093/acprof:oso/9780199772612.001.0001 . 2010. "Excavating Genres" in International Journal of Screendance. Vol. 1.

Whyte, Chirstinn. "Leeds International Film Festival: Screendance CompetitionNovember 2014/15." Shiftwork: Unspooled. Posted 24 Nov. 2015.

http://www.unspooled-writing.blogspot.co.uk/2015/11/leeds-international-filmfestival.html

. "What If... 2010 Catalogue Essay." Shiftwork: Unspooled. Posted 20 May 2012. http://www.unspooled-writing.blogspot.co.uk/2012/05/what-if-festival-2010catalogue-essay.html 


\section{What Are Screendance Competitions Even For? A Response to the 2015 Leeds International Film Festival Screendance Competition}

Hamish MacPherson, Independent Artist

Keywords: screendance, competitions, curation, convention

My relationship to screendance is somewhat like my relationship to dance more generally; working with tiny little things that one could hardly think of as dance and yet I am trying to do so all the same. At the moment I have an interest in gifs, which I would argue are a very particular kind of screendance. Completely limited but all the more interesting for it. And so it is from this little corner that I try to survey contemporary screendance, looking through the peephole that is the International Screendance Competition at the Leeds International Film Festival (LIFF) 2015.

Of the 10 films $^{1}$ on show (shortlisted from 164 entries) two very different films stand out from the otherwise grey in-between.

On the one hand we have "You," directed by Graham Clayton-Chance (UK), a tribute to the late choreographer Nigel Charnock, which wins the audience vote. But it's almost a straight documentation of Dan Watson's charged performance of Charnock's thoughtful choreography. And documentation, we are told at the post-show discussion, is not screendance, so this one scrapes in.

On the other hand we have the Jury's favorite, "Choreography for the Scanner," directed by Mariam Eqbal (USA), which features an animation of a distorted scanned image of a ballet dancer. But is it dance? That's the big question right? The choice causes some surprise in the audience and one person expresses their dismay on Facebook (eliciting an amusingly extensive reply from the Jury ${ }^{2}$ ). This reminds me of people complaining that there's not enough dancing in the Place Prize. ${ }^{3}$ Both cases come down to the question of whether these are dancing or dance-making or choreography competitions. If an animation wins then I guess it's choreography but by using an image that is perhaps most emblematic of dance to a predominantly white European audience it seems to lose its nerve as if to still be in with a chance. If we say that to dance requires an intention and self awareness then an animated picture of a dancer isn't dancing any more or any less than an animated picture of a 
corpse or a tree or a triangle. But arguably you can still make a dance with things that aren't dancing and an animated human certainly feels more like a dance.

So I can see why this is the most interesting work for the judges because it raises the most questions but the internal form of the work is less interesting to me. It saunters along with a light humor and its aesthetics hark back to the past but I wonder how thought-provoking it would be for me without the frame of the competition or this writing I am doing now.

In between these two outliers we have a range of works with recognizable contemporary dance vocabulary within creative camera work, special effects, and editing. Dancing often appears as a worn metaphor for inner youth, emotion, and torment embalmed in slick camera work. The best the Jury can say for the second prize winner "Approaching the Puddle" directed by Sebastian Gimmel (Germany) is that "Whilst the form is neither challenging the dance film genre, or the content a game changer, this film is nonetheless a delightful experience for the audience." But again this is just a problem from my perspectives on dance. Many people just want something ... delightful.

I unsympathetically read most of the works as cases of dance-makers and filmmakers encountering each other far too late, so that they seem to be fascinated by the least interesting aspects of each other's worlds. Getting over-excited by the sexiness of lush images or conventionally athletic bodies. They feel like adverts or music videos but with nothing to sell. Expensive videography meets tired dance moves and normative bodies to create more clichés of what dancing is.

I come away hoping that there are people at school today that are bringing their smart phones into the dance studio so that these media are meaningfully synthesized at their roots. Maybe I am missing something but from this night I couldn't get a sense of what filmmakers and dance makers were really bringing out of each other.

This complaint is not limited to this competition and in the following months I come across similarly glossy but unimaginative examples of conventional contemporary dance in beautifully shot landscapes and the like. Stuff that has currency and visibility because it slots so easily into existing visual norms of commercial platforms, ready and willing to be assimilated into mainstream culture.

The competition raises wider questions of curation, judging and competition. Having a winning entry suggests to me that this represents the more interesting, high-quality screendance around at the moment. But the competition is self-selecting and partial, and the Jury's involvement seems to be an effort to build a wider discussion about screendance from what was available. Which feels like a bit of a compromise. 
I'm left questioning why this was a competition, rather a curated selection of films that seriously engaged with the diversity of screendance. But, again, this is just a reflection of my own priorities and interests.

I wonder then whether those films that are pushing the idea of what screendance could be, would ever put themselves forward for such a competition or whether they even see themselves as screendance. Why would they want to enter the world of screendance other than to make a (interesting, I think) philosophical point about categories of art? For I imagine that artists around the world are already consciously or unconsciously exploring choreographic ideas through film works.

But then I only have to look around at my peers and see they are already making short films and putting them online, and these are part of their practice and their work as much as dancing and writing and talking and all kinds of things. So I wonder what place there is for screendance, with all its established forms and boundaries and requirements. How does it relate to ways that people are using video technology to capture and present and produce movement right now? Genuine question.

\section{Biography}

Hamish MacPherson is a dance artist whose work is interested in how we can think about philosophical and political ideas through personal and group choreographies. He makes performances, installations, workshops, games, writings, images and other things. He has an MRes in Choreography and Performance from Roehampton University and an MA in Global Values and Contemporary Ethics from Kings College, London.

Email: macpherson.hamish@gmail.com

Website: http://www.hamishmacpherson.co.uk

\section{Notes}

1 Information about all 10 films selected is available on the LIFF Screendance Competition webpage: http://www.leedsfilm.com/films/screendance-competition/ 
2 Jury Response, Screening: LIFF Screendance Competition Facebook Event: https://www.facebook.com/events/1492156104432642/

${ }^{3}$ The Place Prize for dance is a UK contemporary dance competition hosted biennially by London dance and performance center 'The Place' and sponsored by financial service company Bloomberg.

\section{References}

Approaching the Puddle. Dir. Sebastian Gimmel. 2014.

http://www.approachingthepuddle.de/

Choreography for the Scanner - In Between Frames Series. Dir. Mariam Eqbal. 2015.

Vimeo. https://vimeo.com/128830552

You. Dir. Graham Clayton-Chance. Chor. Nigel Charnock (from the dance solo

Resurrection, 1991). 2015. Trailer on Vimeo. https://vimeo.com/155108342 


\section{Screendance Cannot be Everything: Defining the Form Ten Years after the $(\mathrm{Hu})$ Manifesto}

Wyn Pottratz, Independent Artist

Keywords: screendance, humanifesto, curator, opensource, video dance

At the recent Light Moves Festival of Screendance in Limerick, Ireland, I was sitting with screendance veteran Simon Fildes as we watched onscreen insects ready themselves for what looked to be a bug audition for National Geographic, minus the scientific commentary. One after another, bugs filled the screen primping their antennas, hanging on branches, spinning their cocoons or staring at other bugs. Curated into this hour-long screendance cinema program Boris Van der Avoort's made-for-gallery work "Imperceptible" dragged out for a lengthy fifteen minutes. Wilted in our seats, Fildes and I turned to each other, relaying the thought that crossed our minds - screendance cannot be everything surely?

Later in the festival symposium, Claudia Kappenberg talked about how experimental film or "expanded cinema," went through a similar ontological crisis in the 1960s and $70 \mathrm{~s}$ that is comparable to screendance today. ${ }^{1}$ Expanded cinema became so overwhelmed with its multiplicity of content that it became "bloated to the point of near meaningless," observed Jonathan Walley. ${ }^{2}$ As a result of ambiguity, expanded cinema morphed into other distinctive forms like "electronic art," "moving-image installation," and "new media." ${ }^{3}$ If screendance is limitless, then the field risks its status among other more definitive art forms, especially when it comes to funding or critical recognition. Kappenberg concluded with a proposition suggested by Walley that perhaps screendance needs its own "laundry list" of parameters to give the form some meaning, though this might be a fruitless task.

Though there are many ways to make a screendance, it may be time to fine-tune what constitutes the form and what does not. After all, the richer the discourse, the more an art takes its form. After a discussion with Fildes, we came up with our own definition: "Screendance is a moving image work, the content of which has choreographic compositional intention, combined with the technical and creative language of cinema." Van der Avoort's work, though visually alluring, demonstrated neither. Furthermore, there was no suggestion that it was made as a screendance, even though it was curated as one. 
Of course, as in dance and cinema, there are edges to definitions, and artists will push these edges. At the 2013 San Francisco Screendance Festival, I attended Siobhan Davies and David Hinton's screening of "All this Can Happen." This work clearly explores the boundary of screendance, re-imagining both filmic and choreographic possibilities in the editing suite, interweaving archival footage and language into an unexpected onscreen dance. "Choreography for the Scanner" controversially won the Leeds International Screendance competition last year by pushing the edges in an expanded cinema sense through the physical processes involved in its animation. It relies on the use of a scanner as a choreographic device, rather than an edit suite.

It's worth reflecting upon how screendance has gained a great deal of momentum in a relatively short period of time. Ten years ago, a group of artists and academics gathered in Findhorn, Scotland at a symposium called Opensource (Video Dance). At the end of the 4 days they drafted the (Hu)Manifesto: Possibilities for Screendance, a series of reference points intended to enrich the discourse within the field. It was an important step forward in creating "external prisms" for viewing work. ${ }^{4}$ Ultimately the list served as a framework for articulating meaning, as the authors put it:

This (Hu)Manifesto asserts that screendance has the potential to articulate metaphor, express conceptual concerns and manifest thematic possibilities. Inherent in the proposition of screendance is the possibility that through an accretion of images of bodies in motion, a larger truth may unfold.

- One that is greater than the impact of each moment experienced in isolation

- One in which sequential images in the context of dance on screen resonate with accompanying frames of reference to manifest a larger understanding of the world

- That in order to accomplish this, the screendance community must by necessity engage itself with rigorous critique that is grounded in both pre-existing and yetto-be articulated methodologies. ${ }^{5}$

The $(\mathrm{Hu})$ Manifesto resulted from practitioners and academics exchanging ideas at an event designed at its core to be communal. ${ }^{6}$ Organizers Jay-Lewin, McPherson, and Fildes believed that most conferences were so tightly scheduled, that little time remained for communication to develop organically. ${ }^{7}$ The organizers thought that deeper levels of discourse may evolve in a more "retreat-like setting," so they experimented with new session formats. One such session invited participants to roam the space, free to join or walk away from conversations at their own will. In this manner, the (Hu)Manifesto was drafted and debated on the final day of the symposium. Given the symposium's openness, it achieved incredible focus, evident through the (Hu)Manifesto. ${ }^{8}$

How knowledge is transferred and shared in the field is crucial to the autonomy of screendance. Though the (Hu)Manifesto was concerned with discourse not definition, 
the act of addressing issues in a range of frameworks allowed those present to be heard differently and ultimately set the stage for a definition. The 2006 and 2007 Opensource symposia's alternative modes of interaction increased the field's ability to traverse ideas, while strengthening its sense of community. As one participant commented, "Looking back now, I sense that screendance took a lurch forward during those four days in June 2006." ${ }^{\prime 9}$ The follow-up symposium that took place the following year in Findhorn created the framework for the development of the Screendance Network and The International Journal of Screendance.

Artists will continue to make work of all sorts, but it's the responsibility of curators and teachers who disseminates information to classify it. Through classrooms, festivals, and journals they hold the power to provoke and the space to invite reflection. And because exemplar screendance work is not particularly easy to find, the field relies heavily on these key individuals to shape experiences. The material they choose to include in their collections becomes the bedrock of the art form and feeds the future. "It always comes down to people, doesn't it?" remarks Claudia Kappenberg, Leader of the MA Performance and Visual Practices at University of Brighton. "It still relies on a massive effort of some very dedicated individuals." 10

Defining the taxonomy of screendance is a challenge perhaps best done by a group of such committed individuals. Now that screendance has moved to a certain level of maturity, perhaps it is time to hash out a new (Hu)Manifesto at another Opensource symposium with the current critically engaged community. When asked who are the individuals responsible for the next (Hu)Manifesto, Fildes responds "Whoever shows up are the right people."

\section{Biography}

American-born Wyn Pottratz is a choreographic filmmaker, dancemaker and movement educator soon-to-be based in Scotland. She received a graduate certificate in screendance under Ellen Bromberg and an MFA from the Modern Dance Department at the University of Utah. She was a recent member of the Bellingham Repertory Dance and owned Wyn Pottratz Pilates where she developed FLIGHT, a barre-inspired workout. Wyn has choreographed for musical theater, modern dance, and video. Fascinated by the geometry of bodies in space, yet irreverent to order, Wyn aims to create onstage worlds that deliver a sensorial experience.

Email: katpotz@gmail.com

Web: http://wyn.dance 


\section{Notes}

${ }^{1}$ Claudia Kappenberg, "The Politics of Discourse in Hybrid Artforms," 2.

2 Jonathan Walley, "Identity Crisis," 27.

3 Idem., 24.

${ }^{4}$ Katrina McPherson and Simon Fildes, "Opensource: Symposium," 17.

${ }^{5}$ Ibid.

${ }^{6}$ Fildes, "Opensource: (Video Dance)," 1.

7 lbid.

${ }^{8}$ Idem., 4.

${ }^{9}$ lbid. 4.

${ }^{10}$ Kappenberg, "Lightmoves."

\section{References}

McPherson, Katrina, and Simon Fildes. "Opensource: Symposium, 20th-24th November 2007, Findhorn, Scotland." Glenferness: Goat Media, 2009. Print.

Fildes, Simon. "Opensource: (Video Dance): New Models for Knowledge Transfer Between Practising Collaborative and Cross-Media Artists," 2007, unpublished. An adaptation of a paper presented by Katrina McPherson at the American Dance Festival, Screendance, State of the Art conference, USA, July 2006. 1-4.

Kappenberg, Claudia. "The Politics of Discourse in Hybrid Artforms." Paper given at Light Moves Festival of Screendance, Ireland, 20th November 2015. Published in Franck Boulègue and Marisa C. Hayes eds., Art in Motion: Current Research in Screendance / Art en mouvement : recherches actuelles en ciné-danse. Cambridge: Cambridge Scholars Publishing, 2015. 1-5.

Walley, Jonathan. "Identity Crisis: Experimental Film and Artistic Expansion." October 137 (Summer 2011): 24-29.

“Imperceptible.” Dir. Boris Van Der Avoort. 2015. Film.

"All This Can Happen." Dir. Siobhan Davies and David Hinton. Perf. John Heffernan. Sioban Davies Dance Production, 2013. Film.

“Choreography for the Scanner." Dir. Mariam Eqbal. 2015. Film.

Kappenberg, Claudia. "Lightmoves." Message to Simon Fildes. 4 February 2016. Email. 



\section{INTERVIEWS}





\section{Screendance: Learning, Teaching, Living}

Harmony Bench, The Ohio State University with

Jason Bahling, Ben Estabrook, Natalie Gotter, Eric Nordstrom, and Ellen Maynard

Keywords: academia, teaching, training, screendance, U.S.

Prompted by recent conversations in the field regarding screendance pedagogy, I was interested to hear from current and former students on the topic of academic and professional training. I asked Ellen Bromberg (University of Utah), Mitchell Rose (The Ohio State University), and Douglas Rosenberg (University of Wisconsin, Madison), all of whom lead screendance certificate programs or focus areas in American universities, for recommendations. I would like to thank Jason, Ben, Natalie, Eric, and Ellen for taking the time to speak with me. What follows is an edited version of our conversation. In line with best practices, all contributors had an opportunity to review their comments prior to publication.

- Harmony Bench, April 2016

\section{Harmony Bench: To begin, could you each just say a few words about your background and how you first encountered screendance?}

Jason Bahling: I kind of fell into screendance, which I think is a common thread among screendance makers. I went to the University of Wisconsin-Madison thinking I was going to do video installation art. But the Inter-Arts and Technology program is housed in the Dance department. That was a bit of a bizarre jump for me at the time, but it was a great way of framing art practice and learning how to communicate nonverbally. We all called it the Doug Rosenberg School of Art.

Ben Estabrook: I had aspirations of going to the Film program at UCLA, but when I got there, I stumbled onto the World Arts and Cultures department because I was interested in documentary film and folklore. David Gere and Vic Marks had a pretty profound impact on me and presented me with the first examples of screendance that I had ever seen. At the time of my studies, John Bishop taught film production, and Judy Mitoma was finishing up her Envisioning Dance book. I made my first dance film in 1999. I later went to graduate school at the University of Utah and got an MFA in Film, and also did the Screendance Certificate with Ellen Bromberg. 
Natalie Gotter: I was interested in screendance because I have a media and advertising background, and screendance seemed like a natural thing to incorporate into my Modern Dance studies. I'm currently half-way through the Screendance Certificate Program at the University of Utah and in my second year of graduate school for dance.

Ellen Maynard: I had some early experiences with screendance in high school working with someone on a senior thesis. I ended up sitting in the editing suite with the film editor to help him edit because he didn't understand what was important in the dance. When I went to the Dance department at The Ohio State University, I was able to work with lots of different people: I was very inspired by Lily Skove who taught dance documentation and Norah Zuniga Shaw who encouraged us to reflect on what it means to use projection. Mitchell Rose comes to filmmaking with more of a concern for the audience. I also got a Video Art minor and worked with Dan Shellenberger, who loved the possibilities of art and of living artfully, and his inspiration was contagious.

Eric Nordstrom: I didn't do screen work until I started my MFA at The Ohio State University. I was focused much more on contact improvisation, which is my movement practice. But at OSU, I worked a lot with Mitchell Rose, who placed a lot of emphasis on the technical aspects of filmmaking and editing. My final thesis project was a dancefilm.

Harmony: Each of you came to screendance differently, and you represent different career stages and different schools of thought. Reflecting on your training, what are some main ideas that inform your work and process, and, perhaps, your own teaching?

Natalie: At the University of Utah, there is an immense sense of freedom in what work we produce, which is very beneficial because everyone in the program has a completely different point of view. Independence and maturity are expected of everyone getting the Certificate. Ellen Bromberg is so passionate about screendance, and is always willing to talk about it and anything I'm creating I know I can always bring to her and ask for her opinion about it. Doug Rosenberg was a distinguished speaker for the Utah Screendance Festival this past fall, and one of the things he said that stood out to me is that we need to find a new way to talk about screendance. It's not just film, and it's not just dance. But that raises a question for me about how we're teaching it, and how we develop that language in screendance curricula.

Jason: I took about five video courses at the University of Wisconsin-Madison. In all of them, the teachers wouldn't sit us down and say, "These are the buttons and how they work." Software programs were changing so fast, it just became clear in the late 1990s or early 2000s that students were going to learn programs faster than you could teach them-so the video courses focused on content. We focused on how you tell stories and how you make creative choices that are more profound and poetic than pixelating 
or a kaleidoscope effect. The question at the core of the teaching was how theory and practice work together. For example in creating a piece, we would constantly come back to the question of "what is this really saying?" on multiple levels: within your own practice, your geographic context and network, and then within art history as a whole.

Ben: I've been fortunate to work with Ellen Bromberg and take workshops with Katrina McPherson and Thierry De Mey, and they all have pretty radically different approaches to exploring the medium of film, and how to bring dance into that. Because I had a background in performance documentation, it was initially really hard for me to not have continuity of the choreography-it took a lot of effort to override my instincts. So it's important to me to expose students to the range of what you can do-that when you're filming, you're gathering these textures that you'll take into the edit to create something entirely new, and to really think about how you're choreographing the dance through editing. There's something so liberating about that. I feel like one of the things I say way too often is that when you're shooting dance, to make sure you have an intention behind the camera. My own workshops focus more on shooting than editing, and I feel like intention is really a hard thing for a filmmaker just starting out-there needs to be thought behind every decision: where are you placing the camera, what is the framing, how are you moving the camera. Sometimes you'll see the camera moving just for the sake of moving. So I like to explore what motivates the camera movement.

\section{Harmony: Are there specific exercises that you have encountered in courses or workshops that have impacted you?}

Ellen: With Lily Skove, we watched Hilary Harris's film "9 Variations on a Dance Theme," and then we tried to do the same thing. That showed me the angle of filming changes the movement. That's a pretty basic statement, but it leads to a lot of possibilities. Lily encouraged us to just try everything out-what can you change about the space? what can you change about the lighting? When teaching us editing, Mitchell Rose would bring these really long strips of paper that represented the film in FinalCut into the computer lab, and he would show us in paper form what a splice was, what a slide was-he would show the techniques of the computer physically, and that was helpful because as dancers we related to a tangible representation of the computer technique.

Ben: Katrina McPherson has a great workshop exercise she does. She'll get the participants in a circle, two will go to the center and start to improvise and a third person will have the camera and will improvise with them. There will be a clear sense of where a shot begins and ends. In reviewing the footage afterward, it's pretty apparent where a shot gets interesting and where we lose interest. So that's a really effective way to get people to think about the beginning and ending of a shot, and thinking about editing while they are shooting. 
Eric: One of the exercises I continue to use in teaching I learned from Mitchell Rose, and the idea is to film a very short movement phrase-maybe 5 seconds-from 12 different camera angles: bird's eye, high-front, side, back, mid-front, side, back, lowfront, side, back, close-up, etc. It's a really useful exercise because it emphasizes how filming the same dance or movement phrase can be dramatically different depending on how you film it. So I use this exercise in my performance class, and I just have students use their cell phone cameras. It helps them as dancers to consider when they are performing, how is the audience seeing this—is it a high shot, a wide shot-how are you being seen?

\section{Harmony: One of the things we see all the time in screendance is the importance of collaboration. Do you have thoughts about how screendance courses and workshops either teach or don't teach students how to collaborate or how to work with a team? Or do you have experiences working collaboratively that you'd like to share?}

Natalie: One of the greatest strengths of the University of Utah is the emphasis on collaboration. That said, everyone is encouraged to be an individual artist, and there's not a lot of real-world training in collaborative relationships that one might encounter outside of academia. Even in the Screendance Certificate, with all of the coursework, you're doing everything totally by yourself: choreographing, directing, shooting, editing, sound editing. We have classmates assisting, but they are in the same boat that you are in, learning everything at once. In being introduced to what all the different options are as a screendance artist, maybe you figure out what role you are most drawn to. In the process you develop an individual artistic voice, but the realworld collaboration skills and expectations are not part of the training. Screendance feels like such a small world, and I wonder if the way it's taught lends itself to being or remaining a small world, which can be both a good thing and a bad thing, because it keeps it much more of an art form instead of something overly commercial. But at the same time, there are benefits to becoming more popular as well.

Ellen: At OSU, we didn't really touch on what it's like to create a film with high production values. The idea that you would have a gaffer or a grip or a lighting person on your dancefilm set-not there. We learned how to do all these roles on our own at a rudimentary level. It is good to have learned the DIY way, because now I can do it myself, but I think it capped my own imagination to what I can accomplish alone. I think it's easy to think that as a director of a dancefilm you play every role-and you get your friend to dance in it. But if you think about One Flat Thing, Reproduced, or Pina, or Co(te)lette-they all have huge film crews. I still think you can make a great film with your iPhone, but I think it's important to know the range of possibilities so that you're not only thinking on a small level from the get-go. As l've been working in more professional production environments, I've been learning about what it means to 
work as part of a crew and what is expected of everyone. They take everything very seriously, and so I have started to take myself and my art more seriously.

Ben: The more I study screendance, the more I think it's important to have a really good collaboration - to have someone who's deeply knowledgeable about film and someone who's deeply knowledgeable about dance. There are elements of film and dance that are really just opposed to each other; film involves a lot of hurry up and wait, so there needs to be mutual understanding to make an effective collaboration. For example, choreographers who aren't familiar with film may not be aware of just how slow it can be, and they might expect to just go, go, go-let's just change this shot. For the filmmaker, that might mean they have to move the dolly and rearrange the lights because now the dancers are in a totally different place. So the filmmaker needs to have some basic knowledge of the needs of dancers, and the dancers and choreographer need to know some basic things about film production and also the way the camera sees. I've worked with a lot of choreographers, and some have a really great intuition of what will work well on film, and those are the ones that I really enjoy working with, and who respect what I do. Others really just want a glorified performance documentation to show their stage piece. So collaboration can be challenging, because you have essentially two directors trying to meld their visions.

\section{Harmony: If you think about the work you've done and what you've learned since graduating, what are some things you wish had been incorporated into your training more?}

Jason: I think it could have been useful to understand how to do business more, especially for freelance artists. Unfortunately, business was something that was always presented like it would taint your artistic work. Outside the academic world, it's really hard to get grants, and individual grants are almost non-existent. So I think learning how to do funding could have been taught more. Even just interacting with people on a business level-I learned how to collaborate quite well, but that give-and-take is really not what happens when you're trying to sell your services. It took me moving to New York City to really understand business, because it's part of the culture here. Everybody's trying to figure out how to make $\$ 1200$ a month for rent alone.

Eric: I wish there had been more emphasis on logistics, like what is the dynamic of working with a client? Do you go in with an idea of your own and then you do it, or do you listen to them and follow their idea? How much do you bring to the table, and how much does the client bring, and what is that negotiation? What are all the things that are indirectly related to what you're doing that are nevertheless logistically necessary? And then what do you charge? What are you worth? I wonder if a way to get some of that information or experience is to have internships or collaborations in the community, where you still have guidance from a professor to help work through some of those negotiations. Making dancefilm trains you in many skills, and while your 
own objective might be to work as a dance or film artist, that work will likely be supported by applying these same skills toward marketing, promotional, or documentary ends.

\section{Harmony: What are your hopes for the future of screendance?}

Ben: It's exciting that more programs and workshops for screendance are beginning to crop up. My hope is that we'll begin to see that people aren't reinventing the wheel, just doing stuff that Maya Deren did eons ago. If people get down their history of screendance, see what's been done and see what's possible, and begin to really push dance on film - that's what I'm really excited about. I've worked with the San Francisco Dance Film Festival for a long time, and when you program a festival, it's amazing how you see so many of the same things again and again. I think many of us would agree that we've adequately explored dance in old, run-down warehouses! We can move on, there are other cool spaces. Two things that are really easy to goof up, or to just not think about, are location and costuming. But, production values have gotten so high. Films look gorgeous in the ways they are shot and lit, so that's really exciting, and I think maybe we can get into meatier stuff now. What does a dance film leave you with to chew on at the end? And what about the dancing and choreography is compelling? This is screendance, so we want to see really strong dancing-and more types of dance, not just modern. It would be really great to see some other forms of dance on film too.

Jason: I wish there was more of a sense of permanence. There's so much throw-away culture and we're swamped with information, so how do things become profound now? I'm hoping screendance will become more mature as its own art form, and I think that's happening with the International Journal of Screendance, and books by Doug Rosenberg and Katrina McPherson, and other journals and articles. I think that slowly there's more maturing of this field. It's been so wide-open for so long; it's sort of disconcerting to be like, "wow, how did this get in to this festival?" which has been my thought sometimes. There are certainly things that seem fresh to a curator or audience, and I think, well, this was done in 1966. Maybe that can't be escaped. But I think that maturity comes from pieces having both a high level of craft and recognizing the history of what has been part of the form. 


\section{Biographies}

Harmony Bench is Assistant Professor in the Department of Dance at The Ohio State University where she teaches in the areas of Dance, Media/Digital Humanities, and Performance Studies. Her writing can be found in Dance Research Journal, The International Journal of Performance Arts and Digital Media, Participations, and The International Journal of Screendance, for which she serves as co-editor with Simon Ellis.

\section{Email: bench.9@osu.edu}

Website: http://www.harmonybench.com/

Jason Bahling is a NYC based videographer, colorist, and time based artist. His videos have shown internationally in galleries, film festivals, and performances. While he actively participates in post-production for broadcast, advertising, documentary and narrative films, Jason primarily enjoys collaborating with choreographers, musicians, and theatre companies. Recent projects include: "Here Now with Sally Gross" and "Circling" with Douglas Rosenberg; "Daughter" with Li Chiao-Ping; and "4 Chambers" an immersive dance piece created with Jody Oberfelder. Jason is a founding partner of The Notion Collective, a multidisciplinary art collective that creates web art, performance art, video art, and installations.

Email: jason.bahling@gmail.com

Website: http://www.jasonbahling.com/

A native of the San Francisco Bay Area, Ben Estabrook specializes in capturing dance on camera. His interest in screendance led him to the University of Utah, where he graduated with an MFA in Film \& Media Arts and a Graduate Certificate in Screendance in 2014. He helped to found the San Francisco Dance Film Festival, for which he is the Technical Director, resident workshop instructor, and a programming committee member. He has given guest lectures on screendance at Stanford University, Mills College, and Brigham Young University.

Email: ben@sfdancefilmfest.org

Website: http://www.sfdancefilmfest.org

Natalie Gotter is a choreographer, instructor, dance performer, and filmmaker currently located in Salt Lake City. She is currently a Modern Dance MFA candidate and Screendance certificate candidate at the University of Utah. Her research focuses on the socially constructed female body and how dance and film can subvert that construction. Her work has been presented in New Orleans, Chicago, Minneapolis and, most recently, Salt Lake City.

Email: negotter@gmail.com 
Eric Nordstrom is a dance performer, choreographer, filmmaker, and teacher living in Portland, OR. He has taught at The Ohio State University, Kenyon College, the University of Oregon, Portland State University, Conduit Dance, and the Seattle Festival of Dance Improvisation. He has provided video production for Portland Opera, Tere Mathern Dance, and Portland Taiko. He studied with filmmaker Mitchell Rose and choreographer Bebe Miller at The Ohio State University, where he earned his MFA in Dance.

Email: dance.eric@gmail.com

Website: https://ppav.me

Ellen Maynard is a Brooklyn-based artist, and a graduate of The Ohio State University Department of Dance. Ellen is co-creator of The Fleet Video Dance Production, a company that documents dance performance throughout New York and creates promos and reels for dance. Ellen's dance films have placed in festivals including the International 60 Seconds Dance Film Festival, the 9th International Screendance Festival, the Third Coast Dance Film Festival, Body In Focus Video Dance Festival of Portugal, and Triskelion Arts Dance Film Lab. Ellen spends her summers as a resident videographer of Bates Dance Festival.

Email: emaynard116@gmail.com

Website: http://www.thefleetNYC.com 


\title{
Unexamined Assumptions: A Conversation between Arabella Stanger and Simon Ellis
}

\author{
Arabella Stanger, University of Roehampton Dance Department \\ Simon Ellis, C-DaRE University of Coventry
}

Keywords: undergraduate, pedagogy, assessment, screendance, habits

I designed and led a final year undergraduate module in screendance for four years in the Dance Department at Roehampton University in London. The module is an introduction to screendance as choreographic practice and students participated in a number of workshops to help them develop their own screendances. The most recent module blog is online at screendance2015.wordpress.com. During those four years student work was co-marked by Arabella Stanger and me. The following conversation between us explores our experiences of marking the student screendance projects.

- Simon Ellis, April 2016

Simon Ellis: I'd like you to talk about your experiences of assessing undergraduate screendance. Has there been anything you've noticed in particular about the experiences?

Arabella Stanger: There are three things that come to mind. First, it's important to say that helping you grade the screendance module was the first time l've graded choreography of any kind. The second thing is that I'm really glad that my first experience of grading art, in fact, was grading these screendance pieces. The impression I have is that for the majority of these students, the screendance module represented their first opportunity to learn how to make a film. It was their first experience of making in that context; it was my first experience of grading in that context. So everyone was doing something new to them, which leaves room for a certain kind of unorthodoxy. Third, and, I'm not sure if I'm right about this, but it seemed like there was a thread or a character that ran through each of the three cohorts of screendance students that I found to be quite distinctive. Like there were different generations of screendance comrades. 
SE: Can you be more specific about that?

AS: Some ideas repeated themselves within each generation and did not repeat themselves cross generationally.

SE: Would you assume that someone or something influenced the class?

AS: Yes, it could be. Through the works I've seen over the past three years, I observed students dislodged from their habits. Perhaps because when composing for the screen they don't have the same type of technical know-how that they may have when they're working simply with bodies, space and time. On the one hand, this displacement from their usual pattern produces some really exciting and weird work. On the other hand, it might explain shared influences in styles within one cohort: like a sui generis set of habits!

SE: Beyond these shared influences, what are the films that stood out in those years of watching and assessing students' screendance works?

AS: The films that I remember straight away are the ones that involved objects and no humans, or at least a hint of a human. The choreographic work was done through an object or with an object. This is something that screendance as a medium makes possible for these students I think. Non screen-based choreography does not present that possibility in such an easy way.

SE: Yes, even though the possibility still exists. And what is it about those films?

AS: I think again it may be something about the dislodging of habits. These films really attended, in very focused ways, to movement as something that would hold attention. Whereas I think, when working with movement as carried or conveyed by a body - the dancer or the choreographer-some blockages might emerge. By blockages I mean the often unexamined assumptions about what a dancer is, what a dancing body is, and what movement is in a dancing body. The body influences movement. When the body's removed those blockages are removed. When you're working with a medium that's clearly not a dancing body you may have no assumptions. For instance, take a bottle of water: you wouldn't have assumptions about how that bottle of water would carry movement, artistically speaking. There is no dance technique for water bottles. I think this dislodging of habits-couched in an absence of formalised technical expectations-may also take place at the level of spectatorship. When I know I am watching a screendance and the first thing I see is a water bottle, I understand what I see without referring that thing to a set of dancework-specific references. Do you know what I mean? 
SE: I do. Some assumptions fade out. Yet, there is always literacy in the makers. One of the things I observed with students working on their first film, is that lovely tension between them being quite literate-they've spent a lot of time looking at moving image on screens-and at the same time being quite naïve about the conventions of film making and screendance filmmaking. I mention naïvety in the best sense of the word.

AS: You're right. What was also clear every single year that I have seen these films was the strong sense of cinematic genre that invades them. It always catches me by surprise and it delights me, but I think it speaks of that literacy you're talking about: the viewing literacy in cinema as a form, which has its own set of genres. Those genres don't necessarily belong to the body of practices that we might call screendance and they don't necessarily belong to the body of practices we call choreography. But I think a lot of the screendance students over the past few years have invoked those genres, and have positioned their practice more as filmmakers rather than screendance makers. A lot of the films are horror movies for instance. Or they're music videos. That's just two, there are more. There are thrillers as well.

SE: What are the things you find yourself paying attention to when you're watching these student films?

AS: Definitely the opening and closing credits. Because there's no such obvious opportunity to frame your work sort of authorially when you're working with choreography, when it's performed by people in front of other people.

SE: Like a programme note, it is different isn't it?

AS: It is different because with the opening credits it is so deeply integrated into the texture of the work that you're watching. So that always stands out to me. Some of the students have found really inventive ways to play with credits. It may be because it is the first time they've had the opportunity to work with those sort of framing devices.

SE: It's curious because as module leader I only stipulated that if they used music they needed to find royalty free music and then credit it according to the Creative Commons license. We didn't discuss the dramaturgy of credits until after it was clear that the students thought credits were an important marker of presenting a film. Then we talked about what are they, what do they might do to the film, or how is it that they're part of the film. You can think of very clear examples in cinema where credits are designed to something more than communicate production details, like tuning or priming an audience for watching.

AS: This is really a speculation but I wonder if there's another side to it, which is the joy of having a real opportunity to acknowledge your collaborators. I've noticed in these closing credits that 'dancers' or 'performers' are communicated very clearly. 
SE: Are there other things you pay attention to when watching these students' films?

AS: Light and color, which are either brand new or newly discovered elements to play with as a choreographer. A number of the films that I've seen have really been choreographies of light; the more minimalist films have been anyway. Again I think there's something about film as a medium that makes that type of work with light manageable, while a big theatre space would not. The scale of the theatre as known and used by the students is fairly large: a frontal theatre, with a developed technical facility. In comparison, the micro scale of the screen allows elements such as light and colour to be concentrated. That invites a type of play that is not intimidating, or doesn't seem out of the student's reach.

SE: The screen also provides directness in terms of what's in the frame or what's outside of the frame. Which is very different from, or I imagine feels very different for them, from when they are sitting in a theatre looking at a frame that is almost shifting based on their perceptual system, based on their eyes and the way they are seeing.

SE: You haven't taught this module but what would you say, based on your own experiences, to a group of students who were just starting a module in screendance?

AS: You have to watch as much as possible all the time. That will help you figure out what it is that you might want to do. Also, watch the details of what it is that you're watching. Like, the details that are produced by all of the decisions that a filmmaker might make in the course of making a film. I don't think that advice is peculiar to screendance. I think I would give that advice to artists working in any medium.

Another piece of advice not peculiar to screendance is: don't worry about not being experts in or masters of the medium. That lack of expertise can be really helpful in making work that people might be surprised in watching. So in a way, what I would tell them is really paradoxical: 'watch everything' and 'ignore everything'. Then I would say that I am genuinely looking forward to seeing what they come up with because, in my experience, what they come up with is really compelling and delightful and often amusing too.

SE: In talking about your experience with following the screendance students, is there something that you've been reminded of?

AS: The experience of the screendance screenings is a very special one. The audience gathered consists of friends and classmate and peers. This audience is a lot more jubilant, I think, than at other assessment performances for which I've been an audience member. Spectators let loose on a greater scale than they do in other choreographic assessments. I think it is because there's no live dancer who they're worried about interrupting but also there's the feeling of being in the cinema, which is a feeling of being taken away to some other place. 
SE: For the students there are two important differences between the screening and the more traditional format to present choreography. For the most part they've never had that experience of having their work watched by others in that kind of environment. It feels it has a certain kind of vulnerability associated with it. The other thing is, as you've pointed out, that there are no dancers. Makers are not having to talk to dancers, or do lights and technical rehearsals. They've done all of the work. It has been finished days before, or sometimes longer. I think that is quite a shocking experience. In a really, for the most part, positive way.

AS: Maybe that's something that I would mention to them if I met them at the beginning of their module: wait for that moment, the shocking moment of the screening.

\section{Biographies}

Arabella Stanger has a BA in Classical Studies and English at King's College London and an MA in Performance and Culture from Goldsmiths, University of London. She holds a PhD from the Department of Theatre and Performance at Goldsmiths. Arabella's research investigates choreography as cultural practice. Her current interests are shaped in this respect by questions of space and particularly of the implications for dance research of Henri Lefebvre's theorisation of space and society. Her teaching and scholarship is also motivated by the pertinence of choreographic practice to diverse fields of aesthetic and intellectual enquiry, including dance, theatre and performance, visual art, new media, and studies of classical antiquity.

\section{Email: arabella.stanger@roehampton.ac.uk}

Simon Ellis is a choreographer, dancer and film-maker interested in practices and ideas to do with (not necessarily at the same time) power, responsibility, memory, dialogue and screens. His work as a scholar includes understanding ways of knowing through writing, choreography and film, and in supporting the development of practice-asresearch (see practiceasresearchblog.wordpress.com). He is a Senior Research Fellow at the Centre for Dance Research (C-DaRE) at Coventry University, and co-edits IJSD with Harmony Bench.

Email: simonkellis@gmail.com Web: http://www.skellis.net 


\section{References}

Bottles of Note. Dir. Kine Samuline. Prod. Kine Samuline. 2013.

https://vimeo.com/79057466

Our Choice. Dir. Matt Hudson. Prod. Matt Hudson. 2013. https://vimeo.com/81386389 


\section{REVIEWS}





\section{Dance Fort: A History by Bebe Miller. 2015. Columbus: Ohio State UP. 49 pp with still images and video. Free iBook. iTunes.}

Hannah Kosstrin, The Ohio State University

Keywords: artist-driven archive, documentation, Bebe Miller, iBook, iPad

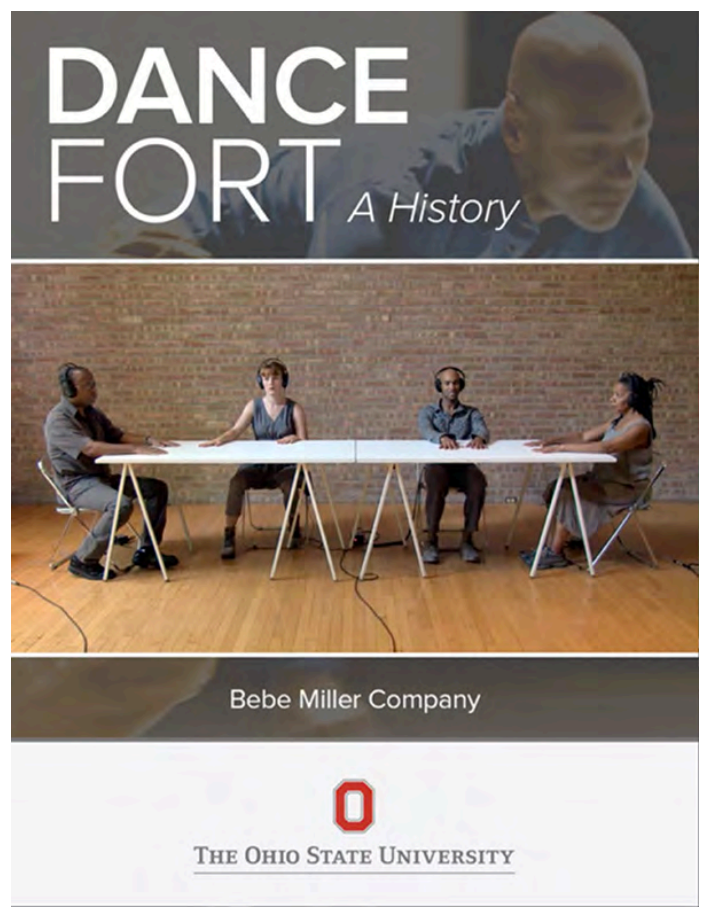

Screenshot of the cover for Dance Fort: $A$ History.
Choreographer Bebe Miller's iBook Dance Fort: A History enriches the landscape of artist-driven archives by presenting a digital platform that is at once a choreographic document and an interactive space for generative play. It is contemporary to the artistdriven Eiko \& Koma Archive Project (2012-2013) and Jennifer Monson's Live Dancing Archive (2013) that feature dance makers' engagements with their choreographic pasts, and to web-based media such as MotionBank's TWO (2013) that use dances' choreographic structures for creative inquiry. Miller intends Dance Fort to be "a means to share company process and methodologies with the dance field, artists in other disciplines and the general public." 1

Developed alongside Bebe Miller Company's collaborative dance $A$ History (2012) as its digital chapbook companion, Dance Fort teaches the reader how to be with $A$ History while serving as a repository for the collaborators' own understandings of the work. Comprised of a curated collection of artifacts from Company members-Miller, performers Angie Hauser and Darrell Jones, dramaturg Talvin Wilks, videographer Lily Skove, installation artist Maya Ciarrocchi, and embedded archivist Rachael RiggsLeyva-Dance Fort features collaborators' notes, sketches, emails, and reflections from 
during and after the rehearsal process, video clips from process and performance accompanied by collaborator voiceovers, and clarifications from the collaborators as to their conceptions of the work from within. Acting both as a record and as a way to understand the inner workings of the dance, Dance Fort mirrors A History, which was a way for Miller to unveil the lived experiences of her company through the past fifteen years. Dance Fort disassembles A History and focuses on its underlying choreographic concepts, helping readers to understand it from the inside out.

As a theatrical work based on a series of improvisational scores, A History is about "storyness," which Miller defines as the way dances make meaning. "Storyness" is, she asserts, "an exploration of intention and focus that feels like history and future are both at play." 2 As a digital book, Dance Fort follows a "storyness" structure as it introduces a guided path through the book along with the ability to jump around from part to part. It invites the reader into an improvisational score that unfolds the various ways in which $A$ History means.

Answering the task of how one performs an archive, for $A$ History the Company mined its own kinesthetic past through the choreography in Verge (2001), Landing/Place (2005), and Necessary Beauty (2008), including the collaborators' bodily histories of their past experiences performing together. As I watched A History, whispers of Bebe Miller Company's past entwined with my own as I remembered seeing these works live-a duet from Verge, a headstand from Landing/Place. I, too have a history of experiencing Miller's work through time. And, one could argue, our understanding of contemporary dance and our place in the world in relation to it comes from carrying our own kinesthetic and empathetic histories along from our experiences of one dance performance to the next. Dance Fort makes these connections visible. Miller explains: "Dance Fort began as a conversation: we were wondering how (and if) audiences could locate the threads of related ideas and questions that were foundational to our creative practice but not so visible in the dances themselves." ${ }^{3}$ Each collaborator's distinct understanding of the work surfaces through reading and hearing their reflections in Dance Fort. It then becomes clear how A History's threads wind into a larger opus that is both the sum of its parts and a larger equation that accounts for relationships within the work and their ability to signify multiply. As in Miller's dances, meaning in Dance Fort emerges through sensory imagery, text, and a manipulated sense of time-a humid and embodied recall that manifests layers of memory as it plumbs the human condition.

Dance Fort contains three sections in addition to a preface and credits: "Tracking the Process," "Angie-ness" (the way Hauser performs and makes decisions while dancing), and "Darrell Drive" (Jones' impetus that manifests in his dancing). Still and moving images effectively ground the iBook's visual narrative, and hyperlinks in the book connect readers to web resources like collaborators' personal websites. The most effective linked resource is a Vimeo-hosted full video of the 75-minute $A$ History 
performed at LIU Brooklyn's Kumble Theater for the Performing Arts on April 12, 2013, followed by a post-performance discussion with Miller, Hauser, and Jones moderated by dance critic Eva Yaa Asantewaa. ${ }^{4}$ The full video offers readers a deeper experience with the dance as they progress through Dance Fort. While it is sometimes physically tricky to find one's place inside the fort beyond swiping back and forth, the book's intellectual mapping allows for slippage to read each part more or less in any order.
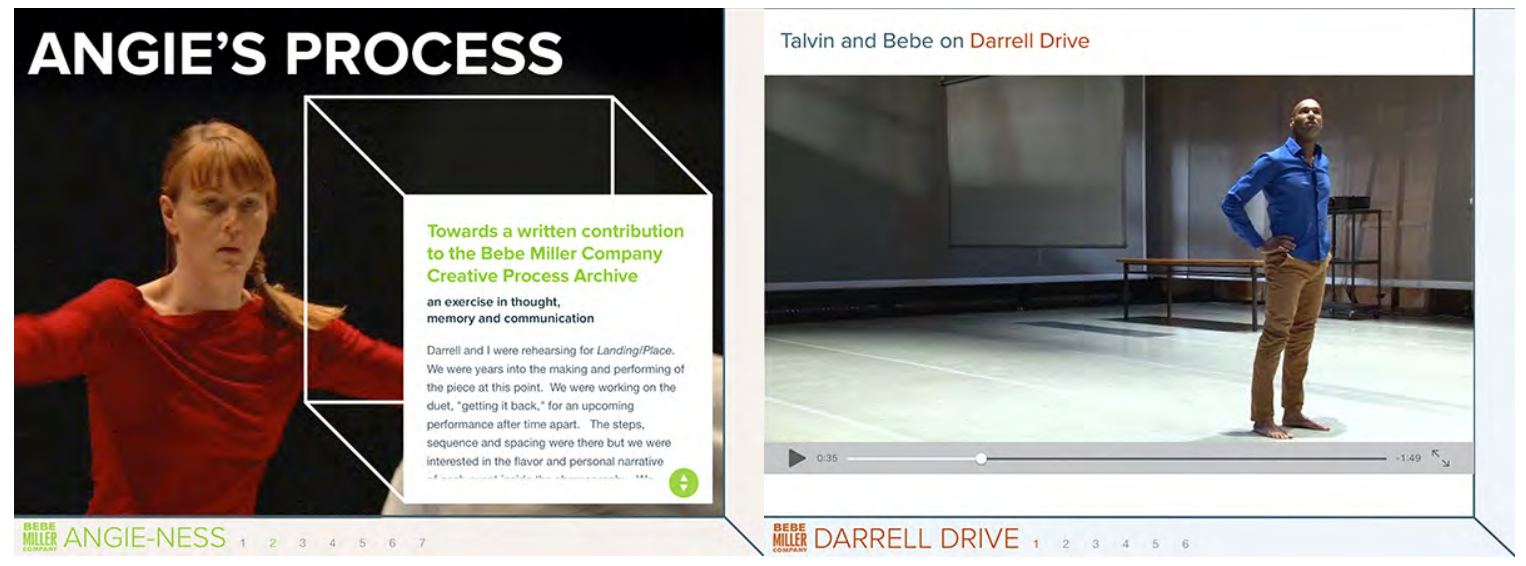

Screenshots. "Angie-ness" and "Darrell Drive" from Dance Fort: A History.

Dance Fort speaks to a group of digital media publications that include artist-driven archives and iPad-based books about contemporary dance. As a digital book about the process of one dance, Dance Fort recalls Merce Cunningham Event, an iPad app by the performing arts journal 2wice (2011). ${ }^{5}$ As differentiated from other Apple-based dance iBooks and apps, such as David Vaughan's Merce Cunningham: 65 Years (2012), or Marc Raymond Strauss and Myron Nadel's Looking at Contemporary Dance (2012), Dance Fort pushes the platform beyond the inclusion of video and links and relies on the user's gestural interactions with videos as generative of its explanations. Dance Fort capitalizes on the iPad platform by making sense of swiping between screens with small annotations or internal scrolling features for individual artifacts. This translates easily to computer viewing with gesture-based devices like a trackpad or the Apple "magic mouse."

As dance documentation tools continue to shift, Dance Fort provides a dynamic way of getting inside the dance without losing sight of the work itself. It provokes productive questions about best practices for engaging with dances outside the theater and what kinds of records are best fitted to choreographies in terms of their process and product. It is a resource for artists, teachers, and students, as well as scholars of contemporary dance, modes of documentation, digitality, and dance on screens. 


\section{Biography}

Hannah Kosstrin, Ph.D., is Assistant Professor in The Ohio State University Department of Dance and is affiliated with the Melton Center for Jewish Studies. She is finishing a book about Anna Sokolow for Oxford University Press, has published in Dance Research Journal, Dance Chronicle, The International Journal of Screendance, and Dance On Its Own Terms: Histories and Methodologies, and is project director for the Labanotation iPad app KineScribe. Kosstrin is Treasurer of the Congress on Research in Dance, and is a member of the Society of Dance History Scholars Editorial Board and the Dance Notation Bureau Professional Advisory Committee.

Email: kosstrin.1@osu.edu

\section{Notes}

${ }^{1}$ Bebe Miller, Dance Fort: $A$ History, iii.

2 Idem., 24.

${ }^{3}$ Idem., 11.

${ }^{4}$ Idem., 4.

5 This app is a companion to a series of ten Merce Cunningham Dance Company Events between 2001 and 2007.

\section{References}

2wice: Merce Cunningham Event. New York: 2wice Arts Foundation, Inc., 2011. iPad App. Merce Cunningham: 65 Years. David Vaughan. New York: Aperture Foundation, 2012. iPad App.

Eiko \& Koma. Eiko and Koma: Archive Project. Accessed February 12, 2016. http://eikoandkoma.org/archive.

Miller, Bebe. Dance Fort: A History. Columbus: Ohio State UP. 2015. iBook. Monson, Jennifer. Live Dancing Archive. 2013. Accessed February 12, 2016. http://www.livedancingarchive.org. 
Palazzi, Maria and Norah Zuniga Shaw. TWO. The Ohio State University's Advanced Computing Center for the Arts and Design and Motion Bank, 2013. Accessed February 12, 2016. http://scores.motionbank.org/two.

Strauss, Marc Raymond and Myron Nadel. Looking at Contemporary Dance: A Guide for the Internet Age. Princeton, NJ: Princeton Book Company, Publishers, 2012. iBook. 


\section{Maya Deren: Incomplete Control by Sarah Keller. 2015. New York and Chichester: Columbia University Press. 296 pp, 26 b\&w images. $\$ 30.00$ paperback. ISBN: 9780231162210.}

Karen Wood, Coventry University

Keywords: Maya Deren, Sarah Keller, fragment, incomplete, ritual

In Maya Deren: Incomplete control, Sarah Keller presents a thought-provoking view of Deren's work that is framed by the notion of incompleteness. While providing some important historical information about Deren, the main body of this book discusses Deren's work as fragmented and unfinished, which was Deren's chosen artistic process. Keller's thinking is centrally focused on liberating Deren's artistic work as an indication of "an aesthetic that respects a rejection of closure and completion," ${ }^{1}$ rather than failure to complete the many projects once begun. Maintaining a close relationship with Deren's archives, Keller gives this avant-garde filmmaker the respect and sensitivity that she and her work thoroughly deserve.

Keller has sifted through archival boxes of notes from incomplete projects that are entwined with her analyses of Deren's published films, books, and music. Placing as much importance on Deren's unfinished work as her (so-called) finished work, Keller nuances the tense spaces between binaries of absence and presence explored by Deren, who did not try to bring these concepts together, but rather, tried to keep them apart in order to exaggerate the tension. An important influence in Deren's work was her time spent in Haiti and her study of rituals. Her search for the spirituality and awareness of otherness inspired her later work in which she embraced the incomplete as an aesthetic. This strategy of Deren's to produce work considering "absence and presence," "fragments," and "plans abandoned"3 led to the openness that Keller eloquently illuminates.

Chapter One comprises of an in-depth analysis of one of Deren's most canonical works, Meshes of the Afternoon (1943). Although this work is the subject of much study and is considered to be complete, finished, and closed, one finds pleasure peering into a filmic structure of incompleteness "through the non-ending forms of recursion, 
reflection, and circles." ${ }^{4}$ Deren's mix of interest in poetry, dance, and photography is evident in her films, and Keller draws close attention to Deren's interdisciplinary curiosities regarding "artistic and intellectual" 5 subjects. In the second part of this chapter, Keller discusses Witches Cradle (1943), a solo endeavor by Deren with minimal input from her then filmmaker-husband Alexander Hammid. Witches Cradle is an example of Deren's various interests combining and producing a binary of "openness and closure, expressed in several different ways." ${ }^{6}$

The following chapter explores three of Deren's six completed works, namely: At Land (1944), A study in Choreography for Camera (1945), and Ritual in Transfigured Time (1946). Providing textual analysis of these films combined with archival notes about the planning process, Keller articulates Deren's growing interest in the use of the camera to explore reality and ritual. Deren's trip to Haiti, funded by the Guggenheim Foundation, was to explore Voudoun rituals. This project was never actually fulfilled; it was "unfinished labor." ${ }^{7}$ However, the time spent in Haiti broadened Deren's creative reach as she produced a nonfiction book, a music album, plans for a six-album compilation, a photographic series, and lectures all inspired by Haitian people and ritual. The book's final chapter follows Deren's work in the last decade and a half of her life (1943 to 1961) and reports on the continued influences of Haiti in Deren's finished and unfinished work.

What is missing in the book is a thorough theoretical engagement with notions of the affective turn and kinesthetic empathy whilst viewing Deren's films. ${ }^{8}$ Keller points towards this possibility in another article, when discussing Deren's work as "aesthetic, cinematic dance ... most immediate and capable of conveying ideas, emotions, and rhythms with directness and force." ${ }^{\prime 9}$ For example, using Deren's later work, grounded in her interest in Haitian Voudoun ritual, gives an insight into Deren's curiosities with dancefilm and affect and would have provided a good ground for theoretical analysis. One could suggest that Keller's book is also 'incomplete' and 'fragmentary'. However, Keller does provide a rich account of Deren's history and her incomplete filmmaking practice.

What I enjoy most about Keller's book is the refreshingly different perspective she provides regarding Deren's artistic process, and further, how she shows that incompleteness, in the form of allowing binaries to exist rather than trying to fix them, can be a fruitful, creative, and imaginative lens through which to consider Deren's avant-garde work. This book will be of interest to students, academics, and artists interested in studying film, and particularly screendance, as a means to get an understanding of an early, exemplary pioneer of experimental film. 


\section{Biography}

Karen Wood is currently a dance practitioner/ researcher/ educator. She works at the Centre for Dance Research at Coventry University as a Research Assistant and for the University of Wolverhampton as a Dance Lecturer. Karen is also working on artistic projects, supported by Arts Council England, collaborating with other art forms, such as neuroscience, fine art, lighting design and music were she creates and performs in dance works, incorporating film, for traditional and non-traditional spaces.

Email:karen.wood@coventry.ac.uk

\section{Notes}

${ }^{1}$ Sarah Keller, Maya Deren: Incomplete Control, 2.

${ }^{2}$ Idem., 85.

${ }^{3}$ Idem., 10.

${ }^{4}$ Idem., 33.

${ }^{5}$ Ibid.

${ }^{6}$ Idem., 60.

${ }^{7}$ Idem., 135.

${ }^{8}$ For an example of a productive incorporation of theoretical frameworks in the study of screendance, see Erin Brannigan, Dancefilm, 2011.

${ }^{9}$ Keller, "Pas de deux," 56.

\section{References}

Brannigan, Erin. Dancefilm: Choreography and the Moving Image. Oxford: Oxford University Press, 2011.

Keller, Sarah. "Pas de deux for dancer and camera in Maya Deren's films." International Journal of Screendance 3 (2013): 53-60.

. Maya Deren: Incomplete Control. New York and Chichester: Columbia University

Press, 2015. 


\section{Moving without a Body: Digital Philosophy and Choreographic Thoughts by Stamatia Portanova. 2013. Cambridge, Massachusetts: The MIT Press. 200 pp, 15 b\&w images. \$32.00 hardcover. ISBN: 9780262018920.}

Ariadne Mikou, University of Roehampton

Keywords: digital technology, choreography, video dance, motion-capture, choreographic software

Recent developments in the fields of digital technology, dance, game design, and medical engineering enable us to extract, store, and abstract human movement through its transformation into digital data. Numbers, as the hidden actors of computer software and scripts, are challenging movement produced by human bodies. The Forsythe Dance Company's 2010 Motion Bank is one of the projects that makes explicit the capacity for digital technology to bring new inputs into the discipline of dance and into the understanding of moving and choreographing.

In Moving without a Body: Digital Philosophy and Choreographic Thoughts Stamatia Portanova examines shifts in choreographic thinking and understanding due to the emergence of digital technologies. She asks "what really happens when the physicality of our movements is translated into numerical code by a technological system (or when this physicality becomes numbers)" (orig. emphasis). ${ }^{1}$ Portanova expands Forsythe's important question underpinning the Synchronous Objects project, regarding the possibility of choreography "to generate autonomous expressions of its principles without the body." 2 She queries: "Is it possible for a choreographic image, object, or structure to possess a body of its own?"3 If yes, how can the technology that has invaded the expanded choreographic process be re-thought and potentially redesigned in order to address this kind of choreographic development?

Portanova understands choreography to be more than "the creative process of joining movements together and of planning changes in speed and direction through a detailed script." ${ }^{4}$ Instead, she places choreography in a larger conceptual context, which refers to any kind of movement organization or connection between points and positions arranged in space. Through this lens, organizing live bodies in motion

The International Journal of Screendance 6 (2016). 
becomes only one of an infinite number of choreographic manifestations. Human technological achievements in the areas of video dance, motion-capture, and software design can also be understood as choreographic. For Portanova, "to think movement is to cut it in perception, to capture it in memory, to count and compose it, in thought." ${ }^{5}$ In other words, to think choreographically involves capture, storage, and manipulation of movement through its abstraction and transformation. Portanova concentrates on dance artists such as Antonin De Bemels, William Forsythe, and Merce Cunningham, whose collaborative, choreographic practices have incorporated video making, motion capture, and interactive software design. Further, she draws on theories from radical empiricism and digital technology, as well as the philosophy of Gilles Deleuze and Alfred North Whitehead.

For Portanova, moving manifests through what she calls a "choreo-nexus" (digital composing and cut of images), as well as "mov-objects" (digital objects derived from movement), and "compu-sitions" (movement composition software). Following Whitehead, Portanova defines a nexus as "a series of disconnected occasions held together by the uniqueness of an idea. This idea integrates the movement, as a multiplicity of different perceptual sensations, into the imagined togetherness of a dance nexus (or a choreo-nexus)." ${ }^{6}$ The concept of the chore-nexus highlights the revolutionary role of the (digital) cut in video editing. Via the digital cut, a movement sequence on screen can become disarticulated and its continuity redistributed into discrete, independent units. ${ }^{7}$ In regard to the creative storage of movement, Portanova proposes the invention of mov-objects, i.e. digital objects that are created through desubjectifying movement from a human source, and then converting it into a reproducible path or shape, with potential for transformation. So doing involves compu-sitions, a term Portanova derives from the words computation and composition. According to Portanova, compu-sition is a way of composing movement through technological intervention, for example of algorhythmic software systems, and it facilitates "a way to creatively think the dance as numbers."

As the title of the book implies, Portanova's focus is on the essence of moving in an expanded choreographic context; moving understood both in a passive and an active tense. Moving in a passive form is something that "occurs in the body (rather than being performed by it)" (orig. emphasis). ${ }^{9}$ Moving in the active form can also involve composing abstract movement without perceiving the source of movement. To this end, Portanova discusses the work of Merce Cunningham, in which screendance avatars are constructed using LifeForms and DanceForms software. This approach is also evident in the 3D film version of "Loops" created by OpenEndedGroup. Here, moving renders choreography as an act of digital or mathematic execution that demands the choreographer to think movement rather than to feel or embody it. Portanova states that movement concepts are "to be thought separately from actual bodily movements," 10 and further, that "a body performs a movement, and a mind 
thinks or choreographs a dance." ${ }^{11}$ Arguably, the latter has been the case with a number of Cunningham's choreographies. However, Portanova seems to occupy an inconsistent position in relation to the body-mind split within digital choreographic making, as evidenced in her statement that:

The thought of movement is not separated from the movement itself and situated in a different point, or temporarily delayed, but coincides with it in the very moment of a motor sensation. This simultaneity of body/mind only appears in the distribution of thought-motion in the body, when thought and action coincide in their bodily spreading or delocalization. ${ }^{12}$

In instances where choreography is generated with a computer software program, there is the danger that Portanova's statements will be misinterpreted. This point of view prioritizes the choreographer's mind over the dancer's body by placing the choreographer in a position of power and the performer in the role of an obeying tool for executing movement. Disregarding notions of choreography where the potential of choreography has been minimized to the act of composing virtuosic steps, but extracting from the medium of choreography the idea of movement composition and organization, can help rethink statements which provoke body-mind misinterpretations of Portanova's arguments.

In Moving Without a Body, Portanova aims to articulate how the software structures that underpin video dance, motion capture, and choreographic software might help us rethink the perception of movement and choreography in a larger context. She elaborates a conversation on the multifaceted nature of choreography that is already in motion, as initiated by Susan Foster's Choreographing Empathy. ${ }^{13}$ Although Portanova does not acknowledge this discourse as it accumulates in Xavier Le Roy's notion of expanded choreography, ${ }^{14}$ she manages to recontextualize choreography. She succeeds to offer a perspective that bears in mind the problematic of digital dance and the choreographic/organizational practices of movement disarticulation.

\section{Biography}

Ariadne Mikou is an interdisciplinary and independent dance artist, movement educator, and emergent dance scholar from Greece interested in dance-making inside theatrical and non-theatrical settings, screendance, dance installations, and photography. She is currently pursuing her fully-funded $\mathrm{PaR} \mathrm{PhD}$ in Choreographic Research in the Dance Department of The University of Roehampton, London, UK.

Email:mikoua@roehampton.ac.uk 


\section{Notes}

${ }^{1}$ Stamatia Portanova, Moving Without a Body, 2.

${ }^{2}$ Idem., 139.

${ }^{3}$ Ibid.

${ }^{4}$ Idem., 97.

${ }^{5}$ Idem., 135.

${ }^{6}$ Idem., 31. For example when the linear progression of a dance sequence on screen is manipulated by the camera and video editing process to construct relational moments of connection between past and present, cause and effect, and stimulus and response.

7 The outcome is a choreography of digital frames where there is no beginning and end, but rather a trace of movement, an amorphous diagram which Portanova calls the presentational nexus.

8 Idem., 99.

${ }^{9}$ Idem., 102.

${ }^{10}$ Idem., 134.

${ }^{11}$ Idem., 5.

12 Idem., 102.

13 Susan Foster exemplifies the shift in the understanding of the notion of choreography from its establishment during 17th century by Raoul-Auger Feuillet until more recently.

${ }^{14}$ Expanded Choreography. / Xavier Le Roy / Macba, 2012

\section{References}

Downie, Mark, Shelley, Eshkar and Paul Kaiser. OpenEndedGroup. Accessed 29 Feb. 2016. http://openendedgroup.com/artworks/loops.html

Forsythe William, Maria Palazzi and Nora Zuniga-Shaw. Synchronous Objects. Accessed 29 Feb. 2016. http://synchronousobjects.osu.edu

Foster, Susan. Choreographing Empathy: Kinesthesia in Performance. London: Routledge, 2011.

Laboratoire du Geste. Expanded Choreography. Situations, Movements, Objects. Accessed 29 Feb. 2016. http://www.laboratoiredugeste.com/spip.php?article583

Portanova, Stamatia. Moving without a Body: Digital Philosophy and Choreographic Thoughts. Cambridge, Massachusetts: The MIT Press, 2013.

The Forsythe Dance Company. Motion Bank. Accessed 29 Feb. 2016. http://motionbank.org 